\title{
Matrix glycoproteins and proteoglycans are paramount in cardiac disease
}

Citation for published version (APA):

Deckx, S. (2016). Matrix glycoproteins and proteoglycans are paramount in cardiac disease. [Doctoral Thesis, Maastricht University]. Datawyse / Universitaire Pers Maastricht. https://doi.org/10.26481/dis.20161021sd

Document status and date:

Published: 01/01/2016

DOI:

10.26481/dis.20161021sd

Document Version:

Publisher's PDF, also known as Version of record

\section{Please check the document version of this publication:}

- A submitted manuscript is the version of the article upon submission and before peer-review. There can be important differences between the submitted version and the official published version of record.

People interested in the research are advised to contact the author for the final version of the publication, or visit the DOI to the publisher's website.

- The final author version and the galley proof are versions of the publication after peer review.

- The final published version features the final layout of the paper including the volume, issue and page numbers.

Link to publication

\footnotetext{
General rights rights.

- You may freely distribute the URL identifying the publication in the public portal. please follow below link for the End User Agreement:

www.umlib.nl/taverne-license

Take down policy

If you believe that this document breaches copyright please contact us at:

repository@maastrichtuniversity.nl

providing details and we will investigate your claim.
}

Copyright and moral rights for the publications made accessible in the public portal are retained by the authors and/or other copyright owners and it is a condition of accessing publications that users recognise and abide by the legal requirements associated with these

- Users may download and print one copy of any publication from the public portal for the purpose of private study or research.

- You may not further distribute the material or use it for any profit-making activity or commercial gain

If the publication is distributed under the terms of Article $25 \mathrm{fa}$ of the Dutch Copyright Act, indicated by the "Taverne" license above, 


\section{Matrix Glycoproteins and \\ Proteoglycans are Paramount \\ in Carcliac Adaptation and Disease}

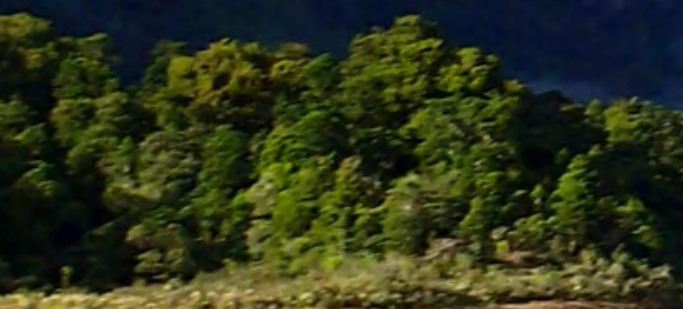




\section{Copyright @ C Sophie Deckx}

Alle rechten voorbehouden. Niets uit deze uitgave mag worden vermenigvuldigd en/of openbaar gemaakt worden door middel van druk, fotokopie, microfilm, elektronisch of op welke andere wijze ook zonder voorafgaande schriftelijke toestemming van de uitgever.

All rights reserved. No part of the publication may be reproduced in any form by print, photo print, microfilm, electronic or any other means without written permission from the publisher.

ISBN 9789461596079

Production Datawyse | Universitaire Pers Maastricht

Foto kaft: (C) Sophie Deckx - Kajakken op de Milford Sound in Nieuw-Zeeland.

Nieuw-Zeeland bezoeken, een PhD behalen... Beiden leken slechts dromen te zijn en ik had nooit verwacht deze te kunnen bereiken... Laat staan ooit te kunnen zeggen dat ik in 1 jaar tijd zowel in Nieuw-Zeeland ben geweest als mijn PhD heb behaald. Maar soms worden dromen toch werkelijkheid, gelukkig heb ik nog veel dromen... 


\section{Matrix Glycoproteins and Proteoglycans are Paramount in Cardiac Adaptation and Disease}

PROEFSCHRIFT

Ter verkrijging van de graad van doctor aan de Universiteit van Maastricht

Op gezag van de Rector Magnificus, Prof. dr. Rianne M. Letschert Volgens het besluit van het College van Decanen

In het openbaar te verdedigen op

21 oktober 2016 om 14 u00

door

SOPHIE DECKX Geboren op 10 april 1987 te Leuven 


\section{Promotor}

Prof. dr. S. Heymans

\section{Copromotor}

Dr. A. Papageorgiou

\section{Beoordelingscommissie}

Prof. dr. F. Prinzen (voorzitter)

Prof. dr. M. Blankesteijn

Dr. A. Gonzalez Miqueo, CIMA, Pamplona, Spanje

Prof. dr. L. Roderick, KULeuven, Leuven, België

Prof. dr. P. Volders

This work was supported by a CARIM-funded PhD grant of the Maastricht University, and by the European Commission's grants FP7 FIBROTARGETS (602904), MEDIA (261409) and CVON 2011 (ARENA).

Financial support by the Dutch Heart Foundation for the publication of this thesis is gratefully acknowledged. 
"L'ignorance est la plus grande maladie du genre humain"

"Aime la vérité, mais pardonne à l'erreur" "Laissez lire, laissez danser, ces deux amusements ne feront jamais de mal au monde" - Voltaire 



\section{CONTENTS}

Chapter 1 General Introduction and Outline of the Thesis

Heart Failure

The Extracellular Matrix

Hypertension and Age- related Heart Failure

Myocardial Infarction

Viral Myocarditis

17

Aims and Outline of this Thesis

Chapter 2 The diverse functions of Osteoglycin: a Deceitful Dwarf or a Master Regulator of Disease?

Chapter 3 Osteoglycin prevents development of Diastolic Dysfunction by reducing Fibroblast Proliferation and Cardiac Fibrosis

Chapter 4 Extracellular SPARC improves Cardiomyocyte Contraction during Health and Disease

Chapter 5 Breeding Strategy Determines Rupture Incidence in Post-Infarct Healing WARPing Cardiovascular Research

Chapter 6 General Discussion

Summary

Samenvatting

Valorization

Dankwoord

Curriculum Vitae 

Chapter

General Introduction and Outline of the Thesis 



\section{HEART FAILURE}

Heart failure (HF) is a serious cardiac condition, affecting approximately 6 million people in Europe ${ }^{1,2}$, and despite continuous improvements in health care, it remains the leading cause of death worldwide ${ }^{3}$. HF carries high mortality with only $50 \%$ survival 5 years after onset of $\mathrm{HF}^{4}$ and in the USA alone, $\mathrm{HF}$ accounts for nearly a quarter of total mortality ${ }^{5}$.

$\mathrm{HF}$ is a clinical syndrome where the heart is no longer capable of providing sufficient oxygen- and nutrient rich blood to meet the body's needs. It is the common final state of multiple cardiovascular diseases, such as myocardial infarction (MI), valvular disease, viral myocarditis (VM), hypertension and cardiac arrhythmias. In addition, HF can also manifest itself as a consequence of ageing. In the clinic, patients present themselves with typical symptoms such as fatigue, breathlessness, and ankle swelling. Since these symptoms are not exclusively HF symptoms, diagnosis of HF can be difficult ${ }^{6}$. Moreover, despite their similar clinical presentation, two types of HF exist being systolic and diastolic HF and the distinction between the two is critical since they each require a different therapeutic strategy. Systolic HF is characterized by impaired contraction of the heart resulting in reduced ejection fraction. Contrary in diastolic HF relaxation is impaired due to stiffening of the heart and ejection fraction is normal or only mildly reduced. Furthermore, current standard treatment mainly focuses on relieving symptoms, without evident effects on the underlying pathophysiology and as a result prognosis of $\mathrm{HF}$ is poor. Especially diastolic HF represents one of the most challenging clinical problems in cardiology, as modern pharmacotherapies, in contrast to systolic HF do not improve outcome, due to incomplete understanding of its pathogenesis ${ }^{7}$. Hence, there is critical need for identifying and understanding the different underlying aetiologies that contribute to the development of systolic and diastolic HF, in order to improve diagnosis as well as treatment. Importantly, similar fundamental pathophysiological changes occur in the hearts of both systolic and diastolic HF patients, such as cardiomyocyte death, cardiomyocyte hypertrophy, cardiac inflammation and fibrosis (Figure 1). Yet, while their contribution is recognised for systolic $\mathrm{HF}^{8,9}$, they are only starting to be understood in the pathogenesis of diastolic $\mathrm{HF}^{7}$.

Systolic HF often results from ischemic heart disease, dilated cardiomyopathy, hypertension or valvular disease. $\mathrm{Ml}$ is the leading cause of systolic $\mathrm{HF}$, where it causes approximately two-thirds of all cases ${ }^{10}$. Dilated cardiomyopathy, often the consequence of acute myocarditis, is the second leading cause of systolic HF. Diastolic HF on the other hand is a hallmark of heart failure with preserved ejection fraction (HFpEF), yet there is more to HFpEF than diastolic dysfunction alone. In fact, some symptoms in HFpEF patients may be attributable to increased large artery stiffness and reduced chronotropic reserve (i.e. the ability to increase heart rate to cope with increased demand), rather than only diastolic dysfunction ${ }^{11}$. Diastolic dysfunction and HFpEF occur mostly in elderly patients with comorbidities such as hypertension, overweight/obesity, diabetes mellitus, and chronic obstructive pulmonary disease ${ }^{12}$. 
Chapter 1

\section{Figure 1}

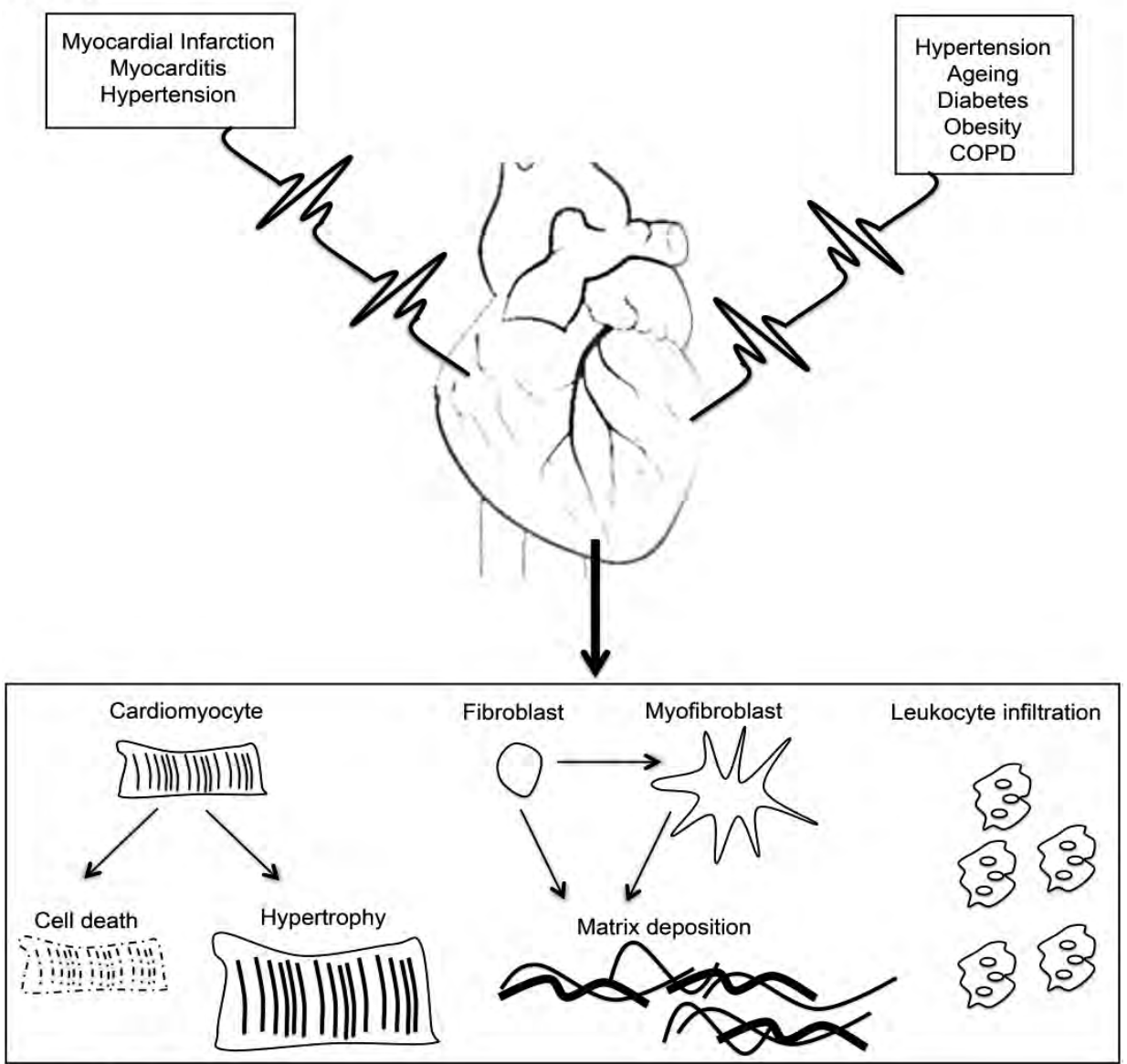

\section{Ejection Fraction}

$5 \%$

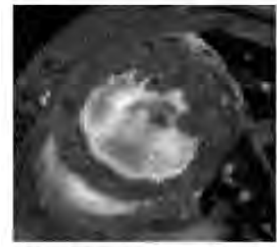

Systolic dysfunction
$45 \%$

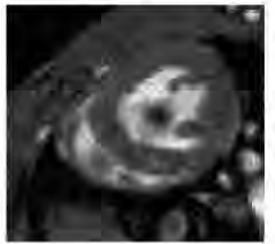

Normal function

Figure 1. Pathophysiological changes in the failing heart. Stress or injury like myocardial infarction, viral infection, ageing or persistent hypertension trigger pathological changes in the heart like cardiomyocyte hypertrophy or death, fibroblast-to-myofibroblast differentiation, fibrosis and inflammation. These changes advocate cardiac remodelling and subsequent development of systolic HF, where contraction is impaired and ejection fraction reduced, or diastolic HF, where relaxation is disturbed but ejection fraction preserved. COPD chronic obstructive pulmonary disease. 


\section{THE EXTRACELLULAR MATRIX}

The heart consists of a cellular and an extracellular matrix (ECM) component. Only 30\% of the cardiac cells is represented by the cardiomyocytes, while they account for most of the myocardial mass. The rest of the cardiac cells include the smaller cardiac fibroblasts, endothelial cells, vascular smooth muscle cells and resident leukocytes. The ECM is a network of proteins filling the extracellular space and providing a structural support to the cardiac cells. Hence, the ECM is composed of structural proteins such as elastin and collagens that provide a scaffold for the cardiac cells and determine the strength or stiffness of the cardiac tissue. In addition, the ECM contains other proteins with nonstructural features. Importantly, besides its structural function, the ECM is a crucial regulator of molecular signals and it orchestrates different cellular responses. Increasing evidence shows that the non-structural proteins directly bind to cell-receptors or growth factors, thereby regulating growth factor availability, activation and presentation to cells. In this way, these non-structural proteins become important modulators of cell behaviour by regulating cell shape, differentiation, migration and proliferation. Moreover, they are important for matrix homeostasis, as they regulate ECM turnover through interactions with matrix metalloproteinases (MMPs) and their inhibitors. Hence, the ECM is a dynamic scaffold providing both structural and functional support to the cardiac tissue.

Cardiac remodelling is the adaptive response of the cellular and extracellular compartments of the heart upon stress signals, such as mechanical loading, ischemia, hormonal signalling or viral infection and even ageing. It is a reaction of the heart to reduce ventricular wall stress due to altered loading or injury ${ }^{13}$. It causes structural alterations of the heart changing cellular size and composition as well as matrix configuration, which underlie the development of HF. During cardiac remodelling, the following fundamental pathophysiological changes occur in the heart: cardiomyocyte death, cardiomyocyte hypertrophy, cardiac inflammation and fibrosis (Figure 1). In addition, a reactivation of the fetal gene program and a metabolic switch take place ${ }^{14}$. Yet despite these common fundamental pathophysiological changes, each cardiac disease displays a specific series of remodelling phases, which may ultimately lead to diastolic (e.g. upon ageing and hypertension) or systolic HF (e.g. after MI or VM). The remodelling processes following hypertensive/age-induced stress, ischemia, or viral infection, will be discussed in more detail below. Unfortunately, these remodelling processes remain incompletely understood.

Importantly, the non-structural matrix glycoproteins and proteoglycans in the heart can influence resident cell behaviour and the different processes during cardiac stress, such as inflammation, fibrosis and myocyte survival.

Matricellular proteins are a family of extracellular glycoproteins that interact with cell surface receptors, growth factors, other matrix proteins and MMPs, but with no evident structural role. They display counteradhesive properties, low expression levels 


\section{Chapter 1}

during normal adult physiology, but increased expression during development and upon injury, and absence of an evident phenotype in mice with targeted gene-disruption. This classification of matricellular proteins was proposed in the mid1900s and started with the "constitutor" proteins such as the thrombospondins and secreted protein acidic and rich in cysteine (SPARC), but this family has been expanding ever since ${ }^{15}$. After nearly two decades of continuous investigation, matricellular proteins have been demonstrated to play crucial roles in disease, and in particular upon cardiac remodelling, where they modulate cell behaviour and cell-matrix interactions ${ }^{16}$. For example, thrombospondin-2 was shown to be crucial in inflammation, fibrosis and myocyte survival of the heart during cardiac ageing ${ }^{17}$, doxorubicin-induced cardiomyopathy ${ }^{18}$, and viral myocarditis $^{19}$, whereas SPARC was identified as an important regulator of procollagen processing after $\mathrm{Ml}^{20}$ and cardiac pressure overload ${ }^{21}$. Recently, von Willebrand A domain Related Protein (WARP) was identified as a small, non-collagenous, secreted glycoprotein in the extracellular matrix of the heart, where it interacts with perlecan, a protein important for stability and critical during cardiac development as well as during wound healing after $\mathrm{Ml}^{22-25}$.

In addition, small leucine rich proteoglycans (SLRPs) are extracellular proteoglycans that are characterized by their small size and similar structure of a leucine rich repeat (LRR) core, flanked by cysteine residues. As a result of the diversity of their LRR core and glycosylation patterns, SLRPs can bind various growth factors, cell surface receptors, as well as other matrix proteins. SLRPs have been shown to be involved in a wide range of processes, like cell proliferation ${ }^{26}$, arteriogenesis ${ }^{27}$, inflammation ${ }^{28,29}$, fibrosis ${ }^{29,}{ }^{30}$, and ageing $^{31}$, and hence this group of proteoglycans play crucial roles in many different diseases ${ }^{29,32,33}$. Osteoglycin (OGN) in particular, is an SLRP with great structural and functional diversity in normal physiology and during disease. OGN has been implicated in cancer ${ }^{34,35}$, eye disease ${ }^{36}$, vascular diseases ${ }^{37,38}$, the metabolic syndrome ${ }^{39}$, and recently OGN was demonstrated to be a crucial collagen cross-linker after $\mathrm{MI}^{40}$.

Because of their influence on resident cardiac cells and on different remodeling processes during cardiac stress, these non-structural ECM glycoproteins, including SPARC and WARP, and proteoglycans, like OGN, in the heart are promising targets for further therapeutic HF research.

\section{HYPERTENSION AND AGE- RELATED HEART FAILURE}

Despite continuous improvements in the treatment of hypertension, the prevalence of hypertension and hypertension-related morbidity and mortality remains high. Amongst adults over twenty, the prevalence of hypertension is estimated to be around $30 \%$ in the USA ${ }^{41}$ and around $45 \%$ in Europe ${ }^{42}$, with a dramatic increase with advanced age in both regions ${ }^{41,42}$. This resulted in an estimated 72000 deaths in the USA alone in $2013^{41}$. Importantly, up to $20 \%$ of hypertensive people are not aware of their 
condition $^{41}$, hence that is why hypertension is often referred to as the silent killer. Moreover, diastolic HF is the most common form of HF in aged hypertensive patients, characterized by decelerated or incomplete diastolic relaxation and increased passive chamber stiffness ${ }^{43-45}$. Importantly, targeted therapy for diastolic HF is lacking.

Ageing is associated with increased sympathetic nervous activity, like dysregulation of the renin - angiotensin II - aldosterone system, resulting in increased inflammatory responses, vascular endothelial dysfunction, vascular remodelling and stiffening, and in the end hypertension ${ }^{46}$. Subsequently, both ageing and hypertension further impose important stress on the heart resulting in cardiac inflammation and successive fibrosis and cardiomyocyte hypertrophy, and ultimately in increased cardiac stiffness and disturbed cardiac relaxation. The mechanisms of cardiac inflammation upon ageing and hypertension remain incompletely understood and can include mechanical stress of the cardiac vessels and ventricular wall as well as a pro-inflammatory effect of humoural factors like aldosterone and angiotensin II. In general it is considered that ageing and hypertension lead to endothelial cell activation, the induction of adhesion molecule expression and the induction of an inflammatory response ${ }^{47}$. Mechanical stress together with the inflammatory response activate fibroblasts and triggers fibroblast to myofibroblast differentiation, which in turn produce chemokines like monocyte chemotactic protein 1 (MCP-1), further recruiting immune cells, especially monocytes/macrophages ${ }^{48}$, into the heart. Next, these inflammatory cells further stimulate the (myo) fibroblasts to deposit matrix proteins in the heart, resulting in increased cardiac fibrosis ${ }^{47}$.

Fibrosis is absent during normal physiology, even under stressed conditions such as during pregnancy or exercise. Yet upon pathophysiological stresses, like ageing and hypertension, fibrosis occurs, and hence it is one of the hallmarks of pathological cardiac remodelling. 3 types of fibrosis exist, based on the location and cause: perivascular, interstitial (or reactive), and replacement (or reparative) fibrosis ${ }^{13}$. In response to ageing and hypertension, mainly interstitial fibrosis develops within the ECM surrounding the myocytes, and it is characterized as a deposition of collagens and other matrix proteins expanding the ECM without myocyte loss. Replacement fibrosis ensues myocyte death, which also happens under sustained hypertension, yet to a lesser extent. Finally, perivascular inflammation and fibrosis develop throughout the heart upon ageing and hypertension, in response to vascular stiffening and increasing vessel wall tension. Overall, persistent fibrosis stiffens the heart and disturbs the cardiac tissue architecture and electrophysiology, which may result in arrhythmias, impaired relaxation, and cardiac (diastolic) dysfunction. Importantly, human cardiac samples implicate a significant contribution of fibrosis in the development of diastolic $\mathrm{HF}^{49-51}$.

Cardiomyocyte hypertrophy is the increase in myocyte size, which is an adaptive and protective process to cope with increased ventricular wall tensions imposed on the heart due to ageing and hypertension. It also occurs during pregnancy and exercise and during these physiological conditions hypertrophy is reversible. However, sustained wall stresses, as during ageing and hypertension, evoke a pathological hypertrophic response, 


\section{Chapter 1}

which is associated with altered myocyte calcium handling, sarcomere dysfunction, oxidative stress and a metabolic switch. These changes can ultimately culminate into cardiomyocyte death ${ }^{13}$. Moreover, (myo) fibroblasts produce cytokines and growth factors upon age- and hypertensive stress, including transforming growth factor beta (TGFbeta), interleukin- 33 (IL-33), tumor necrosis factor alpha (TNF $\alpha$ ), basic fibroblast growth factor (bFGF) and endothelin-1 (ET-1), which directly affect cardiomyocyte function and promote myocyte hypertrophy. Furthermore, fibrosis reduces oxygen and nutrient delivery and impedes proper diffusion to the cardiomyocytes, in a situation when oxygen and nutrient demand is greater. Moreover, decreased capillary density together with increased cardiomyocyte size, will further reduce oxygen and nutrient diffusion to and in the cell interior, further exacerbating cardiomyocyte hypoxia and dysfunction ${ }^{13}$. In addition, inflammatory cells can also cause dephosphorylation of titin, which is a sarcomere protein functioning as an elastic spring and the main determinant of cardiomyocyte stiffness, further contributing to cardiomyocyte (diastolic) dysfunction?

Finally, vascular smooth muscle cells are important mediators of increased vascular constriction, and the main target of hypertension-inducing agents such as angiotensin II, excess of salt and mineralocorticoids, ET-1 or the absence of nitric oxide ${ }^{52}$. Stressed smooth muscle cells also communicate with endothelial cells, fibroblasts and cardiomyocytes, adding up to the complexity of cardiac remodelling upon ageing and hyperten$\operatorname{sion}^{52}$.

\section{MYOCARDIAL INFARCTION}

Ischemic heart disease is one of the most prominent cardiovascular diseases worldwide and the single most common cause of death in Europe, accounting for 1.8 million deaths in Europe each year ${ }^{1}$. Despite a decline in death rates, over one in five women (22\%) and one in five men (20\%) die from this disease ${ }^{1}$. Moreover, the improved clinical management of acute $\mathrm{MI}$ has decreased mortality but in turn it has also increased the prevalence of MI-related HF. In patients surviving an MI, disturbances in the cardiac healing response can lead to adverse remodeling, systolic dysfunction and eventually HF.

Obstruction of the coronary blood flow causes hypoxia and necrosis in the cardiac tissue. Subsequently following an ischemic event, a tightly regulated and wellorchestrated process of wound healing takes place in the heart ${ }^{53}$. Three overlapping phases have been characterized: the inflammatory phase, the proliferative phase and the maturation phase. The first, inflammatory phase occurs between $0-7$ days after infarction. The necrotic cells evoke recruitment of immune cells into the heart, including neutrophils and inflammatory monocytes, that produce MMPs to cleave the existing ECM to allow the immune cells to invade into the cardiac tissue and remove cell debris by phagocytosis ${ }^{54}$. Around day 7 , the proliferative phase starts and granulation tissue begins to form. After clearing the cell debris in the infarcted area, macrophages and 
monocytes produce cytokines and growth factors, like IL-10 and TGFbeta, to repress inflammatory signals, and to promote new blood vessel formation by endothelial cells and vascular smooth muscle cells, and matrix deposition by (myo-) fibroblast activation $^{55}$. During the final maturation phase around day 21 , this granulation tissue regresses and is replaced by a collagenous scar, a tissue rich in matrix proteins and (myo-) fibroblasts ${ }^{56}$.

Because cardiomyocytes have no or only very limited proliferative capacity, scar formation is the only reparative mechanism to prevent cardiac rupture following $\mathrm{MI}$. However, although fibrosis initially functions to sustain cardiac structure, persistent fibrosis may negatively influence cardiac function. Dependent on infarct size, location, the degree of cardiac damage and fibrosis, cardiac dilation and compensatory hypertrophy as well as arrhythmias can occur, which may ultimately lead to cardiac systolic dysfunction and HF.

\section{VIRAL MYOCARDITIS}

VM is an important inflammatory heart disease and an etiological precursor of dilated cardiomyopathy, (acute) HF and sudden cardiac death in young healthy adults. Up to $60 \%$ of patients with dilated cardiomyopathy and myocarditis are virus-positive ${ }^{57}$, yet diagnosis of VM is difficult due to its heterogeneous clinical presentations as acute HF, cardiogenic shock or ventricular arrhythmias. Different infectious agents can cause VM, including adenovirus, parvovirus B19, enteroviruses, hepatitis C virus, and cytomegalovirus $^{58}$. Several other etiologies of myocarditis have been implicated, including parasites, bacteria and fungi, but viral infection is the most common ${ }^{59}$. The best studied are the coxsackie $B$ viruses (CVB), members of the enteroviruses, which are identified in up to $25 \%$ of biopsies from failing VM hearts ${ }^{58,59}$. These enteroviruses access the body via the gastrointestinal or respiratory tract and target the heart secondarily.

Similarly to the healing response after $\mathrm{MI}, \mathrm{VM}$ is usually seen as a series of 3 distinct phases $^{58,59}$. The first 3-4 days are the acute viremic phase, where viral entry, replication and interaction of the virus with myocyte signaling take place. Cellular degradation ensues and intracellular antigens as well as viral pathogens trigger the innate immune system. In addition, resident cardiac cells, including myocytes, fibroblasts, endothelial cells and resident leukocytes produce high levels of pro-inflammatory cytokines, in particular IL-1b, TNF $\alpha$ and interferon $\gamma$ (IFN $\gamma$ ). In concert, these intracellular antigens, viral pathogens and cytokines activate local leukocytes, and increase endothelial expression of adhesion molecules, chemokines and chemokine receptors, collectively resulting in the recruitment of innate immune cells.

The subacute phase starts around day 5 and can last weeks to several months. This phase starts with infiltration of the heart by innate immune cells, including natural killer cells that directly recognize and kill infected cells, and monocytes and macrophages that 


\section{Chapter 1}

secure phagocytosis of dead cells and further increase the expression of proinflammatory cytokines. Subsequently, the adaptive immune system is activated and T- and Blymphocytes enter the heart to further clear infected cells and produce neutralizing antibodies to limit viral replication. Ultimately, the immune response results in elimination of infected and dead cells, in decreased viral presence but unfortunately also in irreversible cardiac damage.

The final phase is characterized by cardiac remodeling. Anti-inflammatory cytokines such as TGFbeta and IL-10, and anti-inflammatory immune cells like regulatory T cells and type 2 macrophages foster resolution of the immune response, activation of fibroblasts and replacement of dead tissue by fibrotic scars. Dependent on the extent of cardiac damage and fibrosis, arrhythmias, cardiac dilation and compensatory hypertrophy may occur, which can ultimately lead to systolic dysfunction. Moreover, incomplete clearance of the virus can result in chronic inflammation of the heart and enhanced development of dilated cardiomyopathy and systolic HF.

So far, research and development of novel therapeutic strategies for VM has mainly focused on processes targeting inflammation, cardiomyocyte degeneration, and fibrosis ${ }^{58-}$ 60 , while only few studies have addressed the effect of viral infection on cardiomyocyte function itself. Importantly, in surviving myocytes viral replication also directly causes defective cardiomyocyte contraction, by modulating time-dependently different cardiomyocyte ion-channels, adding up to the viral-induced cardiac systolic dysfunction ${ }^{61,62}$.

\section{AIMS AND OUTLINE OF THIS THESIS}

This thesis aims to highlight the role of the cardiac extracellular environment in the development of systolic and diastolic dysfunction and concomitant HF. The biological contribution of the secreted matrix proteins OGN, SPARC, and WARP to diastolic or systolic cardiac function was investigated.

Chapter 2 introduces the first extracellular protein, OGN. This small matrix protein has previously caused some confusion, because different names for OGN exist and different transcripts and proteins have been identified. Therefore, a concise overview of this gene, its products and its central role during (patho-) physiology is given. Chapter 3 presents experimental work that further elaborates on the role of OGN during hypertensive- and age- induced cardiac remodelling and especially its importance in diastolic dysfunction. In chapter 4 and 5, experimental work on the role of the extracellular matrix proteins SPARC and WARP in systolic HF is presented. Chapter 4 identifies SPARC as a novel inotropic agent that improves cardiac contraction, both during health and during systolic dysfunction. Chapter 5 describes a redundant role for WARP in the wound healing process after MI. However, this chapter demonstrates how different breeding strategies determine rupture incidence following $\mathrm{Ml}$ in mice, and highlights the im- 
General Introduction and Outline of the Thesis

portance of using the correct mouse controls in cardiovascular research. The value of this thesis' findings and future perspectives will be discussed in chapter 6 . 


\section{REFERENCES}

1. Nichols M TN, Luengo-Fernandez R, Leal J, Gray A, Scarborough P, Rayner M European cardiovascular disease statistics 2012. European Heart Network. 2012

2. Sakata Y, Shimokawa H. Epidemiology of heart failure in asia. Circ J. 2013;77:2209-2217

3. Lozano R, Naghavi M, Foreman K, Lim S, Shibuya K, Aboyans V, Abraham J, Adair T, Aggarwal R, Ahn SY, Alvarado M, Anderson HR, Anderson LM, Andrews KG, Atkinson C, Baddour LM, Barker-Collo S, Bartels DH, Bell ML, Benjamin EJ, Bennett D, Bhalla K, Bikbov B, Bin Abdulhak A, Birbeck G, Blyth F, Bolliger I, Boufous S, Bucello C, Burch M, Burney P, Carapetis J, Chen H, Chou D, Chugh SS, Coffeng LE, Colan SD, Colquhoun S, Colson KE, Condon J, Connor MD, Cooper LT, Corriere M, Cortinovis M, de Vaccaro KC, Couser W, Cowie BC, Criqui MH, Cross M, Dabhadkar KC, Dahodwala N, De Leo D, Degenhardt L, Delossantos A, Denenberg J, Des Jarlais DC, Dharmaratne SD, Dorsey ER, Driscoll T, Duber H, Ebel B, Erwin PJ, Espindola $P$, Ezzati $M$, Feigin V, Flaxman $A D$, Forouzanfar $M H$, Fowkes $F G$, Franklin R, Fransen $M$, Freeman MK, Gabriel SE, Gakidou E, Gaspari F, Gillum RF, Gonzalez-Medina D, Halasa YA, Haring D, Harrison JE, Havmoeller R, Hay RJ, Hoen B, Hotez PJ, Hoy D, Jacobsen KH, James SL, Jasrasaria R, Jayaraman S, Johns N, Karthikeyan G, Kassebaum N, Keren A, Khoo JP, Knowlton LM, Kobusingye O, Koranteng A, Krishnamurthi R, Lipnick M, Lipshultz SE, Ohno SL, Mabweijano J, Maclntyre MF, Mallinger L, March L, Marks GB, Marks R, Matsumori A, Matzopoulos R, Mayosi BM, McAnulty JH, McDermott MM, McGrath J, Mensah GA, Merriman TR, Michaud C, Miller M, Miller TR, Mock C, Mocumbi AO, Mokdad AA, Moran A, Mulholland K, Nair MN, Naldi L, Narayan KM, Nasseri K, Norman P, O'Donnell M, Omer SB, Ortblad K, Osborne R, Ozgediz D, Pahari B, Pandian JD, Rivero AP, Padilla RP, Perez-Ruiz F, Perico N, Phillips D, Pierce K, Pope CA, 3rd, Porrini E, Pourmalek F, Raju M, Ranganathan D, Rehm JT, Rein DB, Remuzzi G, Rivara FP, Roberts T, De Leon FR, Rosenfeld LC, Rushton L, Sacco RL, Salomon JA, Sampson U, Sanman E, Schwebel DC, Segui-Gomez M, Shepard DS, Singh D, Singleton J, Sliwa K, Smith E, Steer A, Taylor JA, Thomas B, Tleyjeh IM, Towbin JA, Truelsen T, Undurraga EA, Venketasubramanian N, Vijayakumar L, Vos T, Wagner GR, Wang M, Wang W, Watt K, Weinstock MA, Weintraub R, Wilkinson JD, Woolf AD, Wulf S, Yeh PH, Yip P, Zabetian A, Zheng ZJ, Lopez AD, Murray CJ, AlMazroa MA, Memish ZA. Global and regional mortality from 235 causes of death for 20 age groups in 1990 and 2010: A systematic analysis for the global burden of disease study 2010. Lancet. 2012;380:2095-2128

4. Pongmoragot J, Lee DS, Park TH, Fang J, Austin PC, Saposnik G, Investigators of the Registry of the Canadian Stroke N, University of Toronto Stroke Program for the Stroke Outcomes Research Canada Working G. Stroke and heart failure: Clinical features, access to care, and outcomes. J Stroke Cerebrovasc Dis. 2016

5. Kochanek KD, Murphy SL, Xu J. Deaths: Final data for 2011. Nat/ Vital Stat Rep. 2015;63:1-120

6. McMurray JJ, Adamopoulos S, Anker SD, Auricchio A, Bohm M, Dickstein K, Falk V, Filippatos G, Fonseca C, Gomez-Sanchez MA, Jaarsma T, Kober L, Lip GY, Maggioni AP, Parkhomenko A, Pieske BM, Popescu BA, Ronnevik PK, Rutten FH, Schwitter J, Seferovic P, Stepinska J, Trindade PT, Voors AA, Zannad F, Zeiher A, Task Force for the D, Treatment of A, Chronic Heart Failure of the European Society of C, Bax JJ, Baumgartner H, Ceconi C, Dean V, Deaton C, Fagard R, Funck-Brentano C, Hasdai D, Hoes A, Kirchhof P, Knuuti J, Kolh P, McDonagh T, Moulin C, Popescu BA, Reiner Z, Sechtem U, Sirnes PA, Tendera M, Torbicki A, Vahanian A, Windecker S, McDonagh T, Sechtem U, Bonet LA, Avraamides P, Ben Lamin HA, Brignole M, Coca A, Cowburn P, Dargie H, Elliott P, Flachskampf FA, Guida GF, Hardman S, lung B, Merkely B, Mueller C, Nanas JN, Nielsen OW, Orn S, Parissis JT, Ponikowski P, Guidelines ESCCfP. Esc guidelines for the diagnosis and treatment of acute and chronic heart failure 2012: The task force for the diagnosis and treatment of acute and chronic heart failure 2012 of the european society of cardiology. Developed in collaboration with the heart failure association (hfa) of the esc. Eur J Heart Fail. 2012;14:803-869

7. van Heerebeek L, Paulus WJ. Understanding heart failure with preserved ejection fraction: Where are we today? Netherlands heart journal : monthly journal of the Netherlands Society of Cardiology and the Netherlands Heart Foundation. 2016

8. Mudd JO, Kass DA. Tackling heart failure in the twenty-first century. Nature. 2008;451:919-928 
9. Oikonomou E, Tousoulis D, Siasos G, Zaromitidou M, Papavassiliou AG, Stefanadis C. The role of inflammation in heart failure: New therapeutic approaches. Hellenic J Cardiol. 2011;52:30-40

10. He J, Ogden LG, Bazzano LA, Vupputuri S, Loria C, Whelton PK. Risk factors for congestive heart failure in us men and women: Nhanes i epidemiologic follow-up study. Arch Intern Med. 2001;161:996-1002

11. Borlaug BA, Melenovsky V, Russell SD, Kessler K, Pacak K, Becker LC, Kass DA. Impaired chronotropic and vasodilator reserves limit exercise capacity in patients with heart failure and a preserved ejection fraction. Circulation. 2006;114:2138-2147

12. Paulus WJ, Tschope C. A novel paradigm for heart failure with preserved ejection fraction: Comorbidities drive myocardial dysfunction and remodeling through coronary microvascular endothelial inflammation. J Am Coll Cardiol. 2013;62:263-271

13. Piek A, de Boer RA, Sillje HH. The fibrosis-cell death axis in heart failure. Heart Fail Rev. 2016;21:199-211

14. Gloschat CR, Koppel AC, Aras KK, Brennan JA, Holzem KM, Efimov IR. Arrhythmogenic and metabolic remodeling of failing human heart. The Journal of physiology. 2016

15. Murphy-Ullrich JE, Sage EH. Revisiting the matricellular concept. Matrix biology : journal of the International Society for Matrix Biology. 2014;37:1-14

16. Bradshaw AD. The role of secreted protein acidic and rich in cysteine (sparc) in cardiac repair and fibrosis: Does expression of sparc by macrophages influence outcomes? Journal of molecular and cellular cardiology. 2015

17. Swinnen M, Vanhoutte D, Van Almen GC, Hamdani N, Schellings MW, D'Hooge J, Van der Velden J, Weaver MS, Sage EH, Bornstein P, Verheyen FK, VandenDriessche T, Chuah MK, Westermann D, Paulus WJ, Van de Werf F, Schroen B, Carmeliet P, Pinto YM, Heymans S. Absence of thrombospondin-2 causes age-related dilated cardiomyopathy. Circulation. 2009;120:1585-1597

18. van Almen GC, Swinnen M, Carai P, Verhesen W, Cleutjens JP, D'Hooge J, Verheyen FK, Pinto YM, Schroen $B$, Carmeliet $\mathrm{P}$, Heymans $\mathrm{S}$. Absence of thrombospondin-2 increases cardiomyocyte damage and matrix disruption in doxorubicin-induced cardiomyopathy. Journal of molecular and cellular cardiology. 2011;51:318-328

19. Papageorgiou AP, Swinnen $M$, Vanhoutte $D$, VandenDriessche $T$, Chuah $M$, Lindner $D$, Verhesen $W$, de Vries B, D'Hooge J, Lutgens E, Westermann D, Carmeliet P, Heymans S. Thrombospondin-2 prevents cardiac injury and dysfunction in viral myocarditis through the activation of regulatory t-cells. Cardiovascular research. 2012;94:115-124

20. Schellings MW, Vanhoutte D, Swinnen M, Cleutjens JP, Debets J, van Leeuwen RE, d'Hooge J, Van de Werf F, Carmeliet P, Pinto YM, Sage EH, Heymans S. Absence of sparc results in increased cardiac rupture and dysfunction after acute myocardial infarction. J Exp Med. 2009;206:113-123

21. Bradshaw AD, Baicu CF, Rentz TJ, Van Laer AO, Boggs J, Lacy JM, Zile MR. Pressure overload-induced alterations in fibrillar collagen content and myocardial diastolic function: Role of secreted protein acidic and rich in cysteine (sparc) in post-synthetic procollagen processing. Circulation. 2009;119:269-280

22. Allen JM, Bateman JF, Hansen U, Wilson R, Bruckner P, Owens RT, Sasaki T, Timpl R, Fitzgerald J. Warp is a novel multimeric component of the chondrocyte pericellular matrix that interacts with perlecan. J Biol Chem. 2006;281:7341-7349

23. Arikawa-Hirasawa E, Watanabe H, Takami H, Hassell JR, Yamada Y. Perlecan is essential for cartilage and cephalic development. Nat Genet. 1999;23:354-358

24. Sasse $P$, Malan D, Fleischmann M, Roell W, Gustafsson E, Bostani T, Fan Y, Kolbe T, Breitbach M, Addicks K, Welz A, Brem G, Hescheler J, Aszodi A, Costell M, Bloch W, Fleischmann BK. Perlecan is critical for heart stability. Cardiovasc Res. 2008;80:435-444

25. Costell M, Gustafsson E, Aszodi A, Morgelin M, Bloch W, Hunziker E, Addicks K, Timpl R, Fassler R. Perlecan maintains the integrity of cartilage and some basement membranes. J Cell Biol. 1999;147:1109-1122

26. Iozzo RV, Schaefer L. Proteoglycans in health and disease: Novel regulatory signaling mechanisms evoked by the small leucine-rich proteoglycans. The FEBS journal. 2010;277:3864-3875

27. Kampmann A, Fernandez B, Deindl E, Kubin T, Pipp F, Eitenmuller I, Hoefer IE, Schaper W, Zimmermann R. The proteoglycan osteoglycin/mimecan is correlated with arteriogenesis. Molecular and cellular biochemistry. 2009;322:15-23 


\section{Chapter 1}

28. Moreth K, lozzo RV, Schaefer L. Small leucine-rich proteoglycans orchestrate receptor crosstalk during inflammation. Cell cycle. 2012;11:2084-2091

29. Nastase MV, lozzo RV, Schaefer L. Key roles for the small leucine-rich proteoglycans in renal and pulmonary pathophysiology. Biochimica et biophysica acta. 2014;1840:2460-2470

30. Hildebrand A, Romaris M, Rasmussen LM, Heinegard D, Twardzik DR, Border WA, Ruoslahti E. Interaction of the small interstitial proteoglycans biglycan, decorin and fibromodulin with transforming growth factor beta. The Biochemical journal. 1994;302 ( Pt 2):527-534

31. Vuillermoz B, Wegrowski Y, Contet-Audonneau JL, Danoux L, Pauly G, Maquart FX. Influence of aging on glycosaminoglycans and small leucine-rich proteoglycans production by skin fibroblasts. Molecular and cellular biochemistry. 2005;277:63-72

32. Schaefer L, lozzo RV. Biological functions of the small leucine-rich proteoglycans: From genetics to signal transduction. The Journal of biological chemistry. 2008;283:21305-21309

33. Rienks M, Papageorgiou AP, Frangogiannis NG, Heymans S. Myocardial extracellular matrix: An everchanging and diverse entity. Circulation research. 2014;114:872-888

34. Zheng CX, Zhao SX, Wang P, Yu HM, Wang CF, Han B, Su B, Xiang Y, Li XS, Li SX, Ma QY, Zhang RX, Wan HY, Song HD. Different expression of mimecan as a marker for differential diagnosis between nsclc and sclc. Oncology reports. 2009;22:1057-1061

35. Cui X, Song B, Hou L, Wei Z, Tang J. High expression of osteoglycin decreases the metastatic capability of mouse hepatocarcinoma hca-f cells to lymph nodes. Acta biochimica et biophysica Sinica. 2008;40:349-355

36. Diskin S, Kumar J, Cao Z, Schuman JS, Gilmartin T, Head SR, Panjwani N. Detection of differentially expressed glycogenes in trabecular meshwork of eyes with primary open-angle glaucoma. Investigative ophthalmology \& visual science. 2006;47:1491-1499

37. Malaud E, Merle D, Piquer D, Molina L, Salvetat N, Rubrecht L, Dupaty E, Galea P, Cobo S, Blanc A, Saussine M, Marty-Ane C, Albat B, Meilhac O, Rieunier F, Pouzet A, Molina F, Laune D, Fareh J. Local carotid atherosclerotic plaque proteins for the identification of circulating biomarkers in coronary patients. Atherosclerosis. 2014;233:551-558

38. Cheng JM, Akkerhuis KM, Meilhac O, Oemrawsingh RM, Garcia-Garcia HM, van Geuns RJ, Piquer D, Merle D, du Paty E, Galea P, Jaisser F, Rossignol P, Serruys PW, Boersma E, Fareh J, Kardys I. Circulating osteoglycin and $\mathrm{ngal} / \mathrm{mmp9}$ complex concentrations predict 1-year major adverse cardiovascular events after coronary angiography. Arteriosclerosis, thrombosis, and vascular biology. 2014;34:1078-1084

39. Petretto E, Sarwar R, Grieve I, Lu H, Kumaran MK, Muckett PJ, Mangion J, Schroen B, Benson M, Punjabi PP, Prasad SK, Pennell DJ, Kiesewetter C, Tasheva ES, Corpuz LM, Webb MD, Conrad GW, Kurtz TW, Kren V, Fischer J, Hubner N, Pinto YM, Pravenec M, Aitman TJ, Cook SA. Integrated genomic approaches implicate osteoglycin (ogn) in the regulation of left ventricular mass. Nature genetics. 2008;40:546-552

40. Van Aelst LN, Voss S, Carai P, van Leeuwen R, Vanhoutte D, Sanders-van Wijk S, Eurlings L, Swinnen M, Verheyen FA, Verbeken EK, Nef H, Troidl C, Cook SA, Brunner-La Rocca HP, Mollmann H, Papageorgiou AP, Heymans S. Osteoglycin prevents cardiac dilatation and dysfunction after myocardial infarction through infarct collagen strengthening. Circulation research. 2014

41. Mozaffarian D, Benjamin EJ, Go AS, Arnett DK, Blaha MJ, Cushman M, Das SR, de Ferranti S, Despres JP, Fullerton HJ, Howard VJ, Huffman MD, Isasi CR, Jimenez MC, Judd SE, Kissela BM, Lichtman JH, Lisabeth LD, Liu S, Mackey RH, Magid DJ, McGuire DK, Mohler ER, 3rd, Moy CS, Muntner P, Mussolino ME, Nasir K, Neumar RW, Nichol G, Palaniappan L, Pandey DK, Reeves MJ, Rodriguez CJ, Rosamond W, Sorlie PD, Stein J, Towfighi A, Turan TN, Virani SS, Woo D, Yeh RW, Turner MB, American Heart Association Statistics C, Stroke Statistics S. Heart disease and stroke statistics-2016 update: A report from the american heart association. Circulation. 2016;133:e38-e360

42. Wolf-Maier K, Cooper RS, Banegas JR, Giampaoli S, Hense HW, Joffres M, Kastarinen M, Poulter N, Primatesta P, Rodriguez-Artalejo F, Stegmayr B, Thamm M, Tuomilehto J, Vanuzzo D, Vescio F. Hypertension prevalence and blood pressure levels in 6 european countries, canada, and the united states. JAMA. 2003;289:2363-2369

43. Zile MR, Baicu CF, Gaasch WH. Diastolic heart failure--abnormalities in active relaxation and passive stiffness of the left ventricle. N Engl J Med. 2004;350:1953-1959 
44. Zile MR, Gottdiener JS, Hetzel SJ, McMurray JJ, Komajda M, McKelvie R, Baicu CF, Massie BM, Carson PE, Investigators IP. Prevalence and significance of alterations in cardiac structure and function in patients with heart failure and a preserved ejection fraction. Circulation. 2011;124:2491-2501

45. Shah AM, Shah SJ, Anand IS, Sweitzer NK, O'Meara E, Heitner JF, Sopko G, Li G, Assmann SF, McKinlay SM, Pitt B, Pfeffer MA, Solomon SD, Investigators T. Cardiac structure and function in heart failure with preserved ejection fraction: Baseline findings from the echocardiographic study of the treatment of preserved cardiac function heart failure with an aldosterone antagonist trial. Circulation. Heart failure. 2014; 7:104-115

46. Sun Z. Aging, arterial stiffness, and hypertension. Hypertension. 2015;65:252-256

47. Van Linthout S, Miteva K, Tschope C. Crosstalk between fibroblasts and inflammatory cells. Cardiovascular research. 2014;102:258-269

48. Heymans S, Corsten MF, Verhesen W, Carai P, van Leeuwen RE, Custers K, Peters T, Hazebroek M, Stoger L, Wijnands E, Janssen BJ, Creemers EE, Pinto YM, Grimm D, Schurmann N, Vigorito E, Thum T, Stassen F, Yin X, Mayr M, de Windt LJ, Lutgens E, Wouters K, de Winther MP, Zacchigna S, Giacca M, van Bilsen M, Papageorgiou AP, Schroen B. Macrophage microrna-155 promotes cardiac hypertrophy and failure. Circulation. 2013;128:1420-1432

49. Azevedo CF, Nigri M, Higuchi ML, Pomerantzeff PM, Spina GS, Sampaio RO, Tarasoutchi F, Grinberg M, Rochitte CE. Prognostic significance of myocardial fibrosis quantification by histopathology and magnetic resonance imaging in patients with severe aortic valve disease. J Am Coll Cardiol. 2010;56:278-287

50. Kasner M, Westermann D, Lopez B, Gaub R, Escher F, Kuhl U, Schultheiss HP, Tschope C. Diastolic tissue doppler indexes correlate with the degree of collagen expression and cross-linking in heart failure and normal ejection fraction. J Am Coll Cardiol. 2011;57:977-985

51. Zile MR, Baicu CF, Ikonomidis JS, Stroud RE, Nietert PJ, Bradshaw AD, Slater R, Palmer BM, Van Buren P, Meyer M, Redfield MM, Bull DA, Granzier HL, LeWinter MM. Myocardial stiffness in patients with heart failure and a preserved ejection fraction: Contributions of collagen and titin. Circulation. 2015;131:12471259

52. Nicoletti A, Michel JB. Cardiac fibrosis and inflammation: Interaction with hemodynamic and hormonal factors. Cardiovascular research. 1999;41:532-543

53. van den Borne SW, Diez J, Blankesteijn WM, Verjans J, Hofstra L, Narula J. Myocardial remodeling after infarction: The role of myofibroblasts. Nat Rev Cardiol. 2010;7:30-37

54. Nahrendorf M, Swirski FK. Innate immune cells in ischaemic heart disease: Does myocardial infarction beget myocardial infarction? Eur Heart J. 2016;37:868-872

55. van der Laan AM, Nahrendorf M, Piek JJ. Republished: Healing and adverse remodelling after acute myocardial infarction: Role of the cellular immune response. Postgrad Med J. 2013;89:52-58

56. Lindsey ML, Mann DL, Entman ML, Spinale FG. Extracellular matrix remodeling following myocardial injury. Ann Med. 2003;35:316-326

57. Mason JW. Myocarditis and dilated cardiomyopathy: An inflammatory link. Cardiovascular research. 2003;60:5-10

58. Corsten MF, Schroen B, Heymans S. Inflammation in viral myocarditis: Friend or foe? Trends Mol Med. 2012;18:426-437

59. Pollack A, Kontorovich AR, Fuster V, Dec GW. Viral myocarditis-diagnosis, treatment options, and current controversies. Nat Rev Cardiol. 2015;12:670-680

60. Hazebroek M, Dennert R, Heymans S. Virus infection of the heart--unmet therapeutic needs. Antivir Chem Chemother. 2012;22:249-253

61. Wessely R, Klingel K, Santana LF, Dalton N, Hongo M, Jonathan Lederer W, Kandolf R, Knowlton KU. Transgenic expression of replication-restricted enteroviral genomes in heart muscle induces defective excitation-contraction coupling and dilated cardiomyopathy. J Clin Invest. 1998;102:1444-1453

62. Steinke K, Sachse F, Ettischer N, Strutz-Seebohm N, Henrion U, Rohrbeck M, Klosowski R, Wolters D, Brunner S, Franz WM, Pott L, Munoz C, Kandolf R, Schulze-Bahr E, Lang F, Klingel K, Seebohm G. Coxsackievirus b3 modulates cardiac ion channels. FASEB journal : official publication of the Federation of American Societies for Experimental Biology. 2013;27:4108-4121 

Chapter

\section{The diverse functions of Osteoglycin: a Deceitful Dwarf or a Master Regulator of Disease?}

Modified from FASEB. 2016;30(8):2651-61.

Sophie Deckx $x^{1,2}$, Stephane Heymans ${ }^{1,2}$, Anna-Pia Papageorgiou ${ }^{1,2}$

${ }^{1}$ Department of Cardiology, Maastricht University, Maastricht, The Netherlands,

${ }^{2}$ Centre for Molecular and Vascular Biology, KULeuven, Leuven, Belgium, 


\section{Chapter 2}

\section{ABSTRACT}

Small leucine rich proteoglycans are emerging as important regulatory proteins within the extracellular matrix where they exert both structural and non-structural functions and hence are modulators of numerous biological processes such as inflammation, fibrosis, and cell proliferation. One proteoglycan in particular, osteoglycin, also known as mimecan, shows great structural and functional diversity in normal physiology and during disease, therefore making it a very interesting candidate for the development of novel therapeutic strategies. Unfortunately, literature on osteoglycin is confusing, as different names for osteoglycin exist, as well as different transcript and protein variants have been described. This review will therefore give a clear overview of the different structures and functions of osteoglycin identified up till now, portray its central role in (patho-) physiology and highlight the importance of post-translational processing such as glycosylation for the diversity of its functions. 


\section{INTRODUCTION}

The extracellular matrix is a complex network of structural and non-structural matrix proteins with a fundamental role in development, homeostasis and pathophysiology. Small leucine rich proteoglycans (SLRPS) are small proteoglycans present in the extracellular matrix, where they are involved in a wide range of processes like inflammation, fibrosis, and cell proliferation ${ }^{1-4}$. Given the diversity of SLRPs, these proteoglycans are interesting targets for matrix-related research. In particular osteoglycin (OGN), a class III SLRP member with multiple glycosylation sites, has been shown to be involved in many physiological processes e.g. collagen fibrillogenesis, cell proliferation and development, and during diverse pathologies such as cardiovascular diseases, cancer and eye disease. Despite the extensive research on OGN, the literature is rather confusing, because different names for OGN such as osteoinductive factor or mimecan have been used, and different transcript and protein variants have been identified. Moreover, posttranslational processing, such as glycosylation, paramount in providing diversity in structure and function, is often poorly described. Hence, an identified function of OGN is rarely annotated to a certain transcript or glycosylated protein variant, adding to the confusion. Therefore, the aim of this review is to give a clear overview of the different structures and functions of OGN known so far, highlight the importance of its glycosylation for the diversity in function, and describe its central role during normal physiology and during different pathological conditions.

\section{OSTEOGLYCIN: A DECEITFUL DWARF}

SLRPs have leucine-rich repeats $(L R R)^{5}$, which are conserved motifs that are present from bacteria to man, and are critical for many processes like protein-protein interactions, signal transduction, cell adhesion and DNA repair ${ }^{5}$. The SLRPs are characterized by their small size and similar structure of an LRR core, flanked by cysteine residues. Based on their chromosomal organization, the number and pattern of their repeats, and the spacing of the $\mathrm{N}$-terminal cysteine residues, SLRPs are divided into 5 classes $^{1,6}$. As a result of the diversity of their LRR core and glycosylation patterns, SLRPs can bind various growth factors (e.g. TGF-beta ${ }^{7}$ ), cell surface receptors (e.g. epidermal growth factor receptors ${ }^{2}$ and insulin growth factor receptors ${ }^{2}$ ), as well as other matrix proteins (e.g. collagens ${ }^{4}$ ). SLRPs were originally identified as proteoglycans in the bone and cartilage but their functions subsequently extended to include corneal transparency ${ }^{8}$, development $^{9}$, regeneration ${ }^{10}$, cancer biology ${ }^{2,11}$, and immunity ${ }^{3}$. Furthermore, they have been shown to be involved in a wide range of processes, like cell proliferation ${ }^{2}$, arteriogenesis $^{12}$, inflammation ${ }^{3,11}$, fibrosis ${ }^{7,11}$, and ageing ${ }^{13}$, and hence this group of proteoglycans play crucial roles in many different diseases ${ }^{6,11,14}$. 


\section{Chapter 2}

In 1990, OGN was identified as a novel SLRP in a fraction of bovine bone and was initially called osteoinductive factor as it induced bone formation ${ }^{15}$. Later the activity was ascribed to contamination of the protein isolates with bone morphogenetic proteins (BMP) -2 and -3 , and thus the protein was renamed 'osteoglycin' ${ }^{16}$. However, the nomenclature of OGN still remained confusing. Funderburgh and colleagues demonstrated at that time that two unrelated proteins, OGN and ketaran sulphate proteoglycan 25 (KSPG25), were actually products of the same gene and concluded that they were likely proteolytic products of the same propeptide. They proposed to call this gene and its products "mimecan", given its small and elusive nature. The choice was based on the Norse legend of the deceptive dwarf Mime, whose head continued to survive and was consulted as a source of wisdom even after being separated from its body ${ }^{17}$. Subsequent research has further complicated rather than clarify matters, as different sizes of the OGN mRNA and protein have been identified, dependent on the tissue source or due to differential splicing, alternative polyadenylation and post-translational modifications such as glycosylation ${ }^{17-19}$. Both names (OGN and mimecan) are randomly used in literature, adding to the confusion. For the purpose of this review, we will use OGN as the general name for all products of the OGN/mimecan gene, and if possible clarify in more detail which of the mRNA or (glycosylated) protein variants it refers to.

\section{OGN IN NORMAL PHYSIOLOGY}

OGN is encoded by one single gene, though many processes affecting the transcription and translation of the OGN gene have been identified (Figure 1). The most extensively described in literature is the bovine OGN gene, but also other species show likewise regulatory processes and diversity on transcript and protein level (Table 1$)^{12,20-24}$. Different regulatory elements in the promoter region of the bovine and human OGN gene, like a p53 DNA binding site, a UV-responsive E-box and multiple interferon stimulated response elements, have been identified and have been shown to induce (e.g. p53 binding, UV irradiation or IRF-2) or decrease (IRF-1) OGN expression ${ }^{19,25,26}$. Moreover, due to different transcription initiation sites, alternative splicing and/or the use of alternative polyadenylation sites, multiple transcript variants exist ${ }^{18,20}$. For example, the bovine OGN gene contains 8 exons and possibly has 8 different mRNA transcripts, due to 2 different transcription initiation sites in exon 1 and exon 2. Furthermore, 2 different splice acceptor sites in the 3rd exon and 2 alternative polyadenylation sites at the $3^{\prime}$ end have been identified ${ }^{18,20}$.

Interestingly, despite this high diversity in OGN mRNA transcripts, only one precursor protein is encoded and whether all transcripts or only certain variants give rise to this precursor protein is not yet known. For the bovine OGN for example, the OGN protein is encoded from exon 3 to $8^{20}$. Yet, all different transcript variants are present within a cell, possibly exerting other functions through RNA-RNA and RNA-protein interac- 
tions $^{27}$. Furthermore, which transcript variant is most abundant is highly tissue dependent. In bovine corneas and keratocytes, mainly a smaller $2.4 \mathrm{~kb}$ mRNA OGN transcript is present, while in other tissues, like cartilage, aorta and skin, larger $2.5 \mathrm{~kb}$ or $2.6 \mathrm{~kb}$ transcripts are present, indicating a tissue-dependent transcript preference ${ }^{17,18}$, and suggesting complex mechanisms in the regulation of OGN gene expression. For example, basic fibroblast growth factor (bFGF) has been shown to modulate the expression of these different transcript variants in a temporal manner in bovine keratocytes in vitro ${ }^{20}$. Sequence analysis revealed that the bovine OGN is synthetized as a 299 amino-acid (aa) precursor, including an 18aa signal sequence at the N-terminus, containing 7 LRRs. After cleavage of the signal sequence, proteolytic cleavage of the carboxyl-terminus results in a $12 \mathrm{kD}$ OGN protein or in the larger $25 \mathrm{kD}$ KSPG $25^{15,17}$. In humans, a 298 aa precursor was identified, showing $94 \%$ homology to the bovine OGN ${ }^{15}$ and later Ujita et al isolated a 298 aa murine precursor OGN, showing $85 \%$ and $86 \%$ identity to human and bovine OGN respectively ${ }^{21}$. In all species similar post-translational processing of the precursor OGN occurs (Figure 1 and Table 1$)^{20-24,28,29}$. In addition, post-translational modifications of the protein increase further the diversity of OGN as one more level of complexity is achieved through glycosylation, which is also tissue- and condition dependent. In bovine keratocytes, OGN is present as a keratan sulfated protein, with large keratan sulfates attached via $\mathrm{N}$-linked connections to the protein backbone ${ }^{30}$, while in other bovine tissues OGN is present as a bigger protein with no or shorter keratan sulfate chains, but with possibly other sugar chains attached to it ${ }^{12,17}$. In a rabbit femoral artery ligation model, Kampmann and colleagues show that OGN is mainly present in the vascular smooth muscle cells (VSMCs) of the collateral arteries as a 36-40 kD glycosylated protein, but with no keratan sulfate chains attached to $i^{12}$.

OGN is ubiquitously expressed with its presence described in bovine cornea, aorta, sclera, skin, cartilage, vagus nerve and in lower amounts in cerebrellum, kidney, intestines, myocardium and skeletal muscle ${ }^{17}$. OGN presence was also demonstrated in human $^{15}$, mouse $^{21}$, rat $^{31}$, rabbit $^{12,32}$, birds $^{23,24}$, dogs $^{33}$ and pigs ${ }^{34}$ where it is present in the same tissues, but also in the pituitary ${ }^{35,36}$ and adrenal gland ${ }^{37}$, lung ${ }^{32,37}$, liver ${ }^{32}$, peripheral vessels ${ }^{32}$, testis $^{21}$, ovary ${ }^{37}$ teeth $^{38}$ and ear ${ }^{23}$.

Most likely, each different OGN variant will have a certain function. Unfortunately, few studies discriminate between the different mRNA and glycosylated protein variants of OGN and hence, which OGN variant is responsible for the described function is not always known. Figure 2 illustrates the identified molecular interactions and processes OGN is involved in, in specific cell types. For clarity only one transcript and protein variant are shown. Therefore, in addition, an overview of the different transcripts and protein structures and their (un-) annotated functions in different species are shown in table 1. Information was found on www.ncbi.nlm.nih.gov, www.uniprot.org and in references described in the text. 


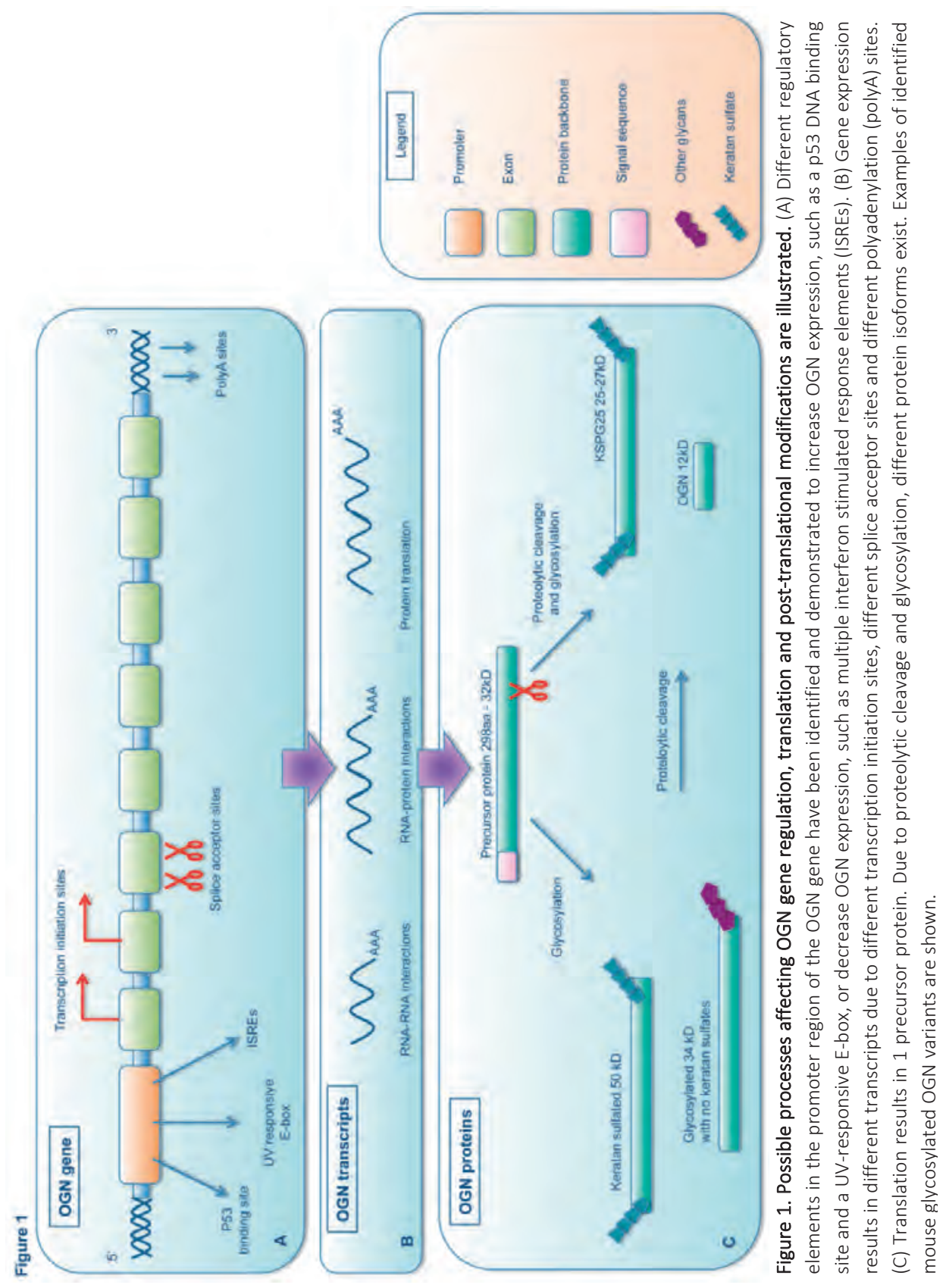


Table 1. The different OGN transcripts and proteins described in different species KS; keratan sulphate

\begin{tabular}{|c|c|c|c|c|c|}
\hline Species & $\begin{array}{l}\text { Transcript variants } \\
\text { described }\end{array}$ & $\begin{array}{l}\text { Precursor } \\
\text { protein length } \\
\text { (aa) }\end{array}$ & $\begin{array}{l}\text { Protein variants } \\
\text { described } \\
\text { (annotated function) }\end{array}$ & Glycosylation type & $\begin{array}{l}\text { Un-annotated } \\
\text { functions }\end{array}$ \\
\hline Bovine & $\begin{array}{l}1.9 \mathrm{~kb} \\
2.4 \mathrm{~kb} \\
2.5 \mathrm{~kb} \\
2.6 \mathrm{~kb}\end{array}$ & 299 & $\begin{array}{l}12 k D \\
25 k D\end{array}$ & $\begin{array}{l}\mathrm{N} \text {-linked KS chains } \\
\mathrm{N} \text {-linked KS chains } \\
\mathrm{N} \text {-linked KS chains, } \\
\text { possibly other } \\
\text { chains attached but } \\
\text { type of glycans still } \\
\text { unidentified }\end{array}$ & $\begin{array}{l}\text { keratocyte } \\
\text { proliferation, collagen } \\
\text { fibrillogeneis }\end{array}$ \\
\hline Human & $\begin{array}{l}2.8 \mathrm{~kb} \\
3.6 \mathrm{~kb}\end{array}$ & 298 & $31.8 \mathrm{kD}$ & $\begin{array}{l}\text { N-linked and O- } \\
\text { linked glycosylation, } \\
\text { type of glycans still } \\
\text { unidentified }\end{array}$ & $\begin{array}{l}\text { (bone) development, } \\
\text { fibroblast } \\
\text { proliferation }\end{array}$ \\
\hline Mouse & $\begin{array}{l}2.0 \mathrm{~kb} ; \\
3.7 \mathrm{~kb}\end{array}$ & 298 & $\begin{array}{l}\text { 12-17kD } \\
\text { 25kD (collagen } \\
\text { fibrillogenesis) } \\
34 \text { kD (collagen } \\
\text { fibrillogenesis) } \\
\text { 50kD (collagen } \\
\text { fibrillogenesis) }\end{array}$ & $\begin{array}{l}\text { All murine protein } \\
\text { variants } \mathrm{N} \text {-linked KS } \\
\text { chains and O-linked } \\
\text { glycosylation but } \\
\text { type of glycans still } \\
\text { unidentified }\end{array}$ & $\begin{array}{l}\text { (bone/intestinal) } \\
\text { development, } \\
\text { immune signaling }\end{array}$ \\
\hline Rat & $\begin{array}{l}1.5 \mathrm{~kb} \\
3.2 / 3.5 \mathrm{~kb}\end{array}$ & 298 & $\begin{array}{l}20 \mathrm{kD} \\
34 \mathrm{kD} \text { (VSMC } \\
\text { proliferation) }\end{array}$ & $\begin{array}{l}\text { ? } \\
\text { N-linked } \\
\text { glycosylation, but } \\
\text { type of glycans still } \\
\text { unidentified } \\
?\end{array}$ & immune signaling \\
\hline Rabbit & $\begin{array}{l}3.2 \mathrm{~kb} \text {, not other } \\
\text { variants described } \\
\text { yet }\end{array}$ & 298 & $\begin{array}{l}\text { 36-40kD (VSMC } \\
\text { proliferation and } \\
\text { arteriogenesis) }\end{array}$ & $\begin{array}{l}\text { N-linked KS chains, } \\
\text { others but type of } \\
\text { glycans still } \\
\text { unidentified }\end{array}$ & / \\
\hline Chicken & $\begin{array}{l}2.09 \mathrm{~kb}, \text { no other } \\
\text { variants described } \\
\text { yet }\end{array}$ & 294 & $\begin{array}{l}\text { 38-40kD (corneal } \\
\text { development) }\end{array}$ & $\begin{array}{l}\text { N-linked KS chains, } \\
\text { possibly other } \\
\text { chains attached but } \\
\text { type of glycans still } \\
\text { unidentified (e.g. } \\
\text { during } \\
\text { development) }\end{array}$ & / \\
\hline
\end{tabular}




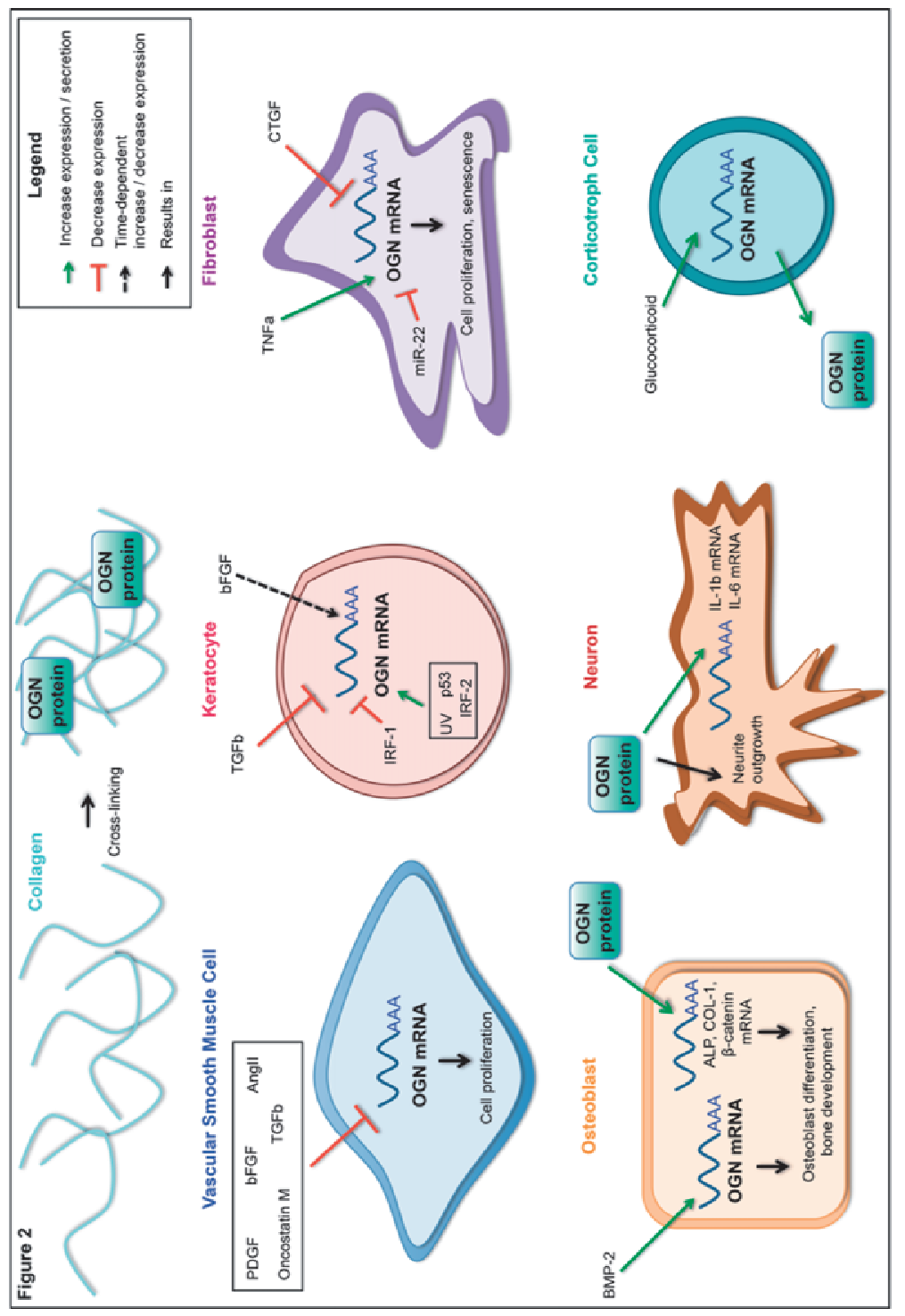

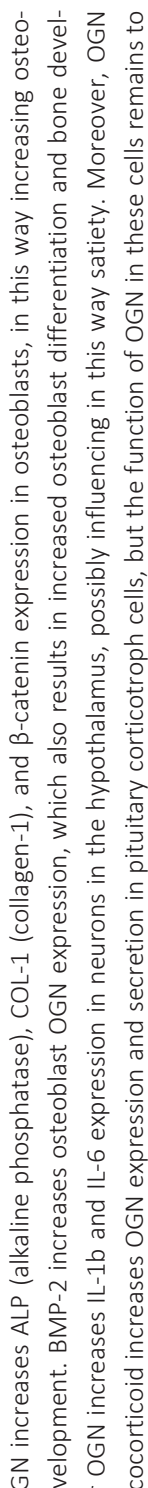

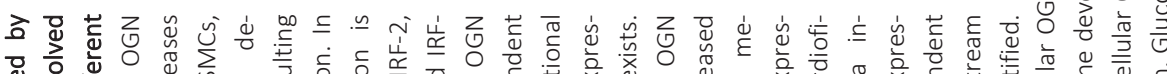

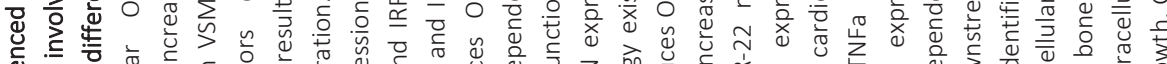

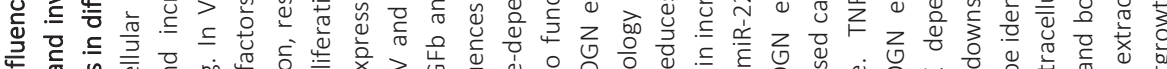

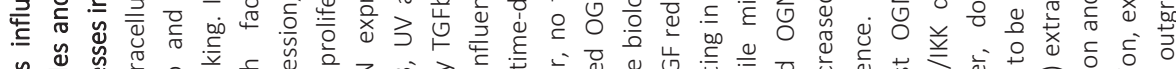

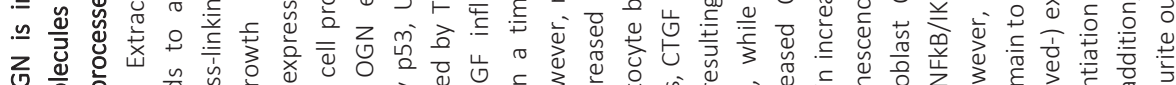

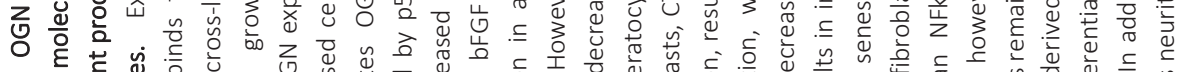
它 ن

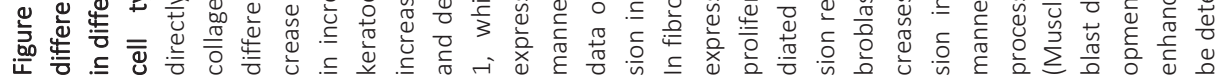




\section{OGN in development}

OGN null mice were developed by Tasheva and colleagues and demonstrated to be viable and fertile. Moreover, they appeared to develop normally and did not display an evident pathological phenotype in a controlled laboratory environment in the initial analysis of these mice. Further analysis revealed no significant changes in corneal clarity or corneal thickness, yet a skin fragility test revealed slightly reduced tensile strength of the skin of OGN null mice compared to WT littermates. This was attributed to a difference in collagen fibrillogenesis, where OGN null mice displayed on average thicker collagen fibrils in both corneal and skin tissue samples ${ }^{39}$. However, Beecher et al investigated the corneal stroma of these OGN null mice using X-ray fiber diffraction studies, (achieving large sampling in order to study the overall structural dimensions of the corneal stroma) and showed larger than normal fibrils in the corneas of OGN null mice existed, but that throughout the whole tissue thickness, the average fibril diameter was unchanged $^{40}$. Furthermore, not all possible functions were explored in the OGN null mice, but the lack of an obvious phenotype could be due to potential compensation by other proteins, such as other SLRPs ${ }^{39}$. Despite the OGN null mice being viable, studies do implicate a role for OGN in development, with OGN having a function downstream of Hedgehog signaling during intestinal development in mice, inhibiting Hedgehog induced smooth muscle cell differentiation, and thus may function as a negative feedback during Hedgehog mediated mesenchymal intestinal development ${ }^{41}$. Moreover, Williamson and colleagues showed increased human and mouse OGN mRNA expression during inner ear development, but no auditory phenotype was present in OGN null mice ${ }^{42}$. Additionally, Dunlevy et al showed steady-state OGN mRNA levels during chick corneal development prior to corneal transparency, which then sharply decreased during adult maintenance ${ }^{24}$. In chicken, only one glycosylated 38-40kD OGN protein isoform was identified (Table 1), though it is less sulfated and hence has fewer or shorter glycosaminoglycan chains attached to the OGN protein during embryonic development. Finally, though initial studies showing that OGN was an osteoinductive factor were later corrected ${ }^{15}$, OGN was demonstrated to be a muscle-derived osteogenic factor ${ }^{29,43,44}$, with increased osteoblast OGN expression during osteoblast differentiation and bone development $^{45-50}$.

\section{Cell Proliferation}

Shanahan and colleagues were the first to implicate a role for OGN in cell prolifera$\operatorname{tion}^{31}$. They identified the OGN gene in rats and studied its expression pattern in aortas, where it is mainly present as a $3.2 \mathrm{~kb}$ transcript but with a minor $1.5 \mathrm{~kb}$ transcript (Table 1). They showed increased OGN in aortas 2 weeks after balloon injury in adult rats and 2 weeks after birth in neonatal rats, when proliferation of VSMCs had seized and matrix modeling is maximal. Moreover, they revealed high expression of OGN mRNA in fully 


\section{Chapter 2}

differentiated adult rat VSMCs, which was down-regulated in cells that had undergone proliferation in vitro. Further in vitro studies showed down-regulation of OGN mRNA expression by bFGF, TGFbeta, platelet-derived growth factor (PDGF), and Angiotensinll (AngII), all cytokines implicated in vascular injury and cell proliferation. In line, another study showed in hypertrophic aortas of sinoaortic-denervated rats, a down-regulation of OGN mRNA expression and a down-regulation of a 34kD OGN protein variant in association with local increases in Angll. In accordance, in vitro exposure of primary VSMCs to Angll decreased OGN expression and importantly, OGN knockdown promoted cell proliferation of the VSMCs induced by either serum or Angl| ${ }^{51}$. Furthermore, OGN mRNA and protein expression was decreased in the developing collateral arteries in a rabbit femoral artery ligation model ${ }^{12}$. In this study, Kampmann and colleagues show a time-dependent regulation of OGN mRNA levels in VSMCs by different factors known to stimulate arteriogenesis, such as oncostatin M, bFGF, TGFbeta, and PDGF ${ }^{12}$. Together these studies indicate that OGN inhibits VSMC cell proliferation but this is not restricted to VSMCs as keratocyte proliferation affects OGN synthesis ${ }^{52,53}$ and connective tissue growth factor (CTGF) decreased OGN mRNA expression in parallel with increased proliferation of human tendon fibroblasts ${ }^{54}$.

\section{Other potential functions}

OGN expression has been associated with many biological processes yet the precise role OGN plays is unclear. For example, OGN has been linked with immunity, as OGN was shown to be an NFKB/IKK-dependent gene in mouse embryonic fibroblasts ${ }^{55}$, whereas in rat articular chondrocytes LPS stimulation through TLR4 increased OGN protein secretion $^{56}$. This is also illustrated by different studies implicating OGN in matrix homeostasis, especially in the cornea. OGN, together with lumican and keratocan, is one of the predominant keratan-sulfated proteoglycans (KSPG) present in vertebrate corneas. This high expression of OGN, combined with its diversity in transcripts and its unique glycosylation, suggests that OGN is important for the development and maintenance of corneal matrix and corneal transparency ${ }^{57-59}$, possibly by regulating collagen fibrillogenesis $^{8}$, yet evidence is lacking. OGN has been most extensively studied in keratocytes from the bovine cornea, where OGN mRNA is mainly present as the smaller $2.4 \mathrm{~kb}$ transcript, and the predominant OGN protein is the KSPG $25^{17}$. OGN has also been demonstrated in other parts of the eye, such as sclera, limbus, choroid, retina, iris and lens ${ }^{23,60,61}$. Moreover, in the lens of OGN null mice increased expression of genes involved in cell adhesion and immune function was found, whilst there was decreased expression of matrix proteins and genes involved in cellular motility ${ }^{61}$. Besides the eye, Shankar and colleagues demonstrated that OGN was up- regulated in choriodecidual tissue during labor, and suggested that OGN is indicative of active tissue remodeling ${ }^{62}$. In addition, OGN was also shown to be present in the corticotroph cells of the pituitary gland of humans, mice (a $25 \mathrm{kD}$ protein) and rats, where its expression and secretion is up regulated by gluco- 
corticoid, but its function remains to be determined ${ }^{36}$. Finally, altered OGN expression during different diseases such as myocardial infarction (MI) and atherosclerosis (see below), where matrix remodeling is prominent, further supports the idea for a role of OGN in matrix homeostasis, yet further research is needed.

\section{OGN IN DISEASE}

Given the high structural and functional diversity of OGN, and its ubiquitous expression, it is not surprising that OGN is involved and crucial in a wide variety of diseases. An overview of the diseases in which OGN has been implicated in is shown in Figure 3.

\section{Eye disease}

OGN expression is decreased during corneal wound healing as keratocytes exhibit a myofibroblast like phenotype, characterized by alpha smooth muscle actin expression and decreased OGN and overall KSPG synthesis ${ }^{52,63}$. For OGN, a shift in mRNA transcripts and overall reduced mRNA and protein levels are seen in bovine keratocytes after TGFbeta stimulation ${ }^{63}$. Also in mice, a decrease in OGN gene expression was found in corneas of BALB/C mice during fungal keratitis ${ }^{64}$. The authors of this study illustrate that alterations in the stromal extracellular matrix might contribute to the acute inflammatory response upon corneal infection. Interestingly, a UV responsive E-box element was identified in the promoter region of the human and bovine OGN gene and this E-box, together with the E-box binding protein upstream transcription factor 1 , is responsible for a UV mediated activation of the OGN gene. UV is a stressor for the eye and can cause many eye diseases such as cataract, photokeratitis and ocular neoplasms. When bovine keratocytes were exposed to UV irradiation, a time-dependent change in OGN expression was observed ${ }^{25}$. Additionally, in human trabecular meshwork cells, an increase in OGN gene expression was demonstrated after incubation with TGFbeta ${ }^{65}$, and importantly, in trabecular meshwork of human eyes with primary open glaucoma, an increase in OGN expression was found ${ }^{66}$. In line with these studies, Dimasi and colleagues studied SNPs in the OGN gene that could correlate with central corneal thickness, which is a risk factor for open angle glaucoma, however they couldn't demonstrate any SNPs in the OGN gene that could correlate. Together, these studies implicate a function for OGN during wound healing and inflammation of the eye.

\section{Cancer}

OGN gene expression was shown to be under control of p53, a known tumor suppressor $^{19}$ and OGN expression is decreased in highly proliferative cells, thus affecting cell proliferation $^{12,31,33,51}$. In the first intron of the bovine and human OGN gene, a p53 DNA 


\section{Chapter 2}

binding sequence was identified and in vitro studies confirmed binding of p53 to this sequence, resulting in the activation of the OGN gene. Importantly, this study also shows reduced or absence of OGN expression in different tumors, such as breast, colon, lung, ovarian, prostatic and pancreatic adenomacarcinomas and in different cancer cell lines, where p53 is frequently mutated or inactivated ${ }^{19}$. Moreover, many other studies showed decreased OGN expression in different cancers such as human gastric cancer ${ }^{67}$, colorectal adenomas $^{68}$, squamous cervical and squamous vaginal cancer ${ }^{69}$, invasive ductal breast carcinomas ${ }^{70}$, laryngeal carcinomas $^{71}$, and mouse and human thyroid tumors $^{72}$, when compared to control tissues. The latter study even showed a progressive decrease in OGN expression from normal tissue to follicular adenoma to aggressive follicular adenoma, indicating that a decrease in OGN expression parallels thyroid tumor progression $^{72}$. Furthermore, OGN is present in human non-small cell lung cancers but not in small cell lung cancers ${ }^{37}$. Another study showed in contrast increased expression of OGN in leiomyomas in African Americans with a predisposition to these type of benign smooth muscle tumors, when compared to Caucasian leiomyomas ${ }^{73}$. Moreover, OGN expression was demonstrated in pituitary glands in mice and humans, where pituitary transcription factor-1 (pit-1) regulates and activates OGN expression through Pit-1 responsive elements in the OGN promoter. In pituitary tumors, OGN expression is different dependent on the tumor-type ${ }^{35}$. Finally, when mouse hepatocarcinoma cells were transfected with OGN, they displayed decreased migration and invasion capacity and decreased metastatic activity to peripheral lymph nodes, while no differences in proliferation or adhesive capacity were $\operatorname{seen}^{74}$. Unfortunately, despite these numerous studies demonstrating altered OGN expression in cancer, functional data on how OGN is involved in cancer pathology is lacking and further research on the matter is needed. 


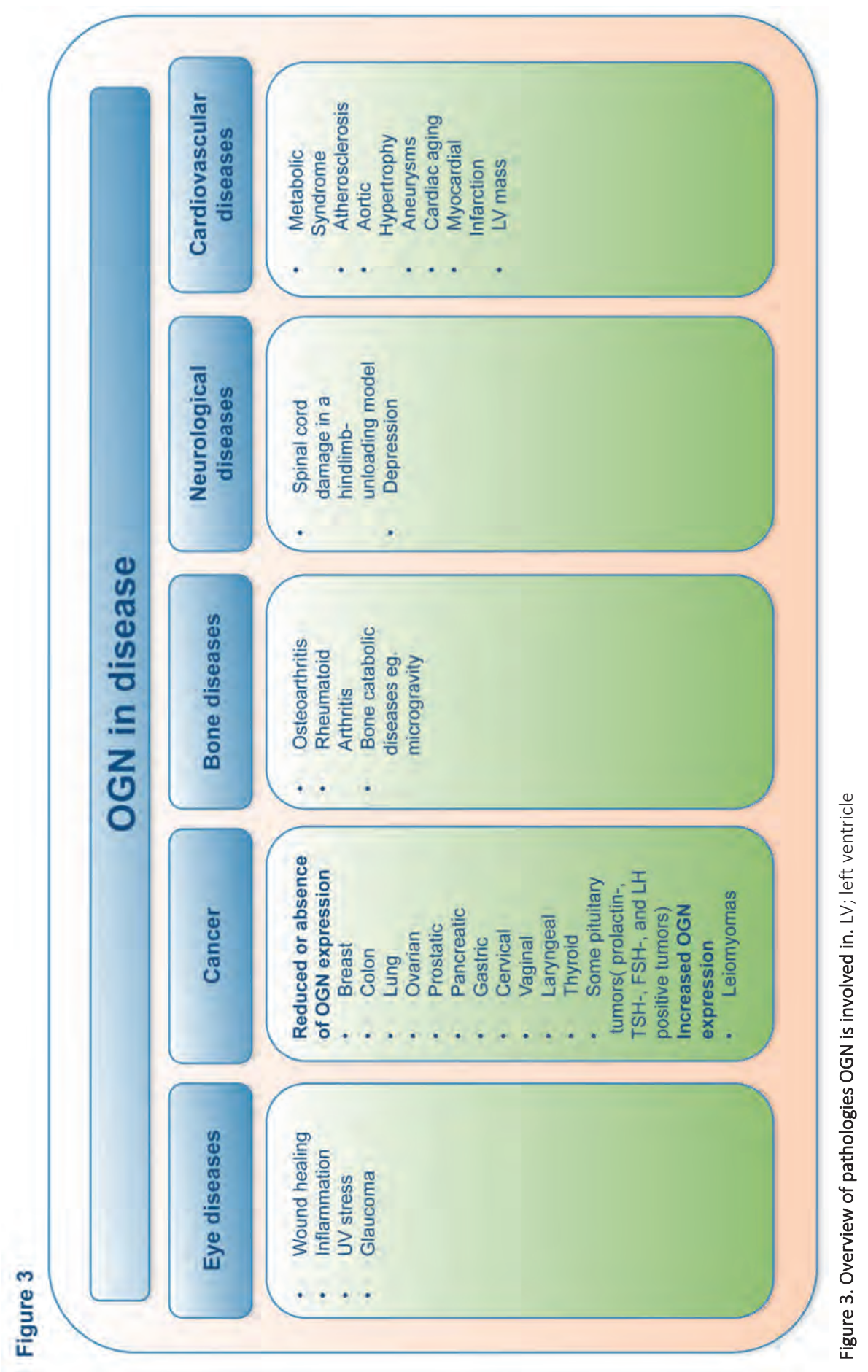




\section{Chapter 2}

\section{Bone disease}

Several studies have implicated OGN in osteoarthritis and rheumatoid arthritis. In rat articular chondrocytes, LPS mediated activation of TLR4 receptors increased metalloproteases and OGN secretion in vitro ${ }^{56}$. In line, OGN can be generated by metalloprotease-mediated degradation of human articular cartilage ${ }^{75}$. Moreover, OGN was shown to be a released protein of osteoarthritic articular cartilage in humans ${ }^{76}$. It was also found in synovial fluid from osteoarthritis patients ${ }^{77}$ and demonstrated to be up-regulated in articular cartilage, yet down-regulated in the acetabular labrum of osteoarthritis patients $^{78}$. Furthermore, low-level laser therapy, which is often used in the treatment of rheumatoid arthritis, increased OGN expression both in the synovial membrane of patients ${ }^{79}$, and in cultured osteoblasts ${ }^{46}$.

\section{Neurological damage/disease}

Chelyshev and colleagues demonstrated in a hind limb-unloading model for bone desorption, damage of the spinal cord in addition to changes seen in the bones and muscles, which was paralleled with a decrease in spinal OGN expression ${ }^{80}$. Furthermore, in a chronic depression model, OGN expression decreased in the amygdala, an important regulator of emotional behavior. OGN expression decreased in the amygdala of mice showing higher immobility (and thus severely depressed mice), while control mice and stressed mice with lower immobility (less depressed mice) had similar OGN expres$\operatorname{sion}^{81}$. Further studies showed a decreased total dendritic length of the central amygdala neurons in the depressed mice and that in vitro OGN enhanced neurite outgrowth, implicating a possible role for OGN on neural outgrowth in this model ${ }^{82}$.

\section{Cardiovascular diseases}

Like other SLRPs and other non-structural matrix proteins, OGN is important in the cardiovascular system and has been demonstrated to be crucial in certain disease contexts.

\section{Metabolic syndrome}

OGN expression has been associated with the metabolic syndrome, as increased levels of the $34 \mathrm{kD}$ OGN protein were found in human obese subjects, when compared to nonobese people, and in general more OGN abundance was found in subcutaneous adipose tissue than in visceral adipose tissue ${ }^{83}$. Furthermore, a study on quantitative trait loci $(\mathrm{QLT})$ relevant to the metabolic syndrome in spontaneous hypertensive rats identified OGN as a QTL on chromosome 17 as a candidate regulator of left ventricular (LV) mass $^{22,84}$. Interestingly, a recent study in mice demonstrated that OGN functions as a satiety hormone in adipose tissue, where it is highly expressed and secreted into the circulation. Importantly, administered OGN limits food intake in mice, possibly by in- 
creasing IL-1beta and IL-6 expression in the hypothalamus, but independent of leptin signaling ${ }^{85}$. Nevertheless, despite many studies implicating OGN in the metabolic syndrome, an actual role for OGN in the pathogenesis of the metabolic syndrome remains to be demonstrated.

\section{Vascular diseases}

OGN is abundant in the normal vasculature, and in atherosclerotic and restenotic lesions of rat, rabbit, human and mouse arteries ${ }^{31,32,86}$. Nevertheless, OGN null mice demonstrated normal histomorphology of the arteries and in a mouse model for atherosclerosis, OGN null mice displayed similar lesion size, similar composition of the extracellular matrix and cellular content and distribution in the lesion. Calcium deposits were similar in incidence, size and distribution. Hence, no role for OGN in the progression of atherosclerosis in mice could be demonstrated ${ }^{86}$. However, in the same mouse model for atherosclerosis, increased levels of circulating MMCN-151, a matrix metalloproteinase-12 (MMP12) mediated cleavage product of OGN, were found ${ }^{87}$. Furthermore, OGN is differentially expressed in vulnerable human carotid plaques, compared to stable plaques, and OGN circulating levels were associated with major adverse cardiovascular events during 1 year follow up in patients who underwent coronary angiography for acute coronary syndrome or stable angina pectoris ${ }^{88,89}$.

Moreover, OGN expression is reduced in hypertrophic aortas induced by sinoaortic denervation in rats, and OGN mRNA levels are negatively correlated with the degree of aortic hypertrophy ${ }^{51}$. However, in spontaneously hypertensive rats with a blood pressure decrease, induced by a 6-week exercise protocol, OGN protein expression was reduced in aortas of these rats when compared to sedentary spontaneous hypertensive rats, without blood pressure reduction ${ }^{90}$. Finally, proteomic analysis to identify potential biomarkers in patients with calcified abdominal or thoracic aortic aneurysms revealed decreased OGN levels in the abdominal but not thoracic aneurysms, when compared to normal adjacent aortic tissue ${ }^{91}$.

\section{Cardiac diseases}

OGN is expressed by cardiac fibroblasts ${ }^{22,92}$ VSMCs $^{92}$, and cardiomyocytes ${ }^{22,93}$. During aging, miR22 levels increase in the heart whilst OGN, its targeted protein, is down regulated with advanced age. Both overexpression of miR22 and silencing of OGN mRNA expression induced cellular senescence of cardiac fibroblasts, hence implicating OGN in age-related cardiac changes ${ }^{92}$. We recently demonstrated increased expression and deposition of the $34 \mathrm{kD}$ OGN protein in the infarcted, but not in the remote cardiac tissue, after $\mathrm{Ml}$, where it is necessary for proper collagen maturation, but does not affect fibroblast behavior, and thus protects against cardiac rupture and adverse remodeling following $\mathrm{Ml}^{93}$. Interestingly, previous in vitro studies demonstrated that a recombinant glycosylated mouse $34 \mathrm{kD}$ OGN could retard collagen fibrillogenesis, which was even more effective after a BMP-1/Tolloid-like proteinase-mediated proteolytic 


\section{Chapter 2}

processing into a $27 \mathrm{kD}$ protein ${ }^{28}$ However, Zhang et al showed that a recombinant glycosylated mouse 50kD OGN binds to and does not retard but actually forms cross-links with collagen in vitro ${ }^{94}$. In line, we showed that OGN directly binds to collagen fibrils and improves collagen cross-linking in vivo after an $\mathrm{Ml}$ and in vitro using the same recombinant OGN as Zhang and colleagues ${ }^{93}$. In addition, in blood of patients with postural orthostatic tachycardia syndrome, autoantibodies against a wide-range of cardiac proteins are present, which may induce alterations in cardiac function. Among these autoantibodies, autoantibodies against OGN were found, hence implicating a role for OGN in cardiac arrhythmia ${ }^{95}$. Furthermore, Petretto and colleagues demonstrated the presence of a $20 \mathrm{kD}$ and a $50 \mathrm{kD}$ OGN protein variant in rat hearts and a partial co-localization of OGN with the cardiomyocyte sarcomere. They associated elevated OGN levels with increased LV mass in humans and rats, however a role for OGN in cardiomyocyte biology has not been identified yet ${ }^{22}$.

\section{OGN AS BIOMARKER}

Multiple studies identified OGN as a possible biomarker for various diseases. Unfortunately, most of these studies use arrays, mass spectrometry, ELISA or other high throughput screening methods and don't distinct the specific OGN variant involved. In a study to identify women at risk for preterm labor and delivery, OGN was identified as a possible biomarker in amniotic fluids ${ }^{96}$. However, Shankar and colleagues demonstrated that OGN was up- regulated in choriodecidual tissue both during term and preterm labor, and suggested that OGN is more indicative of active tissue remodeling, independent of preterm labor or not ${ }^{62}$. Interestingly, OGN was demonstrated to be a direct cleavage product of ADAM-17 in blood. ADAM-17 is responsible for releasing the soluble form of a variety of cell-surface proteins, most of which are related with pathological processes such as cancer and inflammation ${ }^{97}$. Zheng and colleagues demonstrated different expression of OGN as a marker for differential diagnosis between non-small cell lung cancers (positive for OGN) and small cell lung cancers (negative for OGN) ${ }^{37}$. Furthermore, as discussed above, OGN might be a possible biomarker for vascular disease. Circulating OGN levels were associated with major adverse cardiovascular events during 1-year follow up in patients who underwent coronary angiography for acute coronary syndrome or stable angina pectoris ${ }^{88,89}$. The direction of change in circulating OGN levels, predict left ventricular remodeling in heart failure patients ${ }^{98}$, though OGN levels do not increase stepwise with the severity of symptoms and LV dysfunction ${ }^{99}$. In addition, in $29 \%$ of the patients enrolled in the CORONA study, OGN levels were measured but shown to add no predictive information on adverse outcome in heart failure patients ${ }^{100}$. However, we recently reported increased circulating OGN levels in patients with a history of previous $\mathrm{Ml}$, compared to patients with non-ischemic heart failure. 
Here, OGN levels were negatively correlated with ventricular volumes and associated with fibrosis, and thus indicative of adverse remodeling and worse prognosis ${ }^{93}$.

\section{FUTURE PERSPECTIVES}

In summary, OGN has been implicated in many cell types and hence many processes and diseases. Figure 2 illustrates the different molecular interactions and different processes OGN has been implicated in. Nevertheless exact mechanisms for OGN-mediated effects in pathology remain largely undefined. Despite the tremendous efforts already made to understand the OGN gene and its wide variety in transcripts, proteins, expression profiles and functions, a lot is still unknown. We have, for example, identified 3 different glycosylated OGN protein variants in the murine heart, of which the expression patterns change upon different cardiac diseases and during the time-course of the disease (unpublished observations). Probably this reflects the involvement of a specific glycosylated OGN protein variant in a certain pathological process such as fibrosis or inflammation. The multifactorial nature of OGN and its variation in function arising from a post-translational modification makes it difficult to fully grasp, yet also very challenging. Glycosylation is a critical post-translational process that adds onto the protein-core different forms of sugars, thus tremendously increasing the functional variability of the protein. Ninety-five percent of all secreted proteins that encompass the extracellular space are subjected to glycosylation extending their biological functions. Despite the immense biological relevance of glycosylation little is known about the role of the glycome in health and in disease. By identifying the exact transcript and/or glycosylated protein variant involved in each process or disease setting, the development of targeted therapeutic strategies becomes possible. Especially the prospect of using glycosylation as a targeting tool for future therapeutic application opens new windows in medicine. In this way, one could target an organ-specific or disease-specific OGN variant, without affecting the other variants, and thus limiting unwanted side effects. Hence, by understanding its complexity, the deceitful dwarf can no longer be deceitful, allowing the development of targeted therapeutic strategies.

\section{ACKNOWLEDGMENTS}

This work was supported by the European Commission's grants FIBROTARGETS ( $\mathrm{N}^{\circ}$ 602904) and MEDIA ( $\left.N^{\circ} 261409\right)$. 


\section{REFERENCES}

1 lozzo, R. V. The family of the small leucine-rich proteoglycans: key regulators of matrix assembly and cellular growth. Critical reviews in biochemistry and molecular biology 32, 141-174, doi:10.3109/10409 239709108551 (1997).

2 lozzo, R. V. \& Schaefer, L. Proteoglycans in health and disease: novel regulatory signaling mechanisms evoked by the small leucine-rich proteoglycans. The FEBS journal 277, 3864-3875, doi:10.1111/j.17424658.2010.07797.x (2010).

3 Moreth, K., Iozzo, R. V. \& Schaefer, L. Small leucine-rich proteoglycans orchestrate receptor crosstalk during inflammation. Cell cycle 11, 2084-2091, doi:10.4161/cc.20316 (2012).

4 Chen, S. \& Birk, D. E. The regulatory roles of small leucine-rich proteoglycans in extracellular matrix assembly. The FEBS journal 280, 2120-2137, doi:10.1111/febs.12136 (2013).

5 Matsushima, N., Ohyanagi, T., Tanaka, T. \& Kretsinger, R. H. Super-motifs and evolution of tandem leucine-rich repeats within the small proteoglycans--biglycan, decorin, lumican, fibromodulin, PRELP, keratocan, osteoadherin, epiphycan, and osteoglycin. Proteins 38, 210-225 (2000).

6 Rienks, M., Papageorgiou, A. P., Frangogiannis, N. G. \& Heymans, S. Myocardial extracellular matrix: an ever-changing and diverse entity. Circulation research 114, 872-888, doi:10.1161/CIRCRESAHA.114. 302533 (2014).

$7 \quad$ Hildebrand, A. et al. Interaction of the small interstitial proteoglycans biglycan, decorin and fibromodulin with transforming growth factor beta. The Biochemical journal 302 ( Pt 2), 527-534 (1994).

8 Hassell, J. R. \& Birk, D. E. The molecular basis of corneal transparency. Experimental eye research 91, 326335, doi:10.1016/j.exer.2010.06.021 (2010).

9 Dellett, M., Hu, W., Papadaki, V. \& Ohnuma, S. Small leucine rich proteoglycan family regulates multiple signalling pathways in neural development and maintenance. Development, growth \& differentiation 54, 327-340, doi:10.1111/j.1440-169X.2012.01339.x (2012).

10 Igwe, J. C., Gao, Q., Kizivat, T., Kao, W. W. \& Kalajzic, I. Keratocan is expressed by osteoblasts and can modulate osteogenic differentiation. Connective tissue research 52, 401-407, doi:10.3109/03008207. 2010.546536 (2011).

11 Nastase, M. V., Iozzo, R. V. \& Schaefer, L. Key roles for the small leucine-rich proteoglycans in renal and pulmonary pathophysiology. Biochimica et biophysica acta 1840, 2460-2470, doi:10.1016/j.bbagen. 2014.01.035 (2014).

12 Kampmann, A. et al. The proteoglycan osteoglycin/mimecan is correlated with arteriogenesis. Molecular and cellular biochemistry 322, 15-23, doi:10.1007/s11010-008-9935-x (2009).

13 Vuillermoz, B. et al. Influence of aging on glycosaminoglycans and small leucine-rich proteoglycans production by skin fibroblasts. Molecular and cellular biochemistry 277, 63-72, doi:10.1007/s11010-0055073-x (2005).

14 Schaefer, L. \& lozzo, R. V. Biological functions of the small leucine-rich proteoglycans: from genetics to signal transduction. The Journal of biological chemistry 283, 21305-21309, doi:10.1074/jbc.R800020200 (2008).

15 Madisen, L. et al. Molecular cloning of a novel bone-forming compound: osteoinductive factor. DNA and cell biology 9, 303-309 (1990).

16 Bentz, H. et al. Transforming growth factor-beta 2 enhances the osteoinductive activity of a bovine bonederived fraction containing bone morphogenetic protein-2 and 3. Matrix 11, 269-275 (1991).

17 Funderburgh, J. L. et al. Mimecan, the 25-kDa corneal keratan sulfate proteoglycan, is a product of the gene producing osteoglycin. The Journal of biological chemistry 272, 28089-28095 (1997).

18 Tasheva, E. S., Corpuz, L. M., Funderburgh, J. L. \& Conrad, G. W. Differential splicing and alternative polyadenylation generate multiple mimecan mRNA transcripts. The Journal of biological chemistry 272 , 32551-32556 (1997).

19 Tasheva, E. S., Maki, C. G., Conrad, A. H. \& Conrad, G. W. Transcriptional activation of bovine mimecan by p53 through an intronic DNA-binding site. Biochimica et biophysica acta 1517, 333-338 (2001). 
20 Tasheva, E. S., Funderburgh, M. L., McReynolds, J., Funderburgh, J. L. \& Conrad, G. W. The bovine mimecan gene. Molecular cloning and characterization of two major RNA transcripts generated by alternative use of two splice acceptor sites in the third exon. The Journal of biological chemistry 274, 18693-18701 (1999).

21 Ujita, M., Shinomura, T. \& Kimata, K. Molecular cloning of the mouse osteoglycin-encoding gene. Gene 158, 237-240 (1995).

22 Petretto, E. et al. Integrated genomic approaches implicate osteoglycin (Ogn) in the regulation of left ventricular mass. Nature genetics 40, 546-552, doi:10.1038/ng.134 (2008).

23 Corpuz, L. M., Dunlevy, J. R., Hassell, J. R., Conrad, A. H. \& Conrad, G. W. Molecular cloning and relative tissue expression of keratocan and mimecan in embryonic quail cornea. Matrix biology : journal of the International Society for Matrix Biology 19, 693-698 (2000).

24 Dunlevy, J. R., Beales, M. P., Berryhill, B. L., Cornuet, P. K. \& Hassell, J. R. Expression of the keratan sulfate proteoglycans lumican, keratocan and osteoglycin/mimecan during chick corneal development. Experimental eye research 70, 349-362, doi:10.1006/exer.1999.0789 (2000).

25 Tasheva, E. S. \& Conrad, G. W. The UV responsive elements in the human mimecan promoter: a functional characterization. Molecular vision 9, 1-9 (2003).

26 Tasheva, E. S. \& Conrad, G. W. Interferon-gamma regulation of the human mimecan promoter. Molecular vision 9, 277-287 (2003).

27 Tasheva, E. S., Funderburgh, J. L., Funderburgh, M. L., Corpuz, L. M. \& Conrad, G. W. Structure and sequence of the gene encoding human keratocan. DNA sequence : the journal of DNA sequencing and mapping 10, 67-74 (1999).

$28 \mathrm{Ge}, \mathrm{G}$. et al. Bone morphogenetic protein-1/tolloid-related metalloproteinases process osteoglycin and enhance its ability to regulate collagen fibrillogenesis. The Journal of biological chemistry 279, 4162641633, doi:10.1074/jbc.M406630200 (2004).

29 Tanaka, K. et al. Role of osteoglycin in the linkage between muscle and bone. The Journal of biological chemistry 287, 11616-11628, doi:10.1074/jbc.M111.292193 (2012).

30 Weyers, A. et al. Isolation of bovine corneal keratan sulfate and its growth factor and morphogen binding. The FEBS journal 280, 2285-2293, doi:10.1111/febs.12165 (2013).

31 Shanahan, C. M., Cary, N. R., Osbourn, J. K. \& Weissberg, P. L. Identification of osteoglycin as a component of the vascular matrix. Differential expression by vascular smooth muscle cells during neointima formation and in atherosclerotic plaques. Arteriosclerosis, thrombosis, and vascular biology 17, 2437-2447 (1997).

32 Fernandez, B., Kampmann, A., Pipp, F., Zimmermann, R. \& Schaper, W. Osteoglycin expression and localization in rabbit tissues and atherosclerotic plaques. Molecular and cellular biochemistry 246, 3-11 (2003).

33 Yang, C. H. et al. Canine tissue-specific expression of multiple small leucine rich proteoglycans. Veterinary journal 193, 374-380, doi:10.1016/j.tvjl.2012.01.018 (2012).

34 Stratil, A. et al. Porcine OGN and ASPN: mapping, polymorphisms and use for quantitative trait loci identification for growth and carcass traits in a Meishan x Pietrain intercross. Animal genetics 37, 415418, doi:10.1111/j.1365-2052.2006.01480.x (2006).

$35 \mathrm{Hu}, \mathrm{S}$. M. et al. The mimecan gene expressed in human pituitary and regulated by pituitary transcription factor-1 as a marker for diagnosing pituitary tumors. The Journal of clinical endocrinology and metabolism 90, 6657-6664, doi:10.1210/jc.2005-0322 (2005).

$36 \mathrm{Ma}, \mathrm{Q}$. Y. et al. Glucocorticoid up-regulates mimecan expression in corticotroph cells. Molecular and cellular endocrinology 321, 239-244, doi:10.1016/j.mce.2010.02.021 (2010).

37 Zheng, C. X. et al. Different expression of mimecan as a marker for differential diagnosis between NSCLC and SCLC. Oncology reports 22, 1057-1061 (2009).

38 Park, J. G., Ye, Q., Topp, E. M., Misra, A. \& Spencer, P. Water sorption and dynamic mechanical properties of dentin adhesives with a urethane-based multifunctional methacrylate monomer. Dental materials : official publication of the Academy of Dental Materials 25, 1569-1575, doi:10.1016/j.dental.2009.07.010 (2009). 


\section{Chapter 2}

39 Tasheva, E. S. et al. Mimecan/osteoglycin-deficient mice have collagen fibril abnormalities. Molecular vision 8, 407-415 (2002).

40 Beecher, N. et al. An x-ray diffraction study of corneal structure in mimecan-deficient mice. Investigative ophthalmology \& visual science 46, 4046-4049, doi:10.1167/iovs.05-0325 (2005).

41 Huang, $H$. et al. Specific requirement of Gli transcription factors in Hedgehog-mediated intestinal development. The Journal of biological chemistry 288, 17589-17596, doi:10.1074/jbc.M113.467498 (2013).

42 Williamson, R. E. et al. Expression studies of osteoglycin/mimecan (OGN) in the cochlea and auditory phenotype of Ogn-deficient mice. Hearing research 237, 57-65, doi:10.1016/j.heares.2007.12.006 (2008).

43 Tanaka, K. et al. Active vitamin D possesses beneficial effects on the interaction between muscle and bone. Biochemical and biophysical research communications 450, 482-487, doi:10.1016/j.bbrc.2014.05. 145 (2014).

44 Kawao, N. \& Kaji, H. Interactions between muscle tissues and bone metabolism. Journal of cellular biochemistry 116, 687-695, doi:10.1002/jcb.25040 (2015).

45 Balint, E. et al. Phenotype discovery by gene expression profiling: mapping of biological processes linked to BMP-2-mediated osteoblast differentiation. Journal of cellular biochemistry 89, 401-426, doi:10.1002/ jcb.10515 (2003).

46 Hamajima, S. et al. Effect of low-level laser irradiation on osteoglycin gene expression in osteoblasts. Lasers in medical science 18, 78-82, doi:10.1007/s10103-003-0255-9 (2003).

47 Xing, W. et al. Global gene expression analysis in the bones reveals involvement of several novel genes and pathways in mediating an anabolic response of mechanical loading in mice. Journal of cellular biochemistry 96, 1049-1060, doi:10.1002/jcb.20606 (2005).

48 Osawa, A. et al. Activation of genes for growth factor and cytokine pathways late in chondrogenic differentiation of ATDC5 cells. Genomics 88, 52-64, doi:10.1016/j.ygeno.2006.02.013 (2006).

49 Guntur, A. R. \& Rosen, C. J. Bone as an endocrine organ. Endocrine practice : official journal of the American College of Endocrinology and the American Association of Clinical Endocrinologists 18, 758-762, doi:10.4158/EP12141.RA (2012).

$50 \mathrm{Hou}, \mathrm{C}$. et al. Developmental changes and regional localization of Dspp, Mepe, Mimecan and Versican in postnatal developing mouse teeth. Journal of molecular histology 43, 9-16, doi:10.1007/s10735-0119368-9 (2012).

$51 \mathrm{Gu}, \mathrm{X}$. S. et al. Mimecan is involved in aortic hypertrophy induced by sinoaortic denervation in rats. Molecular and cellular biochemistry 352, 309-316, doi:10.1007/s11010-011-0767-8 (2011).

52 Long, C. J. et al. Fibroblast growth factor-2 promotes keratan sulfate proteoglycan expression by keratocytes in vitro. The Journal of biological chemistry 275, 13918-13923 (2000).

53 Berryhill, B. L., Beales, M. P. \& Hassell, J. R. Production of prostaglandin D synthase as a keratan sulfate proteoglycan by cultured bovine keratocytes. Investigative ophthalmology \& visual science 42, 1201-1207 (2001).

54 Seher, A. et al. Gene expression profiling of connective tissue growth factor (CTGF) stimulated primary human tenon fibroblasts reveals an inflammatory and wound healing response in vitro. Molecular vision 17, 53-62 (2011).

$55 \mathrm{Li}, \mathrm{X}$. et al. IKKalpha, IKKbeta, and NEMO/IKKgamma are each required for the NF-kappa B-mediated inflammatory response program. The Journal of biological chemistry 277, 45129-45140, doi:10.1074/jbc.M205165200 (2002).

56 Haglund, L., Bernier, S. M., Onnerfjord, P. \& Recklies, A. D. Proteomic analysis of the LPS-induced stress response in rat chondrocytes reveals induction of innate immune response components in articular cartilage. Matrix biology : journal of the International Society for Matrix Biology 27, 107-118, doi:10.1016/j.matbio.2007.09.009 (2008).

57 Liu, C. Y. et al. The cloning of mouse keratocan cDNA and genomic DNA and the characterization of its expression during eye development. The Journal of biological chemistry 273, 22584-22588 (1998).

58 Kurpakus Wheater, M., Kernacki, K. A. \& Hazlett, L. D. Corneal cell proteins and ocular surface pathology. Biotechnic \& histochemistry : official publication of the Biological Stain Commission 74, 146-159 (1999). 
59 Tasheva, E. S., Conrad, A. H. \& Conrad, G. W. Identification and characterization of conserved cisregulatory elements in the human keratocan gene promoter. Biochimica et biophysica acta 1492, 452459 (2000).

60 Keenan, T. D. et al. Mapping the differential distribution of proteoglycan core proteins in the adult human retina, choroid, and sclera. Investigative ophthalmology \& visual science 53, 7528-7538, doi:10.1167/iovs.12-10797 (2012).

61 Tasheva, E. S. et al. Differentially expressed genes in the lens of mimecan-null mice. Molecular vision 10, 403-416 (2004).

62 Shankar, R. et al. Molecular markers of preterm labor in the choriodecidua. Reproductive sciences 17, 297-310, doi:10.1177/1933719109353454 (2010).

63 Funderburgh, J. L., Funderburgh, M. L., Mann, M. M., Corpuz, L. \& Roth, M. R. Proteoglycan expression during transforming growth factor beta -induced keratocyte-myofibroblast transdifferentiation. The Journal of biological chemistry 276, 44173-44178, doi:10.1074/jbc.M107596200 (2001).

64 Yuan, X., Hua, X. \& Wilhelmus, K. R. Expression of small leucine-rich proteoglycans during experimental fungal keratitis. Cornea 29, 674-679, doi:10.1097/ICO.0b013e3181c29744 (2010).

65 Zhao, X., Ramsey, K. E., Stephan, D. A. \& Russell, P. Gene and protein expression changes in human trabecular meshwork cells treated with transforming growth factor-beta. Investigative ophthalmology \& visual science 45, 4023-4034, doi:10.1167/iovs.04-0535 (2004).

66 Diskin, S. et al. Detection of differentially expressed glycogenes in trabecular meshwork of eyes with primary open-angle glaucoma. Investigative ophthalmology \& visual science 47, 1491-1499, doi:10.1167/iovs.05-0736 (2006).

67 Lee, J. Y., Eom, E. M., Kim, D. S., Ha-Lee, Y. M. \& Lee, D. H. Analysis of gene expression profiles of gastric normal and cancer tissues by SAGE. Genomics 82, 78-85 (2003).

68 Wang, Y. et al. Differential expression of mimecan and thioredoxin domain-containing protein 5 in colorectal adenoma and cancer: a proteomic study. Experimental biology and medicine 232, 1152-1159, doi:10.3181/0701-RM-8 (2007).

69 Lomnytska, M. I. et al. Diagnostic protein marker patterns in squamous cervical cancer. Proteomics. Clinical applications 4, 17-31, doi:10.1002/prca.200900086 (2010).

70 Rower, C. et al. Toponostics of invasive ductal breast carcinoma: combination of spatial protein expression imaging and quantitative proteome signature analysis. International journal of clinical and experimental pathology 4, 454-467 (2011).

$71 \mathrm{Li}$, L. et al. Quantitative proteomics approach to screening of potential diagnostic and therapeutic targets for laryngeal carcinoma. PloS one 9, e90181, doi:10.1371/journal.pone.0090181 (2014).

72 Sponziello, M. et al. Molecular differences between human thyroid follicular adenoma and carcinoma revealed by analysis of a murine model of thyroid cancer. Endocrinology 154, 3043-3053, doi:10.1210/en.2013-1028 (2013).

73 Pan, Q., Luo, X. \& Chegini, N. Genomic and proteomic profiling I: leiomyomas in African Americans and Caucasians. Reproductive biology and endocrinology : RB\&E 5, 34, doi:10.1186/1477-7827-5-34 (2007).

74 Cui, X., Song, B., Hou, L., Wei, Z. \& Tang, J. High expression of osteoglycin decreases the metastatic capability of mouse hepatocarcinoma Hca-F cells to lymph nodes. Acta biochimica et biophysica Sinica 40 , 349-355 (2008).

75 Zhen, E. Y. et al. Characterization of metalloprotease cleavage products of human articular cartilage. Arthritis and rheumatism 58, 2420-2431, doi:10.1002/art.23654 (2008).

76 De Ceuninck, F. et al. Assessment of some tools for the characterization of the human osteoarthritic cartilage proteome. Journal of biomolecular techniques : JBT 16, 256-265 (2005).

77 Balakrishnan, L. et al. Proteomic analysis of human osteoarthritis synovial fluid. Clinical proteomics 11, 6, doi:10.1186/1559-0275-11-6 (2014).

78 Juchtmans, N. et al. Distinct dysregulation of the small leucine-rich repeat protein family in osteoarthritic acetabular labrum compared to articular cartilage. Arthritis \& rheumatology 67, 435-441, doi:10.1002/ art.38930 (2015). 


\section{Chapter 2}

79 Balint, G. et al. Ex vivo soft-laser treatment inhibits the synovial expression of vimentin and alphaenolase, potential autoantigens in rheumatoid arthritis. Physical therapy 91, 665-674, doi:10.2522/ptj.20100065 (2011).

80 Chelyshev, Y. A. et al. Characterization of spinal cord glial cells in a model of hindlimb unloading in mice. Neuroscience 280, 328-339, doi:10.1016/j.neuroscience.2014.09.004 (2014).

81 Jung, S. et al. Decreased expression of extracellular matrix proteins and trophic factors in the amygdala complex of depressed mice after chronic immobilization stress. BMC neuroscience 13, 58, doi:10.1186/1471-2202-13-58 (2012).

82 Jeong, E. Y. et al. Enhancement of IGF-2-induced neurite outgrowth by IGF-binding protein-2 and osteoglycin in SH-SY5Y human neuroblastoma cells. Neuroscience letters 548, 249-254, doi:10.1016/ j.neulet.2013.05.038 (2013).

83 Insenser, M. et al. A nontargeted proteomic approach to the study of visceral and subcutaneous adipose tissue in human obesity. Molecular and cellular endocrinology 363, 10-19, doi:10.1016/j.mce.2012. 07.001 (2012).

84 Pravenec, M. Use of rat genomics for investigating the metabolic syndrome. Methods in molecular biology 597, 415-426, doi:10.1007/978-1-60327-389-3_28 (2010).

85 Cao, H. M. et al. Mimecan, a Hormone Abundantly Expressed in Adipose Tissue, Reduced Food Intake Independently of Leptin Signaling. EBioMedicine 2, 1718-1724, doi:10.1016/j.ebiom.2015.09.044 (2015).

86 Moncayo-Arlandi, J., Lopez-Garcia, A., Fernandez, M. C., Duran, A. C. \& Fernandez, B. Osteoglycin deficiency does not affect atherosclerosis in mice. Atherosclerosis 237, 418-425, doi:10.1016/ j.atherosclerosis.2014.09.016 (2014).

87 Barascuk, N. et al. Levels of Circulating MMCN-151, a Degradation Product of Mimecan, Reflect Pathological Extracellular Matrix Remodeling in Apolipoprotein E Knockout Mice. Biomarker insights 6, 97-106, doi:10.4137/BMI.S7777 (2011).

88 Cheng, J. M. et al. Circulating osteoglycin and NGAL/MMP9 complex concentrations predict 1-year major adverse cardiovascular events after coronary angiography. Arteriosclerosis, thrombosis, and vascular biology 34, 1078-1084, doi:10.1161/ATVBAHA.114.303486 (2014).

89 Malaud, E. et al. Local carotid atherosclerotic plaque proteins for the identification of circulating biomarkers in coronary patients. Atherosclerosis 233, 551-558, doi:10.1016/j.atherosclerosis.2013.12.019 (2014).

90 Feng, H. et al. Aortic wall proteomic analysis in spontaneously hypertensive rats with a blood pressure decrease induced by 6-week load-free swimming. Biomed Rep 3, 681-686, doi:10.3892/br.2015.488 (2015).

91 Matsumoto, K. et al. Proteomic analysis of calcified abdominal and thoracic aortic aneurysms. International journal of molecular medicine 30, 417-429, doi:10.3892/ijmm.2012.985 (2012).

92 Jazbutyte, V. et al. MicroRNA-22 increases senescence and activates cardiac fibroblasts in the aging heart. Age 35, 747-762, doi:10.1007/s11357-012-9407-9 (2013).

93 Van Aelst, L. N. et al. Osteoglycin prevents cardiac dilatation and dysfunction after myocardial infarction through infarct collagen strengthening. Circulation research 116, 425-436, doi:10.1161/CIRCRESAHA. 116.304599 (2015).

94 Zhang, Y., Conrad, A. H. \& Conrad, G. W. Effects of ultraviolet-A and riboflavin on the interaction of collagen and proteoglycans during corneal cross-linking. The Journal of biological chemistry 286, 1301113022, doi:10.1074/jbc.M110.169813 (2011).

95 Wang, X. L. et al. Autoimmunoreactive IgGs from patients with postural orthostatic tachycardia syndrome. Proteomics. Clinical applications 6, 615-625, doi:10.1002/prca.201200049 (2012).

96 Romero, R. et al. Metabolomics in premature labor: a novel approach to identify patients at risk for preterm delivery. The journal of maternal-fetal \& neonatal medicine : the official journal of the European Association of Perinatal Medicine, the Federation of Asia and Oceania Perinatal Societies, the International Society of Perinatal Obstet 23, 1344-1359, doi:10.3109/14767058.2010.482618 (2010).

97 Kawahara, R. et al. Deciphering the role of the ADAM17-dependent secretome in cell signaling. Journal of proteome research 13, 2080-2093, doi:10.1021/pr401224u (2014). 
98 Motiwala, S. R. et al. Measurement of novel biomarkers to predict chronic heart failure outcomes and left ventricular remodeling. Journal of cardiovascular translational research 7, 250-261, doi:10.1007/ s12265-013-9522-8 (2014).

99 Jungbauer, C. G. et al. Panel of emerging cardiac biomarkers contributes for prognosis rather than diagnosis in chronic heart failure. Biomarkers in medicine 8, 777-789, doi:10.2217/bmm.14.31 (2014).

100 Ueland, T. et al. Novel extracellular matrix biomarkers as predictors of adverse outcome in chronic heart failure: association between biglycan and response to statin therapy in the CORONA trial. Journal of cardiac failure 21, 153-159, doi:10.1016/j.cardfail.2014.10.016 (2015). 



\section{Chapter}

\section{Osteoglycin prevents development of Diastolic Dysfunction by reducing Fibroblast Proliferation and Cardiac Fibrosis}

In revision in Hypertension

Sophie Deckx ${ }^{1,2}$, Ward Heggermont ${ }^{2}$, Paolo Carai ${ }^{1,2}$, Tom Dresselaers ${ }^{3}$, Uwe

Himmelreich ${ }^{3}$, Rick van Leeuwen ${ }^{1}$, Wies Lommen ${ }^{3}$, Jolanda van der Velden ${ }^{4,5},{ }^{*}$ Anna-Pia Papageorgiou ${ }^{1,2}$, *Stephane Heymans ${ }^{1,2,5}$

*Authors contributed equally.

${ }^{1}$ Center for Heart Failure Research, Cardiovascular Research Institute Maastricht, The Netherlands,

${ }^{2}$ Molecular and Vascular Biology, Department of Cardiovascular Sciences, KU Leuven, Belgium,

${ }^{3}$ Biomedical MRI Unit, Department of Imageing and Pathology, KU Leuven, Belgium, ${ }^{4}$ Department of Physiology, Institute for Cardiovascular Research, VU University Medical Center, Amsterdam, The Netherlands,

${ }^{5} \mathrm{ICIN}-$ Netherlands Heart Institute, Utrecht, The Netherlands 


\section{Chapter 3}

\section{ABSTRACT}

Persistent hypertension may progress to heart failure, and its pathophysiological relevance consequently increases with ageing. The small leucine rich proteoglycan osteoglycin has been implicated in matrix homeostasis in different organs, including the ischemic heart. However, whether osteoglycin modulates cardiac hypertrophy, fibrosis or dysfunction in hypertensive heart disease during ageing remains unknown.

Osteoglycin expression increases in line with cardiac fibrosis in Angiotensin-II (AngII)induced pressure overloaded hearts of young mice (3 months old). Moreover, absence of osteoglycin (knockout mice) results in exaggerated cardiac fibrosis in hypertensive young ( 3 months) and old (19 months) mice (\% collagen deposition following Angll in osteoglycin null vs. WT: $12.1 \pm 1.7$ vs. $7.5 \pm 1.1 \%$ for old, $p=0.03$, and $9.5 \pm 1.0$ vs. $7.3 \pm$ $1.4 \%$ for young). Importantly, enhanced fibrosis caused increased diastolic dysfunction in both young and old hypertensive osteoglycin null compared to their WT littermates, as determined by magnetic resonance imageing, with osteoglycin expression inversely correlating with TGFbeta expression in vivo. Recombinant osteoglycin reduces fibroblast proliferation and collagen production in human cardiac fibroblasts in vitro.

In conclusion, osteoglycin reduces fibroblast proliferation and collagen production, resulting in decreased cardiac fibrosis, acting as a protective factor against diastolic dysfunction of aged-hypertensive origin. 


\section{INTRODUCTION}

Despite continuous improvements in the treatment of hypertension, the prevalence of hypertension and hypertension-related morbidity and mortality remains high. Amongst adults over twenty, the prevalence of hypertension is estimated to be around $30 \%$ in the USA ${ }^{1}$ and around $45 \%$ in Europe ${ }^{2}$, with a dramatic increase with advanced age in both regions ${ }^{1,2}$. This resulted in an estimated 72000 deaths in the USA alone in $2013^{1}$. Importantly, up to $20 \%$ of hypertensive people are not aware of their condition ${ }^{1}$.

Hypertension and ageing impose important stress on the heart with concomitant cardiac inflammation, fibrosis and hypertrophy, ultimately leading to heart failure (HF). Diastolic HF, or heart failure with preserved ejection fraction (HFPEF), is the most common form of HF in aged hypertensive patients, often going in line with obesity and diabetes $^{3}$. Diastolic HF is characterized by decelerated or incomplete diastolic relaxation and increased passive chamber stiffness ${ }^{4-6}$. Unfortunately, the underlying biologi$\mathrm{cal} /$ molecular mechanisms are incompletely understood, and targeted therapy absent. Recently, endothelial dysfunction and changes in phosphorylation of titin were identified as critical during diastolic $\mathrm{HF}^{3,7}$. Importantly, human cardiac samples of HFPEF patients revealed significant changes in the composition, amount -increased- and structure of fibrillar collagen and non-structural glycoproteins within the extracellular matrix $(\mathrm{ECM})^{8-10}$.

Osteoglycin (OGN) is a class III member of the small leucine rich proteoglycans (SLRP), a group of proteins emerging as important regulatory proteins within the $\mathrm{ECM}^{11,12}$. OGN displays great structural and functional diversity, and has been implicated in a variety of biological processes such as development ${ }^{13}$, bone formation ${ }^{14}$, tumor biology ${ }^{15}$ and corneal transparency ${ }^{16}$. Furthermore, OGN was associated with cardiac hypertrophy in a genome wide analysis of the rat heart ${ }^{17}$. Our group revealed that its collagen cross-linking properties protect against cardiac dilation following myocardial infarction ${ }^{18}$. Here we address its unknown function in hypertensive heart disease with ageing. Our findings reveal that -in addition to its collagen cross-linking properties in infarcted hearts- OGN reduces fibroblast proliferation and collagen production during pressure overload-induced heart failure, in both young and even more so in aged mice resulting in decreased diastolic dysfunction.

\section{RESULTS}

OGN increases with each phase of fibrosis during hypertension

To study the spatiotemporal expression of OGN during the different remodelling processes in the heart upon hypertension, we infused young adult mice ( 3 months old) with Angll for 1, 3, 5, 7, 14 or 28 days (Figure 1A). Interestingly, 2 phases and forms of fibro- 


\section{Chapter 3}

sis are present following Angll infusion (Figure $1 \mathrm{~A}$ and $\mathrm{B}$ and Supplementary Figure 1). The first phase peaks at 5 days and consists of diffuse interstitially deposited fibers, suggestive of purely reactive fibrosis. During the second phase of fibrosis starting at 14 days, these diffuse fibers partly shift into more localized scars, suggestive of mixed reactive and scarring -due to cardiomyocyte dropout- fibrosis (Figure $1 \mathrm{~A}$ and B and Supplementary Figure 1). Infiltration of leukocytes into the heart precedes the first fibrotic phase and peaks at 3 days (Figure $A$ and C), while cardiomyocyte hypertrophy is a slow response becoming significant at 14 days, further progressing at 28 days (Figure $1 \mathrm{~A}$ and D) of Angll infusion. Importantly, expression of the 34-kDa OGN protein increases with each phase of fibrosis, peaking at 3 and 28 days (Figure 1E), indicating a possible role for OGN in fibrosis of the pressure overloaded heart.

OGN decreases during ageing but its absence only moderately enhances agerelated cardiac dysfunction

Cardiac OGN expression is significantly lower in aged (19 months) compared to young mice (3 months), both at transcript and protein level (Figure 2A and B). To assess whether OGN may affect cardiac function along with ageing, we first evaluated cardiac dimensions and contractility with echocardiography in OGN null and WT sham mice at 6, 12 and 18 months, thus without Angll-infusion. End-diastolic volumes (EDV) did not change over time, and did not differ between OGN null and WT mice (Figure 2C). Ejection fraction (EF) was preserved over time in both groups, but slightly lower in the OGN null mice at 12 and 18 months compared to their WT littermates (Figure 2D and E). Heart rates (HR) did not differ over time in OGN null or WT littermates (582 \pm 14 vs. $573 \pm 14$ at 6 months, $561 \pm 14$ vs. $580 \pm 10$ at 12 months and $540 \pm 22$ vs. $544 \pm 9.0$ at 18 months in OGN null and WT mice respectively).

Interestingly, no histological differences of inflammation, fibrosis or cardiomyocyte hypertrophy were found between OGN null mice and their WT littermates, in both young ( 3 months) and old (19 months) sham mice (Figure $2 \mathrm{~F}-\mathrm{J}$ ). However, ageing resulted in both genotypes in significantly increased cardiac fibrosis (Figure $2 \mathrm{~F}$ and $\mathrm{G}$ ), in a trend to reduced presence of resident leukocytes (Figure $2 \mathrm{~F}$ and $\mathrm{H}$ ), and an increase of cardiac hypertrophy as shown by increased cardiomyocyte cross-sectional areas and higher heart weight to tibia length ratios (Figure 2F, I and J). In conclusion, OGN decreases during ageing, but its absence results only in moderately enhanced age-related cardiac dysfunction without histological differences in inflammation, fibrosis or cardiomyocyte hypertrophy both at young or older age. 
Figure 1

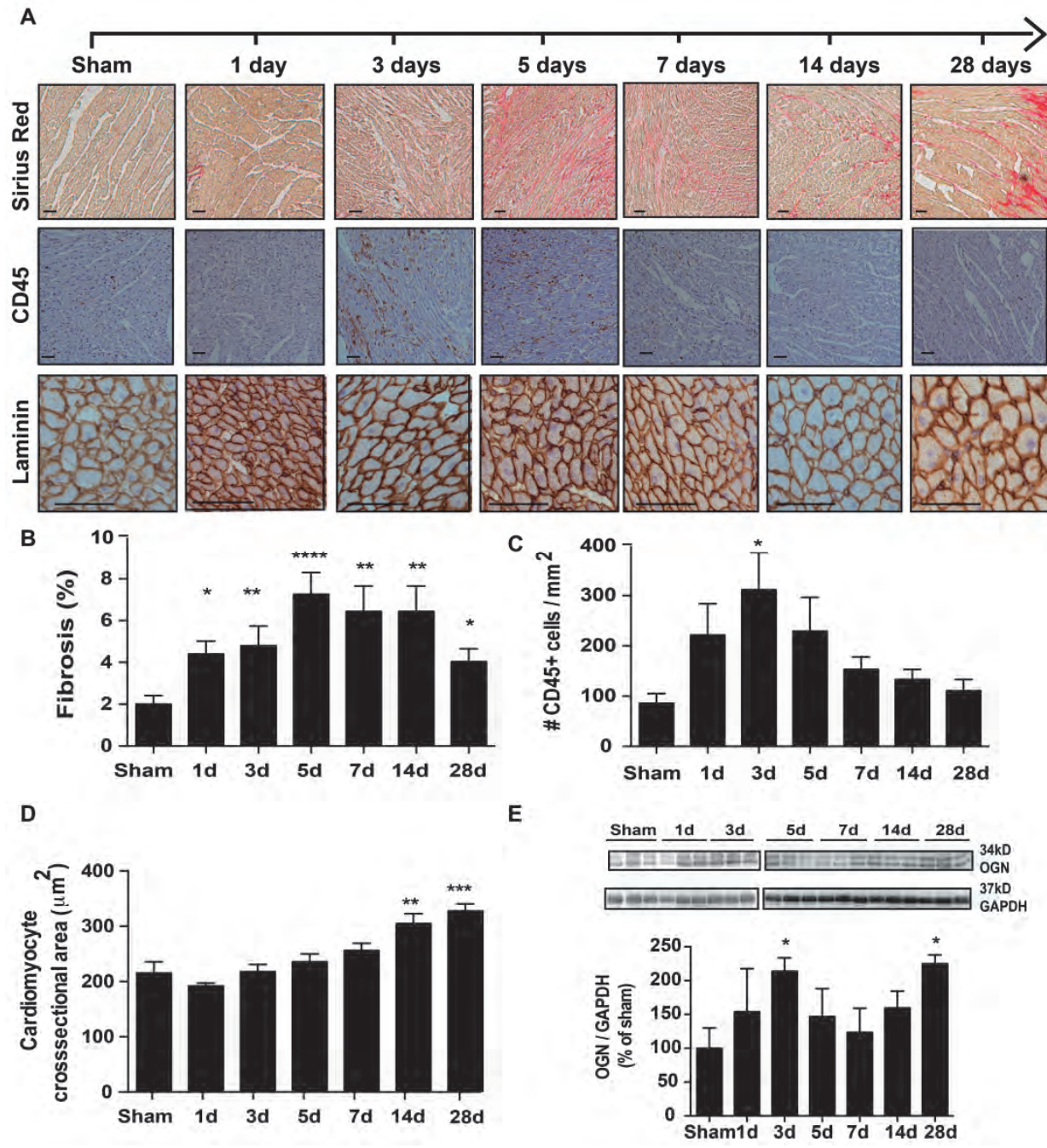

Figure1. OGN expression increases during hypertension. (A) Time-series of the hypertensive- mouse model: we infused young adult mice ( 3 months old) with Angll for 1, 3, 5, 7, 14 or 28 days. (A and B) 2 phases of fibrosis followed Angll. The first phase peaks at 5 days and consists of diffuse interstitially deposited fibers. During the second phase of fibrosis starting at 14 days, these diffuse fibers partly shifts into more localized scars. (A and C) Infiltration of leukocytes into the heart precedes the first fibrotic phase peaking at 3 days (A and D), while cardiomyocyte hypertrophy is a slow response becoming significant at 14 days and peaking at 28 days. (E) The expression of OGN increases with each phase of fibrosis. $n=5$ per group, ${ }^{*} p \leq 0.05,{ }^{* *} p \leq 0.01,{ }^{* * *} p \leq 0.001$, ${ }^{* * * *} \mathrm{p} \leq 0.0001$ vs. sham, scalebars $100 \mu \mathrm{m}$. 


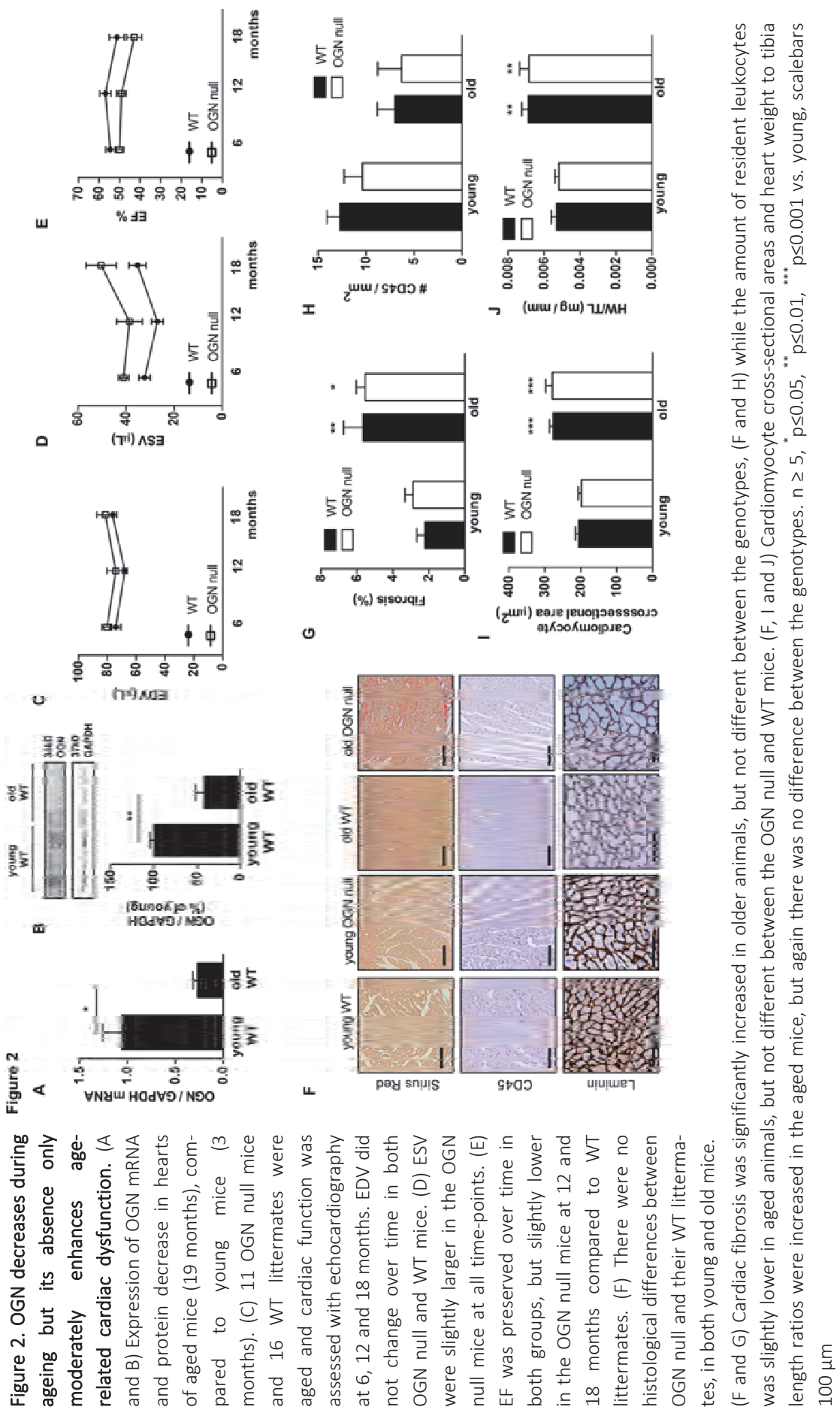




\section{OGN protects against the development of diastolic dysfunction}

We further evaluated a role for OGN in the pressure-overloaded heart. Both young and old OGN null mice and their WT littermates were exposed to Angll for 4 weeks (Figure 3 and 4). Prior and 4 weeks after Angll infusion, cardiac function was analyzed with MRI, to asses both systolic and diastolic function with a higher sensitivity compared to echocardiography in mouse models ${ }^{19}$. The absence of OGN significantly increased mortality following Angll infusion in the old mice (Figure 3A), but not in the young mice (Figure 4A). Importantly, neither age nor genotype affected blood pressure (BP) (Figure 3B and $\mathrm{C}$ and Figure $4 \mathrm{~B}$ and $\mathrm{C}$ ). Angll increased both diastolic and systolic BP to a similar extent in OGN null and WT mice in both old (Figure 3B and C) and young (Figure 4B and C).

In old mice, the absence of OGN significantly increased cardiac weight upon Angllinfusion (Figure 3D), as indicated by significantly higher heart weight to tibia length ratios compared to Angll-treated WT mice (Figure $3 \mathrm{E}$ ). The increase in relative wall thicknesses (RWT) and the decrease in EDV without alterations in ESV (Figure 3F-H) -all indicative of concentric remodeling- were more pronounced in the old Angll-treated OGN null compared to WT mice, in line with increased cardiac weight. EF slightly decreased in the old Angll treated OGN null mice, though this was not significant (Figure 3I). Along with increased LV mass and concentric remodeling, also MRI-measured parameters of diastolic dysfunction were more pronounced in the absence of OGN. E/A ratios significantly increased in old OGN null mice as compared to sham, and compared to WT littermates after AngII, mainly due to a decrease in atrial filling peak, indicative of decreased atrial contraction and LV stiffening (Figure 3J-L). E-values remained similar in both groups (Figure 3K) while A-values significantly decreased in the old OGN null, but not in the WT mice (Figure $3 \mathrm{~L}$ ). In line with preserved E-peaks, the deceleration time (DT) did not differ between WT and OGN null mice (Figure 3M). Also HR did not alter (Figure $3 \mathrm{~N}$ ). Finally, increased lung weights in the old hypertensive OGN null -indicative of lung congestion- confirm the onset of heart failure (Figure 30). 


\section{Chapter 3}

Figure 3

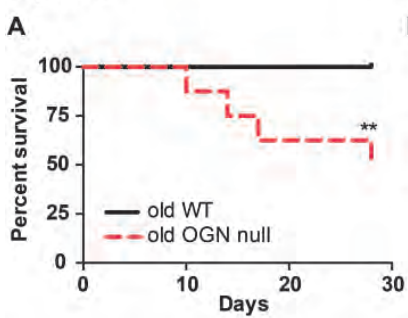

B

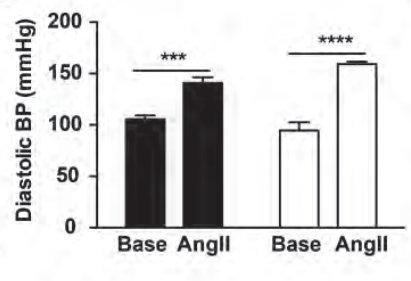

E

D

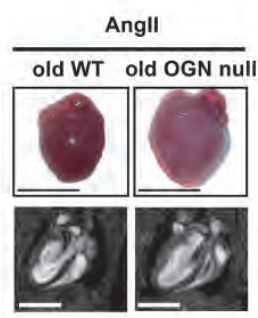

G

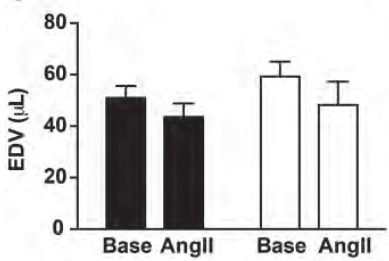

$J$

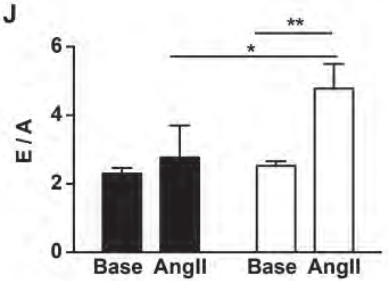

M

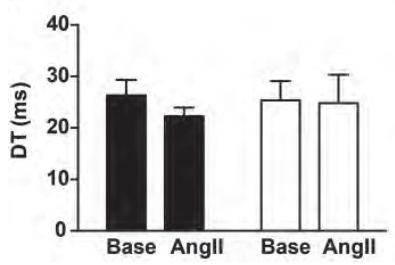

H

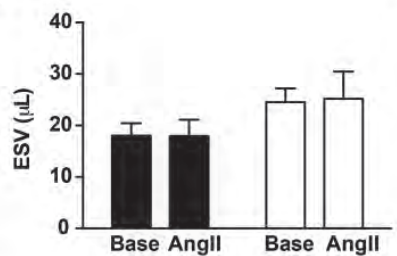

K

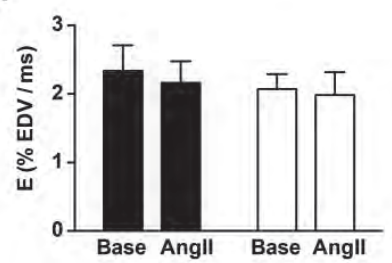

N

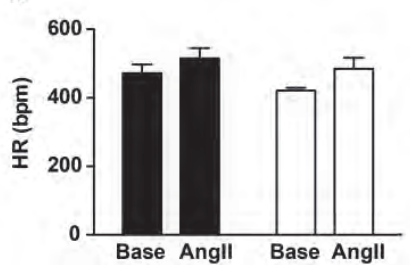

c
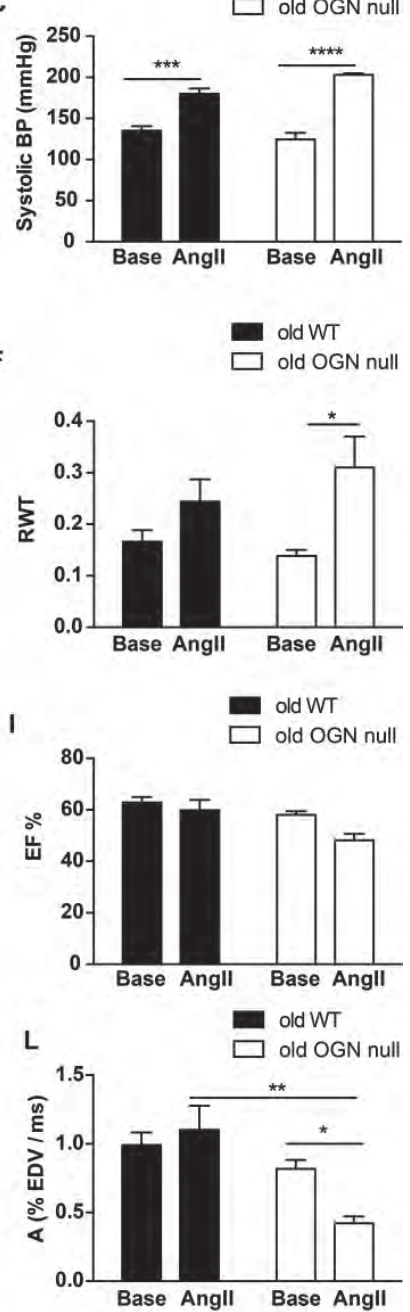

old WT

$\square$ old OGN null

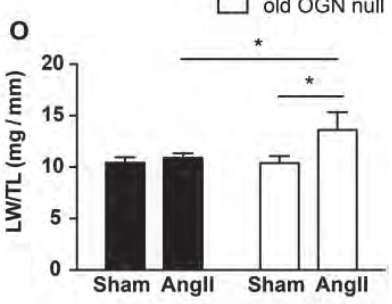

Figure 3. OGN protects against the development of diastolic dysfunction in aged mice (legend on the next page). 
Figure 3. OGN protects against the development of diastolic dysfunction in aged mice. (A) Following Angll, mortality was seen in the old OGN null but not in the WT mice. (B and C) Blood pressures (BP) were not different prior and after Angll in all mice. (D) Hearts were more enlarged in OGN null mice following Angll and (E) heart weight to tibia length $(\mathrm{HW} / \mathrm{TL})$ ratios were more increased in OGN null compared to sham and to hypertensive old WT mice. (F) All old mice displayed concentric remodeling, as shown by increased RWT, especially in the old OGN null mice, and $(G)$ by decreased EDV, but $(H)$ no changes in ESV after Angll. (I) EF was preserved, but slightly more decreased in the old OGN null mice after AngII. (J) E/A ratios were more significantly increased in old OGN null mice as compared to WT littermates after AngII, (K) where E values remained similar in both groups, (L) but A values significantly decreased in the old OGN null, and not in the WT littermates. (M) Deceleration time (DT) or (N) heart rate (HR) was not different prior or after Angll and between the old OGN null and WT mice. (O) Lung weight (LW) to tibia length ratios increased in the hypertensive old OGN null mice compared to sham and to hypertensive old WT mice. $n \geq 4,{ }^{*} p \leq 0.05,{ }^{* *} p \leq 0.01,{ }^{* * *} p \leq 0.001,{ }^{* * * *} p \leq 0.0001$, scalebars $5 \mathrm{~mm}$.

The absence of OGN also increased cardiac weight following Angll in young mice (Figure 4D), but to a similar extend compared to WT littermates (Figure 4E). In line, RWT slightly increased in both groups (Figure 4F). EDVs were unaltered (Figure 4G), while ESVs were slightly increased in young mice, especially in the OGN null mice (Figure 4H). Consequently, EF significantly dropped in the young OGN null, but not the WT mice (Figure 4I). Interestingly, E/A ratios slightly increased in both groups (Figure 4J). While young WT mice had increased $E$ values and preserved $A$ values, young OGN null mice had slightly decreased $E$ values and significantly decreased $A$ values (Figure $4 \mathrm{~K}$ and L). Furthermore, DT was significantly increased in the OGN null mice compared to their WT littermates after AngII (Figure 4M). HR did not differ (Figure 4N). Additionally, a trend to higher lung weights further suggests a progression from cardiac diastolic dysfunction to heart failure in the young OGN null mice ( $p=0.07$, Figure 40). Overall, these data demonstrate that young WT mice are more able to cope with hypertension- induced stress compared to their young OGN null littermates. In summary, OGN prevents diastolic dysfunction upon cardiac pressure-overload and ageing. 


\section{Chapter 3}

\section{Figure 4}

A

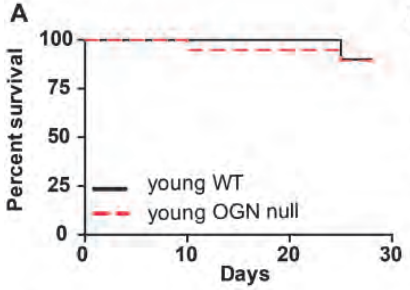

D

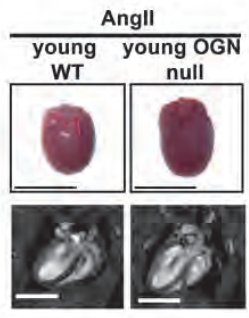

G

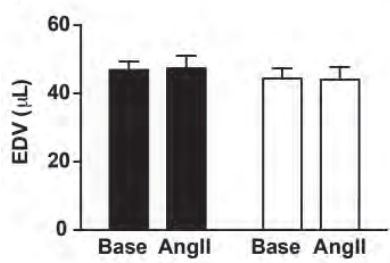

J

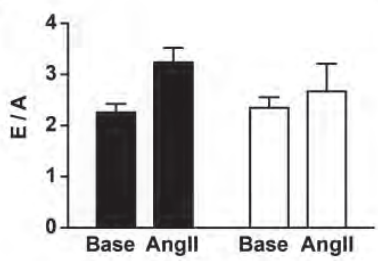

M

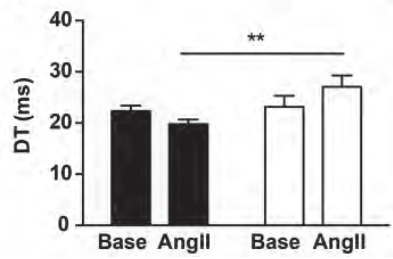

B

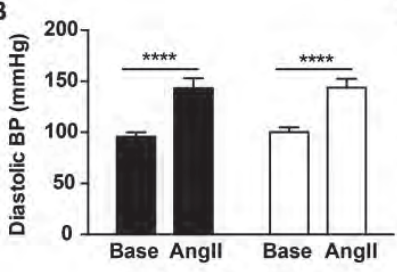

E

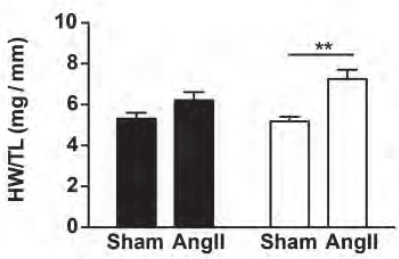

H

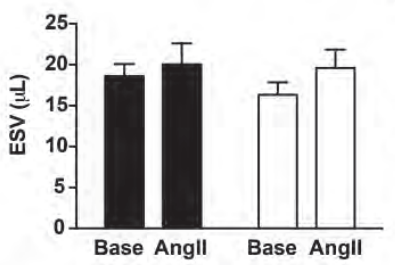

K

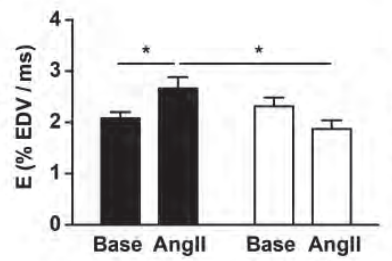

N

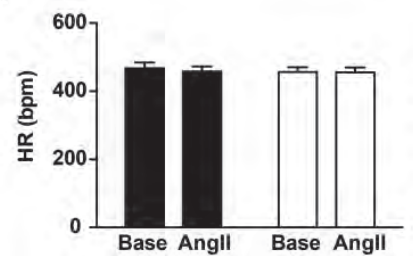

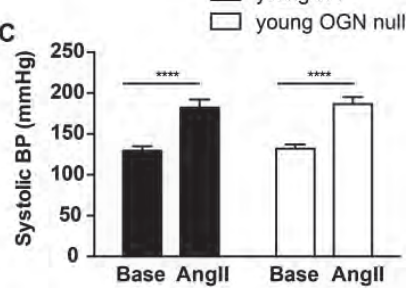

F
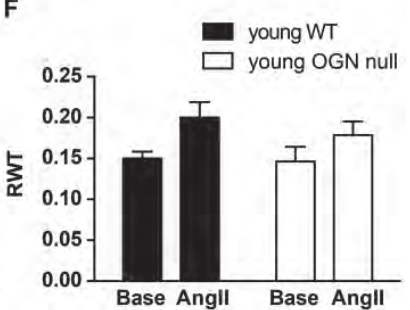

I

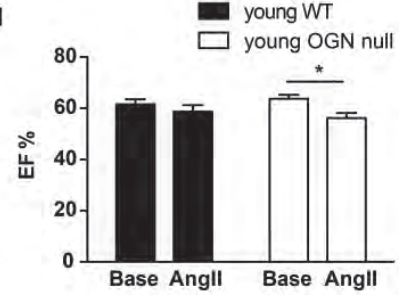

L 1.5 young WT

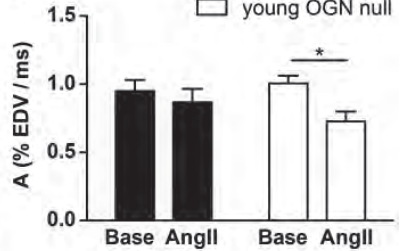

○ $\square$ young WT

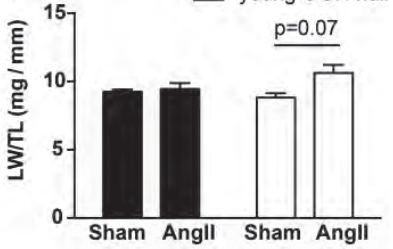

Figure 4. OGN protects against the development of diastolic dysfunction in young mice (legend on the next page). 
Figure 4. OGN protects against the development of diastolic dysfunction in young mice. (A) Angll induced no difference in mortality in young OGN null and WT mice and (B and C) blood pressures (BP) were not different between the OGN null and WT mice prior and after AngII. (D and E) Hearts and heart weight to tibia length $(\mathrm{HW} / \mathrm{TL}$ ) ratios were increased in OGN null an WT mice following Angll. (F) All young mice displayed increased RWT, (G) no changes in EDV, but (H) slight increases in ESV after AngII. (I) EF was preserved in young WT mice, but decreased in the young OGN null mice. (J) E/A ratios were increased in both groups after Angll, (K) where E values increased in the WT and decreased in the OGN null mice. (L) A values significantly decreased in the young OGN null, and not in the WT littermates. (M) Deceleration time (DT) was longer in the young OGN null after Angll compared to the WT mice and (N) heart rate (HR) was no different prior or after Angll and between the old OGN null and WT mice. (O) A trend to higher lung weight (LW) to tibia length ratios was seen in the young hypertensive OGN null mice compared to sham and to young hypertensive WT mice. $n \geq 7,{ }^{*} p \leq 0.05$, ${ }^{* *} \mathrm{p} \leq 0.01,{ }^{* * *} \mathrm{p} \leq 0.001,{ }^{* * *} \mathrm{p} \leq 0.0001$ vs. sham, scalebars $5 \mathrm{~mm}$.

\section{OGN decreases hypertension-induced cardiac fibrosis}

To assess how OGN reduces diastolic dysfunction, fibrosis and cardiomyocyte hypertrophy were histologically compared in AngIl treated OGN null and their WT littermates, both at old and young age, and compared to the previous age- and genotype-matched sham mice. In old mice, hypertension-induced cardiomyocyte hypertrophy did not differ between the OGN null and WT mice (Figure 5A and B). Because of the age-related increase in cardiomyocyte hypertrophy, the Angll- induced increase in cardiomyocyte cross-sectional area was less pronounced in the old mice (Figure 5A and B). Old hypertensive OGN null mice had higher numbers of cardiac leukocytes compared to WT littermates (Figure 5A and 5C) and importantly, cardiac fibrosis was increased in hypertensive hearts of the old OGN null compared to WT littermates (Figure 5A and D). Collagen crosslinking was not different, as assessed by the ratio of orange-red to yellow-green collagen fibers on Sirius red-stained sections under polarized light (Figure 5A and E).

In young mice, cardiomyocyte hypertrophy and the amount of leukocytes did not differ between the OGN null and WT mice (Figure 6A-C), while a trend to increased fibrosis was seen in the hypertensive hearts of young OGN null mice (Figure 6A and D). Collagen cross-linking was not different, as assessed by the ratio of orange-red to yellow-green collagen fibers on Sirius red-stained sections under polarized light (Figure 6A and $\mathrm{E})$. 

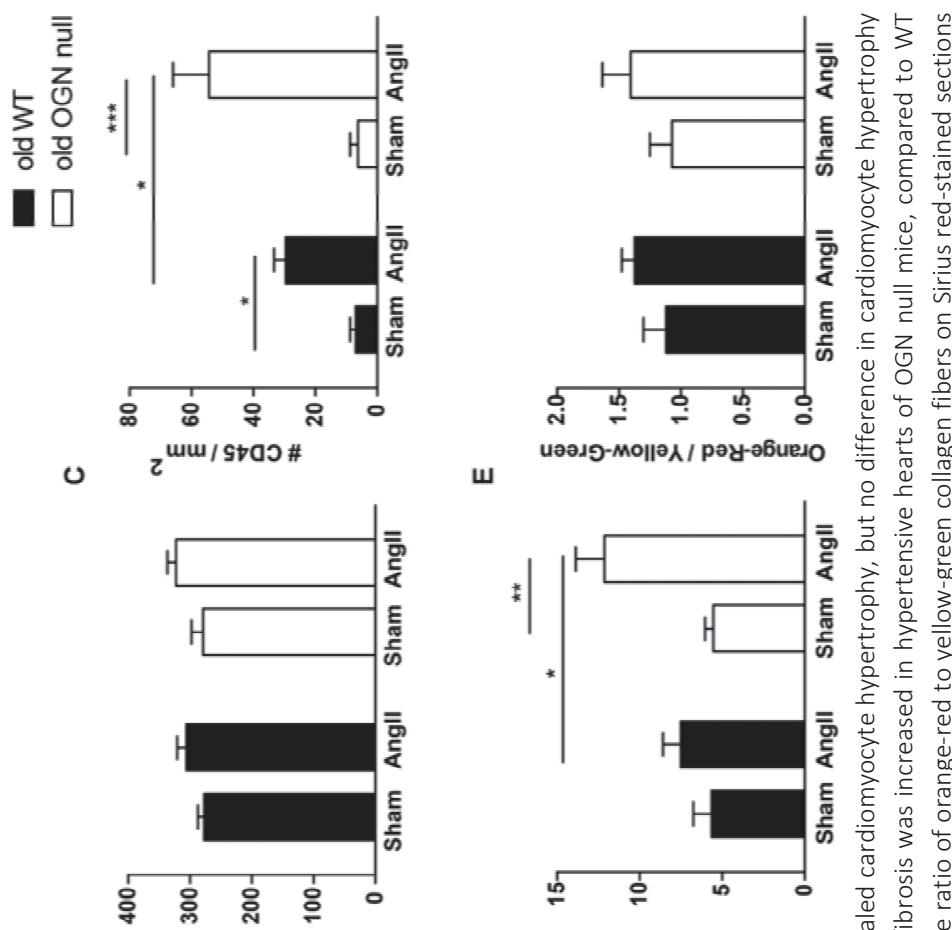

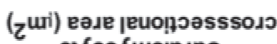

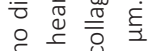

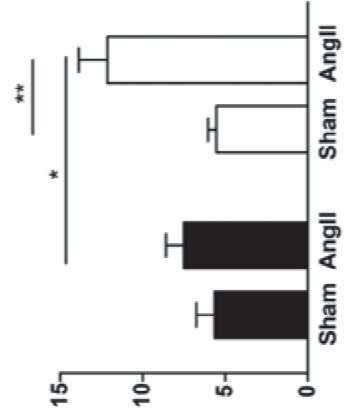

ป

خ ญे

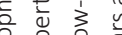

논 $\stackrel{2}{\stackrel{0}{0}}$

등

당 ㅇ

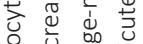

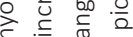

है

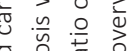

ป 인

(\%) s!sosq!y

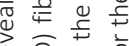

әұКэоКшордеว

m
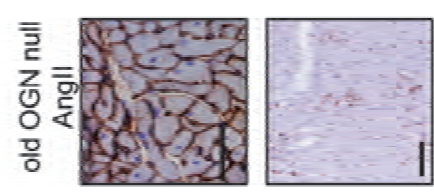

$\circ$
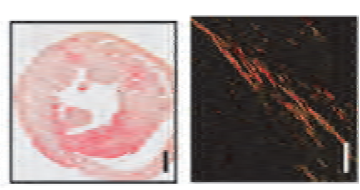

은

$\sim$ 등
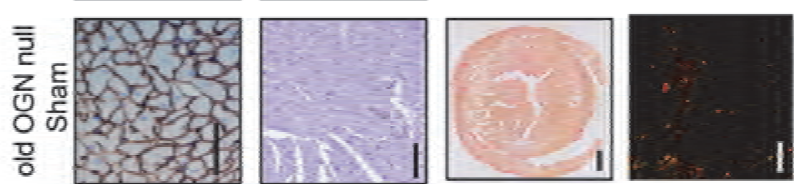

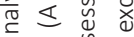

त ర

정 त

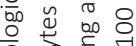

은

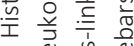

更

잉

ธ

政

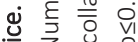

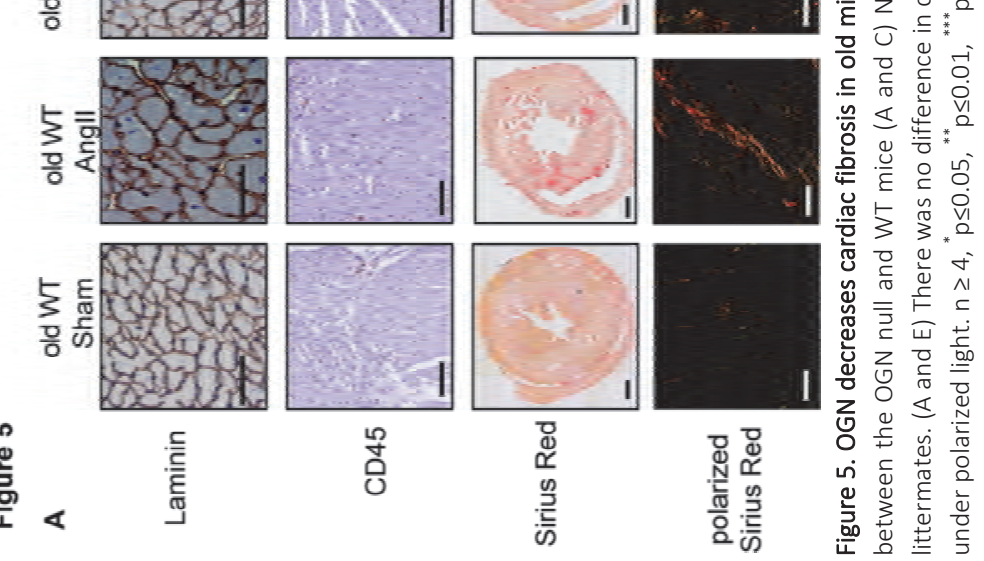



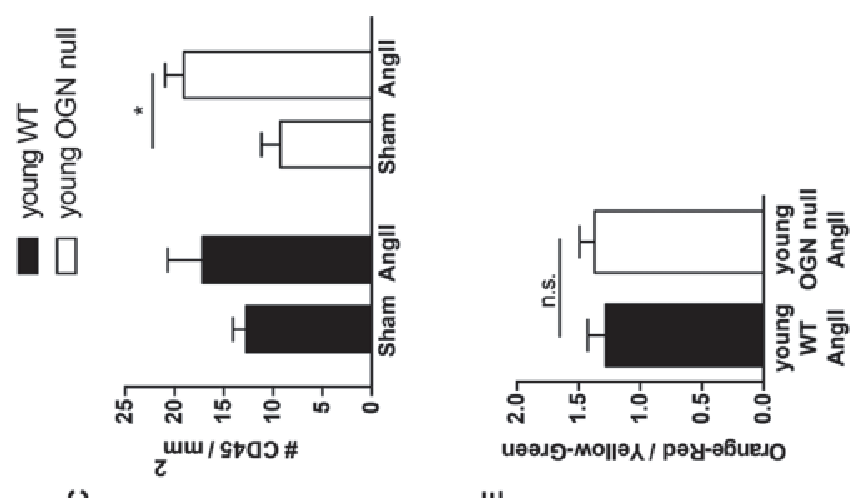

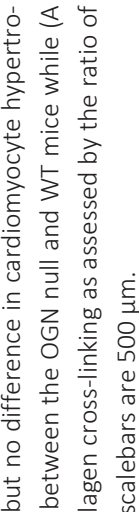

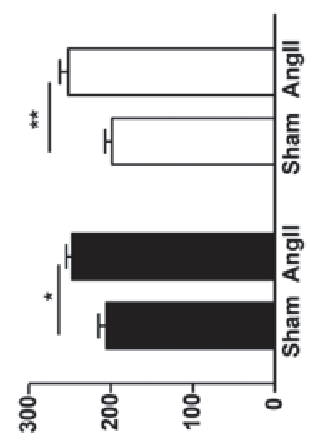

ш
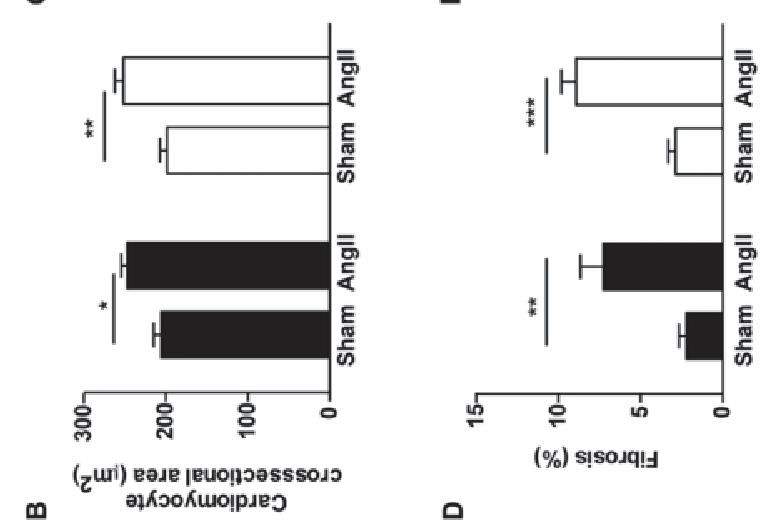

(\%) șsouq!y
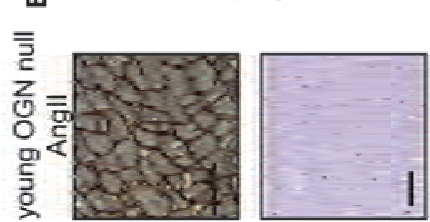

อ
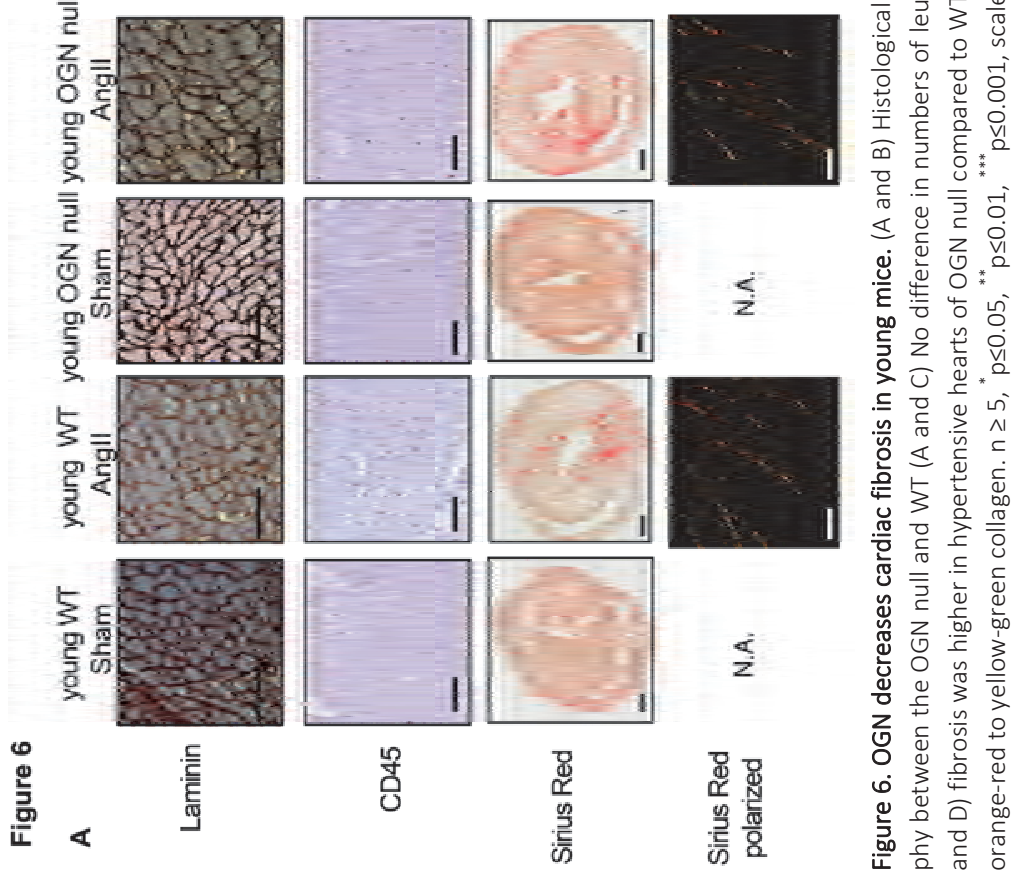
Table 1. Expression of fibroblast -related genes

\begin{tabular}{|c|c|c|c|c|c|c|c|c|}
\hline & \multicolumn{4}{|c|}{ Old } & \multicolumn{4}{|c|}{ Young } \\
\hline & WT Sham & $\begin{array}{l}\text { OGN null } \\
\text { Sham }\end{array}$ & WT AngII & $\begin{array}{c}\text { OGN null } \\
\text { Angll }\end{array}$ & WT Sham & $\begin{array}{l}\text { OGN null } \\
\text { Sham }\end{array}$ & WT Angll & $\begin{array}{c}\text { OGN null } \\
\text { Angll }\end{array}$ \\
\hline TGF $\beta / G A P D H$ & $1.3 \pm 0.4$ & $3.1 \pm 0.6$ & $2.4 \pm 0.9$ & $3.6 \pm 0.7$ & $1.0 \pm 0.3$ & $1.5 \pm 0.3$ & $1.5 \pm 0.5$ & $2.8 \pm 0.8$ \\
\hline COL1A/GAPDH & $0.4 \pm 0.1$ & $0.8 \pm 0.4$ & $1.5 \pm 0.4$ & $3.2 \pm 1.0^{\#}$ & $1.0 \pm 0.5$ & $1.0 \pm 0.2$ & $1.8 \pm 0.8$ & $3.5 \pm 0.8$ \\
\hline COL3A/GAPDH & $0.4 \pm 0.1$ & $0.7 \pm 0.4$ & $2.4 \pm 0.9$ & $3.4 \pm 1.1^{\#}$ & $1.0 \pm 0.3$ & $0.9 \pm 0.3$ & $1.1 \pm 0.3$ & $2.3 \pm 0.8$ \\
\hline aSMA/GAPDH & $0.7 \pm 0.2$ & $0.6 \pm 0.2$ & $1.3 \pm 0.6$ & $1.1 \pm 0.3$ & $1.0 \pm 0.6$ & $1.2 \pm 0.3$ & $1.7 \pm 0.7$ & $1.6 \pm 0.3$ \\
\hline
\end{tabular}

Data are expressed as fold change of young WT sham mice, $n=5, " ~ p \leq 0.05$ vs. sham

OGN reduces fibroblast proliferation, and does not affect cardiomyocyte passive stiffness

Next, we determined how OGN might affect fibroblast proliferation and consequent collagen production. OGN expression decreased in proliferating human cardiac fibroblasts upon TGFB1-stimulation (Figure 7 A-B). Moreover, exposure of human cardiac fibroblasts with recombinant OGN significantly reduced fibroblast proliferation (Figure 7C). In line, si-RNA-mediated reduction (90\%) of OGN expression increased the proliferation of human cardiac fibroblasts, which had a GFP-reporter signal in the promoter of the collagen gene. This OGN knockdown also augmented the collagen GFP-reporter signal, indicative of increased collagen expression (Figure 7D, E). Exposure of cells to TGF $\beta 1$ also increased collagen signal as expected, but again was blunted in the presence of recombinant OGN (Figure 7F). Finally, dermal fibroblasts from young OGN null mice and WT littermates were isolated and cultured. The absence of OGN resulted in a $20 \%$ higher rate of proliferation of fibroblasts (Figure 7G). In vivo, OGN expression inversely correlated with TGF $\beta 1$ in LV samples of sham and hypertensive WT mice (Figure 7H). Furthermore, both old and young OGN null mice displayed a trend to higher fibrosisrelated gene expression (TGF $\beta 1$, COL1 and COL3) compared to their WT littermates, while levels of alpha smooth muscle actin (aSMA) expression did not differ (Table 1), indicating no immediate role for OGN in fibroblast to myofibroblast transition.

To exclude a role for $O G N$ in cardiomyocyte stiffness, we isolated cardiomyocytes from old Angll treated OGN null and WT mice. Though OGN is present in the cardiomyocyte near the sarcomere (Figure 7l), passive forces did not differ in the absence of OGN (Figure 7J).

\section{DISCUSSION}

This study is the first to demonstrate a critical role for OGN in the development of diastolic dysfunction. We studied OGN in hypertensive-induced cardiac dysfunction and 
importantly, included ageing as a comorbidity. Importantly, OGN reduces fibroblast proliferation and cardiac fibrosis and hence protects against the development of diastolic dysfunction in hypertensive/age-induced HF.

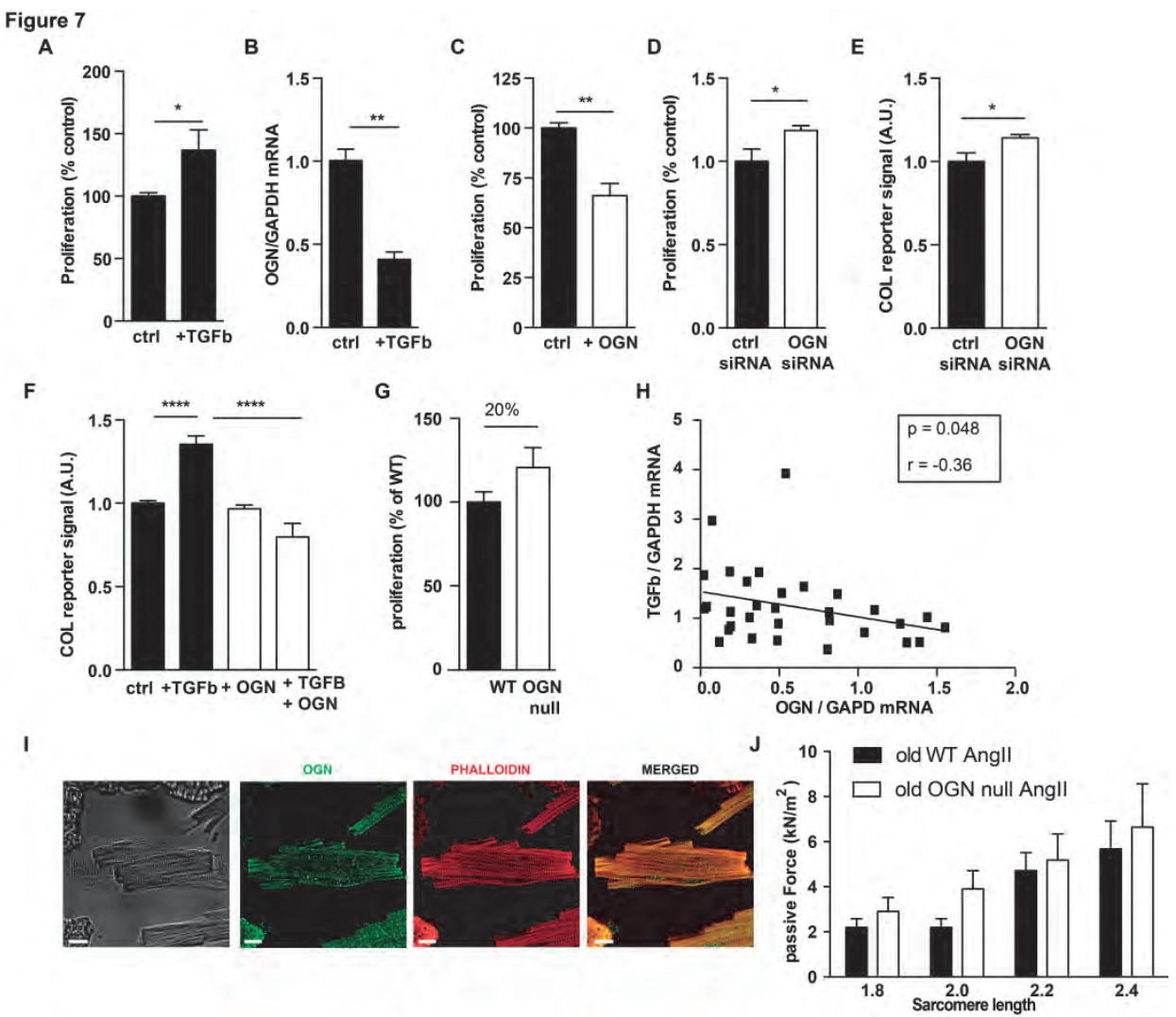

Figure 7. OGN decreases fibroblast proliferation, and does not affect cardiomyocyte passive stiffness. (A) TGFB1-stimulated human cardiac fibroblasts demonstrated increased cell proliferation and (B) in parallel decreased OGN expression, compared to control cells. (C) Exposure of the cells to recombinant OGN reduced fibroblast proliferation. (D) When OGN expression was reduced with siRNA in human cardiac fibroblasts with a GFP-reporter construct in the collagen gene, proliferation was increased and (E) in line collagen reporter signal was increased. (F) Exposure of these cells to TGF 1 1 resulted in increased collagen signal, which was blunted in the presence of recombinant OGN (G). When dermal fibroblasts from young OGN null mice and WT littermates were isolated and cultured, we found higher proliferation rates of OGN null fibroblasts. (H) In LV samples of WT sham and hypertensive mice an inverse correlation of TGF $\beta 1$ expression with OGN was seen. (I) OGN was also detected in the cardiomyocyte, where it localizes near the sarcomere however, (J) there was no difference in passive stiffness in myocytes isolated from old Ang॥ treated OGN null mice and WT littermates. $\mathrm{n} \geq 3,{ }^{*} \mathrm{p} \leq 0.05,{ }^{* *} \mathrm{p} \leq 0.01,{ }^{* * * *} \mathrm{p} \leq 0.0001$ vs. sham scalebars $10 \mu \mathrm{m}$.

Most patients presenting with diastolic HF are elderly with comorbidities such as hypertension, overweight/obesity, diabetes mellitus, and chronic obstructive pulmonary 
disease $^{3}$. Since the prevalence of hypertension increases with ageing, we included age as comorbidity in this study. Ageing in old sham and hypertensive mice went in line with concentric cardiac remodelling and increased cardiac fibrosis but without significant diastolic dysfunction. Importantly, the absence of OGN further increased concentric remodelling and collagen deposition, resulting in severe diastolic dysfunction and pulmonary congestion. The presence of OGN thus protect against the development of diastolic dysfunction and its progression to HFPEF in hypertensive/aged mice. Despite the fact that ageing accentuates the protective properties of OGN, also young WT mice are more able to cope with hypertension compared to their young OGN null littermates as there is a significant drop in EF and $A$ in the young OGN null mice. The absence of OGN did not alter cardiac hypertrophy itself, but increased diastolic dysfunction, and slightly but significantly decreased ejection fraction.

The presence of OGN reduces fibroblast proliferation and cardiac fibrosis both in $v i$ vo and in vitro, and as such protects against the development of diastolic dysfunction and its progression to HF upon hypertension and ageing. These data seem paradoxical to our recent infarct study, where OGN protects against cardiac disruption and adverse remodelling following myocardial infarction by promoting collagen alignment and maturation, without altering total collagen quantity in the infarct scar ${ }^{18}$. Here, upon Angllinfusion in vivo or TGFbeta administration in vitro, OGN gene-inactivation or knockdown increased fibroblast proliferation, collagen production and overall fibrosis, without influencing collagen thickness. The differences in the underlying pathophysiology of the models -reactive fibrosis in pressure-overload versus reparative fibrosis after MI- as well as the structural and functional diversity of OGN may explain these differences. After myocardial infarction, collagen secretion, maturation and cross-linking is an acute and critical process, necessary to replace the necrotic tissue. In aged- and hypertensive hearts, fibrosis occurs due to chronic stress imposed on the hearts, and only a minority represents the replacement of myocyte dropout. In this study, OGN clearly increases with the reactive phases of fibrosis following Angll infusion, and importantly, OGN administration in vitro reduces fibroblast proliferation and collagen expression. In our previous infarct study, OGN expression only increased by 14 days after infarction with infarct scaring, where it promotes scar maturation, while OGN levels in the noninfarcted remote LV remained low both early and late after infarction ${ }^{18}$. Possibly different glycosylated OGN variants are responsible for the different functions described, yet further supportive research on the different glycosylated OGN variants is needed. Other SLRPs have likewise diversity as biglycan increases collagen cross-linking, but not the amount of collagen, after myocardial infarction in mice ${ }^{20}$, while it reduces fibroblast proliferation rate in vitro ${ }^{21}$. Importantly, in both our infarct and age/hypertension studies, OGN exerted no role in myofibroblast differentiation. Furthermore, previous studies report reduced OGN expression in highly proliferative cells, such as cancer cells ${ }^{15}$, in line with our results. 
Importantly, our data reveal a protective role for OGN against diastolic dysfunction upon hypertension. This protective effect could only be related to a reduction in cardiac fibrosis, and not to a decrease of cardiomyocyte hypertrophy or its passive stiffness, the latter measured ex vivo. The higher heart weights in both young and old hypertensive OGN null mice are likely a consequence of increased cardiac fibrosis (and inflammation in old mice) but not to differences in cardiomyocyte hypertrophy. Our results contrast to some extent with a previous study where OGN related to cardiac hypertrophy in functional genomics studies in rats, but where it absence trended to decrease LV mass in mice ${ }^{17}$. Importantly, they only studied young mice after 2 weeks of Angll infusion, and assessed hypertrophy by LV mass, without histologically analyzing cardiac inflammation, fibrosis or cardiomyocyte cross-sectional area. Furthermore, also in our recent infarct study, the absence of OGN did not affect cardiomyocyte hypertrophy in the remote non-infarcted LV at detailed histological analysis ${ }^{18}$.

In conclusion, increased OGN upon pressure-overload reduces fibroblast proliferation and collagen production, protecting against diastolic dysfunction and progression to HF with ageing.

\section{PERSPECTIVES}

Diastolic dysfunction often occurs in aged hypertensive patients. Its prevalence gradualIy increases with 1 percent per year, and is expected to represent two third of the HF population within 2 decades ${ }^{22,23}$. Unfortunately, underlying mechanisms are incompletely understood and targeted therapy lacking. This study is the first to demonstrate a critical role for OGN in reducing diastolic dysfunction, where OGN reduces fibroblast proliferation, fibrosis and in this way decreases diastolic dysfunction. Hence, the perspective of using OGN (mimics) as a target during diastolic dysfunction of agedhypertensive origin opens new windows in medicine, especially in the prevention of HF development.

\section{NOVELTY AND SIGNIFICANCE}

This study is the first to demonstrate a critical role for OGN in diastolic dysfunction. We demonstrate that 2 phases of fibrosis occur following hypertension and that OGN expression increases with each phase of fibrosis. Furthermore, we demonstrate that OGN reduces fibroblast proliferation, fibrosis and diastolic dysfunction. By understanding the multifactorial nature of $\mathrm{OGN}$ and its variation in function during different pathologies, the development of targeted therapies for diastolic HF becomes possible. 


\section{Chapter 3}

\section{MATERIALS AND METHODS}

\section{Mouse models}

The Animal Care and Use Committee of the University of Leuven approved all described study protocols. Experiments were performed according to the official rules formulated in the Belgian law on the care and use of experimental animals (License number 014/2014). All surgery was performed under isoflurane anesthesia (2\% isoflurane, ecuphar) and all efforts were made to minimize suffering. Angiotensin II (Angll, H-1705, Bachem AG, Switzerland) was administered to the mice with the use of osmotic minipumps (Alzet 2004, Durect Corp., Cupertino, California, USA). Pump implatantion surgery was performed as described ${ }^{24}$. For the Angll time-series, 3-months-old WT C57BI/6-J mice (5 mice per group) were purchased from Harlan (Europe) and Angll $(2.5 \mathrm{mg} / \mathrm{kg} /$ day) was infused for indicated time-periods. For the ageing study, $11 \mathrm{OGN}$ null mice and 16 of their WT C57BI/6J littermates were aged in-house and cardiac function was assessed every 6 months with echocardiography. When mice reached the age of 19 months, a group 3 months-old OGN null mice and their WT littermates were included in the experiment, and Angll $(1.5 \mathrm{mg} / \mathrm{kg} /$ day) was administered for 4 weeks. In all experiments, hearts were removed and prepared for molecular and histological analysis. Mice that died during the experiment, died suddenly from aortic rupture or from severe heart failure. The construction of OGN null mice is described in detail elsewhere ${ }^{25}$, mice were backcrossed to the C57BI/6J background for more than 10 generations. Groups were age and gender matched

\section{Histology and microscopy}

Cardiac tissue was was fixed in $1 \%$ paraformaldehyde (PFA; Sigma) in phosphatebuffered saline (PBS) for 4 hours (h), post-fixed in ethanol, dehydrated and embedded in paraffin. Four $\mu \mathrm{m}$ thick sections were made for routine histological and immunohistochemical stainings and were performed as previously described ${ }^{24}$. All morphometric analyses were done on cross-sectional sections. To assess the amount of the newly formed collagen matrix, Picro Sirius Red staining was performed as previously described $^{26}$. The number of CD-45 - staining cells (monoclonal rat antibody, BD, 553076, clone $30-\mathrm{F} 11,5 \mu \mathrm{g} / \mathrm{ml}$ ) was measured per $\mathrm{mm}^{2}$. Myocyte cross-sectional areas were calculated by measuring the inner circumference of 150 myocytes per sample on laminin- stained sections (rabbit antibody, Sigma, L9393, 125 $\mathrm{gg} / \mathrm{ml}$ ). Microscopic analyses were performed using a microscope (Leitz DMRXE; Leica), and QWin morphometry software (Leica). Confocal microscopy was performed on a Zeiss LSM700 microscope (Leica) using the Zen software (Leica). 


\section{Echo analysis}

Mice were anesthetized ( $2 \%$ isoflurane, ecuphar) and echocardiograpy was performed at indicated timepoints by transthoracic echocardiography with a 13- $\mathrm{MHz}$ transducer (i13L, GE ultrasound; Horton Norway) on a Vingmed Vivid 7 scanner (GE ultrasound, Horton, Norway). Heart rates (HR) were recorded, LV diameters at end-diastole (EDD), and end-systole (ESD), were measured, and fractional shortening (FS), and ejection fraction (EF) were calculated.

\section{Cardiac Magnetic Resonance Imageing (MRI)}

For cMRI mice were put prone on a dedicated animal bed with warm water-circulating heating system under spontaneous breathing of gas anesthesia (+/- $1.3 \%$ isoflurane in a flow of $0.3 \mathrm{l} / \mathrm{h} \mathrm{O} 2$ and $0.7 \mathrm{l} / \mathrm{h}$ air) and under continuous monitoring of body temperature $\left(37+/-0.5^{\circ} \mathrm{C}\right)$ and respiration rate $(+/-110-150 \mathrm{bpm})$. cMRI was performed using a Bruker Biospec 9.4 Tesla (horizontal bore, $20 \mathrm{~cm}$ ) small animal MRI scanner (Bruker BioSpin, Ettlingen, Germany) equipped with an actively shielded gradient insert (1200 $\mathrm{mT} / \mathrm{m}$ ) and a 3.5-cm diameter quadrature volume coil (Bruker Biospin). A retrospectively-gated fast low angle shot (FLASH) acquisition sequence was used with following specific parameters: repetition time, $6 \mathrm{~ms}$; echo time $1.6 \mathrm{~ms}$; flip angle, $15^{\circ}$ using a $300 \mu \mathrm{s}$ Gauss pulse; matrix $192 \times 192$, field of view, $30 \times 30 \mathrm{~mm}$; slice thickness, $500 \mu \mathrm{m}$, oblique saturation slice navigator (size 76 , flip angle $2.5^{\circ}$ using a $1 \mathrm{~ms}$ Gauss pulse, slab thickness $3 \mathrm{~mm}$ ), number of repetitions: 125, total acquisition time $2 \mathrm{~min} 29 \mathrm{~s}$. For localization purposes, 2-dimensional (2D) pseudo short-axis and long-axis T1-weighted images were recorded first. Then 2D short axis slices (10 or 11) covering the full heart were recorded (inter-slice distance $0.80-1.05 \mathrm{~mm}$ ). Finally, in order to analyze the enddiastolic filling rate, the short axis acquisition from the mid-ventricular short-axis position was repeated with a slice-thickness of $1 \mathrm{~mm}$ and 1250 repetitions (other parameters identical; total scan time 24min). Data were reconstructed using Paravision 5.1 (Bruker) by zerofilling to a matrix of $320 \times 320$ and verifying retrospective triggering accuracy before final reconstruction (using $70 \%$ of the respiration signal) to 15 or 100 frames for standard cine MRI or end-diastolic filling rate determination, respectively (INTRAGATE, Bruker Biospin). Volumes excluding papillary muscles were derived from manual delineation in ImageJ (http://imageJ.nih.gov/ij; NIH, USA). For systolic function ejection fraction (EF), stroke volume (SV) and relative wall thickness (RWT) were calculated. To assess diastolic function LV volume-time curves were constructed, normalized to the end-diastolic volume and smoothed over a running average of five data points. From this LV-volume-time curve, the derivative, i.e. the LV filling rate curve, was computed and early peak filling rate (E) and late peak filling rate (A), E/A ratio and deceleration time (DT) were calculated. 


\section{Chapter 3}

\section{Blood Pressure Measurements}

Systolic and Diastolic Blood Pressures (BP) were measured at baseline and after 4 weeks of Angll administration in OGN null mice and their WT littermates, by volume-pressure recording using a tail-cuff CODA system (Kent Scientific, San Diego, CA, USA). Mice were trained for 3 consecutive days before each measurement.

\section{RNA isolation and expression}

RNA was isolated from left ventricular (LV) tissue and cell lysates with the mirVana kit (ThermoFischer, AM1560) according to the manufacturer's guidelines and was stored at $-80^{\circ} \mathrm{C}$. RNA was reverse transcribed into complementary DNA with the qScript CDNA synthesis kit (Quanta BioSciences, 95048-025) according to the manufacturer's instructions. Real-time quantitative PCR was performed with SYBR green PCR Master mix (Applied Biosystems). Primers were designed with primer-BLAST (NCBI) and built to contain an intron- exon boundary. Primers were designed for mouse OGN (5'CCTGGAATCTGTGCCTCCTA3'; 5'TCCAGGCGAATCTCTTCAAT3'), mouse TGFß1 (5'GAAGGACCTGGGTTGGAAGT3'; 5'TGGTTGTAGAGGGCAAGGAC3'), mouse COL1 (5'CTTCACCTACAGCACCCTTGTG3'; 5'CTTGGTGGTTTTGTATTCGATGAC3'), mouse COL3 (5'TCGGAACTGCAGAGACCTAAA3'; 5'CCCCAGTTTCCATGTTACAGA3'), mouse aSMA (5'GTCCCAGACATCAGGGAGTAA3'; 5'TCGGATACTTCAGCGTCAGGA3'), human OGN (5'TCCAGTTCTTCCTCCAAGCTCAC3'; 5' AGAGGCACGGATTCCAGGGCA') and mouse GAPDH (5'GGTGGACCTCATGGCCTACA3'; 5'TCGTTCCTGTGACTCGTTCTCTC3') or human GAPDH (5'ACCCACTCCTCCACCTTTGAC3'; 5'ACCCTGTTGCTGTAGCCAAATT3') were used as housekeeping gene.

\section{Western Blotting}

Proteins in LV tissue were separated by SDS-PAGE and were subsequently immunoblotted for the detection of OGN (monoclonal mouse antibody, Santa Cruz Biotechnology, sc374463) and GAPDH (monoclonal mouse antibody, Fitzgerald, 10R-G109a, clone 6C5, $0.1 \mu \mathrm{g} / \mathrm{ml}$ ) overnight at $4^{\circ} \mathrm{C}$. Signals were visualized using Hyperfilm ECL (Amersham Biosciences) and quantified using Image J software. Protein levels were expressed relative to protein levels of GAPDH.

\section{Fibroblast cultures}

Human cardiac fibroblasts were purchased from Promocell (C-12375) and cultured and handled according to the manufacturers instructions. To stimulate cells, cells were starved overnight and subsequently stimulated with $0.5 \mu \mathrm{g} / \mathrm{ml}$ human recombinant OGN (OriGene Technologies, TP323948) or with $10 \mathrm{ng} / \mathrm{ml}$ recombinant human transforming 
growth factor $\beta 1$ (TGF $\beta 1, R \& D$ systems, 240-B-010) for $24 \mathrm{~h}$. The next day, a cellproliferation assay was started or cells were collected in mirVana lysis buffer. Collagenreporter human cardiac fibroblasts were manufactured by Innoprot (Innoprot, Biscay, Spain). Briefly, the synthetic Human $\alpha(I)$ Procollagen Promoter (from -804 to +42 ) was provided from DNA2.0, cloned into a pJ241 plasmid flanked by Sall and Pmel restriction sites. The insert with Human $\alpha(I)$ Procollagen Promoter (from -804 to +42 ) was digested with Sall and Pmel restriction enzymes and subcloned into a pLTVHM vector containing turboGFP protein. The final construct was verified by DNA sequencing. For the generation of lentiviral stocks, viral packageing cells (HEK293T kindly provided by Juan Ortin) were maintained in DMEM supplemented with $10 \%$ FBS and $50 \mu \mathrm{g} / \mathrm{ml}$ gentamicin (Sigma-Aldrich). The lentiviral stock was prepared by transfecting the constructs (pLTVHMpCOL1A1 turboGFP, pCMV8.91 and pMD2G) using the traditional method of calcium phosphate. After 48h, viruses containing supernatants were harvested, filtered, centrifuged, and stored in 1-ml aliquots. Human cardiac fibroblast immortalized (HCFi) cells were infected with virus at the multiplicity of infection of 10. The HCFi was maintained in Dulbecco's modified Eagle's medium (D6429 from Sigma-Aldrich) supplemented with $10 \%$ fetal bovine serum (FBS from sigma-Aldrich). The day before an experiment, cells were starved overnight in DMEM without FBS. After starvation, OGN mRNA expression was reduced, by treatment of the cells with siRNA against OGN (Ambion, 4392420) for 4 hours, or with negative control siRNA (Ambion, 4390843) for control samples. Equal volumes of siRNA and lipofectamine (Invitrogen) were mixed 1/50 in Optimem (Invitrogen) and this mixture was added to the medium on the cells. After 4 hours, the medium of the cardiac fibroblasts was diluted $1 / 1$ with DMEM containing $0.5 \%$ FBS. The next day, medium was refreshed and fibroblasts were treated with $0.5 \mu \mathrm{g} / \mathrm{ml}$ human recombinant OGN and/or $10 \mathrm{ng} / \mathrm{ml}$ TGF $\beta$ for 24 hours. The next day, collagen-reporter signal was measured at $488 \mathrm{~nm}$ and a cell-proliferation assay was started. Dermal mouse fibroblasts were isolated from 3 months-old OGN null mice and WT littermates as previously described ${ }^{27}$. The Animal Care and Use Committee of the University of Leuven approved the described study protocols. Experiments were performed according to the official rules formulated in the Belgian law on the care and use of experimental animals and all efforts were made to minimize suffering. The cells were maintained in DMEM 22320 (Invitrogen), supplemented with 10\% FBS and 1\% penicillinstreptomycin. Second-passage cardiac fibroblasts (70-90\% confluent) were used for a cell proliferation assay. Fibroblast proliferation was measured with a cell proliferation ELISA (Roche, 11647229001) according to the manufacturers instructions.

\section{Immuno-staining of isolated adult mouse cardiac myocyte}

Mice were injected with heparin (1000 U/kg intraperitoneally) and killed by injection of a lethal dose of ketamine and xylazine intraperitoneally. The heart was excised and after cannulation of the aorta, hearts were mounted to a Langendorff perfusion set. The 


\section{Chapter 3}

heart was briefly rinsed with normal Tyrode solution, containing (mmol/L): $137 \mathrm{NaCl}$, $5.4 \mathrm{KCl}, 0.5 \mathrm{MgCl}$, $1 \mathrm{CaCl}$, 11.8 Hepes, 10 2,3-Butanedione monoxime and 10 glucose, $\mathrm{pH}$ was adjusted to 7.4 with $\mathrm{NaOH}$. Subsequently it was perfused with a Ca2+-free solution for $8 \mathrm{~min}$. The Ca2+-free Tyrode solution contained (mmol/L): $130 \mathrm{NaCl}, 5.4 \mathrm{KCl}, 1.2$ KH2PO4, 1.2 MgSO4, 6 Hepes, 10 2,3-Butanedione monoxime, 20 glucose, and pH was adjusted to 7.2 with $\mathrm{NaOH}$. Collagenase II (672Units/ml, Worthington 4176) added to the Ca2+-free solution was subsequently perfused for $8 \mathrm{~min}$. The enzyme was washed out for $3 \mathrm{~min}$. with the Ca2+-free Tyrode solution containing $0.09 \mathrm{mM} \mathrm{CaCl} 2$ and $50 \mathrm{mg} / \mathrm{ml} \mathrm{BSA}$, and $\mathrm{Ca} 2+$ was reintroduced with the Ca2+-free Tyrode solution, to which $0.18 \mathrm{mM} \mathrm{CaCl} 2$ was added. The heart was then removed from the Langendorff perfusion set, the ventricles were disintegrated and further dissociated into single cells by gentle shaking. Ca2+ was further reintroduced with the Ca2+-free Tyrode solution, to which subsequently $0.5 \mathrm{mmol} / \mathrm{L}$ and $1 \mathrm{mmol} / \mathrm{L} \mathrm{CaCl} 2$ was added. Cells were subsequently fixed in 2\% PFA in PBS for 10 min, incubated in $50 \mathrm{mmol} / \mathrm{L}$ glycine for $30 \mathrm{~min}$ to remove autofluorenscence caused by PFA at $488 \mathrm{~nm}$, and stained for OGN (USBiological, 141741, $2 \mu \mathrm{g} / \mathrm{ml}$ ) overnight at $4^{\circ} \mathrm{C}$. The next day cells were first incubated with a secondary goat anti rabbit-alexa 488 labeled antibody for $90 \mathrm{~min}$. at room temperature and cells were subsequently stained with rhodamine phallloidin (Invitrogen, R415) for 20 min at room temperature and afterwards visualized with confocal microscopy on a Zeiss LSM700 microscope (Leica) using the Zen software (Leica).

\section{Passive force measurements in stripped myocytes}

Force measurements were performed in single, mechanically isolated cardiomyocytes as described previously ${ }^{28}$. Cardiac samples were defrosted in relaxing solution (free Mg1, KCl 100, EGTA 2, Mg-ATP 4 and imidazole 10 mmol/L; pH 7.0), mechanically disrupted and incubated for 5 minutes in relaxing solution supplemented with $0.5 \%$ Triton $\mathrm{X}-100$ to remove all membrane structures. Subsequently, cells were washed twice in relaxing solution, after which single cardiomyocytes were attached with silicone adhesive between a force transducer and a motor. Isometric force measurements were subsequently performed on single cardiomyocytes at a sarcomere length of $2.2 \mu \mathrm{m}$. Absolute force values were normalized to cardiomyocyte cross-sectional area and expressed as developed tension (in $\mathrm{kN} \mathrm{m-2).} \mathrm{Passive} \mathrm{tension} \mathrm{(Fpas)} \mathrm{was} \mathrm{determined} \mathrm{by}$ allowing the cardiomyocyte to shorten by $30 \%$ of its length in relaxing solution.

\section{Statistical analysis}

Data were expressed as the mean \pm SEM. Histological and molecular analyses were performed in independent groups. Normal distribution of all continuous variables was tested according to the method of Kolmogorov and Smirnov. An unpaired Student t test for 2 groups or ANOVA, followed by a Bonferroni post hoc test for more groups was 
used in most of the comparisons when groups passed the normality test. When the standard deviation of two groups significantly differed, a Mann-Whitney test for 2 groups or a Kruskal-Wallis test, followed by a Dunn's post hoc test for more groups, was used. For correlations, the Pearson correlation coefficient was calculated when variables passed normality test, or a Spearman correlation coefficient was calculated when the standard deviation of the groups significantly differed. A paired Student's test or repeated measures ANOVA was used to analyze baseline and follow-up echocardiographic, MRI and BP measurements. The survival curves were obtained by the KaplanMeier method and compared by the log-rank test. A two-sided p-value of $\leq 0.05$ was considered statistically significant.

\section{FUNDING}

This work was supported by a CARIM-funded PhD grant of the Maastricht University, and by the European Commission's grants FP7 FIBROTARGETS [602904, for in vitro work], MEDIA [261409 for animal work].

\section{DISCLOSURES}

None. 


\section{REFERENCES}

1 Mozaffarian, D. et al. Heart Disease and Stroke Statistics-2016 Update: A Report From the American Heart Association. Circulation 133, e38-e360, doi:10.1161/CIR.0000000000000350 (2016).

2 Wolf-Maier, K. et al. Hypertension prevalence and blood pressure levels in 6 European countries, Canada, and the United States. JAMA 289, 2363-2369, doi:10.1001/jama.289.18.2363 (2003).

3 Paulus, W. J. \& Tschope, C. A novel paradigm for heart failure with preserved ejection fraction: comorbidities drive myocardial dysfunction and remodeling through coronary microvascular endothelial inflammation. J Am Coll Cardiol 62, 263-271, doi:10.1016/j.jacc.2013.02.092 (2013).

4 Zile, M. R., Baicu, C. F. \& Gaasch, W. H. Diastolic heart failure--abnormalities in active relaxation and passive stiffness of the left ventricle. N Engl J Med 350, 1953-1959, doi:10.1056/NEJMoa032566 (2004).

5 Zile, M. R. et al. Prevalence and significance of alterations in cardiac structure and function in patients with heart failure and a preserved ejection fraction. Circulation 124, 2491-2501, doi:10.1161/CIRCU LATIONAHA.110.011031 (2011).

6 Shah, A. M. et al. Cardiac structure and function in heart failure with preserved ejection fraction: baseline findings from the echocardiographic study of the Treatment of Preserved Cardiac Function Heart Failure with an Aldosterone Antagonist trial. Circulation. Heart failure 7, 104-115, doi:10.1161/CIRCHEART FAILURE.113.000887 (2014).

7 Hidalgo, C. \& Granzier, H. Tuning the molecular giant titin through phosphorylation: role in health and disease. Trends Cardiovasc Med 23, 165-171, doi:10.1016/j.tcm.2012.10.005 (2013).

8 Azevedo, C. F. et al. Prognostic significance of myocardial fibrosis quantification by histopathology and magnetic resonance imageing in patients with severe aortic valve disease. J Am Coll Cardiol 56, 278-287, doi:10.1016/j.jacc.2009.12.074 (2010).

9 Kasner, M. et al. Diastolic tissue Doppler indexes correlate with the degree of collagen expression and cross-linking in heart failure and normal ejection fraction. J Am Coll Cardiol 57, 977-985, doi:10.1016/j.jacc.2010.10.024 (2011).

10 Zile, M. R. et al. Myocardial stiffness in patients with heart failure and a preserved ejection fraction: contributions of collagen and titin. Circulation 131, 1247-1259, doi:10.1161/CIRCULATIONAHA.114. 013215 (2015).

11 Iozzo, R. V. \& Schaefer, L. Proteoglycans in health and disease: novel regulatory signaling mechanisms evoked by the small leucine-rich proteoglycans. The FEBS journal 277, 3864-3875, doi:10.1111/j.17424658.2010.07797.x (2010).

12 Chen, S. \& Birk, D. E. The regulatory roles of small leucine-rich proteoglycans in extracellular matrix assembly. The FEBS journal 280, 2120-2137, doi:10.1111/febs.12136 (2013).

13 Huang, $\mathrm{H}$. et al. Specific requirement of Gli transcription factors in Hedgehog-mediated intestinal development. The Journal of biological chemistry 288, 17589-17596, doi:10.1074/jbc.M113.467498 (2013).

14 Kawao, N. \& Kaji, H. Interactions between muscle tissues and bone metabolism. Journal of cellular biochemistry 116, 687-695, doi:10.1002/jcb.25040 (2015).

15 Tasheva, E. S., Maki, C. G., Conrad, A. H. \& Conrad, G. W. Transcriptional activation of bovine mimecan by p53 through an intronic DNA-binding site. Biochimica et biophysica acta 1517, 333-338 (2001).

16 Zhang, Y., Conrad, A. H. \& Conrad, G. W. Effects of ultraviolet-A and riboflavin on the interaction of collagen and proteoglycans during corneal cross-linking. The Journal of biological chemistry 286, 1301113022, doi:10.1074/jbc.M110.169813 (2011).

17 Petretto, E. et al. Integrated genomic approaches implicate osteoglycin (Ogn) in the regulation of left ventricular mass. Nature genetics 40, 546-552, doi:10.1038/ng.134 (2008).

18 Van Aelst, L. N. et al. Osteoglycin prevents cardiac dilatation and dysfunction after myocardial infarction through infarct collagen strengthening. Circulation research 116, 425-436, doi:10.1161/CIRCRESAHA. 116.304599 (2015).

19 Coolen, B. F. et al. High frame rate retrospectively triggered Cine MRI for assessment of murine diastolic function. Magn Reson Med 69, 648-656, doi:10.1002/mrm.24287 (2013). 
20 Westermann, D. et al. Biglycan is required for adaptive remodeling after myocardial infarction. Circulation 117, 1269-1276, doi:10.1161/CIRCULATIONAHA.107.714147 (2008).

21 Melchior-Becker, A. et al. Deficiency of biglycan causes cardiac fibroblasts to differentiate into a myofibroblast phenotype. The Journal of biological chemistry 286, 17365-17375, doi:10.1074/jbc. M110.192682 (2011).

22 Lam, C. S., Donal, E., Kraigher-Krainer, E. \& Vasan, R. S. Epidemiology and clinical course of heart failure with preserved ejection fraction. Eur J Heart Fail 13, 18-28, doi:10.1093/eurjhf/hfq121 (2011).

23 Dhingra, A. et al. Epidemiology of heart failure with preserved ejection fraction. Curr Heart Fail Rep 11, 354-365, doi:10.1007/s11897-014-0223-7 (2014).

24 Heymans, S. et al. Macrophage microRNA-155 promotes cardiac hypertrophy and failure. Circulation 128, 1420-1432, doi:10.1161/CIRCULATIONAHA.112.001357 (2013).

25 Tasheva, E. S. et al. Mimecan/osteoglycin-deficient mice have collagen fibril abnormalities. Molecular vision 8, 407-415 (2002).

26 Junqueira, L. C., Bignolas, G. \& Brentani, R. R. Picrosirius staining plus polarization microscopy, a specific method for collagen detection in tissue sections. Histochem J 11, 447-455 (1979).

27 Seluanov, A., Vaidya, A. \& Gorbunova, V. Establishing primary adult fibroblast cultures from rodents. J Vis Exp, doi:10.3791/2033 (2010).

28 Sequeira, V. et al. Synergistic role of ADP and $\mathrm{Ca}(2+)$ in diastolic myocardial stiffness. The Journal of physiology 593, 3899-3916, doi:10.1113/JP270354 (2015). 
Chapter 3

\section{SUPPLEMENTARY FIGURES}
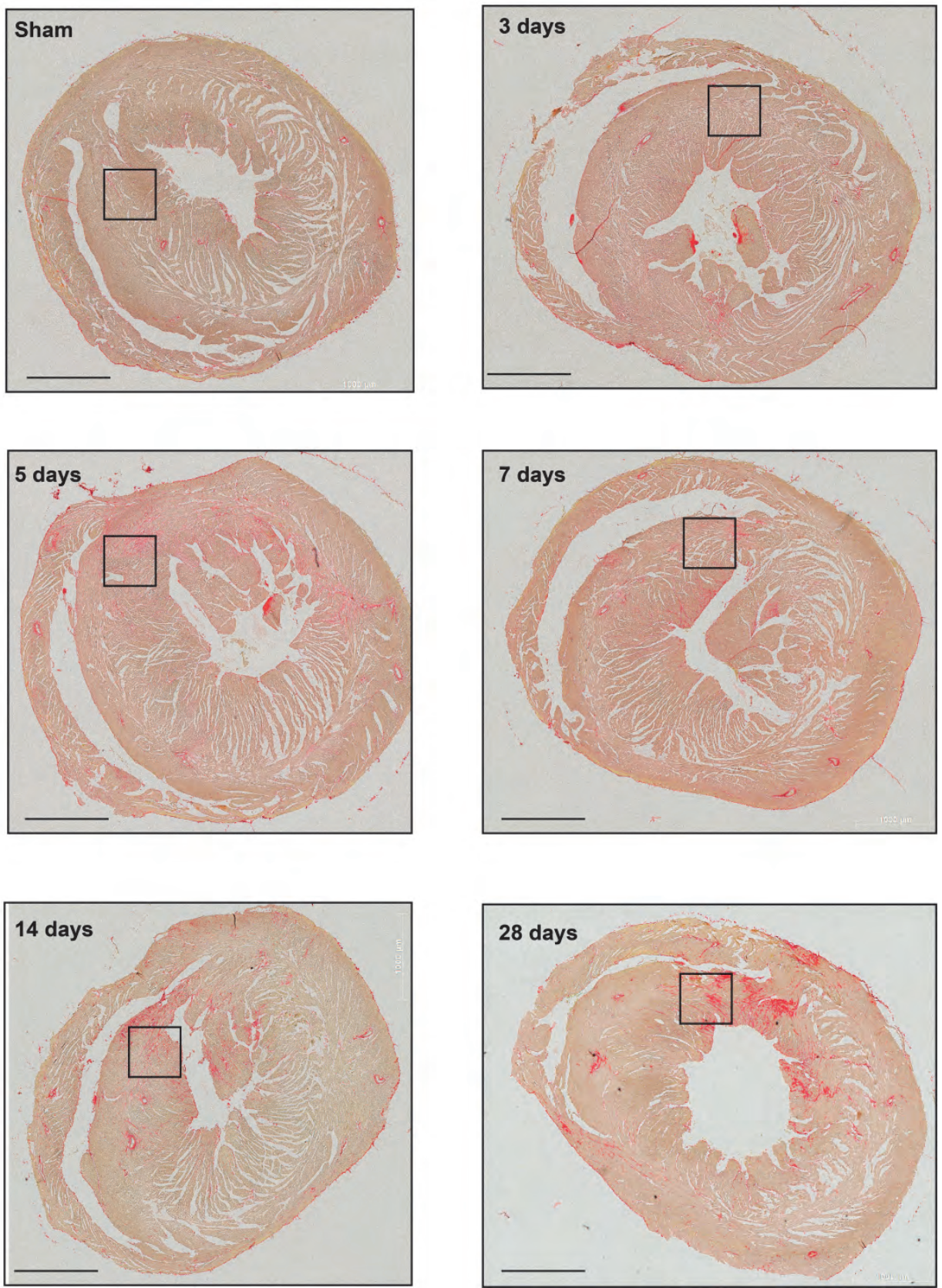

Supplementary Figure 1. Overview images of cardiac fibrosis 0, 3, 5, 7, 14 and 28 days following Angll. 




\section{Extracellular SPARC improves Cardiomyocyte Contraction during Health and Disease}

In preparation for EMBO Molecular Medicine

Sophie Deckx ${ }^{1,2}$, Daniel Johnson ${ }^{2}$, Marieke Rienks ${ }^{1}$, Paolo Carai ${ }^{1,2}$, Davy Vanhoutte ${ }^{1,3}$, Elza Van Deel ${ }^{4}$, Jolanda van der Velden ${ }^{4}$, Karin Sipido ${ }^{2},{ }^{*}$ Stephane Heymans ${ }^{1,2,5},{ }^{*}$ AnnaPia Papageorgiou, ${ }^{1,2}$

*Authors contributed equally.

${ }^{1}$ Department of Cardiology, Maastricht University, 6202 Maastricht, The Netherlands,

${ }^{2}$ Department of Cardiovascular Sciences, KULeuven, 3000 Leuven, Belgium,

${ }^{3}$ Molecular Cardiovascular Biology, Cincinnati Children's Hospital Medical Center, Cincinnati, $\mathrm{OH}$

${ }^{4}$ Department of Physiology, VUmcAmsterdam, 1081 Amsterdam, The Netherlands ${ }^{5} \mathrm{ICIN}-$ Netherlands Heart Institute, Utrecht, The Netherlands 


\section{Chapter 4}

\section{ABSTRACT}

Secreted protein acidic and rich in cysteine (SPARC) is a non-structural extracellular matrix protein that is expressed by cardiac fibroblasts, endothelial cells, and in lower levels by cardiomyocytes. SPARC secretion occurs upon injury and at sites of remodelling in the heart. We have previously shown that SPARC improves cardiac function after myocardial infarction by regulating post-synthetic procollagen processing yet whether SPARC directly affects cardiomyocyte contraction is still unknown. In this study we demonstrate a novel inotropic function for extracellular SPARC in the healthy heart and during myocarditis-induced cardiac dysfunction. We demonstrate SPARC presence on the cardiomyocyte membrane where it co-localizes with the integrin-beta1 and interacts with the integrin-linked kinase. Moreover, extracellular SPARC directly improves cardiomyocyte contraction ex vivo and cardiac function in vivo, in both health and during coxsackie virus-induced cardiac dysfunction.

In conclusion, we demonstrate a novel inotropic function for SPARC in the heart, with potential therapeutic application during cardiac injury. 


\section{INTRODUCTION}

For the treatment of acute heart failure or cardiogenic shock, short-term or mediumterm enhancement of cardiac contraction through inotropic agents can be all it takes to make the difference in clinical outcome ${ }^{1}$. Positive inotropy is the ability to directly and acutely stimulate cardiac contraction and inotropic agents can be both endogenous hormones, such as adrenaline, as well as certain synthetic drugs (e.g. dobutamine, digoxin, amrinone, levosimendan). Viral myocarditis (VM) is an important inflammatory heart disease and an etiological precursor of dilated cardiomyopathy, (acute) heart failure and sudden cardiac death in young healthy adults. Up to $60 \%$ of patients with dilated cardiomyopathy and myocarditis are virus-positive ${ }^{2}$, yet diagnosis of VM is difficult due to its heterogeneous clinical presentations as acute heart failure, cardiogenic shock or ventricular arrhythmias. Viral infection of the heart causes acute myocarditis, progressing into chronic myocarditis, cardiomyocyte damage and death, and initiation of remodelling processes such as fibrosis, ultimately all resulting in decreased contraction of the heart, arrhythmias and cardiac failure. Different infectious agents can cause viral myocarditis, including parvovirus B19, enteroviruses, hepatitis C virus and cytomegalovirus. The best studied are the coxsackie $B$ viruses (CVB), members of the enteroviruses, which are often identified in biopsies from failing VM hearts ${ }^{3}$. So far, research and development of novel therapeutic strategies for viral myocarditis has mainly focused on processes targeting inflammation, cardiomyocyte degeneration, and fibrosis ${ }^{3-}$ 5 , while only few studies have addressed the effect of viral infection on cardiomyocyte function. Importantly, viral replication also directly causes defective cardiomyocyte contraction, by modulating time-dependently different cardiomyocyte ion-channels, adding up to the viral-induced cardiac dysfunction ${ }^{6,7}$. Furthermore, non-structural matrix proteins in the heart can influence different processes during cardiac stress, such as inflammation, fibrosis and myocyte survival. Our group has previously demonstrated that the non-structural matrix proteins trombospondin-2 and osteoglycin can affect inflammation, fibrosis and myocyte survival of the heart during cardiac aging, myocardial infarction, and viral myocarditis ${ }^{8-10}$. However, whether a non-structural matrix protein in the heart can serve as an inotropic agent and influence cardiomyocyte contraction has never been demonstrated.

Secreted protein acidic and rich in cysteine (SPARC) is a non-structural matrix protein in the heart, expressed by endothelial cells, fibroblasts and in lower amounts by cardiomyocytes $^{11,12}$. SPARC is a collagen- and calcium- binding protein that belongs to the group of matricellular proteins. These matrix proteins are characterized by their counteradhesive properties, low expression levels during normal physiology but increased expression during stress and their non-lethal phenotypes of knockout mice ${ }^{11,13,14}$. Typical of matricellular proteins, SPARC secretion occurs upon injury and at sites of remodelling in the heart. Previously, our group has shown that SPARC can improve systolic cardiac function and clinical outcome after myocardial infarction by regu- 


\section{Chapter 4}

lating the post-synthetic procollagen processing during fibrosis ${ }^{15}$. Surprisingly, also in sham-operated mice, an increase in cardiac fractional shortening (FS) was seen when SPARC was overexpressed, yet whether SPARC directly affected cardiomyocyte contraction remained undetermined ${ }^{15}$. Therefore, we decided to study a potential inotropic function for SPARC in the healthy heart in vivo and on isolated cardiomyocytes ex vivo. Furthermore, next to myocardial infarction we investigated in this study a therapeutic potential for SPARC in virus-induced systolic dysfunction.

\section{RESULTS}

\section{SPARC overexpression increases cardiac contraction}

To confirm our previous observation that the extracellular matrix protein SPARC improves cardiac function in healthy adult mice, we repeated the adenoviral-mediated systemic overexpression of SPARC. In line, we performed a dose-response SPARCoverexpression experiment using an AAV9 vector, which shows in addition to systemic also cardiac delivery ${ }^{16}$. SPARC overexpression was confirmed for both vectors (Supplementary Figure $1 \mathrm{~A}$ and $\mathrm{B}$ ). Cardiac contraction was increased 2 weeks after vector administration in both adenoviral- and AAV9- mediated SPARC overexpressing mice, as indicated by increased FS (Table 1). In fact, FS displayed a dose-dependent increase parallel to the administered AAV9-SPARC vector (Table 1). End-diastolic diameter (EDD) but especially end-systolic diameter (ESD) was decreased in the SPARC overexpressing mice. Importantly, further analysis of posterial wall (PWd) and septal wall (IVSd) thickness, as well as heart weight to body weight ratios and histological analysis of cardiomyocyte cross-sectional areas, revealed no indications of cardiomyocyte hypertrophy that could explain for this improved FS (Table 1).

\section{Extracellular SPARC increases cardiomyocyte contraction}

To study how extracellular SPARC can improve cardiac function, we investigated whether extracellular SPARC directly interacts with cardiomyocytes. SPARC is present in the membrane fraction, yet absent in the cytosolic fraction of isolated cardiomyocytes (Figure $1 \mathrm{~A}$ ). We confirmed SPARC presence on the cardiomyocyte membrane, where it colocalizes with integrin-beta1 using immunostaining and confocal microscopy (Figure 1B). Additionally, we could further demonstrate an interaction of SPARC with integrin-linked kinase (ILK) in left ventricular (LV) samples and in isolated cardiomyocytes using immuno-precipitation (Figure 1C). Moreover, SPARC presence on the cardiomyocytes increased when cells were isolated and incubated with SPARC ex vivo for $1 \mathrm{~h}$, as compared to cells incubated in normal buffer without SPARC (Figure 1D). And interestingly, these SPARC-incubated cells demonstrated higher cardiomyocyte shortening (Figure $1 \mathrm{E}$ and 
F), with no significant changes in contraction times (TTP) or relaxation times (RT50) (Supplementary Figure 1C and D).

Table 1. Functional analysis of SPARC overexpressing vectors in healthy mice

\begin{tabular}{|c|c|c|c|c|c|c|}
\hline & \multicolumn{2}{|c|}{ Adenoviral vector } & \multicolumn{4}{|c|}{ Adeno Associated Viral vector } \\
\hline & $\begin{array}{c}\text { R5 } \\
(n=5)\end{array}$ & $\begin{array}{c}\text { SPARC } \\
(n=6)\end{array}$ & $\begin{array}{l}\text { GFP } \\
(n=5)\end{array}$ & $\begin{array}{c}\text { SPARC }\left(10^{9}\right) \\
(n=3)\end{array}$ & $\begin{array}{c}\text { SPARC }\left(10^{10}\right) \\
(n=4)\end{array}$ & $\begin{array}{c}\operatorname{SPARC}\left(10^{11}\right) \\
(n=7)\end{array}$ \\
\hline FS (\%) & $27 \pm 2.0$ & $32 \pm 1.9$ & $25 \pm 2.6$ & $29 \pm 1.9$ & $31 \pm 0.9$ & $33 \pm 1.1^{*}$ \\
\hline $\mathrm{EDD}(\mathrm{mm})$ & $3.8 \pm 0.16$ & $3.3 \pm 0.09 *$ & $3.7 \pm 0.02$ & $3.3 \pm 0.26$ & $3.5 \pm 0.26$ & $3.0 \pm 0.06 *$ \\
\hline $\mathrm{ESD}(\mathrm{mm})$ & $2.8 \pm 0.11$ & $2.2 \pm 0.08^{* *}$ & $2.7 \pm 0.08$ & $2.3 \pm 0.15$ & $2.4 \pm 0.19$ & $2.0 \pm 0.04^{* *}$ \\
\hline PWd (mm) & $\begin{array}{c}0.86 \pm \\
0.03\end{array}$ & $0.90 \pm 0.02$ & $0.82 \pm 0.03$ & $0.93 \pm 0.00$ & $0.92 \pm 0.05$ & $0.89 \pm 0.02$ \\
\hline IVSd (mm) & $\begin{array}{c}0.82 \pm \\
0.03\end{array}$ & $0.81 \pm 0.02$ & $0.78 \pm 0.02$ & $0.84 \pm 0.02$ & $0.80 \pm 0.01$ & $0.82 \pm 0.02$ \\
\hline HW/BW (mg/g) & $4.9 \pm 0.2$ & $4.8 \pm 0.3$ & $4.8 \pm 0.3$ & $4.2 \pm 0.2$ & $4.3 \pm 0.2$ & $5.0 \pm 0.6$ \\
\hline $\begin{array}{l}\text { Cardiomyocyte } \\
\text { cross-sectional } \\
\text { area }\left(\mu \mathrm{m}^{2}\right)\end{array}$ & $214 \pm 8$ & $216 \pm 4$ & $206 \pm 2$ & N.D & N.D & $208 \pm 5$ \\
\hline
\end{tabular}

FS fractional shortening, EDD end-diastolic diameter, ESD end-systolic diameter, PWd posterial wall in diastole, IVSd interventricular septal wall in diastole, HW heart weight, BW body weight, N.D. not determined, ${ }^{*} p<0.05,{ }^{*} p<0.01$ vs. respective control

To mimic more in vivo conditions, we used matrices with physiological stiffness coated either with laminin and collagen $(\mathrm{Lam}+\mathrm{Col})$ or laminin, collagen and SPARC (Lam+Col+SPARC) (Figure 1G). SPARC, a known collagen-binding protein, co-localized with collagen on the matrix (Figure 1G) and importantly, the presence of SPARC did not alter matrix stiffness (Figure $1 \mathrm{H}$ ). Next, we isolated cardiomyocytes from adult rats and cultured them overnight on these matrices. When stimulated at $0.5,1$ and $2 \mathrm{~Hz}$, also rat cardiomyocytes cultured on SPARC-containing matrices demonstrated higher cardiomyocyte shortening at all frequencies when compared to cells cultured on matrices without SPARC (Figure 1I), while TTP and RT50 were not different (Supplementary Figure $1 \mathrm{E}$ and $\mathrm{F}$ ).

In conclusion, these results demonstrate a direct binding of SPARC with the cardiomyocyte membrane, where it interacts with integrin-beta1 and ILK. Moreover, SPARC presence on the membrane increases when cells are incubated in the presence of recombinant SPARC, resulting in increased cardiomyocyte contraction. 
Figure 1

A

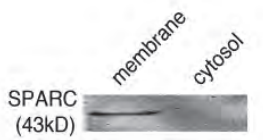

D

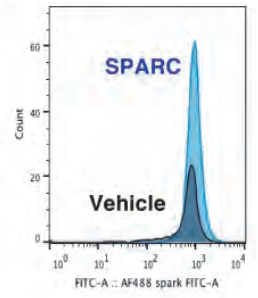

G

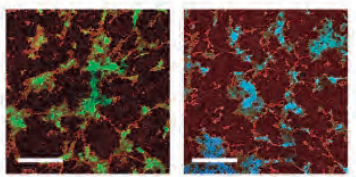

Laminin Collagen SPARC

E
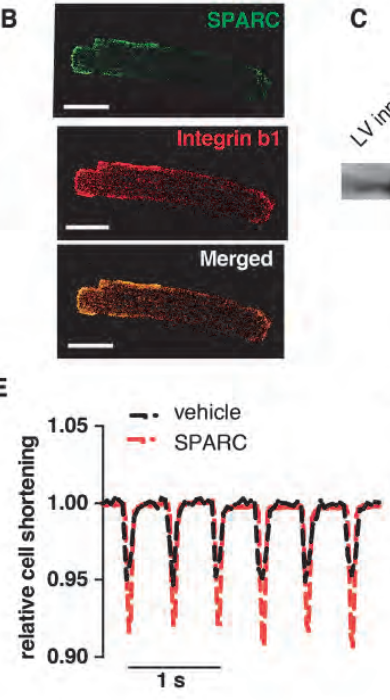

H

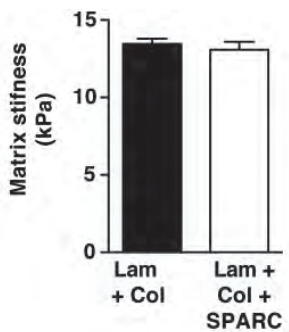

C

F

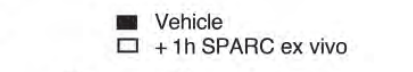

I

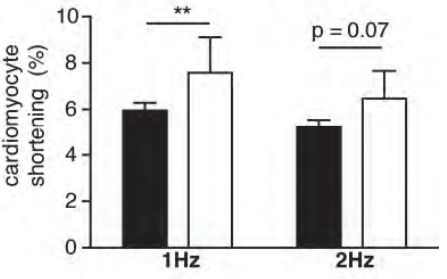

$\mathrm{Lam}+\mathrm{Col}$

$\square \mathrm{Lam}+\mathrm{Col}+$ SPARC

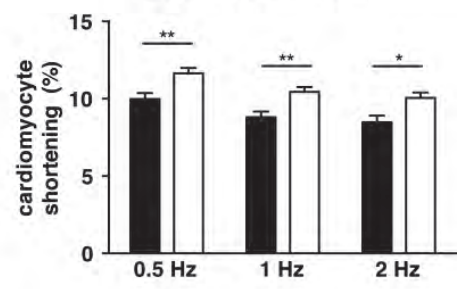

Figure 1. SPARC interacts with integrin-beta1on the cardiomyocyte membrane and improves cardiomyocyte contraction (A) SPARC is present in the membrane fraction, and absent in the cytosolic fraction of isolated cardiomyocytes, as demonstrated by Western Blotting. (B) Using immunostaining and confocal microscopy we confirmed SPARC presence on the cardiomyocyte membrane, where it co-localizes with integrin-beta1. (C) SPARC immunoprecipitation (I.P.) demonstrates interaction with integrin-linked kinase (ILK) in LV samples and in isolated cardiomyoctes. (D) FACS analysis demonstrates increased SPARC staining when cardiomyocytes were isolated and incubated with SPARC ex vivo for $1 \mathrm{~h}$, as compared to cells incubated in normal buffer without SPARC. (E and F) Isolated adult mouse cardiomyocytes displayed higher FS after 1h incubation with SPARC, compared to cells incubated in normal tyrode buffer. ( $G$ and $H$ ) Matrices with physiological stiffness were coated with laminin and collagen (Lam + Col) or laminin, collagen and SPARC (Lam + Col + SPARC). SPARC co-localized with collagen on these matrices, but did not affect matrix stiffness. (I) Adult rat cardiomyocytes were isolated and cultured on these matrices. Cells cultured on SPARC containing matrices displayed higher fractional shortening (FS), compared to cells cultured on matrices coated with $L+C$ alone. $n \geq 5$, bars panel $B$ $10 \mu \mathrm{m}$, panel G $100 \mu \mathrm{m}$. 
SPARC improves cardiomyocyte function in virus-induced heart failure

We subsequently asked whether, next to healthy conditions, SPARC could also improve contraction in conditions where cardiomyocyte function is impaired. Therefore, we studied the effect of adenoviral mediated SPARC overexpression on cardiac function and cardiomyocyte contraction in our VM mouse model. As SPARC is a known collagenbinding protein that increases collagen cross-linking, we chose to use a low-dose VM model with mild fibrosis, to exclude side effects due to alterations in fibrosis. In this model $10^{3}$ PFU CVB3 are injected intraperitoneally, resulting in mild inflammation and fibrosis, and no cardiomyocyte hypertrophy (Figure 2A - D), yet with decreased cardiac contraction as measured by FS (Figure 2E), and onset of cardiac dilation 5 weeks post infection (Figure 2F). Heart rates (HR) are not altered due to viral infection in this model (in beats per minute (bpm): $554 \pm 23$ in sham vs. $532 \pm 14$ in VM). Importantly, also contraction of isolated cardiomyocytes is compromised in this model, as shown by decreased cardiomyocyte shortening of these cells (Figure 2G). Remarkably, these cardiomyocytes do not display prolonged TTP, but RT50 are significantly increased (Supplementary Figure $2 \mathrm{~A}$ and $\mathrm{B}$ ). 


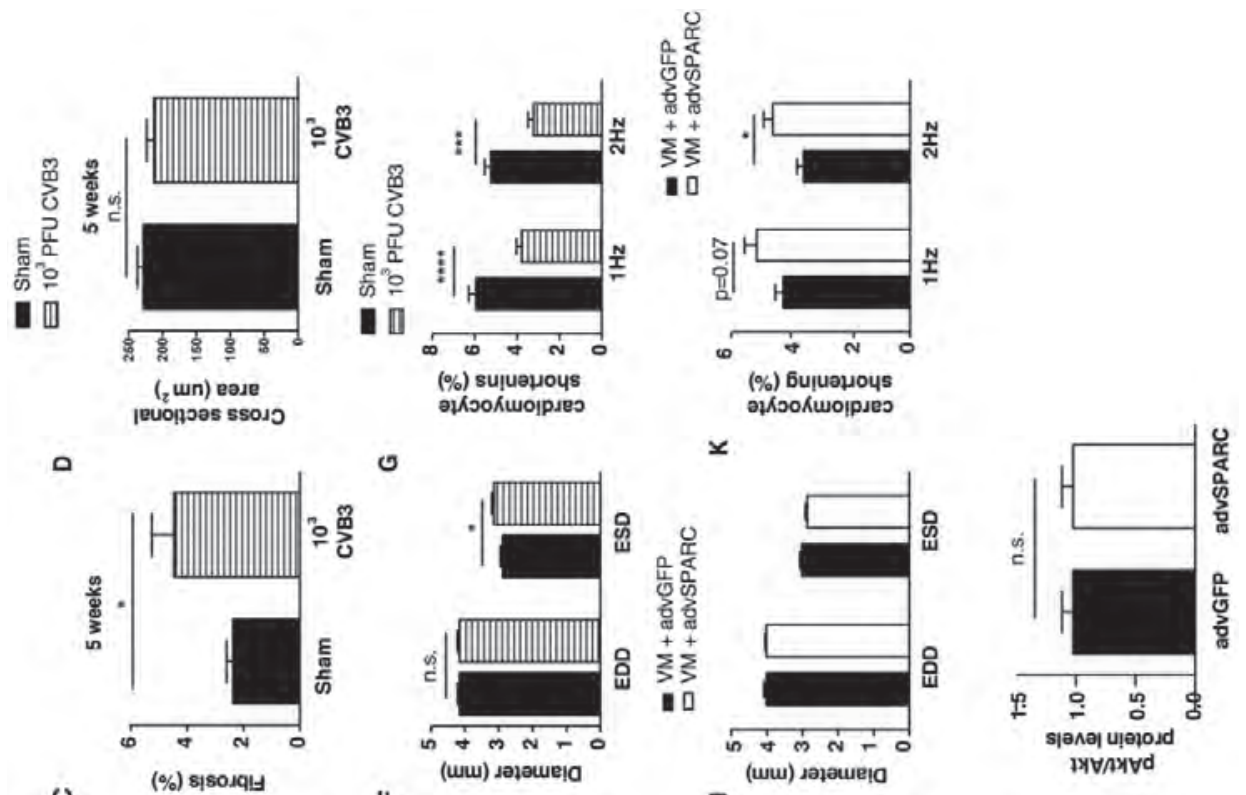

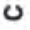

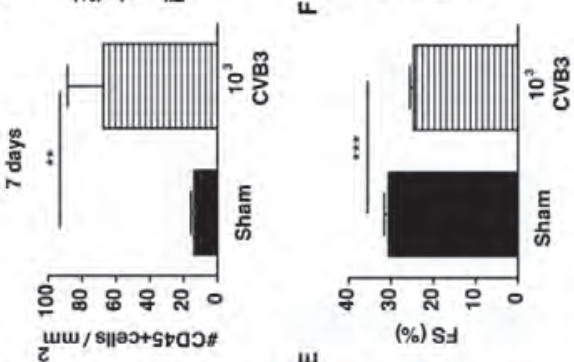

$\supset$
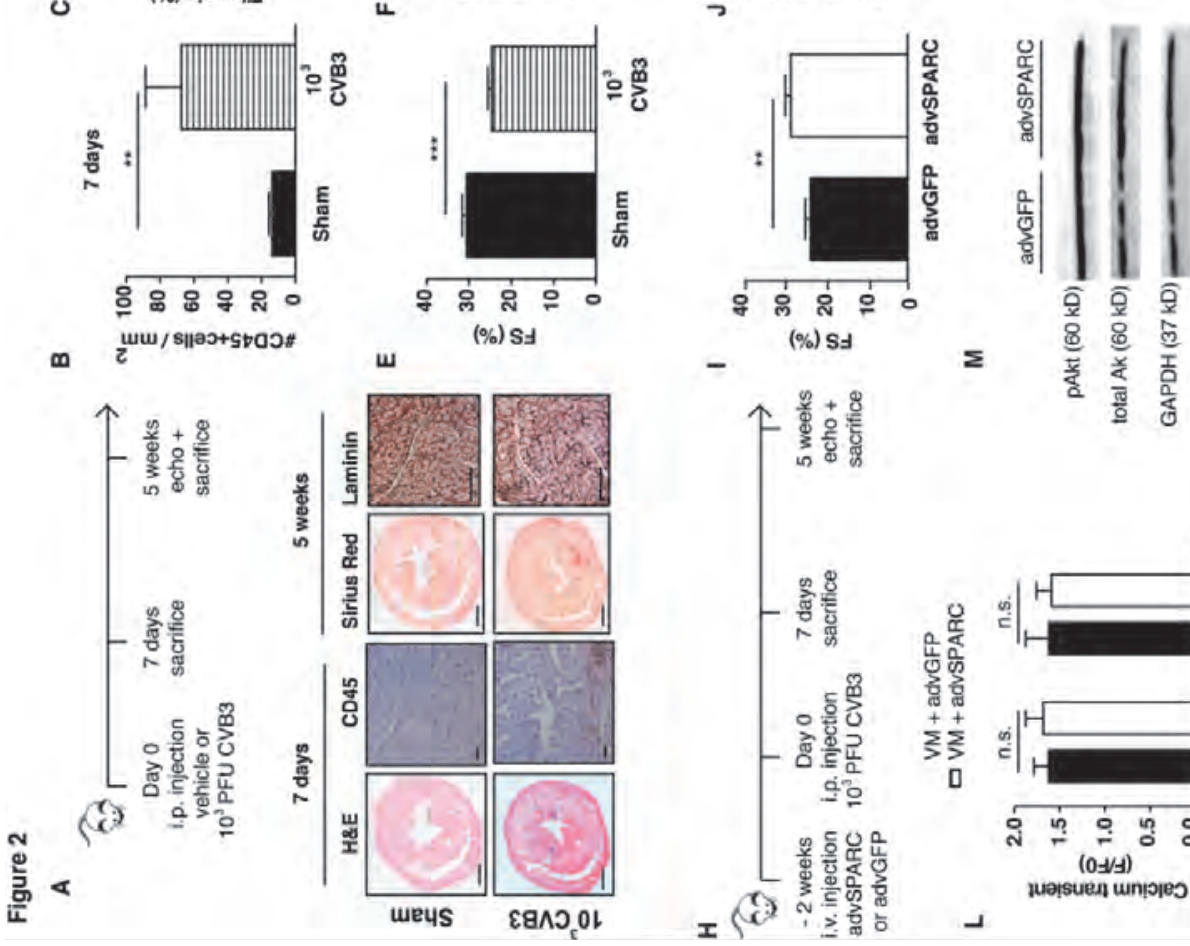

Figure 2. SPARC improves cardiomyocyte function in a mild model of virus-induced heart failure (legend on the next page). 
Figure 2. SPARC improves cardiomyocte function in a mild model of virus-induced heart failure. (A - D) A mild VM mouse models is used, where mice are injected with $10^{3}$ PFU CVB3 intraperitoneally. This results in moderate cardiac inflammation after 1 week), little fibrosis and no cardiomyocyte hypertrophy after 5 weeks. (E and F) Viral infection caused decreased FS and increased ESD. (G) Contraction of isolated cardiomyocytes is also compromised after virus-infection. (H) SPARC is overexpressed with the use of an adenovirus, 2 weeks before mild CVB3 inoculation. (I and J) 5 weeks after CVB3 injection, higher FS were measured in the SPARC overexpressing group, with no differences in EDD, and slightly smaller ESD. (K) Isolated myocytes from the SPARC-overexpressing hearts remained their increased shortening capacities as compared to isolated myocytes from control GFP- hearts. ( $L$ and $M$ ) There were no differences in the $\mathrm{Ca}^{2+}$ transient peak heights, or levels of Akt phosphorylation. $n \geq 5$, bars $1000 \mu m$ for H\&E and Sirius Red stainings, $100 \mu m$ for CD45 and Laminin stainings.

Using this low-dose VM model, we systemically overexpressed SPARC with the adenoviral vector (Figure 2H). 1 week after CVB3 injection, cardiac SPARC levels were increased in the adenoviral-SPARC injected group when compared to the control adenoviral-GFP injected mice (Supplementary Figure 2C, $p=0.09$ ). Slightly decreased cardiac inflammation, as measured by the amount of CD45 positive cells, was seen 1 week after inoculation in the SPARC overexpressing group (Supplementary Figure 2D). 5 weeks after CVB3 injection, higher FS were measured in the SPARC overexpressing group (Figure 21), with no differences in EDD, but slightly smaller ESD, when compared to the control GFP group (Figure 2J), demonstrating that SPARC overexpression prevents the development of compromised cardiac systolic function in our VM model when there is mild inflammation and fibrosis. HRs were not different between the 2 groups (in bpm: $494 \pm 18$ in SPARC-overexpressing mice vs. $484 \pm 14$ in control GFP mice). Importantly, myocyte cross-sectional area, the amount of fibrosis, collagen cross-linking, and the amount of CD45 positive cells in the hearts did not differ between the 2 groups 5 weeks after CVB3 injection (Table 2). Moreover, isolated myocytes from the SPARC-overexpressing hearts retained their increased shortening capacities as compared to isolated myocytes from control GFP- hearts (Figure 2K), indicating a persistent effect of SPARC on cardiomyocyte function. Notably, no effect on contraction or relaxation times was observed (Supplementary Figure 2E and F). Furthermore, despite SPARC being a $\mathrm{Ca}^{2+}$ - binding protein, we could not find indications that SPARC influenced $\mathrm{Ca}^{2+}$-handling, as there were no differences in the $\mathrm{Ca}^{2+}$ transient peak heights (Figure 2L), TTP or RT50 (Supplementary Figure $3 \mathrm{G}$ and $\mathrm{H}$ ) of these isolated myocytes. Moreover, we did not find increased phosphorylation of Akt, which is known to increase intracellular $\mathrm{Ca}^{2+}$-availability and enhance contraction ${ }^{17}$, in LV samples from both groups (Figure $2 \mathrm{M}$ ), further supporting no immediate role for SPARC in $\mathrm{Ca}^{2+}$-handling. Overall, these data demonstrate a protective effect of SPARC on cardiomyocyte function prior the establishment of virusinduced heart failure, with no evident role for SPARC on $\mathrm{Ca}^{2+}$-handling.

Unfortunately, patients most commonly enter the clinic with severe cardiac inflammation and systolic dysfunction. Hence, we next assessed a therapeutic potential for SPARC, using a high-dose CVB3 model with pronounced cardiac inflammation and fibrosis and severely compromised cardiac function (Figure 3). In this model, a higher dose of 


\section{Chapter 4}

CVB3 (10 ${ }^{4}$ PFU CVB3) was injected intraperitoneally in mice, which resulted in severe cardiac inflammation after 1 week, and prominent fibrosis and cardiomycyte hypertrophy after 5 weeks (Figure 3A - D). Here, cardiac function is even more compromised, as shown by severely decreased FS (Figure $3 \mathrm{E}$ ), and significantly increased EDD, indicating severe cardiac dilation in this model (Figure 3F). Moreover, in this model HRs are significantly increased (in bpm: $554 \pm 23$ in sham vs. $626 \pm 5$ in VM, $p=0.0003$ ).

Table 2. Histological analysis of VM mice with SPARC adenoviral overexpression

\begin{tabular}{lll}
\hline & \multicolumn{2}{c}{ 5 weeks VM } \\
\cline { 2 - 3 } & $\begin{array}{l}\text { AdvGFP } \\
(\mathrm{n}=10)\end{array}$ & $\begin{array}{l}\text { AdvSPARC } \\
(\mathrm{n}=8)\end{array}$ \\
\hline Myocyte cross-sectional area $\left(\mu \mathrm{m}^{2}\right)$ & $217 \pm 6$ & $224 \pm 7$ \\
Fibrosis $(\%)$ & $2.4 \pm 0.2$ & $2.6 \pm 0.4$ \\
Orange-red/ yellow-green fibers & $1.15 \pm 0.17$ & $1.61 \pm 0.14$ \\
CD45+ cells / $\mathrm{mm}^{2}$ & $6.67 \pm 2.73$ & $6.57 \pm 3.0$ \\
\hline
\end{tabular}

Table 3. Histological analysis of VM mice with $72 \mathrm{~h}$ vehicle or SPARC infusion

\begin{tabular}{lll}
\hline & $\begin{array}{l}5 \text { weeks VM }+7 \\
2 \mathrm{~h} \text { vehicle } \\
(\mathrm{n} \geq 5)\end{array}$ & $\begin{array}{l}5 \text { weeks VM }+ \\
72 \mathrm{~h} \text { SPARC } \\
(\mathrm{n} \geq 6)\end{array}$ \\
\hline Myocyte cross-sectional area $\left(\mu \mathrm{m}^{2}\right)$ & $260 \pm 10$ & $253 \pm 13$ \\
Fibrosis (\%) & $15.2 \pm 2.1$ & $20.3 \pm 2.6$ \\
Orange-red/ yellow-green fibers & $1.28 \pm 0.09$ & $2.14 \pm 0.21^{* *}$ \\
CD45+ cells / $\mathrm{mm}^{2}$ & $57.5 \pm 8.3$ & $84.1 \pm 3.8$ \\
\hline
\end{tabular}

$* * p<0.01$ vs. vehicle 
Figure 3

A

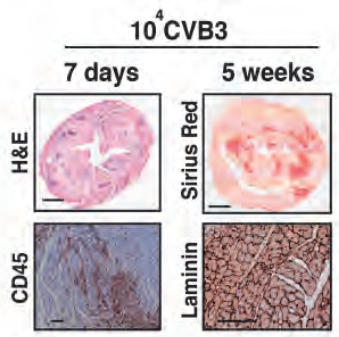

D

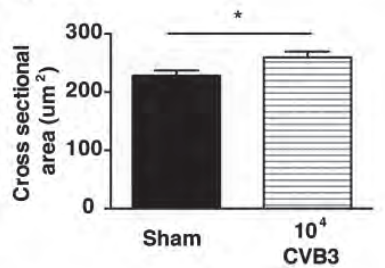

G
C

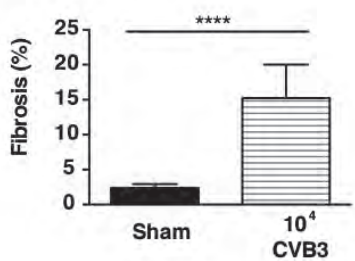

$\mathbf{F}$
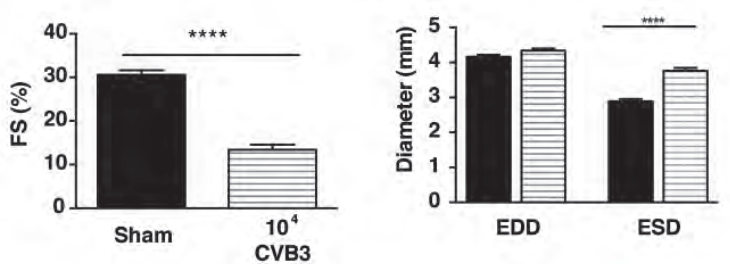

H
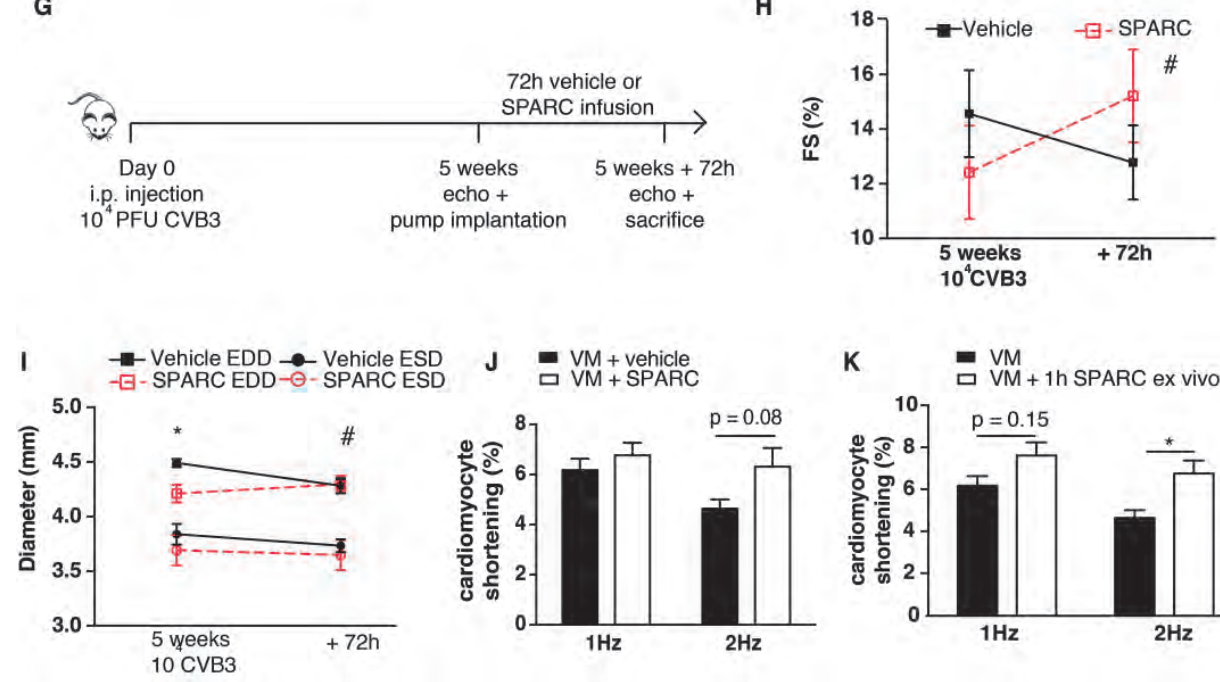

K $\quad=\mathrm{VM}$

ㅁ VM +1 h SPARC ex vivo

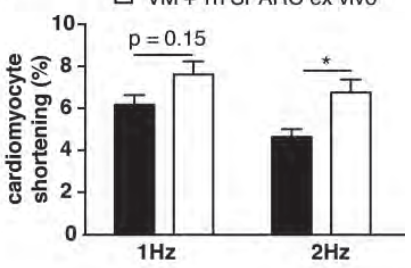

Sham

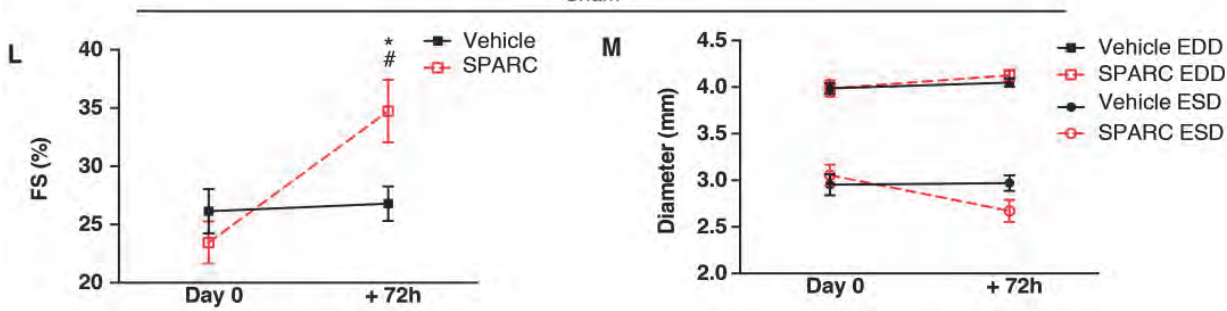

Figure 3. SPARC has therapeutic potential in severely virus-induced heart failure (legend on the next page). 
Figure 3. SPARC has therapeutic potential in severely virus-induced heart failure

$(A-D)$ In the more severe VM model mice are injected with $10^{4}$ PFU CVB3, which results in severe cardiac inflammation after 1 week, and prominent fibrosis, but no cardiomycyte hypertrophy after 5 weeks. (E and F) Viral infection caused severely decreased FS and dilation of the heart. (G) Mice were infused with SPARC or vehicle for 72h, 5 weeks after high-dose CVB3 inoculation, when dilated cardiomyopathy with severe inflammation and fibrosis had been established. (H) FS was increased in the SPARC treated group, while FS in the vehicle group continued to decline. (I) EDD were slightly smaller in the SPARC group prior to treatment, compared to the vehicle group, but did not change due to the SPARC treatment, while in the vehicle group EDD were slightly decreased after $72 \mathrm{~h}$. ESD were not different between groups or between time-points. (J) A trend to increased FS was seen in isolated cardiomyocytes from SPARC-treated mice when compared to cells isolated from vehicle-treated mice. (K) When cardiomyocytes were isolated from the severely sick, untreated mice, incubation of the cells with SPARC for 1 h ex vivo also resulted in increased FS, compared to control cells. ( $\mathrm{L}$ and M) Also healthy mice demonstrated higher FS when SPARC was administered for 72 hours, compared to vehicle-administered mice. This resulted in decreased ESD but not decreased end-diastolic diameters EDD in SPARC-administered mice, while diameters did not change in vehicle-administered mice. $n \geq 5$, bars $1000 \mu m$ for H\&E and Sirius Red stainings, $100 \mu m$ for CD45 and Laminin stainings.

After 5 weeks, when dilated cardiomyopathy with severe inflammation and fibrosis had been established, we infused mice with SPARC or vehicle for $72 \mathrm{~h}$ with the use of an osmotic minipump and measured cardiac function prior and after $72 \mathrm{~h}$ of SPARC or vehicle infusion (Figure 3G). FS were increased in the SPARC treated group, while FS in the vehicle group continued to decline (Figure $3 \mathrm{H}$ ). EDD were slightly smaller in the SPARC group prior to treatment, compared to the vehicle group, but did not change due to the SPARC treatment (Figure 3I), while in the vehicle group EDD were slightly decreased after $72 \mathrm{~h}$ (Figure 3I). ESD were not different between groups or between time-points (Figure 3I), and HRs were not different either at start (in bpm: 637 \pm 5 in SPARC treated vs. $616 \pm 8$ in vehicle treated mice) or due to the SPARC treatment (in bpm: 580 \pm 14 in SPARC treated vs. $570 \pm 18$ in vehicle treated mice). Moreover, myocyte cross-sectional area and the amount of CD45 positive cells in the hearts did not differ between the 2 groups (Table 3). Yet, while the amount of fibrosis did not differ, collagen cross-linking was increased in the SPARC-treated group as compared to the vehicle group (Table 3), confirming the previously demonstrated effect of SPARC on collagen-crosslinking. Nevertheless, despite this higher collagen cross-linking, we found next to increased cardiac contraction, also a trend to increased shortening of isolated cardiomyocytes from these SPARC-treated mice when compared to cells isolated from vehicle-treated mice (Figure 3J), with again no differences in TTP or RT50 (Supplementary Figure $3 \mathrm{I}$ and J). Moreover, when cardiomyocytes were isolated from these severely sick, untreated mice, incubation of the cells with SPARC for $1 \mathrm{~h}$ ex vivo also resulted in increased cardiomyocyte shortening, compared to control cells (Figure 3K), again without influencing TTP or RT50 (Supplementary Figure $\mathrm{K}$ and $\mathrm{L}$ ).

Overall, these data demonstrate a therapeutic potential of SPARC on cardioymocyte function after severe dilated cardiomyopathy has been established.

Furthermore, when we infused healthy adult mice with SPARC or vehicle for $72 \mathrm{~h}$, we also found increased FS compared to baseline measurements and compared to vehicle- 
mice (Figure 3L), confirming our previous results with healthy mice. SPARC administration caused decreased ESD, but not EDD, while diameters did not change in hearts of vehicle-mice (Figure 3M). HRs were not different at start (in bpm: $519 \pm 6$ in SPARC administered vs. $503 \pm 7$ in vehicle administered mice) or after SPARC administration (in bpm: $556 \pm 12$ in SPARC administered vs. $524 \pm 19$ in vehicle administered mice). Importantly, SPARC administration did not affect cardiomyocyte hypertrophy, the amount of fibrosis, collagen cross-linking, or the amount of CD45 cells (Table 4).

Table 4. Histological analysis of hearts after $72 \mathrm{~h}$ vehicle or SPARC administration

\begin{tabular}{lll}
\hline & $\begin{array}{l}\text { Vehicle } \\
(\mathrm{n} \geq 6)\end{array}$ & $\begin{array}{l}\text { SPARC } \\
(\mathrm{n} \geq 4)\end{array}$ \\
\hline Myocyte cross-sectional area $\left(\mu \mathrm{m}^{2}\right)$ & $237 \pm 12$ & $252 \pm 29$ \\
Fibrosis (\%) & $3.1 \pm 0.4$ & $2.9 \pm 0.4$ \\
Orange-red/yellow-green fibers & $0.54 \pm 0.07$ & $0.55 \pm 0.05$ \\
CD45+ cells/ $\mathrm{mm}^{2}$ & $13.81 \pm 5.65$ & $10.34 \pm 9.94$ \\
\hline
\end{tabular}

\section{DISCUSSION}

This study is the first to demonstrate a direct role for a non-structural matrix protein on cardiomyocyte contraction. In our previous study we demonstrated increased cardiac contraction when SPARC was overexpressed in infarcted mice, but surprisingly, also in sham-operated mice ${ }^{15}$. Yet, whether SPARC directly affected cardiomyocyte contraction remained undetermined ${ }^{15}$, hence we decided to investigate in this study a potential inotropic function for SPARC, in both health and during systolic dysfunction. As we previously already demonstrated improved systolic function after myocardial infarction, we chose broaden the therapeutic potential and investigated SPARC in viral myocarditis, where cardiomyocyte contraction is impaired. Using different ex vivo and in vivo models, we show that extracellular SPARC increases cardiomyocyte contraction, during health and disease, possibly by interacting with the integrin-beta1-ILK complex on the cardiomyocyte membrane.

Earlier research by Barker and colleagues already demonstrated in lung fibroblasts the interaction of SPARC with integrin-beta1 resulting in increased contractile signalling through activation of ILK. Using SPARC null and WT fibroblasts, they showed that SPARC is required for fibronectin-induced ILK-activation, which resulted in increased contractile signalling through decreased myosin light chain phosphatase (MLCP) activity and increased MLC phosphorylation in these pulmonary fibroblasts ${ }^{18}$. In cardiomyocytes, MLCV2 was identified to be a critical regulator of cardiomyocyte contraction, by promoting actin-myosin interaction ${ }^{19}$. We hypothesize that SPARC increases cardiomyocyte contraction through its interaction with the integrin-beta1-ILK complex on the cardiomyocyte membrane, resulting in decreased MLCP activity and hence increased phos- 


\section{Chapter 4}

phorylation of MLC2v, causing increased actin-myosin interaction and thus augmented cardiomyocyte contraction (Figure 4).

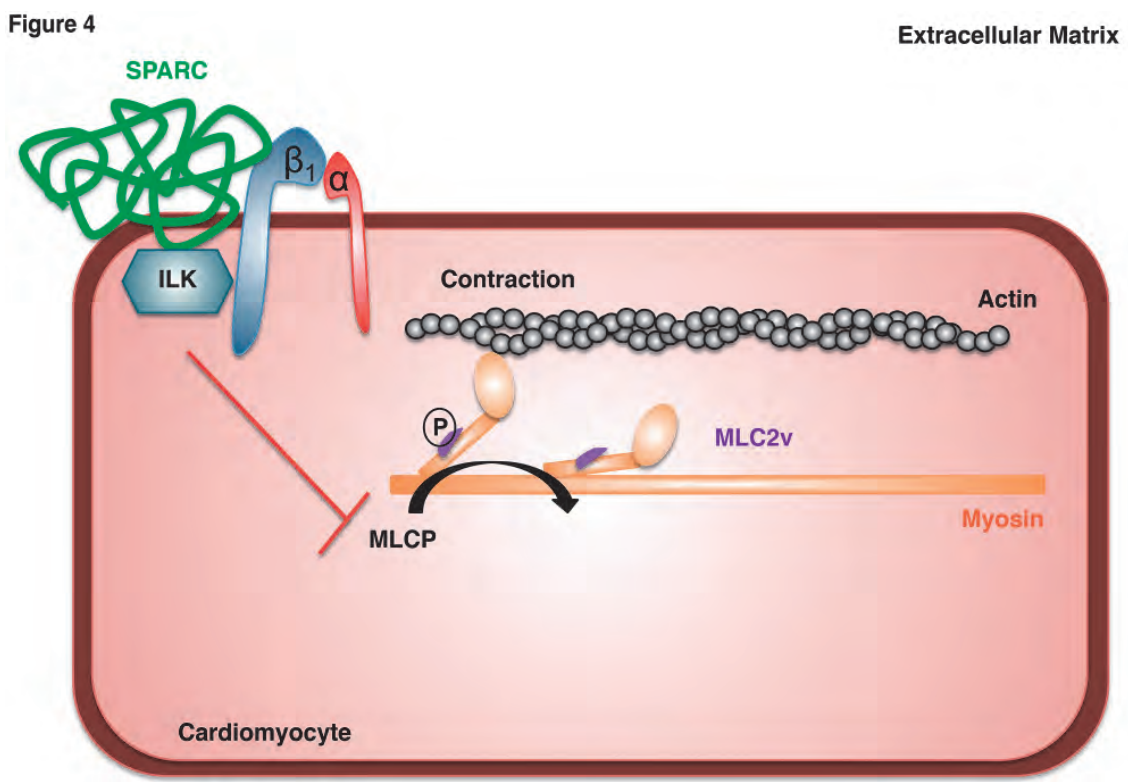

Figure 4. Hypothesis on how SPARC improves cardiomyocyte contraction.

Interestingly, in a study using competition monoclonal antibodies and peptides, the copper-binding domain of SPARC was identified to be required for the interaction of SPARC with integrin-beta1, resulting in increased ILK signalling. In the latter study, stressed lens epithelial cells displayed improved survival in vitro due to this interaction $^{20}$. However, though Mooney and colleagues demonstrated improved survival through intergrin-beta1 signalling in mesangial cells, SPARC failed to promote survival in this study ${ }^{21}$. In line with increased contractile signalling in fibroblasts as demonstrated by Barker et al. ${ }^{18}$, we demonstrate here that extracellular SPARC increases cardiomyocyte contraction, possibly through its interaction with integrin-beta1 and increased downstream ILK signalling. We did not investigate a potential protective effect of SPARC on myocyte survival in this study, but could not find evidence for decreased stress in VM hearts of SPARC overexpressing or SPARC treated mice, as shown by equal amounts of fibrosis and CD45 positive cells, and the absence of cardiomyocyte hypertrophy in these hearts after 5 weeks of VM. Furthermore, SPARC overexpression did not result in altered levels of phosphorylated Akt, which is known to regulate cardiomyocyte hypertrophy and apoptosis ${ }^{22,23}$. On the other hand, we did see slightly reduced leukocyte infiltration in SPARC overexpressing hearts, 1 week after CVB3 infection. So if SPARC would minister any protective effect during VM, it is most likely through affecting leukocyte infiltration into the heart, and not by directly promoting cardiomyocyte survival. 
Furthermore, we also demonstrate a rapid effect of SPARC on collagen cross-linking in vivo as collagen cross-linking is augmented in VM hearts with severe fibrosis, but not in VM hearts with little fibrosis or in healthy hearts after 3 days of SPARC administration. Importantly, despite and independent of this higher cross-linking, FS of the heart and of the isolated cardiomyocytes was higher in all SPARC administered animals.

In conclusion, this study is the first to demonstrate a novel inotropic function for SPARC, likely by interacting with the integrin-beta1 on the cardiomyocyte membrane, resulting in increased downstream contractile signalling. Moreover, we demonstrate a potential therapeutic application during coxsackie virus induced cardiac injury.

\section{THE PAPER EXPLAINED}

PROBLEM: Viral myocarditis (VM) is a devastating disease, responsible for significant morbidity and mortality in previously healthy young adults. Current therapies are symptomatic whilst causal therapies are lacking.

RESULTS: In this study we identify the extracellular matrix protein SPARC as a novel inotropic agent that can prevent the onset of virus-induced cardiac dysfunction and furthermore improve cardiac function when dilated cardiomyopathy has already been established. Importantly, this inotropic activity of SPARC is not restricted to conditions of viral myocarditis, but was also seen in health.

IMPACT: This research identifies SPARC as a novel inotropic agent in health and during myocarditis-induced cardiac dysfunction, and raises further prospects for other diseases, like myocardial infarction, where cardiac function is compromised.

\section{MATERIALS AND METHODS}

\section{Mouse models}

The Animal Care and Use Committee of the University of Leuven approved all described study protocols. Experiments were performed according to the official rules formulated in the Belgian law on the care and use of experimental animals. All experimental protocols respected the Declaration of Helsinki. For SPARC overexpressing experiments, an adenoviral vector designed by Barker et al. ${ }^{18}$ was used. Adenovirus was produced by 293 cells that were collected and purified as previously described ${ }^{24} .1 \times 10^{10}$ adenoviral PFU containing R5 or SPARC was injected into the tail of 12 week old C57BI6 mice. In parallel, a dose response SPARC overexpressing experiment was performed using adeno-associated vectors (AAV) 9, which were kindly provided by prof. M. Giacca, and $10^{9}-10^{11}$ PFU AAV9 containing GFP or SPARC was injected into the tail of 12 week old C57BI6 mice. 


\section{Chapter 4}

For viral myocarditis (VM) experiments, 3 or 5 weeks old male susceptible $\mathrm{C} 3 \mathrm{H}$ mice (Harlan, Boxmeer, The Netherlands) were inoculated intraperitoneally with $10^{3}$ or $10^{4}$ PFU CVB3 (Nancy Strain) or PBS. Adenoviral overexpression experiments used the adenoviral vector designed by Barker et al. and $1 \times 10^{10}$ adenoviral PFU containing GFP or SPARC was injected into the tail vein of 3 weeks old mice 2 weeks prior to the CVB3 inoculation. For SPARC administration experiments, mice were subcutaneously infused for 72 hours with SPARC $(40 \mu \mathrm{g} / \mathrm{kg} / \mathrm{d})$ or vehicle (PBS) by Alzet osmotic minipump 1003D. Pump implantation surgery was performed as described ${ }^{25}$ under ketamine and xylazine anesthesia at a dose of $100 \mathrm{mg} / \mathrm{kg}$ and $10 \mathrm{mg} / \mathrm{kg}$ respectively, and all efforts were made to minimize suffering. In all experiments, plasma was collected and hearts were removed and prepared for myocyte isolations or histological and molecular analysis.

\section{Echo analysis}

Mice were anesthetized (2\% isoflurane, ecuphar) and echocardiograpy was performed at indicated timepoints by transthoracic echocardiography with a 13- $\mathrm{MHz}$ transducer (i13L, GE ultrasound; Horton Norway) on a Vingmed Vivid 7 scanner (GE ultrasound, Horton, Norway). LV diameters at end-diastole (EDD), and end-systole (ESD), were measured, and fractional shortening (FS) was calculated.

\section{Adult mouse cardiac myocyte isolations}

Mice were injected with heparin (1000 U/kg intraperitoneally) and killed by injection of a lethal dose of ketamine and xylazine intraperitoneally. The heart was excised and after cannulation of the aorta, hearts were mounted to a Langendorff perfusion set. The heart was briefly rinsed with normal Tyrode solution, containing (mM): $137 \mathrm{NaCl}, 5.4$ $\mathrm{KCl}, 0.5 \mathrm{MgCl}_{2}, 1 \mathrm{CaCl}_{2}, 11.8$ Hepes, 10 2,3-Butanedione monoxime and 10 glucose, $\mathrm{pH}$ was adjusted to 7.4 with $\mathrm{NaOH}$. Subsequently it was perfused with a $\mathrm{Ca}^{2+}$-free solution for $8 \mathrm{~min}$. The $\mathrm{Ca}^{2+}$-free Tyrode solution contained $(\mathrm{mM}): 130 \mathrm{NaCl}, 5.4 \mathrm{KCl}, 1.2 \mathrm{KH}_{2} \mathrm{PO}_{4}$, $1.2 \mathrm{MgSO}_{4}, 6$ Hepes, 10 2,3-Butanedione monoxime, 20 glucose, and $\mathrm{pH}$ was adjusted to 7.2 with $\mathrm{NaOH}$. Collagenase II (672Units/ml, Worthington 4176) added to the $\mathrm{Ca}^{2+-}$ free solution was subsequently perfused for $8 \mathrm{~min}$. The enzyme was washed out for 3 min. with the $\mathrm{Ca}^{2+}$-free Tyrode solution containing $0.09 \mathrm{mM} \mathrm{CaCl}_{2}$ and $50 \mathrm{mg} / \mathrm{ml} \mathrm{BSA}$, and $\mathrm{Ca}^{2+}$ was reintroduced with the $\mathrm{Ca}^{2+}$-free Tyrode solution, to which $0.18 \mathrm{mM} \mathrm{CaCl}_{2}$ was added. The heart was then removed from the Langendorff perfusion set, the ventricles were disintegrated and further dissociated into single cells by gentle shaking. $\mathrm{Ca}^{2+}$ was further reintroduced with the $\mathrm{Ca}^{2+}$-free Tyrode solution, to which subsequently $0.5 \mathrm{mM}$ and $1 \mathrm{mM} \mathrm{CaCl}$ was added. Next, cell shortening was measured using edge tracking (lonoptix) during electrical field stimulation at 1 and $2 \mathrm{~Hz}$. Field stimulation was achieved with 5 ms square pulses of constant voltage, at $20 \%$ above threshold. The cell shortening is expressed as the fractional shortening, i.e. normalized to resting cell 
length, $\Delta \mathrm{L} / \mathrm{L} 0 * 100 \%$. During field stimulation cells were superfused with normal Tyrode solution at $37^{\circ} \mathrm{C}$. [Ca2+]i was measured with fluo-3, and is reported as the fluorescence normalized to baseline values, after background subtraction, F/FO. To measure the effect of SPARC ex vivo on cells, recombinant SPARC $(1 \mu \mathrm{g} / \mathrm{ml})$ was added to half of the freshly isolated cell suspension, while the other half was left in normal Tyrode solution. After 1 hour incubation, cell shortenings were measured as described above.

\section{In vitro experiments with adult rat cardiac myocytes}

Cardiac myocytes were isolated by enzymatic disassociation from adult Wistar rats as previously described ${ }^{26}$. Experiments were performed in accordance with the Guide for the Animal Care and Use Committee of the VU University Medical Center (VUmc) and with approval of the Animal Care Committee of the VUmc. All experimental protocols respected the Declaration of Helsinki. For experiments, freshly isolated cardiomyocytes were cultured at $37^{\circ} \mathrm{C}$ overnight on polyarcrylamide gels (25\% Acrylamide $40 \%, 13 \%$ Bis $2 \%)$ with a stiffness of approximately $15 \mathrm{kPa}$. Prior to culture, these gels were coated with laminin $(10 \mu \mathrm{g} / \mathrm{ml})$, collagen $(50 \mu \mathrm{g} / \mathrm{ml})$ with and without recombinant SPARC $(1 \mu \mathrm{g} / \mathrm{ml}$, PeproTech $120-36)$ in 0.1M HEPES, overnight at $4^{\circ} \mathrm{C}$. The cardiac myocytes were plated in plating medium (M199 medium, Gibco, 31150-022, with 1\% PenicilineStreptavidine and $5 \%$ fetal bovine serum) onto the coated gels, and after 1 hour incubation at $37^{\circ} \mathrm{C}$, medium was replaced to culture medium (M199 medium with $1 \%$ Peniciline-Streptavidine, $0.2 \%$ Insulin Transferrin Sodium selenite and 0.1\% Cytochalasin D). After overnight incubation at $37^{\circ} \mathrm{C}$, unloaded cell shortenings of the adherent cardiac myocytes were measured in the culture medium, using different frequencies of electrical field stimulation and analyzed using lonOptix software (IonOptix LLC, Milton, MA). Data are presented as fractional shortening (\% diastolic length), time to peak of contraction (TTP) and 50\% relaxation time (RT50).

\section{Histology and microscopy}

Cardiac tissue was processed and histochemical and immunohistochemical analyses were performed as previously described ${ }^{27-29}$, and all morphometric analyses were done on crossectional sections. Hematoxylin and eosin - stained sections ( $4 \mu \mathrm{m}$ ) were used to assess overall morphology. The number of CD-45 - staining cells (monoclonal rat anti-

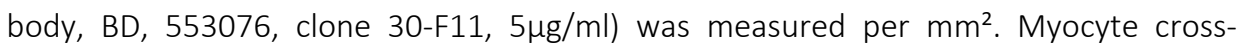
sectional areas were calculated by measuring the inner circumference of 150 myocytes per sample on laminin- stained sections (rabbit antibody, Sigma, L9393, 125 $\mathrm{\mu g} / \mathrm{ml}$ ). To assess the amount and cross-linking of fibrosis, Picro Sirius Red staining was performed as previously described ${ }^{29,30}$. Microscopic analyses were performed using a microscope (Leitz DMRXE; Leica), and QWin morphometry software (Leica). All analyses were performed according to standard operating procedures. 


\section{Chapter 4}

Immunostaining of isolated cardiac myocytes

Adult cardiac myocytes were isolated from healthy mice as described above, fixed in $2 \%$ PFA in PBS for $10 \mathrm{~min}$, incubated in $50 \mathrm{mM}$ glycine for $30 \mathrm{~min}$ to remove autofluorenscence caused by PFA at $488 \mathrm{~nm}$, and subsequently stained for SPARC (polyclonal goat antibody, R\&D systems, AF492, $5 \mu \mathrm{g} / \mathrm{ml}$ ) overnight at $4^{\circ} \mathrm{C}$. The next day cells were first incubated with a secondary donkey-anti goat-alexa 488 labeled antibody for $90 \mathrm{~min}$. at room temperature and some cells were subsequently stained for integrin beta1 (monoclonal rat antibody, BD, 553715, $0.5 \mu \mathrm{g} / \mathrm{ml}$ ) for 4 hours at room temperature and afterwards incubated with a secondary goat-anti rat-alexa 568 labeled antibody for $90 \mathrm{~min}$. at room temperature. Cells were visualized with confocal microscopy on a Zeiss LSM700 microscope (Leica) using the Zen software (Leica), or analyzed using a BD FACSAria III flow cytometer (Becton Dickinson (BD), San Jose, CA) and FlowJo software (Ashland, Oregon).

\section{Immunostaining of the coated matrices}

Matrices were produced and coated as described and stored at $4^{\circ} \mathrm{C}$ prior to staining. Matrices were washed with PBS and subsequently stained for SPARC (polyclonal goat antibody, R\&D systems, AF491, $5 \mu \mathrm{g} / \mathrm{ml}$ ), laminin (polyclonal rabbit antibody, Sigma, L9393, $5 \mu \mathrm{g} / \mathrm{ml}$ ) and collagen (monoclonal rat antibody, Merck Millipore, MAB 1912, $1 / 100$ ) overnight at $4^{\circ} \mathrm{C}$. The next day matrices were incubated with a secondary donkey-anti goat-alexa 660, goat-anti rabbit-alexa 568 and, goat-anti rat-alexa 488 labeled antibodies for $90 \mathrm{~min}$. at room temperature and matrices were visualized with confocal microscopy on a Zeiss LSM700 microscope (Leica) using the Zen software (Leica).

\section{Myocyte fractionation}

Adult cardiac myocytes were isolated from healthy mice as described, incubated in lysis buffer, containing (mM): 5 Tris $\mathrm{HCl}, 5 \mathrm{NaCl}, 2$ EDTA, $1 \mathrm{CaCl}_{2}, 1 \mathrm{MgCl}_{2}, 2 \mathrm{DTT}$ and $\mathrm{pH}$ was adjusted to 7.4. Phosphatase inhibitors (2\%, Sigma, P044 and P5726) and protease inhibitors (4\%, Roche, 11697498001) were added to the buffer, and cells were incubated overnight at $4^{\circ} \mathrm{C}$. The next day, the cell suspension was centrifuged for 1 hour at maximum speed at $4^{\circ} \mathrm{C}$ and supernatant was collected as cytoplasmic fraction, the pellet was dissolved in lysis buffer and collected as the membrane fraction.

\section{Immunoprecipitation}

For immunoprecipitation, left ventricular tissue or isolated cardiomyocytes were lysed in immunoprecipitating buffer containing (mM): $150 \mathrm{NaCl}, 20$ Tris, 5 EDTA, 1\% Triton X100 and $\mathrm{pH}$ was adjusted to $\mathrm{pH} 7.5$ using $\mathrm{NaOH}$. Phosphatase inhibitors (2\%, Sigma, 
P044 and P5726) and protease inhibitors (4\%, Roche, 11697498001) were added to the buffer. Dynabeads M-280 (Sheep anti rabbit a-Ig, Life Technologies, 2018-06) were washed with lysis buffer and incubated with SPARC antibody (monoclonal rabbit antibody, Sino Biological Inc, 50494-R001, 3ug in 200uL buffer) or rabbit serum as negative control, for 2 hours at $4^{\circ} \mathrm{C}$. Next, beads were washed and incubated with lysates overnight at $4^{\circ} \mathrm{C}$. The next day, the non-bound lysates were collected and resolved for SDSPAGE, beads were washed and beads-bound immune complexes were resolved for SDSPAGE. Samples were subsequently immunoblotted for the detection of ILK (polyclonal rabbit antibody, CST, 3862, 1/1000).

\section{Western Blotting}

Proteins were isolated from plasma (30uL of 1/25 plasma diluted in PBS was loaded), left ventricular tissue, or from isolated cardiomyocytes, separated by SDS-PAGE and subsequently immunoblotted for the detection of pAkt (monoclonal rabbit antibody, Cell signaling, 4060, 1/1000), and total Akt (polyclonal rabbit antibody, Cell signaling, 9272, 1/1000), SPARC (polyclonal goat antibody, R\&D systems, AF492, 5 $\mathrm{g} / \mathrm{ml}$ ) and GAPDH (monoclonal mouse antibody, Fitzgerald, 10R-G109a, clone 6C5, 0.1 $\mathrm{g} / \mathrm{ml}$ ) overnight at $4^{\circ} \mathrm{C}$. Signals were visualized using Hyperfilm ECL (Amersham Biosciences) and quantified using Image J software.

\section{RNA isolation and expression}

RNA was isolated from left ventricular tissue with the RNeasy Mini kit (QIAGEN) according to the manufacturer's guidelines and was stored at $-80^{\circ} \mathrm{C}$. RNA was reverse transcribed into complementary DNA with the iScript cDNA synthesis kit (BioRad) according to the manufacturer's instructions. Real-time quantitative PCR was performed with SYBR green PCR Master mix (Applied Biosystems). Primers were designed with primerBLAST (NCBI) and built to contain an intron- exon boundary. Primers were designed for mouse SPARC (5'GAGGAGGTGGTGGCTGCTGACAA3'; 5'CACCTTGCCATGTTTGCAAT3'), and mouse GAPDH (5'GGTGGACCTCATGGCCTACA3'; 5'TCGTTCCTGTGACTCGTTCTCTC3') was used as housekeeping gene.

\section{Statistical analysis}

Data were expressed as the mean \pm SEM. Histological and molecular analyses in shamoperated and VM groups were performed in independent groups. For echocardiographic measurements, analyses were performed in independent groups, except for the experiment where SPARC or vehicle was infused with an osmotic minipump for $72 \mathrm{~h}$, there repeated measures were performed. Normal distribution of all continuous variables was tested according to the method of Kolmogorov and Smirnov. An unpaired Student 's t 


\section{Chapter 4}

test for 2 groups or ANOVA, followed by a Bonferroni post hoc test for more groups was used in most of the comparisons when groups passed the normality test. When the standard deviation of two groups significantly differed, a Mann-Whitney test for 2 groups or a Kruskal-Wallis test, followed by a Dunn's post hoc test for more groups, was used. A paired Student's t test was used to analyze baseline and follow-up echocardiographic measurements, a Wilcoxon test was used when data did not pass normality test. A two-sided $p$-value of $\leq 0.05$ was considered statistically significant.

\section{FUNDING}

This work was supported by a CARIM-funded PhD grant, and by the European Commission's grants FIBROTARGETS [602904], MEDIA [261409], and ARENA [CVON 2011].

\section{DISCLOSURES}

None. 


\section{REFERENCES}

1 Lymperopoulos, A., Garcia, D. \& Walklett, K. Pharmacogenetics of cardiac inotropy. Pharmacogenomics 15, 1807-1821, doi:10.2217/pgs.14.120 (2014).

2 Mason, J. W. Myocarditis and dilated cardiomyopathy: an inflammatory link. Cardiovascular research 60, 5-10 (2003).

3 Corsten, M. F., Schroen, B. \& Heymans, S. Inflammation in viral myocarditis: friend or foe? Trends Mol Med 18, 426-437, doi:10.1016/j.molmed.2012.05.005 (2012).

4 Pollack, A., Kontorovich, A. R., Fuster, V. \& Dec, G. W. Viral myocarditis-diagnosis, treatment options, and current controversies. Nat Rev Cardiol 12, 670-680, doi:10.1038/nrcardio.2015.108 (2015).

5 Hazebroek, M., Dennert, R. \& Heymans, S. Virus infection of the heart--unmet therapeutic needs. Antivir Chem Chemother 22, 249-253, doi:10.3851/IMP2047 (2012).

6 Wessely, R. et al. Transgenic expression of replication-restricted enteroviral genomes in heart muscle induces defective excitation-contraction coupling and dilated cardiomyopathy. J Clin Invest 102, 14441453, doi:10.1172/JCl1972 (1998).

7 Steinke, K. et al. Coxsackievirus B3 modulates cardiac ion channels. FASEB journal : official publication of the Federation of American Societies for Experimental Biology 27, 4108-4121, doi:10.1096/fj.13-230193 (2013).

8 Swinnen, M. et al. Absence of thrombospondin-2 causes age-related dilated cardiomyopathy. Circulation 120, 1585-1597, doi:10.1161/CIRCULATIONAHA.109.863266 (2009).

9 Van Aelst, L. N. et al. Osteoglycin prevents cardiac dilatation and dysfunction after myocardial infarction through infarct collagen strengthening. Circulation research 116, 425-436, doi:10.1161/CIRCRESAHA. 116.304599 (2015).

10 Papageorgiou, A. P. et al. Thrombospondin-2 prevents cardiac injury and dysfunction in viral myocarditis through the activation of regulatory T-cells. Cardiovascular research 94, 115-124, doi:10.1093/cvr/cvs077 (2012).

11 Harris, B. S. et al. SPARC regulates collagen interaction with cardiac fibroblast cell surfaces. Am J Physiol Heart Circ Physiol 301, H841-847, doi:10.1152/ajpheart.01247.2010 (2011).

12 Chen, H., Huang, X. N., Stewart, A. F. \& Sepulveda, J. L. Gene expression changes associated with fibronectin-induced cardiac myocyte hypertrophy. Physiol Genomics 18, 273-283, doi:10.1152/physiol genomics.00104.2004 (2004).

13 Murphy-Ullrich, J. E. \& Sage, E. H. Revisiting the matricellular concept. Matrix biology : journal of the International Society for Matrix Biology 37, 1-14, doi:10.1016/j.matbio.2014.07.005 (2014).

14 Bradshaw, A. D. \& Sage, E. H. SPARC, a matricellular protein that functions in cellular differentiation and tissue response to injury. J Clin Invest 107, 1049-1054, doi:10.1172/JCI12939 (2001).

15 Schellings, M. W. et al. Absence of SPARC results in increased cardiac rupture and dysfunction after acute myocardial infarction. J Exp Med 206, 113-123, doi:10.1084/jem.20081244 (2009).

16 Vandendriessche, T. et al. Efficacy and safety of adeno-associated viral vectors based on serotype 8 and 9 vs. lentiviral vectors for hemophilia B gene therapy. J Thromb Haemost 5, 16-24, doi:10.1111/j.15387836.2006.02220.x (2007).

17 Cittadini, A. et al. Adenoviral gene transfer of Akt enhances myocardial contractility and intracellular calcium handling. Gene Ther 13, 8-19, doi:10.1038/sj.gt.3302589 (2006).

18 Barker, T. H. et al. SPARC regulates extracellular matrix organization through its modulation of integrinlinked kinase activity. The Journal of biological chemistry 280, 36483-36493, doi:10.1074/jbc.M 504663200 (2005).

19 Sheikh, F., Lyon, R. C. \& Chen, J. Getting the skinny on thick filament regulation in cardiac muscle biology and disease. Trends Cardiovasc Med 24, 133-141, doi:10.1016/j.tcm.2013.07.004 (2014).

20 Weaver, M. S., Workman, G. \& Sage, E. H. The copper binding domain of SPARC mediates cell survival in vitro via interaction with integrin beta1 and activation of integrin-linked kinase. The Journal of biological chemistry 283, 22826-22837, doi:10.1074/jbc.M706563200 (2008). 


\section{Chapter 4}

21 Mooney, A. et al. Type IV collagen and laminin regulate glomerular mesangial cell susceptibility to apoptosis via beta(1) integrin-mediated survival signals. Am J Pathol 155, 599-606 (1999).

22 Terada, Y. et al. Hyperosmolality activates Akt and regulates apoptosis in renal tubular cells. Kidney Int 60, 553-567, doi:10.1046/j.1523-1755.2001.060002553.x (2001).

23 Chaanine, A. H. \& Hajjar, R. J. AKT signalling in the failing heart. Eur J Heart Fail 13, 825-829, doi:10.1093/eurjhf/hfr080 (2011).

$24 \mathrm{He}, \mathrm{T}$. C. et al. A simplified system for generating recombinant adenoviruses. Proc Natl Acad Sci U S A 95, 2509-2514 (1998).

25 Heymans, S. et al. Macrophage microRNA-155 promotes cardiac hypertrophy and failure. Circulation 128, 1420-1432, doi:10.1161/CIRCULATIONAHA.112.001357 (2013).

26 Kaestner, L. et al. Isolation and genetic manipulation of adult cardiac myocytes for confocal imaging. J Vis Exp, doi:10.3791/1433 (2009).

27 Heymans, S. et al. Inhibition of plasminogen activators or matrix metalloproteinases prevents cardiac rupture but impairs therapeutic angiogenesis and causes cardiac failure. Nat Med 5, 1135-1142, doi:10.1038/13459 (1999).

28 Lutgens, E. et al. Chronic myocardial infarction in the mouse: cardiac structural and functional changes. Cardiovasc Res 41, 586-593 (1999).

29 Vanhoutte, D. et al. Increased expression of syndecan-1 protects against cardiac dilatation and dysfunction after myocardial infarction. Circulation 115, 475-482, doi:10.1161/CIRCULATIONAHA. 106.644609 (2007).

30 Junqueira, L. C., Bignolas, G. \& Brentani, R. R. Picrosirius staining plus polarization microscopy, a specific method for collagen detection in tissue sections. Histochem J 11, 447-455 (1979). 


\section{SUPPLEMENTARY FIGURES}

\section{Supplementary Figure 1}
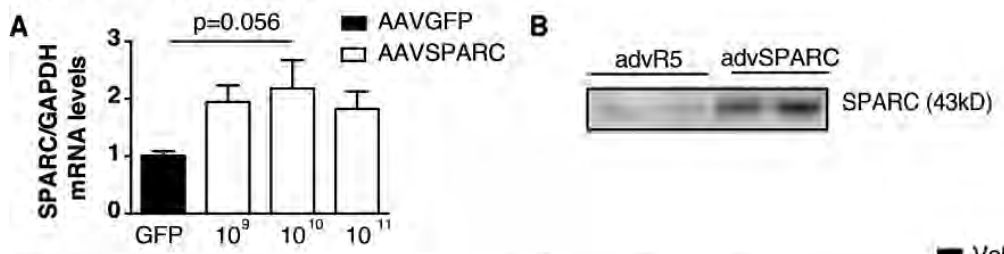

C

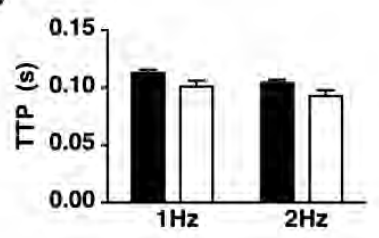

D

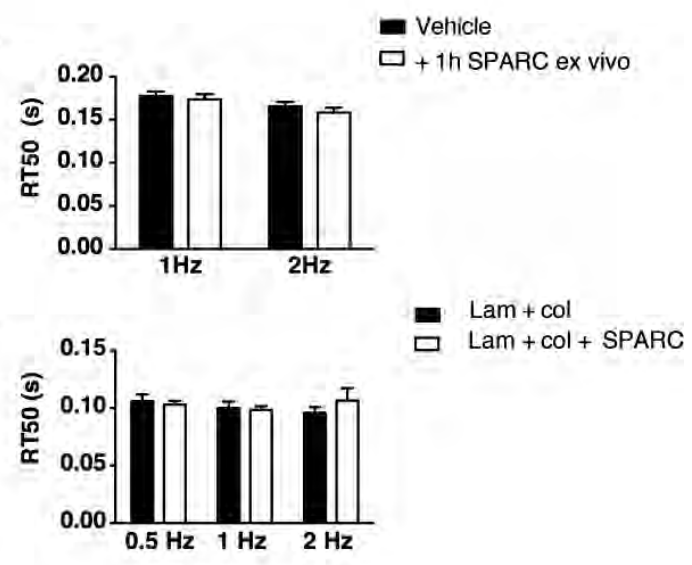

E

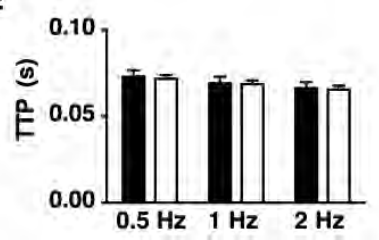

\section{$\mathbf{F}$}

Supplementary Figure 1. (A and B) Confirmation of SPARC overexpression. Cardiac SPARC mRNA levels are increased as assessed with RT-PCR in AAV9 treated mice. Using Western Blot we demonstrate systemic increased SPARC protein levels in plasma of adenoviral treated mice (30uL of 1/25 plasma diluted in PBS was loaded). ( $C$ and $D$ ) Incubation of isolated adult mouse cardiomycoytes with recombinant SPARC for 1 h ex vivo does not affect contraction - and relaxation times (TTP and RT50). (D and E) TTP and RT50 are not altered in rat cardiomyocytes grown on a matrix with SPARC. $n \geq 5$ 
Chapter 4

Supplementary Figure 2

A

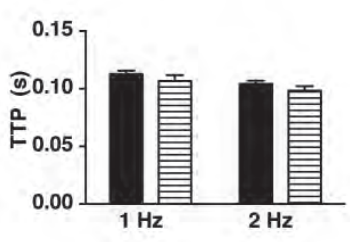

B

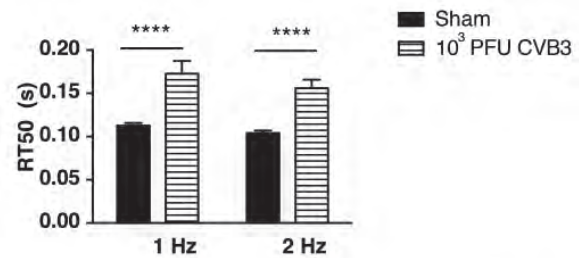

c

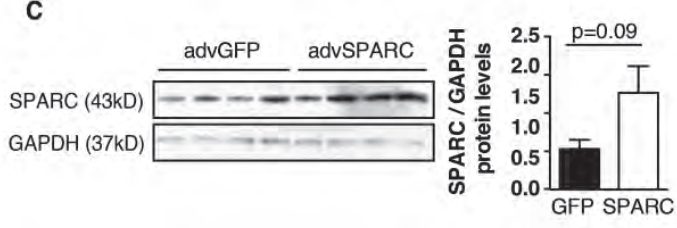

D

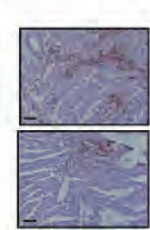

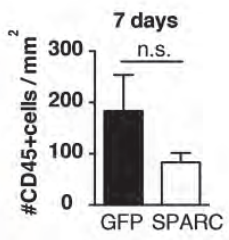

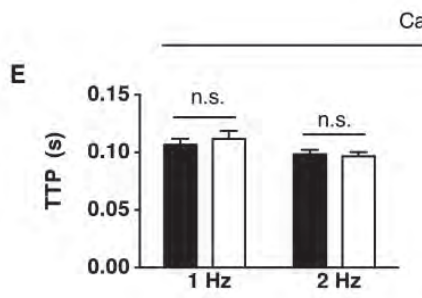

Cardiomyocyte shortening

$\mathbf{F}$

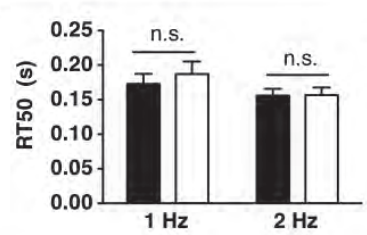

- $\mathrm{VM}+$ advGFP

口 $\mathrm{VM}+$ advSPARC

Calcium transients

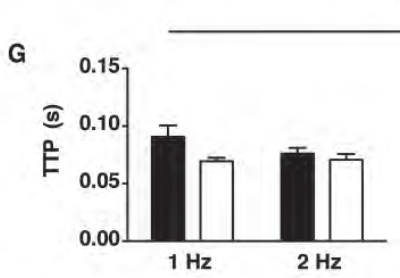

H
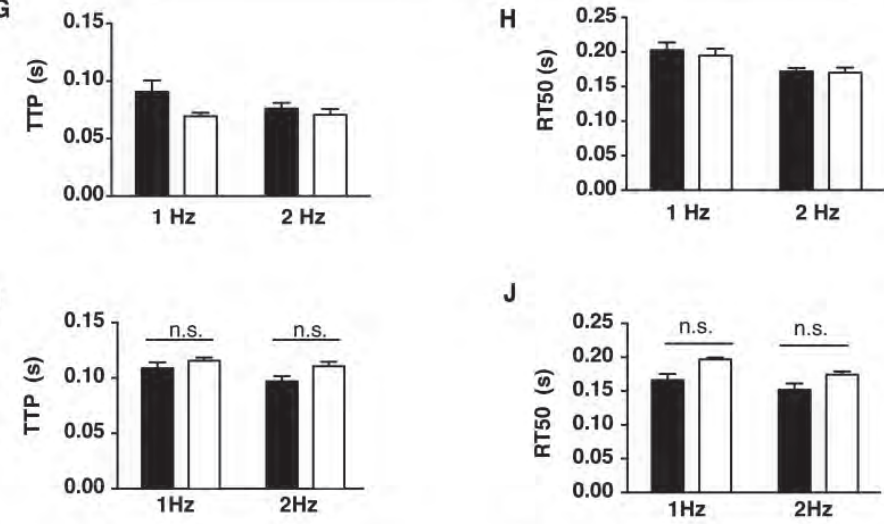

K

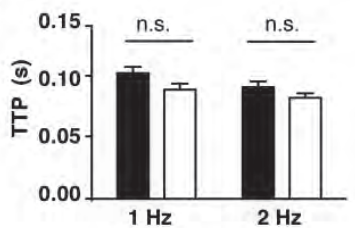

J

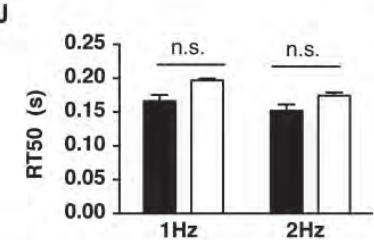

L

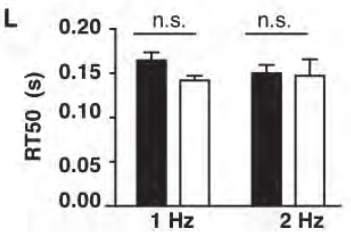

- $\mathrm{VM}+\operatorname{advGFP}$

ㅁ $V M+a d v S P A R C$
- $\mathrm{VM}+$ Vehicle

口 VM + SPARC

Supplementary Figure 2 (Legend on the next page). 


\section{Supplementary Figure 2}

(A and B) Viral infection does not influence TTP but increases RT50 in isolated cardiomyocytes from virusinfected mice. (C) Cardiac SPARC is almost significantly overexpressed in the adenoviral-SPARC injected group when compared to the control adenoviral-GFP injected mice, as shown by Western Blotting. (D) Slightly decreased cardiac inflammation, as measured by the amount of CD45 positive cells, was seen in the SPARC overexpressing group. ( $E$ and F) No effect on contraction or relaxation times was observed when SPARC was overexpressed. ( $\mathrm{G}$ and $\mathrm{H}$ ) There were no differences in the $\mathrm{Ca}^{2+}$ transient peak TTP or RT50 in cells from the SPARC overexpressing VM mice. (I and J) Cardiomyocytes from SPARC-treated mice demonstrated no differences in TTP or RT50. ( $K$ and L) When cardiomyocytes were isolated from severely sick, untreated mice, incubation of the cells with SPARC for 1 h ex vivo did not influence TTP or RT50. $n \geq 4$ 



\section{Chapter}

\section{Breeding Strategy Determines Rupture Incidence in Post-Infarct Healing WARPing Cardiovascular Research}

Modified from PLoS One. 2015;10(9):e0139199.

Sophie Deckx ${ }^{1,2}$, Paolo Carai ${ }^{1,2}$, John Bateman ${ }^{3,4}$, Stephane Heymans ${ }^{1,2}$, Anna-Pia Papageorgiou $^{1,2}$

${ }^{1}$ Department of Cardiology, Maastricht University, Maastricht, The Netherlands,

${ }^{2}$ Centre for Molecular and Vascular Biology, KULeuven, Leuven, Belgium,

${ }^{3}$ Murdoch Children's Research Institute, University of Melbourne, Royal Children's Hospital, Parkville, Victoria, Australia,

${ }^{4}$ Department of Paediatrics, University of Melbourne, Royal Children's Hospital, Parkville, Victoria, Australia 


\section{Chapter 5}

\section{ABSTRACT}

\section{Background}

Von Willebrand A domain Related Protein (WARP), is a recently identified extracellular matrix protein. Based upon its involvement in matrix biology and its expression in the heart, we hypothesized that WARP regulates cardiac remodeling processes in the postinfarct healing process.

\section{Methods and results}

In the mouse model of myocardial infarction (MI), WARP expression increased in the infarcted area 3-days post-MI. In the healthy myocardium WARP localized with perlecan in the basement membrane, which was disrupted upon injury. In vitro studies showed high expression of WARP by cardiac fibroblasts, which further increases upon TGF $\beta$ stimulation. Furthermore, WARP expression correlated with aSMA and COL1 expression, markers of fibroblast to myofibroblast transition, in vivo and in vitro. Finally, WARP knockdown in vitro affected extra- and intracellular basic fibroblast growth factor production in myofibroblasts. To investigate the function for WARP in infarction healing, we performed an $\mathrm{MI}$ study in WARP knockout (KO) mice backcrossed more than 10 times on an Australian C57BI/6-J background and bred in-house, and compared to wild type (WT) mice of the same C57BI/6- J strain but of commercial European origin. WARP KO mice showed no mortality after $\mathrm{MI}$, whereas $40 \%$ of the WT mice died due to cardiac rupture. However, when WARP KO mice were backcrossed on the European C57BI/6-J background and bred heterozygous in- house, the previously seen protective effect in the WARP KO mice after MI was lost. Impor- tantly, comparison of the cardiac response post-MI in WT mice bred heterozygous in-house versus commercially purchased WT mice revealed differences in cardiac rupture.

\section{Conclusion}

These data demonstrate a redundant role for WARP in the wound healing process after $\mathrm{MI}$ but demonstrate that the continental/breeding/housing origin of mice of the same C57BI6-J strain is critical in determining the susceptibility to cardiac rupture and stress the importance of using the correct littermate controls. 


\section{INTRODUCTION}

Ischemic heart disease is one of the most prominent cardiovascular diseases (CVD) and can lead to sudden death or to heart failure (HF). Despite a decline in death rates, the burden of CVD remains high, with over 5 million people suffering from HF in the United States ${ }^{1}$. Therefore, it is critical to identify novel pathogenic mechanisms for designing new treatment strategies, in order to prevent the progression of this disease. The cardiac response after $\mathrm{MI}$ is a tightly regulated and well-orchestrated process of wound healing. Following an ischemic event, there is rapid formation of granulation tissue, a tissue rich in leukocytes, vessels and proliferating fibroblasts. This granulation tissue regresses and is replaced by collagenous matrix proteins, which will constitute the mature scar tissue $^{2}$. Disturbances in this healing response lead to adverse infarct healing, cardiac rupture and HF. Our group has previously demonstrated that the matrix reinforcing capacities of the non-structural proteins Thrombospondin-2, Osteonectin and Osteoglycin are critical in coping with increased loading ${ }^{3}$, advanced aging ${ }^{4}$ or ischemia, ${ }^{5,6}$ of the heart.

WARP, a small, non-collagenous, secreted glycoprotein, was recently identified and shown to be expressed in the extracellular matrix of the heart. WARP contains a von Willebrand factor type A domain ${ }^{7}$ and the expression of WARP is restricted to permanent cartilages and to basement membranes of peripheral nerves, skeletal and cardiac muscle and the central nervous system vasculature ${ }^{8}$. Interestingly, in basement membranes it interacts with perlecan, a protein important for stability and critical during cardiac development as well as during wound healing after $\mathrm{MI}^{9-12}$. WARP interacts with the heparan sulphate chains containing domain I of perlecan, where also the interaction of basic fibroblast growth factor (bFGF) and vascular endothelial growth factor (VEGF) take place ${ }^{13}$, growth factors essential during infarct healing ${ }^{14-20}$. Furthermore, WARP interacts with collagen $\mathrm{VI}^{21,22}$, a known HF- related gene ${ }^{3,21,22}$. Collectively, these studies support the hypothesis that WARP is needed during infarct healing and cardiac remodeling.

Using in vitro and in vivo models, we assessed the role for WARP during the different remodeling phases after $\mathrm{MI}$. Our results were unexpectedly overshadowed by the influence of the breeding conditions of the WARP KO and WT mice of the same C57BI6-J strain. The use of genetically manipulated mice is a widespread tool to study the effects of a specific gene in cardiac remodeling. The importance of the genetic background of the inbred strain used in the generation and analysis of transgenic and KO animals ${ }^{23-26}$ has been recognized but little is known about the regional differences within the same strain that affect susceptibility to CVD in mice. Our data demonstrate that the breeding conditions (such as genetic background, continental source and housing) are critical factors that determine the susceptibility to CVD and stress the importance of using the correct littermate controls. Finally, though WARP is highly expressed by cardiac fibroblasts and is associated with the activation of myofibroblasts in vivo and in vitro, it does not appear to play a critical role in the wound healing following $\mathrm{MI}$. 


\section{RESULTS}

\section{WARP expression is induced during cardiac remodeling}

To assess the role of WARP during the different phases of cardiac remodeling after MI, we executed a time-series of a mouse model of permanent coronary occlusion in C57BI/6-J WT mice, and examined WARP levels in left ventricle (LV) tissue samples of sham-operated mice and of mice 3, 7 and 14 days after MI (Fig. 1). Real-time PCR showed an induction of WARP gene expression after MI starting already at 3 days post ligation. WARP mRNA levels peaked 7 days after MI, and decreased back at 14 days, but not completely back to baseline levels (Fig. 1a). Western blot analysis of WARP protein expression and immunohistochemistry showed a similar induction of WARP protein levels after $\mathrm{MI}$ in the infarcted LV, significantly increasing at 3 and 7 days post ligation and then slightly decreasing again at 14 days, but not back to baseline levels (Figs. $1 \mathrm{~b}$ and c). Confocal microscopy revealed a unique pattern for WARP in the infarcted heart. In the un-infarcted regions of the LV, WARP is localized in the extracellular matrix and in line with previous reports, WARP co-localized with perlecan ${ }^{9}$, a marker for the basement membrane, showing a network of WARP and perlecan as a honeycomb-structure surrounding the cardiomyocytes (Fig. 1d). However, in the infarcted LV, this honeycombstructure is reduced at 3 days and completely absent at 7 and 14 days after $\mathrm{Ml}$ and importantly, the interaction between WARP and perlecan is disrupted (Fig. 1d). The early increased expression of WARP mRNA and protein levels is in parallel with the influx of inflammatory cells in the damaged myocardium and with the formation of the granulation tissue post infarction ${ }^{2}$. However, co-staining of WARP and CD45-postitive leukocytes revealed no localization of WARP on inflammatory cells (Fig. 1 e). Furthermore, WARP did not co-localize with the alpha smooth muscle actin of the vessels (Fig. 1e). These results suggest a function for WARP in scar formation but not during inflammation.

\section{WARP expression correlates with fibroblast to myofibroblast transition and regulates bFGF levels}

Because the early increased expression of WARP post-infarction is in parallel with the transition of cardiac fibroblasts into myofibroblasts and with the formation of the granulation tissue post infarction, we correlated WARP expression levels in the infarcted LV tissue with $\alpha$ - smooth muscle actin (aSMA) and collagen I (COL1) expression levels, 2 elements that mark the conversion of fibroblast to myofibroblast ${ }^{27}$. We found highly significant correlations of WARP with these markers (Figs. 2a and b), indicating a possible role for WARP in myofibroblast transformation.

When in vitro WARP expression levels were measured in un-stimulated neonatal rat cardiac fibroblasts and cardiomyocytes, we found a 17 fold higher WARP expression in 
cardiac fibroblasts as compared to cardiomyocytes (Fig. 2c). Furthermore, WARP expression in cardiac fibroblasts increased significantly after TGF $\beta$ stimulation (Fig. 2d), a known pro-fibrotic growth factor that stimulates the conversion of fibroblast to myofibroblast following $\mathrm{MI}^{20}$ whereas Endothelin-1 stimulation (an inducer of cardiomyocyte hypertrophy) did not affect WARP expression in the cardiomyocytes (Fig. 2e). WARP expression levels also significantly correlated with aSMA and COL1 expression levels in cardiac fibroblasts in vitro, however these correlations were less strong as compared to our in vivo results, as shown by the lower $\mathrm{R}^{2}$ values (Fig. $2 f$ and g). Since WARP and bFGF have been shown to interact with the same domain on perlecan ${ }^{13}$, and since bFGF is a known inhibitor of fibroblast to myofibroblast conversion ${ }^{20,28}$, we investigated the effect of WARP on the extracellular and intracellular bFGF protein levels in cardiac fibroblasts. siRNA against WARP caused an $88 \%$ reduction of WARP gene expression in un-stimulated cells and a $90 \%$ reduction in stimulated cells (data not shown). TGF $\beta$ stimulation in scrambled control siRNA treated fibroblasts resulted in extracellular bFGF protein levels significantly decreasing (Fig. 2h), whilst intracellular bFGF levels did not change (Fig. 2i).

WARP knockdown alone did not affect extra-or intra-cellular bFGF levels. However, when cells were stimulated with TGF (and WARP knocked down) there was no significant decrease in extracellular bFGF levels anymore (Fig. 2h). Furthermore intracellular bFGF levels in the WARP-siRNA treated cells were increased as compared to the unstimulated WARP siRNA treated cells and as compared to the stimulated scrambled siRNA treated cells ( $p=0.08$ ) (Fig. 2i). Interestingly, WARP knockdown also resulted in a decrease in aSMA levels $(1.05 \pm 0.25$ in the control siRNA group versus $0.23 \pm 0.05$ in the WARP siRNA group, $p=0.001)$, but not in COL1 levels $(1.06 \pm 0.05$ in the control siRNA group versus $1.13 \pm 0.10$ in the WARP siRNA group). Overall, these data demonstrate that WARP expression correlates with markers of fibroblast to myofibroblast transition and indicate that WARP may influence the transition of fibroblasts into myofibroblasts by affecting bFGF levels. 


\section{Figure 1}

a

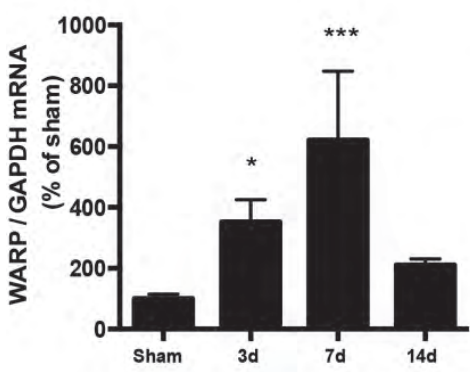

c

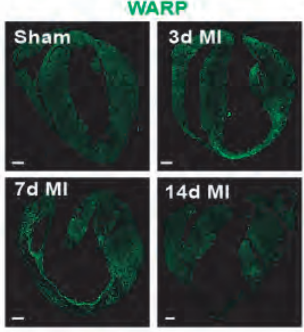

d

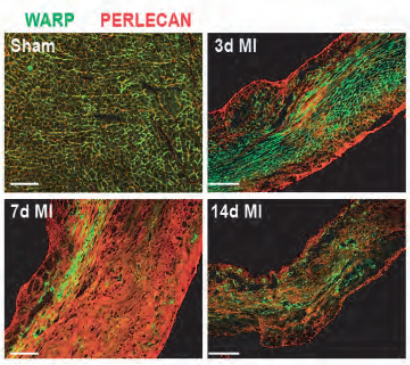

b
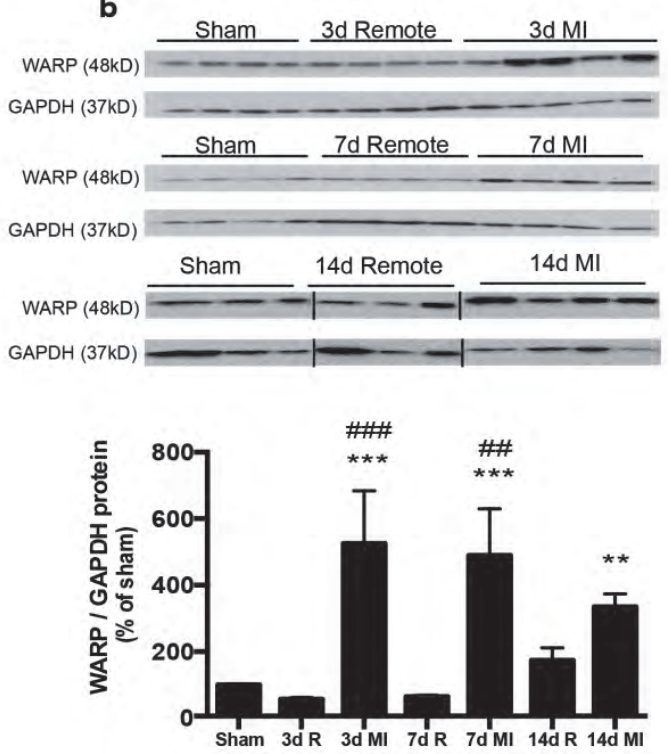

e

WARP CD46

WARP ASMC

WARP PERLECAN
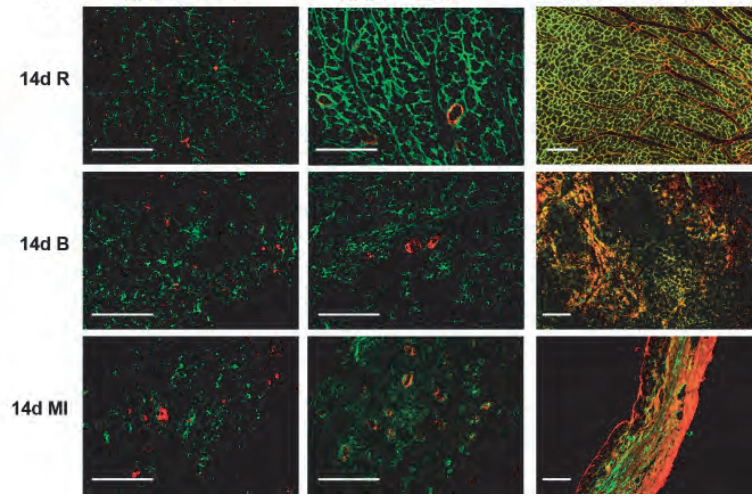

Figure 1. WARP expression pattern in the heart. (a) WARP mRNA levels were induced 3 and 7 days after MI. WARP mRNA levels peaked at 7 days after $\mathrm{MI}$ and then decreased again at 14 days. (b) Western blot analysis and (c) immunohistochemistry also showed an induction of WARP protein levels in the infarcted LV at 3, 7, and 14 days after MI. Because of different sample-loading, the blots of the 14 days MI were cut and pasted in the same order as the blots of the 3 and 7 days MI. Images of the original unadjusted blots are provided in $\mathrm{S}$ Fig.1. ( $d$ and e) Confocal microscopy confirmed the co-localization of WARP with perlecan in the uninfarcted heart, showing a network of WARP and perlecan as a honeycomb-structure surrounding the cardiomyocytes. In the infarcted LV zones, the WARP-perlecan honeycomb-structure is reduced at 3 days after $\mathrm{MI}$ and completely absent at 7 and 14 days after $\mathrm{MI}$ and the interaction between WARP and perlecan is disrupted. (e) WARP did not localize on CD45 positive leukocytes or in alpha smooth muscle cells lining the vessels in the remote, border and infarcted zone of the heart 14 days after $\mathrm{MI} . \mathrm{n} \geq 3 ;{ }^{*} \mathrm{p} \leq 0.05 ; * * \mathrm{p} \leq 0.005 ;{ }^{* *} \mathrm{p} \leq 0.001$

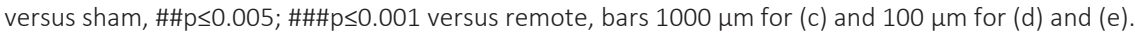


Figure 2
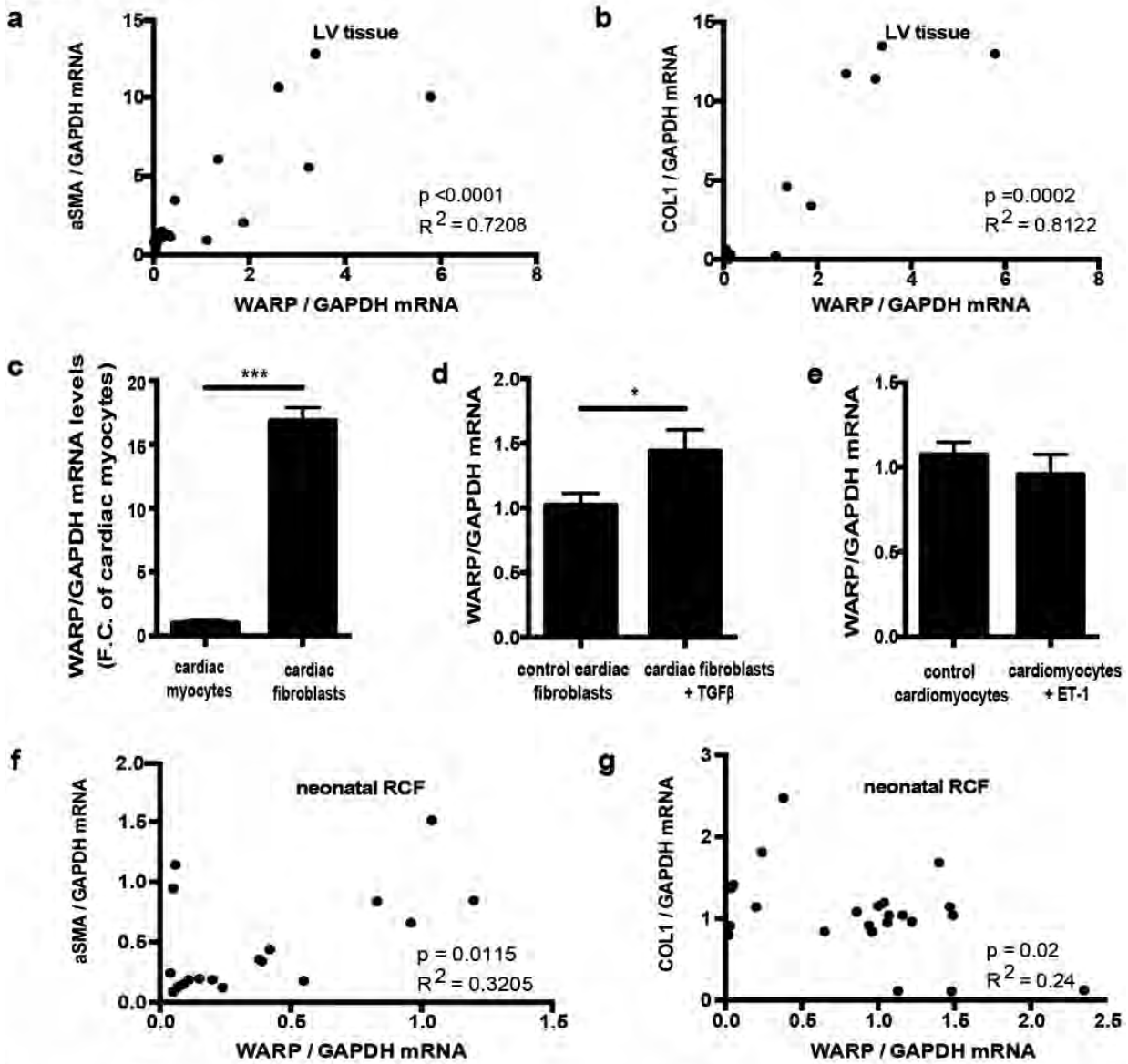

h

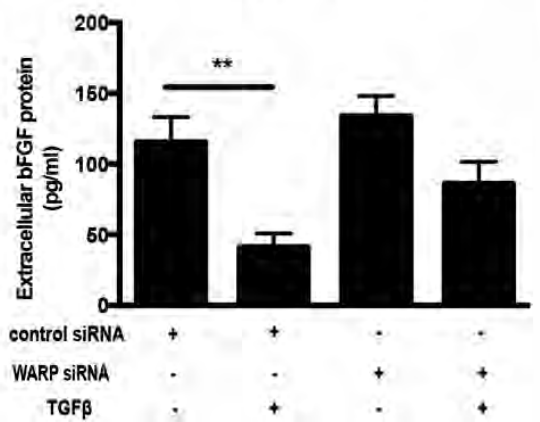

$\mathbf{i}$

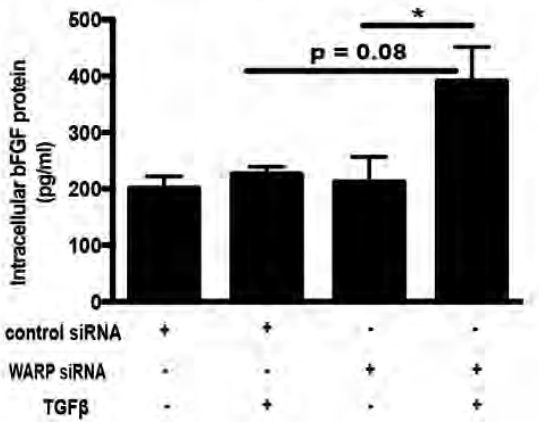

Figure 2. WARP expression correlates with myofibroblast transformation and affects cardiac bFGF levels. (a) WARP mRNA levels correlate with aSMA and (b) COL1 levels in infarcted LV tissue. (c) WARP mRNA levels are 17 fold higher in neonatal rat cardiac fibroblasts compared to cardiac myocytes. (d) Treatment of the cardiac fibroblasts with TGF $\beta$, a known pro-fibrotic stimulus, increased WARP expression, (e) while there was no change in WARP expression after treatment of the cardiomycoytes with Endothelin-1. (f) In isolated cardiac fibroblasts WARP expression correlates with aSMA and (g) COL1 expression. (h) TGF $\beta$ stimulation of scrambled 


\section{Chapter 5}

control siRNA treated fibroblasts caused a significant decrease in extracellular bFGF protein levels, (i) whilst intracellular bFGF levels did not change. WARP knockdown alone did not affect extra-or intra-cellular bFGF levels but when cells were stimulated with TGF $\beta$ under knockdown conditions there was no significant decrease in extracellular bFGF levels anymore and a trend to increased intracellular bFGF levels was seen in the WARP-siRNA treated cells $(p=0.08) . n \geq 3 ;{ }^{*} p<0.05 ;{ }^{* * *} p<0.001 ;{ }^{* * * *} p<0.0001$

\section{In-house bred Australian C57BI/6-J WARP KO mice are protected from cardiac rupture and adverse infarct healing}

To further elucidate the role of WARP in cardiac remodeling after MI, we used the mouse model of permanent coronary occlusion in mice lacking WARP. WARP KO mice were backcrossed more than 10 times on a C57BI/6-J background in Australia, imported to Europe, bred in-house, and subjected to the ligation of the left descending coronary artery in parallel with commercial WT mice of the same KO mice showed significant improved survival as compared to commercial European WT mice 14 days after MI: 100\% of the in-house bred Australian WARP KO mice ( $n=13)$ survived while $40 \%$ of the commercial European WT mice (6 out of 15) died as a result of cardiac rupture (Fig. 3a). There were no differences in heart weight to body weight or lung weight to body weight ratios (Table 1). This improved survival was not caused by smaller or thinner infarcts in the in-house bred Australian WARP KO mice as histological analysis of the infarcted areas revealed slightly larger infarct sizes in the WARP KO mice (Table 1 and Figs. $3 \mathrm{~b}$ and c), which were equal in thickness (Table 1 and Fig. $3 b)$. In the in-house bred Australian WARP KO group, the infarcts contained more viable cells compared to the commercial European WT mice (Table 1 and Fig. 3b). Leukocyte infiltration or capillary density, as measured by the amount of CD45 positive leukocytes and CD31 positive capillaries in the remote and infarcted areas (Table 1), did not differ and could therefore not explain the improved cell viability in the infarcts of in-house bred Australian WARP KO mice. During proper infarct healing, collagen matures, and the fraction of thick, tightly cross-linked orange-red collagen fibers gradually replace the loosely assembled thin yellow-green fraction of collagen fibers ${ }^{5,29}$. Despite a significant difference in mortality due to cardiac rupture, analysis of Picro Sirius Red stained sections showed no difference in total collagen content in the infarcted areas between the two groups (Table 1). Furthermore, there was no difference in collagen maturation, as shown by the equal fractions of orange-red and yellow-green collagen fibers in the infarcts of in-house bred Australian WARP KO and the commercial European WT mice (Table 1).

Genetic background, and not the absence of WARP, determines predisposition to cardiac rupture

The Australian WARP KO mice were backcrossed on a European C57BI/6-J background (three times) and a myocardial infarction study was performed with these "Europeanized" WARP KO mice and their WT littermates, with all of them bred in-house. There 
were no significant differences in mortality between KO and WT mice anymore: $29 \%$ of the "Europeanized" WARP KO (4 out of 14) and 13\% of the WT littermates (2 out of 14) died due to cardiac rupture (Fig. 3d). Moreover, while the "Europeanized" WARP KO mice did worse after MI, the WT mice had improved survival due to the crossbreeding. In the mice surviving $\mathrm{MI}$, no difference in heart weight to body weight or lung weight to body weight ratios was seen (Table 2), and infarct size (Table 2 and Figs. 3e and f) and thickness (Table 2 and Fig. 3e) were equal in both groups. Furthermore, the amount of viable cells in the infarcted area and the amount of leukocytes, and capillary density in remote and infarcted tissue did not differ between both genotypes (Table 2 and Fig. $3 e)$. There was no difference in total collagen content and collagen maturation in the infarcts of the "Europeanized" WARP KO mice and WT littermates (Table 2). Finally, systolic function, as measured by echocardiography, was not different between the two groups (Table 3).

Table 1. Morphological and histological analysis in surviving commercial EU WT and in-house bred AUS WARP KO mice.

\begin{tabular}{|c|c|c|c|c|}
\hline & \multicolumn{2}{|c|}{ Sham } & \multicolumn{2}{|c|}{$\mathrm{Ml}$} \\
\hline & $\begin{array}{l}\text { EU WT com } \\
(n=4)\end{array}$ & $\begin{array}{l}\text { AUS WARP KO in- } \\
\text { house } \\
(n=4)\end{array}$ & $\begin{array}{l}\text { EU WT com } \\
(n=9)\end{array}$ & $\begin{array}{l}\text { AUS WARP KO in- } \\
\text { house } \\
(n=13)\end{array}$ \\
\hline HW / BW (mg/g) & $4.27 \pm 0.12$ & $3.94 \pm 0.18$ & $4.75 \pm 0.14$ & $4.80 \pm 0.26$ \\
\hline \multirow[t]{3}{*}{ LW / BW (mg/g) } & $6.56 \pm 0.58$ & $6.41 \pm 0.76$ & $6.64 \pm 0.44$ & $6.26 \pm 0.34$ \\
\hline & \multicolumn{2}{|c|}{ Remote } & \multicolumn{2}{|c|}{ Infarct } \\
\hline & $\begin{array}{l}\text { EU WT com } \\
(n=5)\end{array}$ & $\begin{array}{l}\text { AUS WARP KO in- } \\
\text { house } \\
(n=7)\end{array}$ & $\begin{array}{l}\text { EU WT com } \\
(n=5)\end{array}$ & $\begin{array}{l}\text { AUS WARP KO in- } \\
\text { house } \\
(n=7)\end{array}$ \\
\hline Infarct size (\%) & N.A. & N.A. & $39.10 \pm 2.433$ & $50.93 \pm 2.39^{\# \#}$ \\
\hline Infarct thickness (A.U.) & N.A. & N.A. & $100.00 \pm 19.50$ & $79.70 \pm 4.44$ \\
\hline Viable area (\%) & N.A. & N.A. & $15.45 \pm 0.60$ & $29.29 \pm 4.06^{\# \#}$ \\
\hline CD45 count (cells/mm²) & $26 \pm 5$ & $60 \pm 20$ & $274 \pm 36^{* *}$ & $200 \pm 55$ \\
\hline CD31 count (vessels $/ \mathrm{mm}^{2}$ ) & $1707 \pm 271$ & $2389 \pm 456$ & $118 \pm 27^{* *}$ & $169 \pm 58^{* * *}$ \\
\hline Collagen deposition (\%) & N.A. & N.A. & $61.17 \pm 4.12$ & $52.75 \pm 3.24$ \\
\hline $\begin{array}{l}\text { Fraction } O-R \text { thick/Y-G thin } \\
\text { collagen fibers }\end{array}$ & N.A. & N.A. & $\begin{array}{l}0.5 \pm 0.05 / \\
0.5 \pm 0.05\end{array}$ & $\begin{array}{l}0.4 \pm 0.05 / \\
0.6 \pm 0.05\end{array}$ \\
\hline
\end{tabular}

MI indicates myocardial infarction; EU European; AUS Australian; WT wild type; KO knock out; WARP Von Willebrand A domain related protein; com commercial; HW heart weight; BW body weight; LW lung weight; N.A. not applicable; A.U. arbitrary units; mm millimeter.

${ }^{\#} \mathrm{p} \leq 0.01$ WT vs KO Infarct; ${ }^{*} \mathrm{p} \leq 0.05 ;{ }^{*} \mathrm{p} \leq 0.01 ; * * * \mathrm{p} \leq 0.001$ Remote vs Infarct. 


\section{Figure 3}
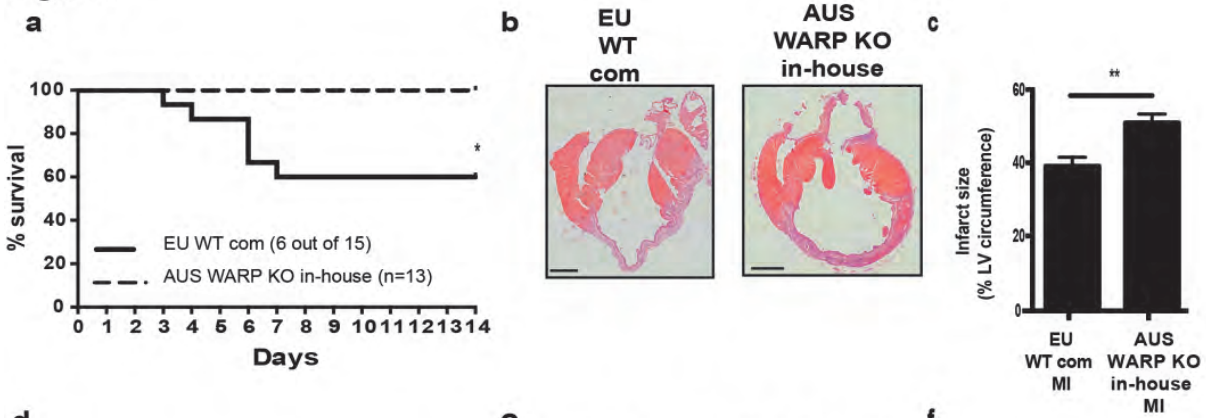

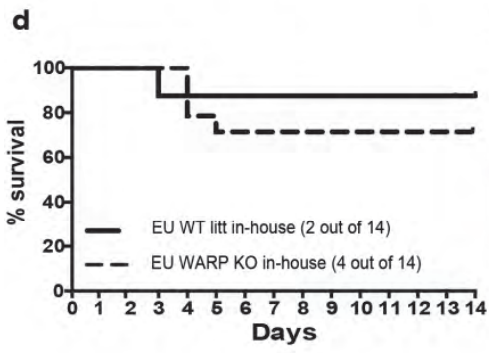

e
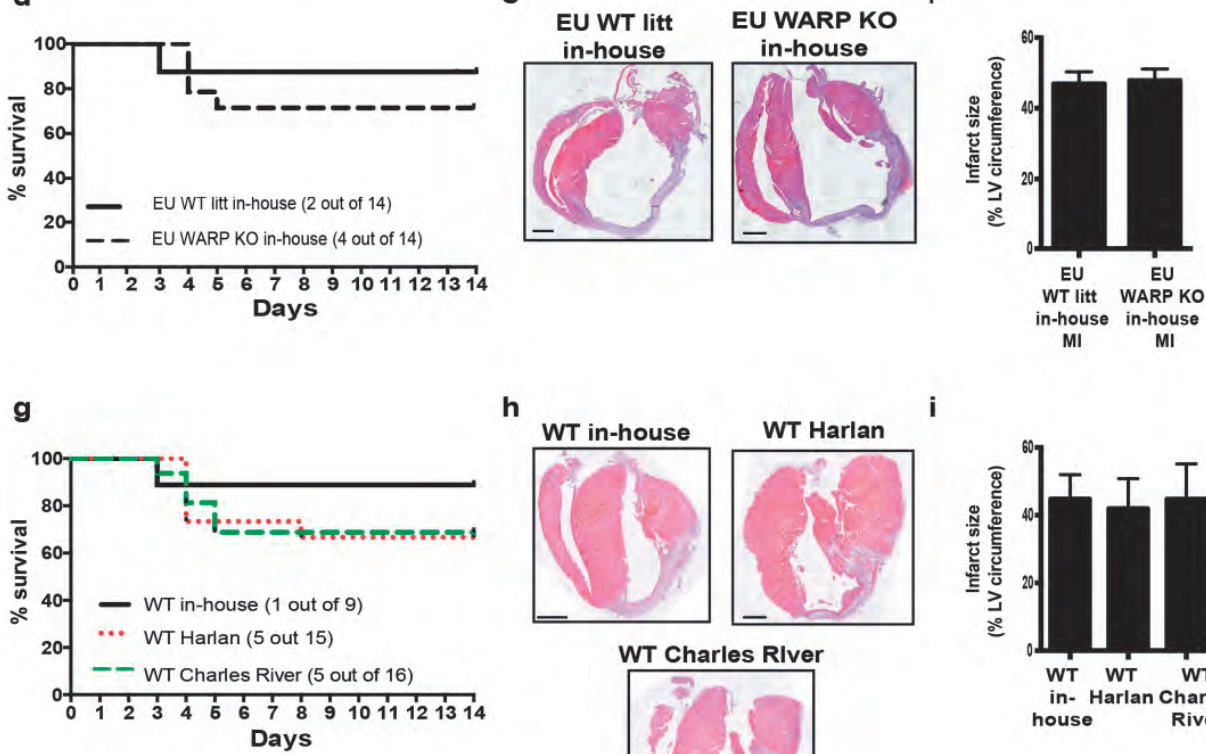

h

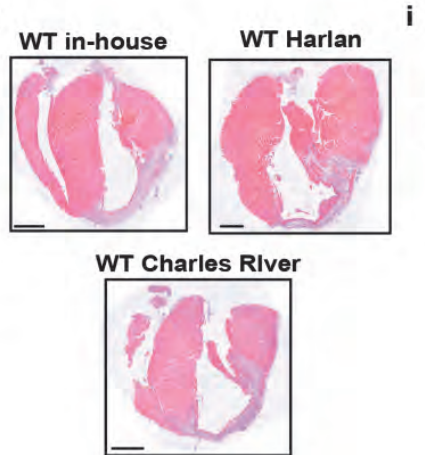

i

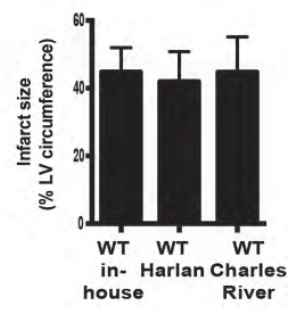

Figure 3. Genetic background, and not the absence of WARP, determines predisposition to cardiac rupture. (a) Improved survival in in-house bred Australian (AUS) WARP KO mice compared to commercial (com) European (EU) WT mice after an MI is shown by a Kaplan-Meier curve. (b \& c) Histological analysis of LV sections of infarcted hearts (hematoxylin-eosin stained) revealed larger infarct sizes in in-house bred AUS WARP KO mice compared to EU WT com mice. (d) There was no difference in survival anymore when AUS WARP KO mice were backcrossed to the European C57BI/6-J background and all mice were bred in-house. (e \& f) Infarct sizes are the same after mice were backcrossed to the European C57BI/6-J background. (g) Breeding/housing influences predisposition to cardiac rupture post-MI. WT mice bred in-house show improved survival after infarction when compared to commercial WT mice purchased from 2 different providers: Harlan and Charles River. (h\&i) Despite the difference in survival, no difference in infarct size was seen between in-house bred and commercially purchased WT mice. $n \geq 3 ;{ }^{*} p<0.05 ;{ }^{* *} p<0.01$; bars $1000 \mu \mathrm{m}$.

Interestingly, in the in-house bred WT colony littermates a different response post-MI was seen when compared with the commercially sourced WT mice, with less cardiac 
rupture (29\% vs $40 \%$ respectively) and slightly bigger infarct sizes ( $48 \%$ vs $39 \%$ respectively). This might not be solely related to the difference in continental origin and consecutive crossbreeding, but also to housing conditions, experimental variation or single nucleotide polymorphisms (SNPs) ${ }^{30}$. Therefore we compared the cardiac response following $\mathrm{MI}$ in our in-house colony WT mice with C57BL/6-J WT mice purchased from Harlan and also with C57BL6J WT mice purchased from Charles River, which have the same SNPs as Australian C57BLJ mice.

Commercial WT mice (from both Harlan and Charles River) continued to show higher mortality 14 days after MI: 33\% of the commercial WT mice from Harlan (5 out of 15) and $31 \%$ of the commercial WT mice from Charles River (5 out of 16) died while only 11 $\%$ of the in-house bred WT mice (1 out of 9) died as a result of cardiac rupture (Fig. 3g). There were no differences in heart weight to body weight or lung weight to body weight ratios (Table 4). The improved survival was not related to smaller or thinner infarcts as histological analysis of the infarcted areas revealed similar infarct sizes in all the WT mice (Table 4 and Figs. 3h and i), which were equal in thickness (Table 4 and Fig. 3h).

Table 2. Morphological and histological analysis in in-house bred EU WT litt and EU WARP KO mice.

\begin{tabular}{|c|c|c|c|c|}
\hline & \multicolumn{2}{|c|}{ Sham } & \multicolumn{2}{|c|}{$\mathrm{MI}$} \\
\hline & $\begin{array}{l}\text { EU WT litt } \\
\text { in-house } \\
(n=5)\end{array}$ & $\begin{array}{l}\text { EU WARP KO } \\
\text { in-house } \\
(n=7)\end{array}$ & $\begin{array}{l}\text { EU WT litt } \\
\text { in-house } \\
(n=12)\end{array}$ & $\begin{array}{l}\text { EU WARP KO } \\
\text { in-house } \\
(n=10)\end{array}$ \\
\hline HW / BW (mg/g) & $3.79 \pm 0.22$ & $4.10 \pm 0.08$ & $5.29 \pm 0.26^{\# \#}$ & $5.71 \pm 0.37^{\# \#}$ \\
\hline \multirow[t]{3}{*}{ LW / BW (mg/g) } & $6.22 \pm 0.32$ & $6.69 \pm 0.25$ & $8.20 \pm 1.12$ & $7.66 \pm 0.79$ \\
\hline & \multicolumn{2}{|c|}{ Remote } & \multicolumn{2}{|c|}{ Infarct } \\
\hline & $\begin{array}{l}\text { EU WT litt } \\
\text { in-house } \\
(n \geq 4)\end{array}$ & $\begin{array}{l}\text { EU WARP KO } \\
\text { in-house } \\
(n \geq 6)\end{array}$ & $\begin{array}{l}\text { EU WT litt } \\
\text { in-house } \\
(n \geq 4)\end{array}$ & $\begin{array}{l}\text { EU WARP KO } \\
\text { in-house } \\
(n \geq 6)\end{array}$ \\
\hline Infarct size (\%) & N.A. & N.A. & $47.96 \pm 4.91$ & $47.88 \pm 3.22$ \\
\hline Infarct thickness (A.U.) & N.A. & N.A. & $100.00 \pm 10.73$ & $93.56 \pm 10.85$ \\
\hline Viable area (\%) & N.A. & N.A. & $18.03 \pm 1.91$ & $11.36 \pm 3.30$ \\
\hline CD45 count (cells $/ \mathrm{mm}^{2}$ ) & $58 \pm 15$ & $90 \pm 16$ & $147 \pm 8^{*}$ & $155 \pm 69$ \\
\hline CD31 count (vessels $/ \mathrm{mm}^{2}$ ) & $1769 \pm 73$ & $1899 \pm 141$ & $86 \pm 21^{* * *}$ & $81 \pm 22^{* * *}$ \\
\hline Collagen deposition (\%) & N.A. & N.A. & $50.8 \pm 3.4$ & $51.8 \pm 3.3$ \\
\hline $\begin{array}{l}\text { Fraction } O-R \text { thick/Y-G thin } \\
\text { collagen fibers }\end{array}$ & N.A. & N.A. & $\begin{array}{l}0.4 \pm 0.04 / \\
0.6 \pm 0.04\end{array}$ & $\begin{array}{l}0.4 \pm 0.07 / \\
0.6 \pm 0.07\end{array}$ \\
\hline
\end{tabular}

MI indicates myocardial infarction; EU European; WT wild type; KO knock out; WARP Von Willebrand A domain related protein; com commercial; litt littermate; HW heart weight; BW body weight; LW lung weight; N.A. not applicable; A.U. arbitrary units; $m m$ millimeter.

${ }^{\#} \mathrm{p} \leq 0.05 ;{ }^{\# \#} \mathrm{p} \leq 0.01$ sham vs Ml; *p $\leq 0.05 ;{ }^{* * *} \mathrm{p} \leq 0.001$ Remote vs Infarct. 
Table 3. Functional analysis in in-house bred EU WT litt and EU WARP KO mice.

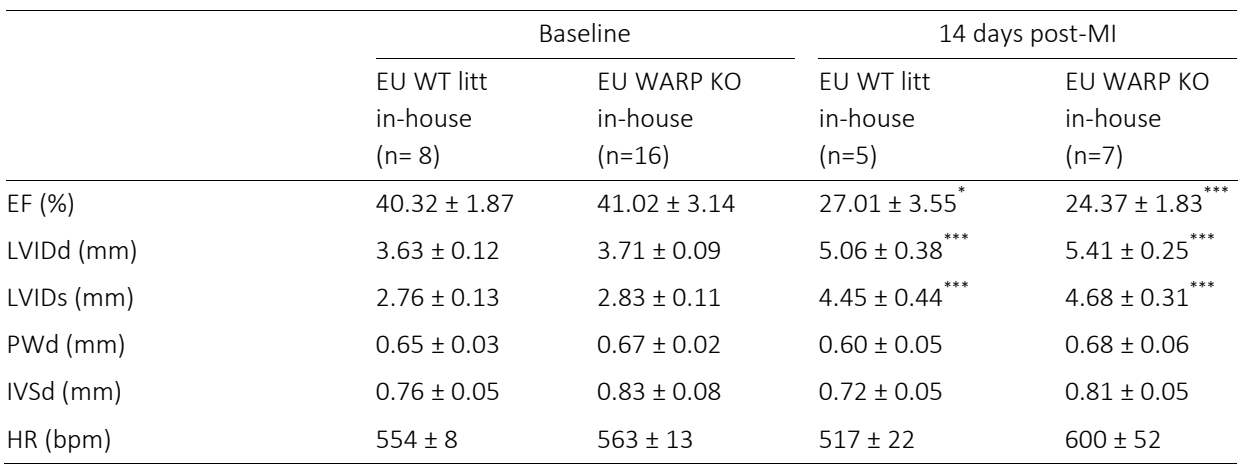

MI indicates myocardial infarction; EU European; WT wild type; KO knock out; WARP Von Willebrand A domain related protein; com commercial; litt littermate; EF ejection fraction; LVIDd left ventricular internal diameter diastolic; LVIDs left ventricular internal diameter systolic; PWd posterior wall diastolic; IVSd interventricular septum diastolic; HR heart rate; $\mathrm{mm}$ millimeter; bpm beats per minute. ${ }^{* *} p \leq 0.01 ;{ }^{* *} p \leq 0.001$ in baseline vs MI.

Table 4. Morphological and histological analysis of surviving infarcted WT mice bred in-house and of commercial source.

\begin{tabular}{llll}
\hline & $\begin{array}{l}\text { WT in-house } \\
(\mathrm{n}=8)\end{array}$ & $\begin{array}{l}\text { WT Harlan } \\
(\mathrm{n}=10)\end{array}$ & $\begin{array}{l}\text { WT Charles River } \\
(\mathrm{n}=11)\end{array}$ \\
\hline $\mathrm{HW} / \mathrm{BW}(\mathrm{mg} / \mathrm{g})$ & $5.08 \pm 0.30$ & $4.88 \pm 0.18$ & $4.63 \pm 0.15$ \\
$\mathrm{LW} \mathrm{/} \mathrm{BW}(\mathrm{mg} / \mathrm{g})$ & $8.92 \pm 1.51$ & $7.59 \pm 0.31$ & $8.69 \pm 1.08$ \\
Infarct size (\%) & $44.79 \pm 4.11$ & $41.93 \pm 3.13$ & $44.72 \pm 4.26$ \\
Infarct thickness (A.U.) & $100 \pm 5.18$ & $102.39 \pm 12.74$ & $91.32 \pm 7.41$ \\
\hline
\end{tabular}

HW heart weight; BW body weight; LW lung weight; A.U. arbitrary units

\section{DISCUSSION}

We hypothesized that WARP plays a role in the wound healing response following $\mathrm{MI}$ as WARP expression was induced at 3 and 7 days after $\mathrm{MI}$, in association with TGF $\beta$ induced myofibroblast transformation ${ }^{20,28}$. WARP expression correlated with aSMA and COL1 expression, 2 markers of fibroblast to myofibroblast transition, in vivo and in vitro, and WARP reduced extra- and intracellular bFGF, a growth factor shown to be protective in cardiac remodeling after $\mathrm{MI}^{19}$. We therefore assessed the role for WARP during cardiac remodeling in an $\mathrm{MI}$ model using in-house bred Australian C57BI/6-J WARP KO mice and commercial European WT C57BI/6-J mice. The results indicated a crucial role for WARP in cardiac remodeling as a consequence of ischemic heart disease yet subsequent experiments using "Europeanized" WARP KO and their WT littermates, all of them bred in-house, revealed that in fact the continental/breeding/housing origin was responsible for the previously seen protective effect in the WARP KO mice. In line, dif- 
ferences were observed in the commercial sourced WT mice and the in-house colony bred WT mice. Thus the breeding strategy of the mice, the continental and breeding origin in combination with the housing conditions, determined the rupture incidence and not the absence of WARP.

Earlier research already addressed the importance of the genetic background in susceptibility to CVD and exercise induced cardiac function and remodeling ${ }^{24,25,31-33}$. Van den Borne and colleagues studied the $\mathrm{Ml}$ model in 5 different mouse strains (BalbC, $\mathrm{C} 57 \mathrm{BI} / 6, \mathrm{FVB}, 129 \mathrm{S6}$, and Swiss) in order to determine which mouse strain is the best choice to study different aspects of ischemic heart disease. They concluded that the 12956 mouse is best to study infarct rupture, while BalbC and Swiss mice are better models to study infarct thinning after $\mathrm{Ml}^{34}$. Research done by Gorog and colleagues compared commercial outbred mice, i.e. mice that are maintained as closed colonies of genetically-variable composition, with WT offspring of 2 in-house bred heterozygous colonies of the same C57BI/6-J strain and showed a difference in susceptibility to global ischemia in Langendorff-perfused hearts ${ }^{35}$. Although now most researchers are aware of the importance of the genetic background of the inbred strain used in the generation of transgenic and knockout mice, there is insufficient recognition of the regional differences and substrain-variability that influences susceptibility to CVD in mice. Within the C57BI/6-J strain, there are genetic differences, which could be responsible for such a phenotype like we see in this study. Several distributors of the C57BI/6-J strain exist, where breeding stocks are kept separate, allowing the accumulation of genetic differences due to genetic drift and individual variability. Recently, Zurita and colleagues and Mekada and colleagues described genetic polymorphisms among C57BI/6 strains ${ }^{23,26}$. Among 1449 SNPs investigated, C57BI/6-J mice purchased from Harlan differ at 3 SNPs when compared to C57BI/6-J mice purchased from Australia or from Charles River ${ }^{23}$. Of these 3 SNPs, 1 is associated with the Naaladl2 ( $\mathrm{N}$-acetylated alpha-linked acidic dipeptidase-like 2) gene. This gene has not yet been annotated in mice and hence has no known molecular function. The 2 other SNPs are not associated with genes (information found at the SNPs collection of the Mouse Genome Database, phenome.jax.org/SNP/, at the Mouse Genome Informatics, www.informatics.jax.org/marker, and at ensembl.org). It is however unlikely that SNPS are responsible for the differences in rupture rates post $\mathrm{MI}$ seeing as mortality rates were similar in WT mice purchased from Harlan and from Charles River.

The use of genetically manipulated mice is a widespread tool to study the effects of a specific gene in models of cardiovascular disease (CVD). Thanks to intercontinental collaborations, air travel is commonplace these days for genetically manipulated mice, with numerous labs breeding their KO mice in-house and purchasing the WT mice from a commercial source. Unfortunately, the literature poorly describes breeding strategies, genetic backgrounds or the continental source of mice studied, thereby making it difficult to estimate how many studies have mistakenly attributed a phenotype. This study highlights the importance of implementing a breeding strategy that takes such factors 


\section{Chapter 5}

into consideration, stresses the importance of using the correct littermate controls and conveying this information in publications.

In summary, this study indicates a putative function for WARP in the cardiac fibroblast to myofibroblast transition, yet a redundant role in the acute healing process following MI. Finally, more importance should be paid to the continental and especially housing/breeding origin of mice used in research and may be another argument to reduce the use of animals in cardiovascular research.

\section{MATERIALS AND METHODS}

In vitro experiments in neonatal rat cardiac fibroblasts and myocytes

Cardiac fibroblasts and myocytes were isolated by enzymatic disassociation from 2-dayold neonatal Lewis rats as previously described ${ }^{36}$. The Animal Care and Use Committee of the University of Leuven approved the described study protocols. Experiments were performed according to the official rules formulated in the Belgian law on the care and use of experimental animals and all efforts were made to minimize suffering (License number 161/2011). For experiments, second-passage cardiac fibroblasts (70-90\% confluent) and freshly isolated cardiomyocytes in 6-well plates were used. The cardiac fibroblasts were maintained in medium (DMEM 22320, Invitrogen) supplemented with $10 \%$ fetal bovine serum (FBS) and 1\% penicillin-streptomycin and the cardiomyocytes were maintained in medium (80\% DMEM 11966, 20\% M199, Invitrogen) supplemented with $0.2 \%$ glucose, $0.125 \%$ gentamycin, $1.25 \%$ penicillin-streptomycin and $10 \%$ bovine serum albumin. Both cell types were incubated at $37^{\circ} \mathrm{C}$ in a humidified chamber. The day before an experiment, the cardiac cells were starved overnight in DMEM without antibiotics or serum. After starvation, cardiomyocytes were stimulated with ET-1 $(10 n M)$, for 24 hours and thereafter supernatants were collected and cells were lysed and collected in radioimmunoprecipitation assay (RIPA) buffer containing $2 \%$ phosphatase-inhibitors and 4\% protease-inhibitors for protein isolation or in RLT buffer (QIAGEN) containing 1\% $\beta$-mercapto-ethanol for RNA isolation. After starvation of the cardiac fibroblasts, WARP mRNA expression was reduced, by treatment of the cells with siRNA against WARP (Invitrogen) for 4 hours, or with negative control siRNA (Invitrogen) for control samples. Equal volumes of siRNA and lipofectamine (Invitrogen) were mixed $1 / 50$ in Optimem (Invitrogen) and $500 \mu \mathrm{l}$ of this mixture was added to the $1.5 \mathrm{ml}$ of medium on the cells. After 4 hours, the medium of the cardiac fibroblasts was diluted $1 / 1$ with DMEM containing $0.5 \%$ FBS and $1 \%$ penicillin-streptomycin. The next day, the medium was refreshed and 4 hours later the fibroblasts were treated with $1 \mathrm{ng} / \mathrm{ml}$ transforming growth factor $\beta$ (TGF $\beta$ ) (PeproTech) for 24 hours. Supernatants and cells were collected as described for cardiomyocytes. 


\section{Mouse models}

The Animal Care and Use Committee of the University of Leuven approved all described study protocols. Experiments were performed according to the official rules formulated in the Belgian law on the care and use of experimental animals (License number 121/2008). All surgery was performed under ketamine and xylazine anesthesia at a dose of $100 \mathrm{mg} / \mathrm{kg}$ and $10 \mathrm{mg} / \mathrm{kg}$ respectively, and all efforts were made to minimize suffering. Experimental $\mathrm{Ml}$ and sham operation were performed as previously described ${ }^{37}$. Briefly, animals were anesthetized, fixed in the supine position and after tracheal intubation, positive pressure respiration was initiated (MiniVent Ventilator; Harvard Apparatus). Pectoral muscles were dissected and retracted. Left thoracotomy was performed in the fourth intercostal space and after opening of the pericardium, the left anterior descending artery was ligated. Infarction was evident from discoloration of the distal myocardial tissue. After layered closure of intercostal muscles and skin, the animals recovered at $37^{\circ} \mathrm{C}$. Sham-operated animals were subjected to similar surgery but no ligature was placed. Death within $24 \mathrm{~h}$ was considered a complication of surgery or due to cardiogenic shock (fatal MI); these animals (<5\%) were excluded from further analysis. Only animals with infarct sizes $>25 \%$ were included in the final analysis. WT C57BI/6-J mice were purchased from Harlan (Europe), Charles River (Europe), and WARP KO C57BI/6-J mice were kindly provided by Professor JF Bateman. These WARP KO C57BI/6-J mice resulted from heterozygous breeding of WARP +/- mice, termed Vwa1+/-, which were produced under contract by Ozgene Pty Ltd., Western Australia and backcrossed on a C57BI/6-J background more than 10 times. For an MI time series 18 WT mice purchased from Harlan on the European C57BI/6-J background of 7 to 13 weeks old were used and mice were sacrificed after 3, 7 or 14 days. For the first MI study, 20 WT mice of commercial European C57BI6/J origin (Harlan) and 20 WARP KO mice of Australian origin, bred in-house, (7 to 13 weeks) were used; all experiments were performed using gender and age-matched mice and mice were sacrificed after 14 days. Next, WARP KO mice were backcrossed $3 \times$ on the European C57BI/6-J background and bred heterozygous in-house. A new MI study using 21 WARP KO mice and 21 WT littermates ( 9 to 15 weeks) was performed. MI and sham operation were performed as in the first experiments and mice were sacrificed after 14 days. Finally, an MI study using 9 in-house bred WT mice, 15 WT mice purchased from Harlan and 16 WT mice purchased from Charles River ( 6 to 12 weeks) was performed as in the first experiments and mice were sacrificed after 14 days. In all experiments, hearts and lungs were removed, and hearts were prepared for molecular and histological analysis. Humane endpoints were used during all experiments: animals were monitored daily for grade of activity, healing of the surgical wound, weight loss, normal breathing and absence of ruffled fur, but no mice needed to be sacrificed prior to experimental endpoints. Mice that died during the experiment, died suddenly from cardiac rupture. 


\section{Histology and microscopy}

Cardiac tissue was processed and histochemical and immunohistochemical analyses were performed as previously described ${ }^{37-39}$, and all morphometric analyses were done on midsagittal sections. Hematoxylin and eosin - stained sections ( $4 \mu \mathrm{m})$ were used to assess the infarct size, infarct thickness and residual viable area. Percentage of infarct size was expressed as the fractional circumference of the infarcted versus infarcted plus non-infarcted left ventricle (LV) wall and septum, which was assessed by measuring the midline circumference of the LV. Infarct thickness was measured as the mean of 12 measurements across the infarcted LV wall. Residual viable area was determined as the percentage of the total infarcted area. The number of CD-45 - staining cells (monoclo-

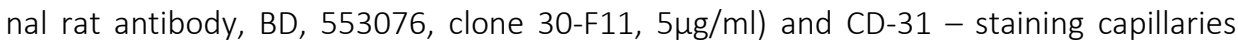
(monoclonal rat antibody, BD, 557355, clone MEC13.3, $1 \mu \mathrm{g} / \mathrm{ml}$ ) in the infarct zone was measured per $\mathrm{mm}^{2}$. For colocalization studies, sections were stained for WARP (polyclonal goat antibody, R \& D Systems, AF4927, antigen NSO-derived rmWARP isoform1, $2 \mu \mathrm{g} / \mathrm{ml}$ ), perlecan (monoclonal rat antibody, Millipore, MAB19480, clone A7L6, $1 \mu \mathrm{g} / \mathrm{ml}$ ),

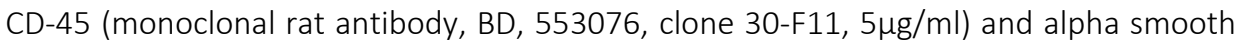
muscle cells (monoclonal mouse antibody, Sigma, C6198, clone 1A4, 1 $\mu \mathrm{g} / \mathrm{ml}$ ) and subsequently incubated with Biotin-labeled secondary antibodies followed by amplification with the signal amplification system (streptavidin-HRP-C-fluorescein/Cy3; PerkinElmer). Nuclei were stained with DAPI (Invitrogen). To assess the amount of the newly formed collagen matrix, Picro Sirius Red staining was performed as previously described ${ }^{39,40}$. Microscopic analyses were performed using a microscope (Leitz DMRXE; Leica), and QWin morphometry software (Leica). Confocal microscopy was performed on a Zeiss CLSM 510 Meta NLO microscope (Leica) using the Zen software (Leica). All analyses were performed according to standard operating procedures.

\section{RNA isolation and expression}

RNA was isolated from sham and infarcted tissue or cell lysates with the RNeasy Mini kit (QIAGEN) according to the manufacturer's guidelines and was stored at $-80^{\circ} \mathrm{C}$. RNA was reverse transcribed into complementary DNA with the iScript cDNA synthesis kit (BioRad) according to the manufacturer's instructions. Real-time quantitative PCR was performed with SYBR green PCR Master mix (Applied Biosystems). Primers were designed with primer-BLAST (NCBI) and built to contain an intron- exon boundary. Primers were designed for mouse WARP (5'GATCTTCCTATCATTGCCCG3'; 5'AAGCCACTGGACAGAACCTC3'), rat WARP (5'AGCTCCGGCTGAGAAGCACCT3'; 5'GGCTGCATCGCATCAATAATGGCAC3'), mouse aSMA (5'GTCCCAGACATCAGGGAGTAA3'; 5'TCGGATACTTCAGCGTCAGGA3'), rat aSMA (5'GTCCCAGACACCAGGGAGTGA3'; 5'TCGGATACTTCAGGGTCAGGA3'), mouse COL1 (5'CTTCACCTACAGCACCCTTGTG3'; 5' CTTGGTGGTTTTGTATTCGATGAC3'), rat COL1 (5' CCGCCCGCACATGC3'; 5' CTCCATGTTGCAGTAGACCTTGAT3'), and mouse GAPDH 
(5'GGTGGACCTCATGGCCTACA3'; 5'TCGTTCCTGTGACTCGTTCTCTC3') or rat GAPDH (5'GGTGGACCTCATGGCCTACA3'; 5'TCGTTCCTATGACTCTCGTTCTCTC3') were used as housekeeping gene.

\section{Western Blotting}

Proteins in sham, remote, and infarcted tissue were separated by SDS-PAGE and were subsequently immunoblotted for the detection of WARP (polyclonal goat antibody, R\&D systems, AF4927, antigen NSO-derived rmWARP isoform $1,0.2 \mu \mathrm{g} / \mathrm{ml}$ ) and GAPDH (mon-

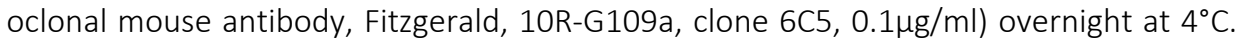
Signals were visualized using Hyperfilm ECL (Amersham Biosciences) and quantified using Image J software. Protein levels were expressed relative to protein levels of GAPDH.

\section{bFGF- ELISA}

To release and quantify extracellular bFGF in fibroblast cultures, the supernatants were removed and fibroblasts were incubated with $0.25 \mathrm{ml}$ of $20 \mathrm{mM}$ Tris- $\mathrm{HCl}(\mathrm{pH} \mathrm{7.2)}$ and 2 $\mathrm{M} \mathrm{NaCl}$ for 2 min as previously described ${ }^{41}$. The bFGF in this medium was quantified using a bFGF detection ELISA kit (R\&D Systems, DFB50) according to the manufacturer's instructions. The fibroblasts remaining were lysed and collected in RIPA buffer as described above and used to quantify intracellular bFGF in the same ELISA as described above.

\section{Echo analysis}

Mice were anesthetized ( $2 \%$ isoflurane, ecuphar) and echocardiograpy was performed at day 0 and day 14 by transthoracic echocardiography with a 13-MHz transducer (i13L, GE ultrasound; Horton Norway) on a Vingmed Vivid 7 scanner (GE ultrasound, Horton, Norway). Heart rate (HR) and LV diameters at end-diastole (LVIDd), end-systole (LVIDs), septal wall thickness (ISd), LV posterior wall thickness in end diastole (PWd), were measured, and ejection fraction (EF) was calculated.

\section{Statistical analysis}

Data were expressed as the mean \pm SEM. For echocardiographic measurements repeated measures were performed. Histological and molecular analyses in sham-operated and infarcted groups were performed in independent groups. Normal distribution of all continuous variables was tested according to the method of Kolmogorov and Smirnov. An unpaired Student' $s$ t test for 2 groups or ANOVA, followed by a Bonferroni post hoc test for more groups was used in most of the comparisons when groups passed the 


\section{Chapter 5}

normality test. When the standard deviation of two groups significantly differed, a Mann-Whitney test for 2 groups or a Kruskal-Wallis test, followed by a Dunn's post hoc test for more groups, was used. For correlations, the Pearson correlation coefficient was calculated when variables passed normality test, or a Spearman correlation coefficient was calculated when the standard deviation of the groups significantly differed. A paired Student's t test was used to analyze baseline and follow-up echocardiographic measurements. The survival curve after MI was obtained by the Kaplan-Meier method and compared by the log-rank test. A two-sided $p$-value of $\leq 0.05$ was considered statistically significant.

\section{ACKNOWLEDGMENTS}

This research was funded by a CARIM-funded PhD grant, by ZonMW MKMD: To publish negative or neutral animal experimental data-module amendment 21, and by the European Commission's grants Nº 602904 (FIBROTARGETS), N²61409 (MEDIA), and the CVON 2011 (ARENA). 


\section{REFERENCES}

1 Go, A. S. et al. Executive summary: heart disease and stroke statistics--2013 update: a report from the American Heart Association. Circulation 127, 143-152, doi:10.1161/CIR.0b013e318282ab8f (2013).

2 Lindsey, M. L., Mann, D. L., Entman, M. L. \& Spinale, F. G. Extracellular matrix remodeling following myocardial injury. Ann Med 35, 316-326 (2003).

3 Schroen, B. et al. Thrombospondin-2 is essential for myocardial matrix integrity: increased expression identifies failure-prone cardiac hypertrophy. Circ Res 95, 515-522, doi:10.1161/01.RES.0000141019. 20332.3e (2004).

4 Swinnen, M. et al. Absence of thrombospondin-2 causes age-related dilated cardiomyopathy. Circulation 120, 1585-1597, doi:10.1161/CIRCULATIONAHA.109.863266 (2009).

5 Schellings, M. W. et al. Absence of SPARC results in increased cardiac rupture and dysfunction after acute myocardial infarction. J Exp Med 206, 113-123, doi:10.1084/jem.20081244 (2009).

6 Van Aelst, L. N. et al. Osteoglycin Prevents Cardiac Dilatation and Dysfunction After Myocardial Infarction Through Infarct Collagen Strengthening. Circulation research, doi:10.1161/CIRCRESAHA.116.304599 (2014).

7 Fitzgerald, J., Tay Ting, S. \& Bateman, J. F. WARP is a new member of the von Willebrand factor A-domain superfamily of extracellular matrix proteins. FEBS Letters 517, 61-66 (2002).

8 Allen, J. M., Brachvogel, B., Farlie, P. G., Fitzgerald, J. \& Bateman, J. F. The extracellular matrix protein WARP is a novel component of a distinct subset of basement membranes. Matrix Biol 27, 295-305, doi:10.1016/j.matbio.2008.01.005 (2008).

9 Allen, J. M. et al. WARP is a novel multimeric component of the chondrocyte pericellular matrix that interacts with perlecan. J Biol Chem 281, 7341-7349, doi:10.1074/jbc.M513746200 (2006).

10 Arikawa-Hirasawa, E., Watanabe, H., Takami, H., Hassell, J. R. \& Yamada, Y. Perlecan is essential for cartilage and cephalic development. Nat Genet 23, 354-358, doi:10.1038/15537 (1999).

11 Sasse, P. et al. Perlecan is critical for heart stability. Cardiovasc Res 80, 435-444, doi:10.1093/cvr/cvn225 (2008).

12 Costell, M. et al. Perlecan maintains the integrity of cartilage and some basement membranes. J Cell Biol 147, 1109-1122 (1999).

13 Whitelock, J. M., Melrose, J. \& lozzo, R. V. Diverse cell signaling events modulated by perlecan. Biochemistry 47, 11174-11183, doi:10.1021/bi8013938 (2008).

14 Zachary, I. \& Morgan, R. D. Therapeutic angiogenesis for cardiovascular disease: biological context, challenges, prospects. Heart 97, 181-189, doi:10.1136/hrt.2009.180414 (2011).

15 Liao, S. et al. Biological functions of the low and high molecular weight protein isoforms of fibroblast growth factor-2 in cardiovascular development and disease. Dev Dyn 238, 249-264, doi:10.1002/ dvdy.21677 (2009).

16 Detillieux, K. A., Sheikh, F., Kardami, E. \& Cattini, P. A. Biological activities of fibroblast growth factor-2 in the adult myocardium. Cardiovasc Res 57, 8-19 (2003).

17 Zentilin, L. et al. Cardiomyocyte VEGFR-1 activation by VEGF-B induces compensatory hypertrophy and preserves cardiac function after myocardial infarction. Faseb J 24, 1467-1478, doi:10.1096/fj.09-143180 (2010).

18 Tao, Z. et al. Coexpression of VEGF and angiopoietin-1 promotes angiogenesis and cardiomyocyte proliferation reduces apoptosis in porcine myocardial infarction (MI) heart. Proc Natl Acad Sci U S A 108, 2064-2069, doi:10.1073/pnas.1018925108 (2011).

19 Virag, J. A. et al. Fibroblast growth factor-2 regulates myocardial infarct repair: effects on cell proliferation, scar contraction, and ventricular function. Am J Pathol 171, 1431-1440, doi:10.2353/ajpath. 2007.070003 (2007).

20 Fedak, P. W. et al. Cell therapy limits myofibroblast differentiation and structural cardiac remodeling: basic fibroblast growth factor-mediated paracrine mechanism. Circulation. Heart failure 5, 349-356, doi:10.1161/CIRCHEARTFAILURE.111.965889 (2012). 
21 Hansen, U. et al. WARP interacts with collagen VI-containing microfibrils in the pericellular matrix of human chondrocytes. PLoS One 7, e52793, doi:10.1371/journal.pone.0052793 (2012).

22 Allen, J. M. et al. Mice lacking the extracellular matrix protein WARP develop normally but have compromised peripheral nerve structure and function. J Biol Chem 284, 12020-12030, doi:10.1074/ jbc.M806968200 (2009).

23 Zurita, E. et al. Genetic polymorphisms among C57BL/6 mouse inbred strains. Transgenic Res 20, 481489, doi:10.1007/s11248-010-9403-8 (2011).

24 Gorog, D. A. et al. Varying susceptibility to myocardial infarction among C57BL/6 mice of different genetic background. J Mol Cell Cardiol 35, 705-708 (2003).

25 van den Borne, S. W. et al. Mouse strain determines the outcome of wound healing after myocardial infarction. Cardiovasc Res 84, 273-282, doi:10.1093/cvr/cvp207 (2009).

26 Mekada, K. et al. Genetic differences among C57BL/6 substrains. Exp Anim 58, 141-149 (2009).

27 Goldsmith, E. C., Bradshaw, A. D., Zile, M. R. \& Spinale, F. G. Myocardial fibroblast-matrix interactions and potential therapeutic targets. Journal of molecular and cellular cardiology 70, 92-99, doi:10.1016/j.yjmcc. 2014.01.008 (2014).

28 Sun, Y. \& Weber, K. T. Infarct scar: a dynamic tissue. Cardiovascular research 46, 250-256 (2000).

29 Fomovsky, G. M. \& Holmes, J. W. Evolution of scar structure, mechanics, and ventricular function after myocardial infarction in the rat. Am J Physiol Heart Circ Physiol 298, H221-228, doi:10.1152/ajpheart .00495 .2009 (2010).

30 Zurita, E. et al. Genetic polymorphisms among C57BL/6 mouse inbred strains. Transgenic research 20, 481-489, doi:10.1007/s11248-010-9403-8 (2011).

31 Barnabei, M. S., Palpant, N. J. \& Metzger, J. M. Influence of genetic background on ex vivo and in vivo cardiac function in several commonly used inbred mouse strains. Physiol Genomics 42A, 103-113, doi:10.1152/physiolgenomics.00071.2010 (2010).

32 Shah, A. P. et al. Genetic background affects function and intracellular calcium regulation of mouse hearts. Cardiovasc Res 87, 683-693, doi:10.1093/cvr/cvq111 (2010).

33 Lerman, I. et al. Genetic variability in forced and voluntary endurance exercise performance in seven inbred mouse strains. Journal of applied physiology 92, 2245-2255, doi:10.1152/japplphysiol.01045.2001 (2002).

34 van den Borne, S. W. et al. Mouse strain determines the outcome of wound healing after myocardial infarction. Cardiovasc Res 84, 273-282, doi:cvp207 [pii]

10.1093/cvr/cvp207 (2009).

35 Gorog, D. A. et al. Varying susceptibility to myocardial infarction among C57BL/6 mice of different genetic background. J Mol Cell Cardiol 35, 705-708, doi:S0022282803000828 [pii] (2003).

36 De Windt, L. J. et al. Cloning and cellular distribution of a group II phospholipase A2 expressed in the heart. J Mol Cell Cardiol 29, 2095-2106, doi:S0022-2828(97)90444-2 [pii]

10.1006/jmcc.1997.0444 (1997).

37 Lutgens, E. et al. Chronic myocardial infarction in the mouse: cardiac structural and functional changes. Cardiovasc Res 41, 586-593 (1999).

38 Heymans, S. et al. Inhibition of plasminogen activators or matrix metalloproteinases prevents cardiac rupture but impairs therapeutic angiogenesis and causes cardiac failure. Nat Med 5, 1135-1142, doi:10.1038/13459 (1999).

39 Vanhoutte, D. et al. Increased expression of syndecan-1 protects against cardiac dilatation and dysfunction after myocardial infarction. Circulation 115, 475-482, doi:10.1161/CIRCULATIONAHA.106. 644609 (2007).

40 Junqueira, L. C., Bignolas, G. \& Brentani, R. R. Picrosirius staining plus polarization microscopy, a specific method for collagen detection in tissue sections. Histochem J 11, 447-455 (1979).

41 Khalil, N., Xu, Y. D., O'Connor, R. \& Duronio, V. Proliferation of pulmonary interstitial fibroblasts is mediated by transforming growth factor-beta1-induced release of extracellular fibroblast growth factor-2 and phosphorylation of p38 MAPK and JNK. J Biol Chem 280, 43000-43009, doi:M510441200 [pii] 10.1074/jbc.M510441200 (2005). 


\section{SUPPLEMENTARY FIGURES}

\section{S Figure 1}

\section{WARP $(48 \mathrm{kD})$ blots}
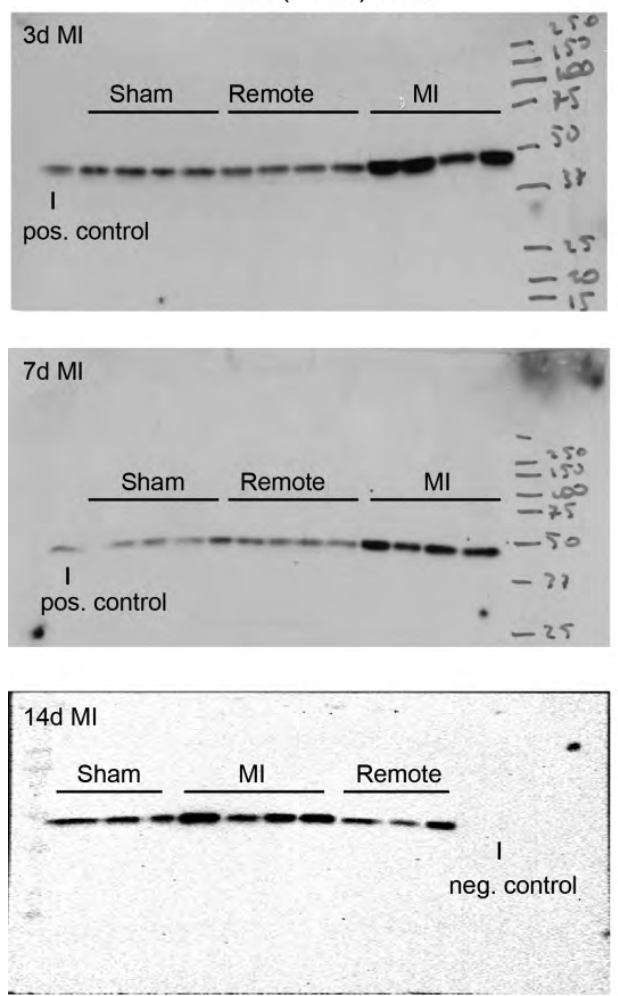

GAPDH (37kD) blots
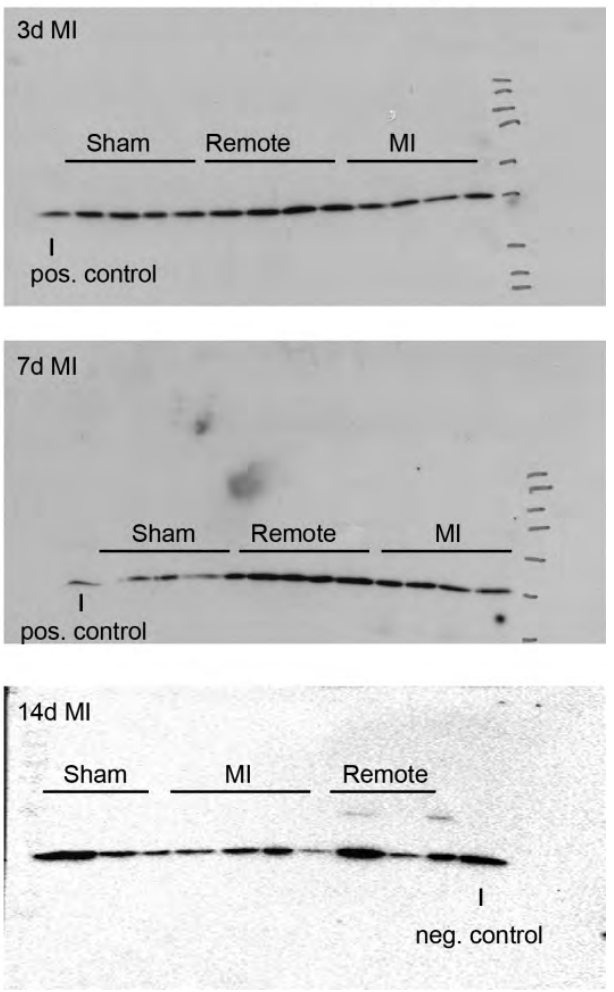

S Figure 1. Original unadjusted blots for WARP expression pattern in the heart. 

Chapter

General Discussion 


\section{Chapter 6}

It is only 4 decades ago that people broadened their horizon moving away from the cardiac cellular component to take a closer look at the extracellular matrix ${ }^{1}$. It took 20 more years to conclude that the cardiac ECM is more than collagen types I and III, which are important for the transmission of mechanical forces and overall tissue stiffness, and that the ECM is in fact a dynamic entity where changes in its structures are important in the development of $\mathrm{HF}^{2}$. Further research revealed that the ECM is a complex meshwork of not only structural proteins like collagens, but it also comprises non-structural proteins and sugars. Matrix glycoproteins and proteoglycans are now well recognised as important modulators of many processes, including matrix homeostasis, inflammation, and myocyte survival.

In this thesis the contribution of the proteoglycan, OGN, and 2 glycoproteins, SPARC and WARP, in HF was explored. Previous work demonstrated an important role for OGN and SPARC in scar maturation following $\mathrm{MI}^{5,6}$. Here we describe novel functions for OGN and SPARC in the failing heart. In Chapter 3 OGN is identified to be critical in preventing the development of diastolic dysfunction and HF by modulating fibroblast proliferation and cardiac fibrosis upon ageing and hypertension. Chapter 4 describes a novel inotropic function for SPARC, demonstrating that extracellular SPARC directly improves cardiomyocyte contraction and cardiac systolic function in both health and disease. Finally, this thesis demonstrates a redundant role for WARP in post-infarct healing, yet it reveals how crucial breeding strategies of mice are in cardiovascular research, and it demonstrates the importance of using the right controls when investigating infarct- healing.

\section{DECIPHER DIASTOLIC DYSFUNCTION - MATRIX MATTERS}

$\mathrm{HFpEF}$ and diastolic dysfunction represent one of the most challenging clinical problems in cardiology, as modern pharmacotherapies do not improve outcome, in contrast to systolic HF. Recently a new paradigm for HFpEF was presented in which it was proposed that it is the comorbidities that drive the structural, functional and signalling changes in the heart, through systemic endothelial inflammation ${ }^{8}$. A pro-inflammatory state of the coronary endothelium results in increased production of reactive oxygen species, which limits NO availability for adjacent cardiomyocytes. This results in turn in increased cardiomyocyte hypertrophy and in decreased titin phosphorylation and hence cardiomyocyte stiffness. In addition, endothelial inflammation is also associated with myocardial capillary rarefaction, adding to the oxidative stress and resulting cardiomyocyte hypertrophy and -stiffness. Moreover, coronary endothelial inflammation promotes migration of leukocytes, which stimulate myofibroblast formation and matrix deposition. In concert, both cardiomyocyte stiffness and interstitial fibrosis provoke diastolic dysfunction and the onset of diastolic $\mathrm{HF}^{8}$. 
This thesis did not include comorbidities such as overweight/obesity, diabetes mellitus, and chronic obstructive pulmonary disease, but investigated OGN in age-and hypertensive induced cardiac remodelling. Ageing in old sham and hypertensive mice went in line with concentric cardiac remodelling and increased cardiac fibrosis but without significant diastolic dysfunction. Importantly, the absence of OGN further increased concentric remodelling and collagen deposition, resulting in severe diastolic dysfunction and pulmonary congestion. Thus, the presence of OGN protects against the development of diastolic dysfunction and its progression to diastolic $\mathrm{HF}$ in hypertensive/aged mice. Furthermore, this thesis demonstrates increased presence of OGN upon hypertensive- induced matrix deposition in the heart, where the presence of OGN reduces fibroblast proliferation and cardiac fibrosis both in vivo and in vitro, and as such protects against the development of diastolic dysfunction and its progression to HF upon hypertension and ageing. In addition, no role for OGN on cardiomyocyte stiffness or hypertrophy could be demonstrated, while endothelial dysfunction and inflammation, and oxidative stress were not studied. The absence of differences in myocyte hypertrophy and -stiffness might indicate no immediate role for OGN in oxidative stress and endothelial inflammation or rarefaction, but this needs further investigation. Given the high diversity in structure and function of OGN, as discussed in chapter 2, where OGN has been implicated in cell proliferation and has been linked with immunity, it is not unlikely that OGN might also play a role in cardiac inflammation upon ageing and hypertension. Interestingly, OGN was shown to be an NFKB/IKK-dependent gene ${ }^{9}$ and Angll mediates its inflammatory effect, at least in part, through NFKB activation and the subsequent production of inflammatory mediators including IL-6 and IL-1beta ${ }^{10}$. Moreover, in the absence of OGN, we did see increased leukocyte presence in the heart upon age- and hypertensive induced cardiac remodelling. Hence, an additional effect of extracellular OGN on leukocyte recruitment, activation or proliferation, besides reducing fibroblast proliferation and fibrosis, is possible, but has yet to be established.

Interestingly, OGN has also been implicated in the metabolic syndrome, another important comorbidity of HFpEF, next to hypertension and ageing. Increased levels OGN were found in human obese subjects, when compared to non-obese people, and in general more OGN abundance was found in subcutaneous adipose tissue than in visceral adipose tissue ${ }^{11}$. Moreover, a recent study identified OGN as a satiety hormone in adipose tissue, where it is highly expressed and secreted into the circulation. ImportantIy, administered OGN limited food intake in this study in mice, possibly by increasing IL1 beta and IL-6 expression in the hypothalamus, but independent of leptin signaling ${ }^{12}$. In addition, a study on quantitative trait loci (QLT) relevant to the metabolic syndrome in spontaneous hypertensive rats identified OGN as a QTL on chromosome 17 as a candidate regulator of left ventricular (LV) mass ${ }^{13,14}$. However, despite many studies implicating OGN in the metabolic syndrome, an actual role for OGN in the pathogenesis of the metabolic syndrome and HFpEF remains to be demonstrated. 


\section{Chapter 6}

Nevertheless, this thesis identifies OGN as a novel protective factor against diastolic dysfunction of aged-hypertensive origin and hence opens new windows to target/prevent diastolic dysfunction upon hypertension and ageing, by targeting or mimicking compounds of the extracellular matrix, such as OGN. Some drugs targeting matrix components, for example MMP-9 inhibitors, are already under evaluation to treat diastolic HF and HFpEF ${ }^{15}$. MMP-9 is, like OGN, important for matrix homeostasis, and in mice, MMP-9 levels increase with ageing and precede the development of diastolic dysfunction, whereas genetic deletion of MMP-9 attenuates this effect, in part by regulating matrix remodelling ${ }^{16}$. Importantly, currently treatment for HFpEF and systolic HF are the same, however, a number of recent clinical trials have demonstrated that treatment is less effective or even ineffective in HFpEF patients ${ }^{15}$. Given the heterogeneity of HFpEF patients, stratification of patients into subgroups is required, as identification of patient-specific structural and functional abnormalities could help in treatment selection to increase therapeutic responsiveness. Importantly, this will also further improve the development of new therapeutic strategies for HFpEF and diastolic dysfunction ${ }^{7}$, such as targeting OGN, as clinical trials with selected patient populations will demonstrate specific patient-subgroup responsiveness and no longer fail to reach statistical significance due to the heterogeneity of the patient population.

\section{THE EXTRACELLULAR MATRIX SPARCS CARDIAC CONTRACTION}

VM is an important precursor of sudden cardiac death, dilated cardiomyopathy, and (acute) HF in young healthy adults. Under these clinical conditions, often inotropes are administered to support cardiac function and enhance cardiac output. Inotropes have become a cornerstone in the management of conditions with systolic dysfunction ${ }^{18}$, yet over the last decades, the number of newly developed inotropes has been surprisingly low and hence, current drug selection is limited ${ }^{19}$. Inotropes improve cardiac contraction by either mobilizing calcium or increasing calcium sensitivity of the cardiomyocytes. Importantly, the strategy of increasing contraction through increasing intracellular calcium contents comes at a cost: 1) it increases oxygen consumption, needed for reinternalization of calcium during diastole, which might be dangerous in ischemic patients, 2) some inotropes have a chronotropic effect further increasing oxygen demand, 3) while other drugs induce phosphorylation of troponin, which results in calcium-desensitization and hence less efficient contraction, 4) furthermore it might cause disturbed intracellular calcium levels, leading to arrhythmias and 5) it might even cause impaired relaxation ${ }^{19}$. This is illustrated by two meta-analyses on the mid- to long-term use of 2 calcium mobilizers, dobutamine and PDE inhibitors, which revealed worse prognosis and no benefit for patient survival ${ }^{20,21}$. Hence, drugs that increase cardiac contraction without altering calcium concentrations, the so-called calcium sensitizers, become more interesting for safer inotropy. However, very few calcium sensitizers have been fully described and 
developed, and currently only for 3 drugs (pimobendan, levosimendan and omecamtiv) preclinical and clinical data are available, where only omecamtiv seems to be a 'pure' inotrope, while the other 2 have other clinical effects but also adverse outcomes (such as hypotension and atrial arrhythmias) ${ }^{19}$. Unfortunately, this 'pure' calcium sensitizer also has a drawback, as it increases systolic ejection time at the cost of relaxation time, which is absent in the 'non-pure' calcium sensitizers, probably due to their pleiotropic effects. Hence the question arises whether a safe inotrope has to be 'pure' or not, but since mortality data on omecamtiv are still lacking, this cannot be answered yet ${ }^{19}$. Moreover, because of limited drug availability, there is a need to identify novel inotropes to further improve clinical management of systolic HF patients.

SPARC is one the "founding" members of the matricellular proteins, and has been extensively studied. It was Paul Bornstein who introduced the term "matricellular proteins" to describe a family of extracellular proteins that interact with cell surface receptors, growth factors, other matrix proteins and MMPs, but with no evident structural role. Like other matricellular proteins, SPARC demonstrates counteradhesive properties, low expression levels during normal adult physiology, but increased expression during development and upon injury, and absence of an evident phenotype in mice with targeted gene-disruption. Since then SPARC has been described in a wide variety of diseases, including (pancreatic) cancer ${ }^{22}$, cardiac disease ${ }^{23}$, and glaucoma ${ }^{24}$. In cancer SPARC is involved in proliferation, cell cycle progression, apoptosis, cell adhesion, migration, metastasis, and angiogenesis, yet its role is still controversial as conflicting results have been reported and the pathways of SPARC signalling not well established ${ }^{25}$. Importantly in cardiac disease, SPARC is involved in procollagen processing during pressure overload $^{26}$, ageing ${ }^{27}$ and after $\mathrm{MI}^{5}$. The latter study demonstrated improved survival of the mice and increased cardiac contraction when SPARC was overexpressed during MI in mice. Surprisingly, also sham-operated mice displayed an increase in cardiac fractional shortening and ejection fraction when SPARC was overexpressed. Yet whether SPARC directly affected cardiomyocyte contraction remained undetermined ${ }^{5}$. This has led to the question whether SPARC may exert a potential inotropic function in the healthy heart and during disease.

In this thesis we identify SPARC as a possible calcium-sensitizing inotrope. Importantly, this is the first time an extracellular matrix protein has been shown to directly influence cardiomyocyte contraction. Our results demonstrating increased cardiac FS after SPARC administration in virus-induced systolic dysfunction, despite increased collagen cross-linking, highlight the potential for SPARC as a novel therapeutic inotrope. Moreover, because SPARC has been already extensively studied, pleiotropic effects, such as increased collagen cross-linking, can be well estimated. Hence, this study raises further prospects for other diseases like MI, where cardiac function is compromised. 


\section{DO ANIMAL MODELS WARP CARDIAC RESEARCH?}

$\mathrm{HF}$ in humans is a complex syndrome with many underlying etiologies, such as $\mathrm{MI}$, valvular disease, VM, hypertension, cardiac arrhythmias, and/or aging. In order to study HF and its underlying aetiologies, specific animal models of HF, like the experimental $\mathrm{MI}$ mouse model or the Angll - hypertensive mouse model, have been developed, mimicking the clinical settings as closely as possible. Importantly, next to being a representative clinical model, models should also be reproducible, accessible to the scientific world, and economical in order to allow experiments in sufficient sample sizes ${ }^{28}$. Yet, despite tremendous work on the development of "the perfect model", the use of animal models in cardiac research will continue to have its drawbacks as processes like inflammation are species and even strain-dependent ${ }^{29,30}$. Hence, no single animal model will successfully mimic the exact pathophysiology of human HF.

In this thesis we used 3 mouse- models to study cardiac (patho-) physiology. Importantly, the availability of genetically manipulated mice, where a gene can be introduced or shut down, even within a specific cell type, together with the low housing costs, has made mouse models an invaluable tool to study the pathogenesis of HF. Unfortunately, researchers do not always take the time to plan proper backcrossing, in order to generate the correct genetic controls, and instead buy commercial WT mice to use as control. This thesis highlights the importance of the breeding strategy of mice in cardiac research, as it is a crucial determinant of rupture incidence post-MI. Of note, the literature poorly describes breeding strategies, genetic backgrounds or the continental source of mice studied, thereby making it difficult to estimate how many studies have mistakenly attributed a phenotype. Furthermore, pathological responses are influenced by the strain of the mice used. Previous studies have already demonstrated this for hypertension ${ }^{31,32}, \mathrm{MI}^{33}$ and $\mathrm{VM}^{34}$. Hence, in addition to the importance of breeding strategies, awareness of mouse strain differences is crucial in tailoring experimental studies and in interpreting results. In conclusion, this thesis emphasizes the importance of implementing a breeding strategy that takes such factors into consideration, stresses the importance of using the correct littermate controls and especially, conveying this information in publications. Nevertheless, despite their drawbacks, some of the animal models have now become golden standard in cardiac research and importantly, they have already led to the development of new therapies ${ }^{35,36}$.

In conclusion this thesis demonstrates that matrix proteins are paramount in cardiac adaptation and during the development of HF, and represent important novel targets for HF therapy. 


\section{REFERENCES}

1. Frank JS, Langer GA. The myocardial interstitium: Its structure and its role in ionic exchange. J Cell Biol. 1974;60:586-601

2. Pelouch V, Dixon IM, Golfman L, Beamish RE, Dhalla NS. Role of extracellular matrix proteins in heart function. Molecular and cellular biochemistry. 1993;129:101-120

3. Rienks M, Papageorgiou AP, Frangogiannis NG, Heymans S. Myocardial extracellular matrix: An everchanging and diverse entity. Circulation research. 2014;114:872-888

4. Frangogiannis NG. Matricellular proteins in cardiac adaptation and disease. Physiol Rev. 2012;92:635-688

5. Schellings MW, Vanhoutte D, Swinnen M, Cleutjens JP, Debets J, van Leeuwen RE, d'Hooge J, Van de Werf F, Carmeliet P, Pinto YM, Sage EH, Heymans S. Absence of sparc results in increased cardiac rupture and dysfunction after acute myocardial infarction. J Exp Med. 2009;206:113-123

6. Van Aelst LN, Voss S, Carai P, Van Leeuwen R, Vanhoutte D, Sanders-van Wijk S, Eurlings L, Swinnen M, Verheyen FK, Verbeken E, Nef H, Troidl C, Cook SA, Brunner-La Rocca HP, Mollmann H, Papageorgiou AP, Heymans S. Osteoglycin prevents cardiac dilatation and dysfunction after myocardial infarction through infarct collagen strengthening. Circulation research. 2015;116:425-436

7. van Heerebeek L, Paulus WJ. Understanding heart failure with preserved ejection fraction: Where are we today? Netherlands heart journal : monthly journal of the Netherlands Society of Cardiology and the Netherlands Heart Foundation. 2016

8. Paulus WJ, Tschope C. A novel paradigm for heart failure with preserved ejection fraction: Comorbidities drive myocardial dysfunction and remodeling through coronary microvascular endothelial inflammation. J Am Coll Cardiol. 2013;62:263-271

9. Li X, Massa PE, Hanidu A, Peet GW, Aro P, Savitt A, Mische S, Li J, Marcu KB. Ikkalpha, ikkbeta, and nemo/ikkgamma are each required for the nf-kappa b-mediated inflammatory response program. The Journal of biological chemistry. 2002;277:45129-45140

10. Lahera V, Cachofeiro V, de Las Heras N. Interplay of hypertension, inflammation, and angiotensin ii. Am J Hypertens. 2011;24:1059

11. Insenser M, Montes-Nieto R, Vilarrasa N, Lecube A, Simo R, Vendrell J, Escobar-Morreale HF. A nontargeted proteomic approach to the study of visceral and subcutaneous adipose tissue in human obesity. Molecular and cellular endocrinology. 2012;363:10-19

12. Cao HM, Ye XP, Ma JH, Jiang H, Li SX, Li RY, Li XS, Guo CC, Wang ZQ, Zhan M, Zuo CL, Pan CM, Zhao SX, Zheng CX, Song HD. Mimecan, a hormone abundantly expressed in adipose tissue, reduced food intake independently of leptin signaling. EBioMedicine. 2015;2:1718-1724

13. Pravenec M. Use of rat genomics for investigating the metabolic syndrome. Methods in molecular biology. 2010;597:415-426

14. Petretto E, Sarwar R, Grieve I, Lu H, Kumaran MK, Muckett PJ, Mangion J, Schroen B, Benson M, Punjabi PP, Prasad SK, Pennell DJ, Kiesewetter C, Tasheva ES, Corpuz LM, Webb MD, Conrad GW, Kurtz TW, Kren V, Fischer J, Hubner N, Pinto YM, Pravenec M, Aitman TJ, Cook SA. Integrated genomic approaches implicate osteoglycin (ogn) in the regulation of left ventricular mass. Nature genetics. 2008;40:546-552

15. Zouein FA, de Castro Bras LE, da Costa DV, Lindsey ML, Kurdi M, Booz GW. Heart failure with preserved ejection fraction: Emerging drug strategies. J Cardiovasc Pharmacol. 2013;62:13-21

16. Chiao YA, Ramirez TA, Zamilpa R, Okoronkwo SM, Dai Q, Zhang J, Jin YF, Lindsey ML. Matrix metalloproteinase-9 deletion attenuates myocardial fibrosis and diastolic dysfunction in ageing mice. Cardiovascular research. 2012;96:444-455

17. Nichols M TN, Luengo-Fernandez R, Leal J, Gray A, Scarborough P, Rayner M European cardiovascular disease statistics 2012. European Heart Network. 2012

18. Overgaard CB, Dzavik V. Inotropes and vasopressors: Review of physiology and clinical use in cardiovascular disease. Circulation. 2008;118:1047-1056

19. Pollesello P, Papp Z, Papp JG. Calcium sensitizers: What have we learned over the last 25years? Int J Cardiol. 2016;203:543-548 


\section{Chapter 6}

20. Tacon CL, McCaffrey J, Delaney A. Dobutamine for patients with severe heart failure: A systematic review and meta-analysis of randomised controlled trials. Intensive Care Med. 2012;38:359-367

21. Nony P, Boissel JP, Lievre M, Leizorovicz A, Haugh MC, Fareh S, de Breyne B. Evaluation of the effect of phosphodiesterase inhibitors on mortality in chronic heart failure patients. A meta-analysis. Eur J Clin Pharmacol. 1994;46:191-196

22. Rossi MK, Gnanamony M, Gondi CS. The 'sparc' of life: Analysis of the role of osteonectin/sparc in pancreatic cancer (review). Int J Oncol. 2016;48:1765-1771

23. Bradshaw AD. The role of secreted protein acidic and rich in cysteine (sparc) in cardiac repair and fibrosis: Does expression of sparc by macrophages influence outcomes? Journal of molecular and cellular cardiology. 2015

24. Wallace DM, Pokrovskaya O, O'Brien CJ. The function of matricellular proteins in the lamina cribrosa and trabecular meshwork in glaucoma. J Ocul Pharmacol Ther. 2015;31:386-395

25. Vaz J, Ansari D, Sasor A, Andersson R. Sparc: A potential prognostic and therapeutic target in pancreatic cancer. Pancreas. 2015;44:1024-1035

26. Bradshaw AD, Baicu CF, Rentz TJ, Van Laer AO, Boggs J, Lacy JM, Zile MR. Pressure overload-induced alterations in fibrillar collagen content and myocardial diastolic function: Role of secreted protein acidic and rich in cysteine (sparc) in post-synthetic procollagen processing. Circulation. 2009;119:269-280

27. Bradshaw AD, Baicu CF, Rentz TJ, Van Laer AO, Bonnema DD, Zile MR. Age-dependent alterations in fibrillar collagen content and myocardial diastolic function: Role of sparc in post-synthetic procollagen processing. Am J Physiol Heart Circ Physiol. 2010;298:H614-622

28. Hongo M, Ryoke T, Ross J, Jr. Animal models of heart failure recent developments and perspectives. Trends Cardiovasc Med. 1997;7:161-167

29. Dewald O, Ren G, Duerr GD, Zoerlein M, Klemm C, Gersch C, Tincey S, Michael LH, Entman ML, Frangogiannis NG. Of mice and dogs: Species-specific differences in the inflammatory response following myocardial infarction. Am J Pathol. 2004;164:665-677

30. Marques SM, Campos PP, Castro PR, Cardoso CC, Ferreira MA, Andrade SP. Genetic background determines mouse strain differences in inflammatory angiogenesis. Microvasc Res. 2011;82:246-252

31. Cicila GT. Strategy for uncovering complex determinants of hypertension using animal models. Curr Hypertens Rep. 2000;2:217-226

32. Peng $H$, Yang XP, Carretero OA, Nakagawa $P$, D'Ambrosio $M$, Leung $P, X u J$, Peterson EL, Gonzalez GE, Harding $P$, Rhaleb NE. Angiotensin ii-induced dilated cardiomyopathy in balb/c but not c57bl/6j mice. Exp Physiol. 2011;96:756-764

33. van den Borne SW, van de Schans VA, Strzelecka AE, Vervoort-Peters HT, Lijnen PM, Cleutjens JP, Smits $J F$, Daemen MJ, Janssen BJ, Blankesteijn WM. Mouse strain determines the outcome of wound healing after myocardial infarction. Cardiovascular research. 2009;84:273-282

34. Corsten MF, Schroen B, Heymans S. Inflammation in viral myocarditis: Friend or foe? Trends Mol Med. 2012;18:426-437

35. Pfeffer JM, Pfeffer MA, Braunwald E. Influence of chronic captopril therapy on the infarcted left ventricle of the rat. Circulation research. 1985;57:84-95

36. Patten RD, Hall-Porter MR. Small animal models of heart failure: Development of novel therapies, past and present. Circulation. Heart failure. 2009;2:138-144 
Summary 
Important structural, functional and signalling changes occur in the heart in the development of heart failure (HF). These changes ultimately result in the incapability of the heart to meet the body's needs, which is accompanied by non-specific clinical symptoms like shortness of breath, fatigue, and ankle swelling, which can make diagnosis of HF difficult. The distinction between systolic HF where cardiac contraction is impaired, and diastolic HF where relaxation is compromised, is important. Yet current treatment for all HF patients is the same, despite this difference in systolic or diastolic dysfunction. Moreover, modern pharmacotherapies do not improve outcome in diastolic HF, in contrast to systolic HF, due to incomplete understanding of its pathogenesis. Consequently, there is a critical need for identifying and understanding the different underlying aetiologies that contribute to the development of systolic and diastolic HF, in order to improve diagnosis as well as treatment, as HF still represents the main cause of death worldwide.

This thesis aimed to gain insight in the role of the cardiac extracellular environment in the development of systolic and diastolic dysfunction and concomitant HF. The secreted matrix proteins osteoglycin (OGN), SPARC, and WARP and their roles in diastolic or systolic cardiac function were investigated. In this thesis, first an introduction is given on HF pathophysiology following hypertension and ageing, myocardial infarction (MI), or viral myocarditis (VM). Next, an in-depth literature study on the small proteoglycan $\mathrm{OGN}$ is presented. This proteoglycan displays great structural and functional diversity in normal physiology and during disease, therefore making it a very interesting candidate for the development of novel therapeutic strategies. Unfortunately, literature on OGN so far has been confusing, as different names for OGN exist, as well as different transcript and protein variants have been described. Therefore a clear overview of the different structures and functions of OGN is provided in chapter 2, where this chapter not only emphasizes the central role of OGN in (patho-) physiology, but further highlights the importance of post-translational processing such as glycosylation for the diversity of its functions, which opens a new angle for treatment strategies.

Subsequently, a therapeutic potential for the extracellular proteoglycan OGN and the glycoproteins SPARC and WARP is investigated and discussed in chapters 3 to 5 . Here experimental evidence is provided to demonstrate a protective role for OGN in the development of diastolic dysfunction, a so far unknown inotropic function for SPARC in the healthy and diseased heart, and a redundant role for WARP in the infarcted heart.

Chapter 3 demonstrates increased presence of OGN upon hypertensive- induced matrix deposition in the heart, resulting in reduced fibroblast proliferation and cardiac fibrosis. As such, OGN protects against the development of diastolic dysfunction and its progression to $\mathrm{HF}$ upon hypertension and ageing, and hence represents an interesting potential target for new therapies. The glycoprotein SPARC on the other hand, is identified as a possible calcium-sensitizing inotrope. This thesis describes for the first time a direct influence of a non-structural extracellular matrix protein on cardiomyocyte contraction during health as well as systolic dysfunction. Since the number of newly devel- 
oped drugs to support cardiac function and enhance cardiac output has been surprisingly low, available inotropes are limited, and hence there is a need to identify novel inotropes to further improve clinical management of systolic HF patients. This thesis identifies SPARC as a possible new target for this. Finally, chapter 5 describes a redundant role for WARP in the wound healing process after MI. However, this chapter demonstrates how different breeding strategies determine rupture incidence following $\mathrm{Ml}$ in mice, and emphasizes the importance of using the correct mouse controls in cardiovascular research.

In conclusion, this thesis presents important biological contributions of OGN and SPARC in diastolic and systolic cardiac function respectively, whereas WARP was demonstrated not to be crucial for the healing response following MI. These findings increase the current knowledge on HF pathophysiology and will help in the development of new therapeutic strategies for either diastolic or systolic HF. 

Samenvatting 
Belangrijke veranderingen in structuur, functie en signalering vinden plaats in het hart tijdens de ontwikkeling van hartfalen (HF). Deze veranderingen veroorzaken uiteindelijk het falen van het hart waardoor het niet meer kan voldoen aan de noden van het lichaam. Dit gaat gepaard met atypische symptomen zoals vermoeidheid, kortademigheid en opgezwollen enkels, wat de diagnose van HF moeilijk maakt. Belangrijk is het onderscheid tussen de twee soorten HF, waarbij in systolisch HF de samentrekking (of contractie) van het hart verstoord is, terwijl bij diastolisch HF het ontspannen (of relaxatie) van het hart niet meer vlot verloopt. Toch is de huidige behandeling van alle patiënten met HF hetzelfde, ondanks deze verschillen in systolische of diastolische dysfunctie. Meer nog, huidige moderne therapieën verbeteren de prognose van patiënten met diastolisch HF niet, doordat de pathogenese van deze ziekte helaas nog onvoldoende gekend is. Het identificeren en het ontrafelen van de onderliggende etiologiën die uiteindelijk systolisch of diastolisch HF veroorzaken is dus uiterst belangrijk. Op deze manier kan zowel de diagnose als de behandeling van HF verbeterd worden. Gezien HF wereldwijd nog steeds doodsoorzaak nummer 1 is, staat het belang hiervan zeker niet ter discussie.

Dit proefschrift had als doel de bijdrage van de extracellulaire matrix in het hart in de ontwikkeling van systolische en diastolische dysfunctie en resulterend HF te onderzoeken. De matrix eiwitten osteoglycine (OGN), SPARC en WARP en hun rol in diastolische of systolische functie werden onderzocht. In deze thesis wordt eerst een introductie gegeven tot de pathofysiologie van HF ten gevolge van hypertensie en ouderdom, na een myocardiaal infarct of ten gevolge van een virale hartontsteking (myocarditis). Vervolgens wordt in een diepgaande literatuurstudie het eiwit OGN gedetailleerd beschreven. Dit eiwit vertoont een enorme structurele en functionele verscheidenheid zowel gedurende normale fysiologie als tijdens ziekte. Helaas is de literatuur over OGN tot nu toe erg verwarrend, doordat er verschillende namen, transcripten en eiwitten voor OGN geïdentificeerd en beschreven werden. Daarom wordt er een helder overzicht van de verschillende structuren en functies van OGN gegeven in hoofdstuk 2. Dit hoofdstuk benadrukt de central role van OGN in (patho-) fysiologie, maar beklemtoont ook het belang van post-translationele modificaties, zoals glycosylatie van eiwitten, voor de diversiteit in functies van OGN. Dit opent een nieuwe invalshoek voor het ontwikkelen van nieuwe therapiëen.

Vervolgens worden de therapeutische mogelijkheden van deze extracellulaire matrix eiwitten OGN, SPARC en WARP bestudeerd en beschreven in hoofdstukken 3 tot 5 . Hier wordt met experimentele data aangetoond dat OGN een beschermende functie uitoefent tijdens de ontwikkeling van diastolische dysfunctie, SPARC een tot nu toe ongekende inotrope functie uitoefent in gezonde en zieke harten, terwijl WARP niet cruciaal is voor de genezing na een myocardiaal infarct.

Hoofdstuk 3 beschrijft hoe de expressie van OGN toeneemt in lijn met de fibrose in het hart ten gevolge van hypertensie, en zo de proliferatie van fibroblasten en de fibrose ten gevolge van de hypertensie doet verminderen. Op deze manier beschermt OGN 
tegen de ontwikkeling van diastolische dysfunctie en de progressie tot HF ten gevolge van hypertensie en ouderdom. OGN is dus een interessant mogelijk doelwit voor niewe therapieën. Het eiwit SPARC aan de andere kant, wordt geïdentificeerd als een mogelijk calcium-sensitizerende inotrope stof. Deze thesis is de eerste studie die een direct effect van een niet-structureel matrix eiwit op de spiercontractie van het hart beschrijft, en dit zowel in gezonde als zieke harten. Door het lage aantal nieuwe ontwikkelde inotrope medicijnen om de hartfunctie te ondersteunen, is de keuze in beschikbare inotrope medicatie erg beperkt. De identificatie van nieuwe inotrope stoffen is dus erg belangrijk, om zo patiënten met systolisch HF beter te kunnen behandelen. Deze thesis identificeert SPARC als een mogelijk nieuwe inotrope stof. Tot slot wordt in hoofdstuk 5 een overbodige rol voor WARP in het genezingsproces na een myocardiaal infarct beschreven. Niettemin wordt het belang benadrukt van de kweek-strategie van muizen in cardiovasculair onderzoek, gezien dit een cruciale factor is in de incidentie van hartruptuur na een infarct. Het gebruik van de juiste controle- proefdieren wordt hier extra beklemtoond.

Samenvattend presenteert dit proefschrift een belangrijke biologische bijdrage voor OGN en SPARC in diastolische en systolische functie van het hart respectievelijk, terwijl een niet-cruciale role voor WARP aangetoond werd in het genezingsproces na een infarct. Deze bevindingen verruimen onze huidige kennis van de pathofysiologie van HF, wat zal helpen in de ontwikkeling van nieuwe therapeutische strategieën om diastolisch en systolisch HF te helpen genezen. 

Valorization 


\section{L'ignorance est la plus grande maladie du monde}

Despite efforts for decades, HF remains the leading cause of death worldwide. Eventhough clinical management has improved, resulting in decreased mortality, the incidence of cardiac diseases and HF remains too high. In addition, HF also has a huge impact on the economical society, in terms of health expenditure, as well as by disabling and immobilizing people, making them unable to work. Fundamental research, as described in this thesis, is vital for understanding HF pathophysiology and for the discovery of novel therapeutic strategies that eventually will prevent the onset of $\mathrm{HF}$, and improve quality of life of thousands of people.

In this thesis I highlight the paramount role of the cardiac extracellular environment in the development of systolic and diastolic dysfunction and concomitant HF. The biological diversity of the extracellular protein, OGN, is described in chapter 2 whereas its role during hypertensive- and age- induced cardiac remodelling and in particular its importance during diastolic dysfunction is described in chapter 3. Chapter 4 identifies SPARC as a novel inotropic agent that improves cardiac contraction, both during health and during systolic dysfunction induced by viral myocarditis. And last but not least, a redundant role for WARP in the wound healing process after $\mathrm{MI}$ is described in chapter 5. Also highlighted is the importance of breeding strategies in cardiovascular research.

Moreover, this thesis reveals therapeutic potential for OGN and SPARC. HFpEF and diastolic dysfunction represent one of the most challenging clinical problems in cardiology, as modern pharmacotherapies do not improve outcome, in contrast to systolic HF, and the heterogeneity of HFpEF patients further impedes treatment of these patients. Identification of patient-specific structural and functional abnormalities will help in treatment selection to increase therapeutic responsiveness. This thesis identifies OGN as a novel protective factor against diastolic dysfunction of aged-hypertensive origin and hence opens new windows to target/prevent diastolic dysfunction upon hypertension and ageing, by targeting or mimicking compounds of the extracellular matrix, such as OGN. In addition, a specific therapy for suspected myocarditis patients is unfortunately also still lacking, but increasing cardiac contraction trough inotropes might be beneficial for these patients. Yet over the last decades, the number of newly developed inotropes has been surprisingly low and hence, current drug selection is limited. Here, SPARC is identified as a possible calcium-sensitizing inotrope.

Unfortunately the pipeline from fundamental research and therapeutic target discoveries, to the development of new therapies is long, and despite the tremendous efforts done so far in fundamental research, we still don't fully grasp HF pathophysiology. To get there, I personally believe an open mind is key. Researchers should not ignore other fields and other opinions. This is especially true since matrix biology is not only of importance in cardiac diseases, but also in other diseases such as cancer. Hence, I believe we will only benefit when we stop ignoring or competing with other research fields and start an open communication with other researchers from various disciplines. In 
addition, clear communication towards the general public on our fundamental scientific findings will further increase awareness, increase appreciation for its relevance and value in the search for novel therapeutic strategies, which I believe, will in the end help in our combat against cardiac (and other) diseases.

\section{Aime la vérité mais pardonne à l'erreur}

Besides the paramount role of the cardiac extracellular environment in $\mathrm{HF}$ and its therapeutic potential, this thesis also highlights the importance of breeding strategy of mice in cardiovascular research. The use of genetically manipulated mice is a widespread tool to study the effects of a specific gene in models of cardiovascular disease and thanks to intercontinental collaborations, air travel is commonplace these days for genetically manipulated mice. Unfortunately, the competitive environment causes numerous labs to breed their KO mice in-house and to purchase the WT mice from a commercial source, in order to save time and money.

In this thesis I stress the important influence breeding strategy and housing environment can exert on research results. However, the literature poorly describes breeding strategies, genetic backgrounds or the continental source of mice studied, thereby making it difficult to estimate how many studies have mistakenly attributed a phenotype. Using the correct littermate controls and respecting good laboratory scientific practices and particularly, conveying this information in publications, will definitely help us not only in limiting false leads for therapies but in unraveling HF (and other) pathophysiology.

Laissez lire, laissez danser, ces deux amusements ne feront jamais de mal au monde

A PhD is more than this reading alone; it is 4 years of pushing boundaries, both boundaries of scientific knowledge, and personal boundaries. A PhD is hard work, where you learn to keep going when things keep on failing, where you overcome your own limits (such as my initial fear for the very aggressive mice), but where you also get the opportunity to build up an international network, and travel the world. In addition, I learned to put things in perspective, to appreciate things (such as reading and dancing). 4 years of pushing boundaries changed my perspective and taught me that I could achieve things I had been dreaming off. And somehow it made the world seem a little bit smaller... 

Dankwoord 
Daar is het dan, het moment dat je je dankwoord mag schrijven. Ik besef het eerlijk gezegd zelf nog niet zo goed...het boekje is af, enkel de verdediging nog en dan... hoofdstuk afgesloten... Het is alleszins een hoofdstuk waar ik met veel plezier (en ook wel wat trots) op terugkijk, waarin ik veel geleerd heb op wetenschappelijk en persoonlijk vlak. Maar bovenal heb ik ontzettend veel interessante mensen leren kennen, sommigen waarvan ik weet dat het, ondanks de chaos en drukte van ons leven, vrienden voor het leven zullen zijn. Dat het zo'n mooi hoofdstuk van mijn leven is geworden, dank ik aan ontelbaar veel mensen, waarvan ik enkelen hier graag in het bijzonder wil bedanken.

Professor Heymans, Stephane, ik leerde je kennen als één van mijn docenten tijdens mijn eerste jaar van de CARIM-Master. Je presenteerde toen jouw onderzoek aan ons, en ik werd onmiddellijk aangestoken door jouw enthousiasme. Ik heb je toen meteen gevraagd of ik mijn Master thesis in jouw groep mocht doen. En ja hoor, dat mocht zeker, en het klikte, want ik mocht nog 4 jaar blijven. Ik wil je in het bijzonder bedanken voor al de kansen die je me hebt gegeven: zo ben ik 2 weken naar Porto gegaan, onderzoek doen in het lab van professor Leite-Moreira, ik ging naar meetings in Londen, Colorado, Barcelona, Oxford, .... En tot slot ging ik nog eens 2 weken onderzoek doen in Amsterdam in de groep van professor Van der Velden. Het onderzoek dat we samen deden vond ik ontzettend interessant, maar wat ik ook erg apprecieerde is dat wetenschap niet altijd alles was, er was ook ruimte voor onze persoonlijkheid in jouw groep. Je hebt dan wel geen academicus van me kunnen maken, een wereldburger zeker wel!

Anna, eerlijk, er zijn geen woorden voor...Zo'n goeie co-promoter had ik nooit durven dromen. Maar blijkbaar worden dromen dus soms toch waar ;). Jouw advies - altijd tothe-point - stuurde me doorheen de jaren op zowel wetenschappelijk als persoonlijk vlak. Was het nu een western blot die weer eens niet lukte, of een jongen waar ik me toch maar eens voor moest openstellen, bij jou kon ik terecht. Ik mis de 'koffietjes met bouchée' na de middag, de gezellige uurtjes samen onderweg van en naar Maastricht, de slappe lach die we meer dan eens hebben gehad (en probeer maar eens te stoppen met lachen naast jou). Dat mijn doctoraat zo mooi is geworden, zowel op wetenschappelijk als persoonlijk vlak, dank ik echt aan jou. Jouw persoonlijkheid, hoe je het werk aanpakt (maximum efficiency!!!) en hoe je in het leven staat (een klein beetje chaos af en toe is toch ok ;) ), ... we zaten op dezelfde golflengte. Ik hoop écht dat we elkaar nog veel zullen blijven horen en zien!

Mijn paranimfen Marieke en Paolo, hoe kan het ook anders dan dat jullie dat zijn! Marieke, ondanks je vreselijke ervaringen met het Belgische trein-netwerk (geloof me been there done that, verschrikkelijk!), vond je het nooit een probleem om naar Leuven te komen. Of we nu gingen dansen tot in de vroege uurtjes, samen doorheen de Australische woestijn trokken, of ja waarom niet, een halve marathon gingen lopen in het putje 
van de winter, op het strand ergens boven Amsterdam, geen plan leek ons onmogelijk en altijd was het ontzettend leuk met jou! En ook in het lab stond je me bij en heb je me enorm geholpen (je zou bijna vergeten dat we collega's waren). Ik ben er zeker van dat we samen nog veel leuke momenten gaan beleven, waar ook ter wereld!

Paolo, ook jou dank ik ontzettend veel, van je goede raad, tot je harde werk of je luisterend oor, je stond altijd klaar. "U-uuuh" zal voor eeuwig aan jou gelinkt zijn (ik zie je vingertje al gaan). We hebben zoveel plezier gemaakt samen in het lab, van onozel doen tot samen zingen op Kylie Minogue (en oh ja ondertussen toch ook wat muisjes opereren of myocyten isoleren), het waren ontzettend leuke momenten die ik echt ga missen.

Ward en Lucas, jullie waren als de 2 grote broers en ik het kleine zusje van de "Leuvenfamilie" ;). Ook jullie stonden altijd klaar voor goede raad of hulp, en een mopje ertussendoor kon zeker ook, al ging het West-Vlaams soms wel m'n petje te boven. Lucas, jouw onuitputtelijke energie en inzet vind ik echt bewonderenswaardig en zal ik altijd in mijn achterhoofd houden als mijn eigen inzet het eens wat af laat weten. Ward, vooral tijdens jouw laatste jaar heb ik je echt goed leren kennen. Je bent een ontzettend warme persoon, toch wel anders dan ik (iets gestructureerder en georganiseerder ;) ) maar het klikte echt! Dank je voor al de fijne momenten!

Uiteraard ook dank aan alle collega's in Maastricht! Blanche en Marc, dank voor jullie feedback, uitstekende ideeën en de interessante papers die jullie me meermaals doorstuurden. Jullie deur stond altijd open, dank je om op zo'n warme manier mee deel uit te maken van mijn begeleiding. Partners in crime: Maarten, Wouter D, Tim, George, Robin, Monika, Steffi, het was altijd fijn om jullie te zien! Ondanks de Leuven-Maastricht afstand waren we toch een team en was het nooit een probleem een ander om hulp te vragen. Heel veel succes met jullie toekomst allemaal! Rick, Wouter $V$ en Kevin, de 3 wijzen van Maastricht, dank je voor al jullie hulp, ongezouten mening en ervarings-gefundeerd advies! Julie et Alexandra, (pardonne mes erreurs) grace à vous, ce n'était jusque néérlandais ou anglais qu'on parlait, mais de temps en temps je pouvais pratiquer mon francais, merci! C'était très amusant de vous avoir à Louvain de temps en temps. Je vous souhaite beaucoup de succes dans vos vies! Barbara en Lilian, de kapiteins van het schip, dankje voor de gezellige babbels en vooral om me telkens weer doorheen het administratieve doolhof te loodsen (écht, als Belgische werd ik helemaal gek van al die Nederlandse regeltjes en vooral de striktheid waarmee deze opgevolgd werden ;) )!

Dan, we've spent quite some time together isolating myocytes and measuring contractions... Those were sometimes crazy days but with you it was always fun! Thanks for everything! 
Ook in het lab in Leuven zijn er ontelbaar veel mensen die me op een of andere manier geholpen hebben, van (uiterst-noodzakelijke) koffie zetten in de ochtend tot technische hulp met een kleuring, een microscoop die raar deed, het FACS-toestel dat (weer eens) geblokkeerd zat, maar ook al de gezellige babbeltjes in de gang. Jullie zijn, zoals ik zei, ontelbaar, waardoor, mijn excuses, ik jullie niet allemaal bij naam vermeld, maar bovenal onvervangbaar en van onschatbare waarde geweest tijdens mijn periode in het Leuvense lab. DANK AAN JULLIE ALLEMAAL!

Many thanks also go to my commission members professors Prinzen, Volders, Blankesteijn, Roderick and Dr. Arantxa Gonzalez, for the critical evaluation of this thesis. I admire your professional and scientific achievements. It is a great honour that you accepted to be jury member for my thesis.

En dan, uiteraard, mijn vrienden, ook al weten jullie meestal niet zo goed wat ik de voorbije jaren precies heb uitgestoken ("iets met muizen" en "iets over het hart toch eh?"), zonder jullie had ik het nooit volgehouden! Chicas Amber, Eline, Evelien, Julie, Lize en Yana, geen groep waar ik me zo in thuis voel als bij jullie! Dank je voor al de leuke reisjes die we tot nu toe al samen gemaakt hebben (en nog gaan maken sowieso!), voor al de gezellige kook-avondjes, feest-avonden, babbels, zelfs huil-momenten, ... Jullie vriendschap is onmisbaar voor mij! Ook de matigerds, Lotte, Marthe, Nele, Nuria en Sanne, dank je voor alle leuke momenten samen, jullie aanwezigheid zorgt altijd voor sfeer, geen naam die slechter bij jullie past dan matig :)!

Lize! Als kebabahcowboys gaan we al jaren samen door het leven! Het is fantastisch hoe jij me altijd weer goede raad kan geven en aan het lachen kan brengen. Ik kan niet beschrijven hoeveel je betekent voor mij!

Anke, lieve meid, wat zou ik toch zonder jou zijn? Van samen als puber in de klas, tot getuige op jouw trouw, tot in de diepste dalen en tot op alle hoogtepunten van mijn doctoraat, op elk moment sta je aan mijn zij. Dankje om er altijd te zijn voor mij! Jij introduceerde me ook tot jouw vriendengroep met Sander, Deef, Jokke, Sarah, Lore V, Lore $U$ en Nina, waarmee ik sindsien ook al geweldige momenten heb beleefd, dankje!

Jente, we kunnen elkaar huilend bellen op momenten dat de hele wereld tegen ons lijkt te zijn, altijd altijd eindigen we al lachend. Jouw vriendschap (die teruggaat tot in de eeuwigheid!) geeft me zoveel energie. Ik ben er zeker van dat we nog véle leuke en mooie momenten gaan beleven samen! Samen ook met Flore, de drieling hoe kan het anders ;) . Flore, ook jij bedankt, voor alles, je bent echt een pracht-vriendin!

Matti \& Bolle, ik woonde met jullie samen tijdens het grootste stuk van mijn doctoraat. Het was een super leuke tijd en ik weet dat jullie echt vrienden voor het leven zijn, 
dankje! Lynn, last but not least, je bent een top-madam die me er altijd weer doorheen weet te trekken! Ik kijk echt uit naar onze véle oude markt avondjes die nog zullen komen, je weet me altijd aan het lachen te brengen met je hilarische verhalen, merci!

Uiteraard zou ik hier niet zijn zonder mijn familie. Mama en papa, aan jullie dank ik letterlijk àlles. Het is echt fantastisch hoe jullie er altijd zijn voor ons. Alle kansen hebben we gekregen, maar jullie hebben ons nooit ergens toe verplicht. We mochten zelf ons eigen pad kiezen, zonder beoordeeld te worden als het al eens een wat mindere keuze bleek te zijn. En advies kunnen we wel altijd bij jullie krijgen, als we erom vragen, want jullie mening opdringen, doen jullie niet. Dank je om zo'n geweldige ouders te zijn! Laura en Wim, waar ergens jullie je ook op deze wereld bevinden, altijd zijn jullie er voor mij. Er is geen uitvalsbasis waar ik me zo thuis en gekoesterd voel als bij jullie (en mama en papa uiteraard ;) ), dankje voor alles! Boetie en Hannah, jullie ook bedankt voor alle leuke eet-en babbelmomentjes, ik hoop dat er nog vele komen! Liesbeth en Oli, jullie zijn als een zus en broer voor mij en dat zegt alles, dank je! 

Curriculum Vitae 


\section{PERSONAL INFORMATION}

Name Sophie Deckx

Date of birth April 101987 in Leuven

Nationality Belgian

\section{EDUCATION}

Dates October 2011 - December 2015

University Maastricht University, Maastricht

Title of Ph.D. Medical Sciences (Faculty of Health and Life Sciences, Department qualification of Cardiology)

Ph.D. project Extracellular matrix glycoproteins are protective in heart failure

Supervision Prof. Dr. Stephane Heymans

Anna Papageorgiou, Ph.D.

Dates September 2009 - June 2011

University Maastricht University, Maastricht

Title of Research Master in Cardiovascular Biology and Medicine

qualification Final grade: 7.9/10

Masters The role of WARP in cardiac matrix integrity

thesis

Supervision Prof. Dr. Stephane Heymans

Anna Papageorgiou, Ph.D.

Dates September 2005 - June 2009

University GroepT, Leuven

Title of Master in Industrial Sciences

qualification Focus Biochemical Engineering

Magna cum Laude

Masters The initial validation of a perfusion bioreactor for skeletal tissue engi-

thesis neering

Supervision Inge Holsbeeks, Ph.D. Ir.

Jan Schrooten, Ph.D. Ir. 
Dates September 1999 - June 2005

School Heilig Hart Instituut Heverlee, Heverlee

Title of quali- Modern languages - Mathematics

fication Final grade: $79 \%$

\section{WORK EXPERIENCE}

Dates May 2016 -

Company Materialise

Position Clinical Engineer

Description Processing orthopedic surgeries as a clinical engineer. This involves technical support to surgeons and internal and external communication with all stakeholders such as surgeons, other engineers, customer support,...

Dates October 2011 - December 2015

University Maastricht University, Department of Cardiology, Maastricht Catholic University Leuven, Centre for Molecular and Vascular Biology, Leuven

Activity Ph.D. project

Description Preclinical research on new therapeutic applications of matricellular proteins in different cardiomyopathies. In this research techniques such as MRI and echocardiography, FACS and Electrical Field Simulation of individual cardiomyocytes, were used.

Dates April 2015

University VUMC, Department of Physiology, Amsterdam

Activity Collaboration in context of the Ph.D. project

Description To acquire the technique of active and passive force measurements on individual cardiomyocytes at the research lab of prof. J. van der Velden.

Dates March 2012

University Universidade do Porto, department of physiology and cardiac surgery, Porto

Activity Collaboration in context of the Ph.D. project

Description To acquire the technique of intra-cardiac pressure-volume loop measurements in mouse-models at the research lab of prof. A. Leite Moreira. 
Dates November 2010 - June 2011

University Maastricht University, Department of Cardiology, Maastricht

Catholic University Leuven, Centre for Molecular and Vascular Biology, Leuven

Activity Senior internship: 8 months internship for the Masters thesis

Description Preclinical research on new therapeutic applications of the matricellular protein WARP in ischemic and hypertensive heart failure at the research lab of prof. S. Heymans.

Dates April 2010 - June 2010

University Catholic University Leuven, Centre for Molecular and Vascular Biology

Activity Junior internship: 12 weeks internship for the junior thesis

Description Preclinical research on the effect of particulate matter on blood coagulation at the research lab of prof. M. Hoylaerts.

Dates January 2009 - April 2009

University Catholic University Leuven, Lab for Skeletal Development and Joint Disorders

Activity 12 weeks internship for the Masters thesis

Description Preclinical research in skeletal tissue engineering at the research lab of prof. F. Luyten.

\section{PUBLICATIONS AND PRESENTATIONS}

Date August 2016

Description The diverse functions of Osteoglycin: a deceitful dwarf or a master regulator of disease?

Deckx S, Heymans S, Papageorgiou A

FASEB

Date September 2015

Description The continental drift: how identical genetic background but different continental origin WARP matrix related cardiovascular research in postinfarct healing. Deckx S, Carai P, Bateman F, Heymans S, Papageorgiou A PlosOne 
Date November 2015

Description The microRNA-221/-222 cluster balances the antiviral and inflammatory response in myocarditis.

Corsten M, Heggermont W, Papageorgiou A, Tijsma A, Deckx S, Verhesen W, Thibaut HJ, Carai P, van Leeuwen R, Custers K, Summer G, Hazebroek $M$, Verheyen F, Neyts J, Schroen B, Heymans S

European Heart Journal

Data 7- 8 december 2015

Description Oral presentation at the annual meeting of the European consortium "MEDIA", Amsterdam, The Netherlands

Date 5-7 March2015

Description Posterpresentation at the Dutch-German meeting, Grainau, Germany

Date 21-24 January 2015

Description Posterpresentation at the ESC Heart Failure Wintermeeting, Les Diablerets, Switzerland

Date September $2^{\text {nd }} 2014$

Description Oral presentation at the annual meeting of the Europan consortium "Fibrotargets", Barcelona, Spain

Date July $5^{\text {th }} 2014$

Description Invited oral presentation at the basic science meeting "Frontiers in CardioVascular Biology 2014", Barcelona, Spain

Date 24-28 March 2014

Description Posterpresentation at the Keystone Symposium "Fibrosis from Bench to Bedside", Colorado, USA

\section{GRANTS AND PRICES}

Date 4-6 July 2014

Title Travel award

Description Travel grant for "Frontiers in CardioVascular Biology 2014" 
Date July 2013

Title Publish negative or neutral animal experiment data Description Dutch ZonMW subsidy

Date June $22^{\text {nd }} 2011$

Title CARIM Ph.D. Award

Description Competition for a CARIM-sponsored Ph.D. 
